University of South Florida

DIGITAL COMMONS

@ UNIVERSITY OF SOUTH FLORIDA
Digital Commons @ University of

South Florida

$10-1-2008$

\title{
Transit Ridership, Reliability, and Retention
}

CUTR

Follow this and additional works at: https://digitalcommons.usf.edu/cutr_nctr

\section{Recommended Citation}

"Transit Ridership, Reliability, and Retention," National Center for Transit Research (NCTR) Report No. CUTR-NCTR-RR-2005-08, Center for Urban Transportation Research, University of South Florida, 2008. DOI: https://doi.org/10.5038/CUTR-NCTR-RR-2005-08

Available at: https://scholarcommons.usf.edu/cutr_nctr/160

This Technical Report is brought to you for free and open access by the National Center for Transit Research (NCTR) Archive (2000-2020) at Digital Commons @ University of South Florida. It has been accepted for inclusion in Research Reports by an authorized administrator of Digital Commons @ University of South Florida. For more information, please contact digitalcommons@usf.edu. 


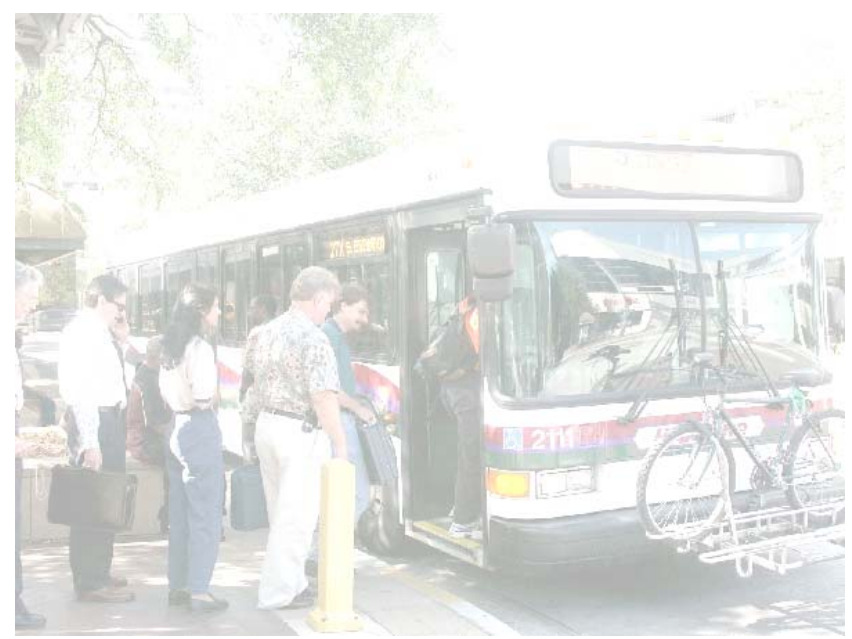

\section{Transit Ridership, Reliability, and Retention}

Final Report

October 2008

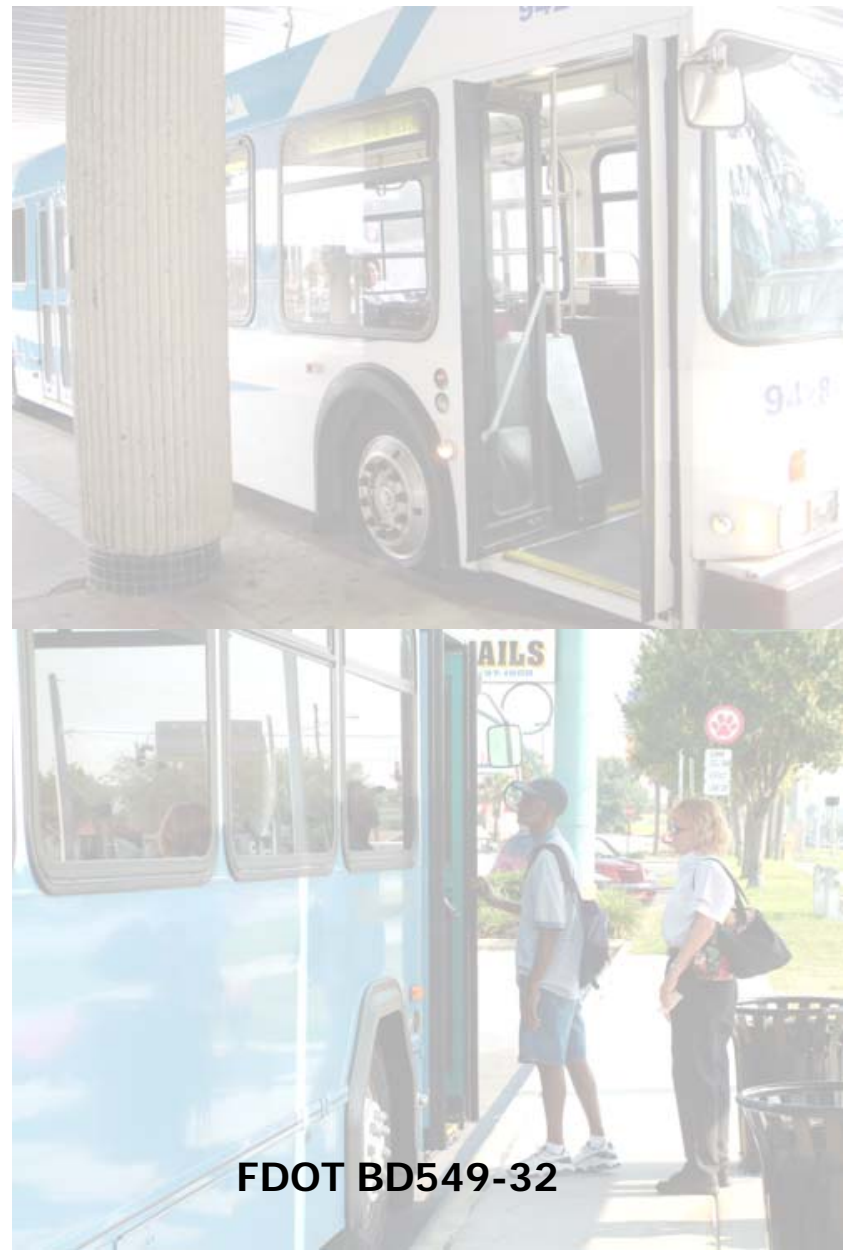




\section{Disclaimer}

The opinions, findings, and conclusions expressed in this publication are those of the authors and not necessarily those of the State of Florida Department of Transportation. 


\section{TRANSIT RIDERSHIP, RELIABILITY, AND RETENTION}

\section{Final Report}

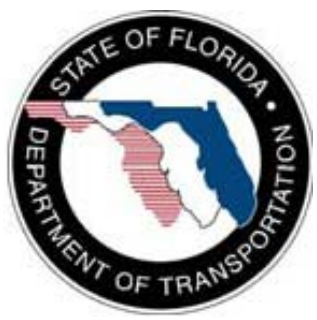

State of Florida Department of Transportation

Public Transit Office

605 Suwannee Street

Tallahassee, FL 32399-0450

(850) $414-4500$

Project Manager: Tara Bartee

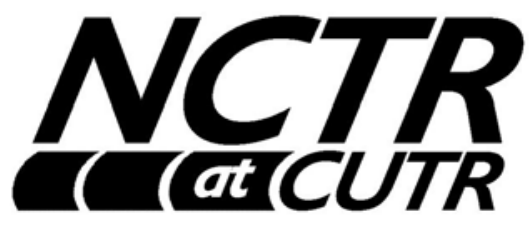

National Center for Transit Research Center for Urban Transportation Research

University of South Florida

4202 E. Fowler Avenue, CUT 100

Tampa, FL 33620-5375

(813) $974-3120$

Final Report, October 2008

FDOT BD-549-32 

TECHNICAL REPORT STANDARD TITLE PAGE

\begin{tabular}{|c|c|c|c|}
\hline $\begin{array}{l}\text { 1. Report No. } \\
\text { NCTR-776-07 }\end{array}$ & 2. Government Accession No. & \multicolumn{2}{|c|}{ 3. Recipient's Catalog No. } \\
\hline \multirow{2}{*}{\multicolumn{2}{|c|}{$\begin{array}{l}\text { 4. Title and Subtitle } \\
\text { Transit Ridership, Reliability, and Retention }\end{array}$}} & \multicolumn{2}{|c|}{$\begin{array}{l}\text { 5. Report Date } \\
\text { October } 2008\end{array}$} \\
\hline & & \multicolumn{2}{|c|}{ 6. Performing Organization Code } \\
\hline \multicolumn{2}{|c|}{$\begin{array}{l}\text { 7. Author(s) } \\
\text { Perk, Victoria; Jennifer Flynn; and Joel Volinski }\end{array}$} & \multicolumn{2}{|c|}{ 8. Performing Organization Report No. } \\
\hline \multirow{2}{*}{\multicolumn{2}{|c|}{$\begin{array}{l}\text { 9. Performing Organization Name and Address } \\
\text { National Center For Transit Research (NCTR) } \\
\text { University of South Florida CUT } 100 \\
4202 \text { East Fowler Avenue, Tampa, FL } 33620\end{array}$}} & \multicolumn{2}{|l|}{ 10. Work Unit No. } \\
\hline & & \multicolumn{2}{|c|}{$\begin{array}{l}\text { 11. Contract or Grant No. } \\
\text { FDOT BD } 549-32\end{array}$} \\
\hline \multirow{2}{*}{\multicolumn{2}{|c|}{$\begin{array}{l}\text { 12. Sponsoring Agency Name and Address } \\
\text { Office of Research and Special Programs (RSPA) } \\
\text { U.S. Department of Transportation, Washington, D.C. } 20590 \\
\text { Florida Department of Transportation } \\
605 \text { Suwannee Street, MS 26, Tallahassee, FL } 32399\end{array}$}} & \multicolumn{2}{|c|}{ 13. Type of Report and Period Covered } \\
\hline & & \multicolumn{2}{|c|}{ 14. Sponsoring Agency Code } \\
\hline \multicolumn{4}{|c|}{$\begin{array}{l}\text { 15. Supplementary Notes } \\
\text { Supported by a Grant from the USDOT Research and Special Programs Administration, and the Florida } \\
\text { Department of Transportation }\end{array}$} \\
\hline \multicolumn{4}{|c|}{$\begin{array}{l}\text { 16. Abstract } \\
\text { This project explores two major components that affect transit ridership: travel time reliability and rider } \\
\text { retention. It has been recognized that transit travel time reliability may have a significant impact on } \\
\text { attractiveness of transit to many current and prospective riders. Accuracy of predictions of transit } \\
\text { ridership based on transit travel time reliability is becoming increasingly important. Knowledge of what } \\
\text { transit improvements the potential transit customer responds to will help transit agencies to provide } \\
\text { better services. In addition, transit agencies are constantly attempting to keep the riders they have and } \\
\text { attract new riders to their service. A good understanding of these riders is necessary to develop and } \\
\text { implement strategies for retaining them. Armed with an understanding of why people stop using transit } \\
\text { and what makes a loyal transit customer, transit agencies can focus their planning and marketing } \\
\text { efforts in ways that retain and increase ridership. Finally, infrequent riders represent a promising } \\
\text { potential growth market. Transit agencies across the country have used a variety of strategies to } \\
\text { increase the frequency of usage by infrequent riders. These strategies fall into a number of categories, } \\
\text { including marketing, fare structure, network structure, and passenger information systems. This } \\
\text { research will benefit the transit industry by enhancing its performance and relevance. }\end{array}$} \\
\hline $\begin{array}{l}\text { 17. Key Words } \\
\text { Public transit, transit performance, } \\
\text { on-time performance, travel time, } \\
\text { reliability, transit use }\end{array}$ & $\begin{array}{l}\text { 18. Distribution Statement } \\
\text { Available to the pub } \\
\text { Service (NTIS), } 528 \\
\text { 487-4650, http://ww } \\
\text { http://www.nctr.usf. }\end{array}$ & $\begin{array}{l}\text { e National } \\
\text { Road, Spri } \\
\text { nd through }\end{array}$ & $\begin{array}{l}\text { Information } \\
22161,(703) \\
\text { web site at }\end{array}$ \\
\hline $\begin{array}{l}\text { 19. Security Classif. (of this report) } \\
\text { Unclassified }\end{array}$ & $\begin{array}{l}\text { 20. Security Classif. (of this page) } \\
\text { Unclassified }\end{array}$ & $\begin{array}{l}\text { 21. No. of pages } \\
160\end{array}$ & 22. Price \\
\hline
\end{tabular}




\section{EXECUTIVE SUMMARY}

This research project explores three major components that affect transit ridership: travel time reliability, rider cessation, and the characteristics of infrequent riders. It has been recognized that transit travel time reliability may have a significant impact on attractiveness of transit to many current and prospective riders. There is a need to determine to what level a correlation between travel time reliability and transit ridership might exist. In addition, transit agencies are constantly attempting to keep the riders they have and attract new riders to their service. Increased rider retention may be a more realistic approach to building ridership than attracting new riders. Finally, increasing trip making by infrequent riders also represents a promising potential growth market.

Regarding rider retention, much of the literature focuses on existing users or non-users, but little is known about ex-users. Transit on-board surveys across the country consistently show a high percentage of new riders over time. Given relatively stable total ridership, the constant existence of these new riders suggests a sizable degree of cessation of transit use. Little is known about people who stop using transit. In fact, the joint national effort between the Federal Transit Administration and the American Public Transportation Association called the Transit Performance Monitoring System (TPMS) recently identified high user turnover as a key research need. A good understanding of these riders is necessary to develop and implement strategies for retaining them.

There is very little information about the patterns of transit use by individuals over time. Who stops using transit, who remains loyal to transit, and who begins using transit? What are the triggering events or changes in demographic and socio-economic characteristics that bring about mode shifts to and away from transit? Panel survey data (measurement of travel characteristics over time for the same sample of individuals) is required to answer such important questions.

Finally, while infrequent riders can represent a majority of the rider population (based on on-board survey results examined for this project), they represent a relatively small share of total transit trips and have the potential to become a much larger market. Because infrequent riders have already made the first, often intimidating, step to try transit, it is potentially easier to induce them to use transit more than to attract new riders. Infrequent riders have implications to several areas of transit operations and planning, including fare 
media, modeling, and benefit analysis. More important, transit agencies across the country have used a variety of strategies to increase the frequency of usage by infrequent riders. These strategies fall into a number of categories, including marketing, fare structure, network structure, and passenger information systems.

To analyze the issues discussed above, extensive use was made of raw data and results from on-board survey data, transit customer satisfaction surveys, and household travel surveys including the Puget Sound Transportation Panel (PSTP). Data and results were gathered directly from transit agencies or other local agencies, and from online sources.

\section{Transit Reliability}

Reliability certainly is one of the service characteristics most important to transit customers, while service quality and customer satisfaction have in turn been linked to higher levels of retention, and possibly even ridership gain. Interestingly, studies of travel behavior suggest that, depending on trip length and total travel time, the cost of unreliable service may actually be greater than the cost of travel time. Over time, the inconvenience, uncertainty, and added time costs of unreliable service diminish user confidence and may result in ridership declines. Thus, improving the consistency of transit waiting and travel time might foster a larger, more satisfied, and more committed base of customers.

BRT and other limited-stop services show great promise for boosting customer satisfaction and ridership by improving reliability, particularly for the work commute. The literature indicates that, improved service reliability, as well as significant increases in customer satisfaction and ridership, have occurred following the implementation of many of these services. Improved reliability was attributed to the fewer stops and more efficient boarding (i.e. shorter dwell times) typical of BRT lines. However, factors and improvements that coincided with the implementation of these services make it difficult to determine the degree to which the ridership increases were caused by improved travel time reliability. Thus, the nature of the relationship between reliability and ridership growth remains unclear. More than any single factor, it is perhaps the right combination of a wide range of quality service elements that will cultivate a growing clientele.

A number of advanced technologies offer some promising solutions for improved reliability. Agencies can use advanced communications and location technologies to 
manage the unforeseen events that interfere with service reliability. These technologies enable agencies to monitor schedule adherence in real time and adjust service instantaneously. One of the most robust examples is Portland's Bus Dispatching System (BDS), which tracks buses in space and time by using a combination of advanced technologies including a computer-aided dispatch (CAD) and control center, automatic passenger counting (APC) systems, a two-way radio system enabling voice and data communication between drivers and dispatchers, and automatic vehicle location and control (AVLC) in tandem with global positioning system (GPS) technology. Such technologies are often able to achieve considerable improvements in OTP merely by providing schedule adherence information to operators in real time.

Aside from supplying transit operators with on-the-spot information, emerging technologies such as AVLC may decrease the anxiety of waiting by providing real-time schedule information to customers. Research suggests that out-of-vehicle waiting time is perceived to pass more slowly than an equal amount of in-vehicle travel time. Additional analysis has shown that a higher degree of certainty regarding the duration of a wait will reduce a traveler's burden of waiting, and that real-time customer information may have the ability to act as a surrogate for reliability. Informing riders of when vehicles will actually arrive allows them to plan their arrival to meet with that of the vehicle. Thus, realtime information shows promise not only for reducing the hardship of uncertainty while waiting, but also for reducing the length of the wait.

Of course, without adequate fleet maintenance and practical route and schedule design, even the most advanced technologies will be of little use for achieving reliable transit service. Planning actions and policies that may improve reliability include parking restrictions to ease traffic congestion, prohibiting left turns, simplifying route structures and avoiding long routes, reducing the number of stops and duration of dwell times, giving signal priority to transit vehicles, and designating transit-only lanes.

\section{Transit Cessation and Retention}

Some existing literature on this topic indicated the existence of a natural transit life cycle that tends to result in the eventual cessation of use. As such, ridership retention strategies should seek to prolong this life cycle. Data from household travel surveys in Washington, D.C. and Pinellas County, Florida, indicate that most users stop using transit when they 
gain access to a car (i.e., when they have a choice). The second most common reason is a change in job, job location, or residential location. Smaller percentages of respondents indicated dissatisfaction with transit service characteristics as their reason for ceasing transit usage. For example, only six percent of the respondents in the Washington, D.C., survey reported that they stopped using transit because it was not "reliable enough."

Similar findings emerged from a close examination of the 10 survey waves from the Puget Sound Transportation Panel (PSTP). Just prior to making a mode switch, most respondents indicated a change in occupation or job location. It is reasonable to assume that these changes might add or remove transit as a viable alternative mode, depending upon the hours and location of both the workplace and residence, and the available transit services.

However, the PSTP also included a series of attitude surveys, which did indicate that those most concerned about being on time, those most annoyed by travel delays, and those who experienced problems associated with late transit vehicles are more likely to switch to driving. With a pattern of service problems, choice riders will certainly be more likely to switch. In addition, the training of bus operators in the provision of excellent customer service cannot be emphasized enough. The operators are the "face" of the agency and often the only point of contact for the customer. If the user has other alternatives available, especially his or her own car, a few negative experiences (or even a single such experience) might result in less frequent use or a cessation of use altogether.

It is also important to re-emphasize the importance of customer satisfaction to retention and ridership growth. Successful niche marketing can be used to improve service quality and boost customer satisfaction levels. Research discussed in the literature evaluates the success of niche marketing based on its ability to influence customers to use, reuse, and recommend public transit to other consumers. Survey analysis indicated that consumers are most likely to reuse, expand, and recommend transit services that they perceive as safe, well-organized, and more convenient than driving. This finding suggests that promoting these three aspects of service may allow transit agencies to most effectively leverage their investments in niche service marketing. Moreover, if transit agencies want to use niche marketing strategies to increase ridership on their traditional services, they must not only deliver service excellence, but promote it as well, using the best operators and equipment available. 


\section{Infrequent Riders}

In addition to postponing rider cessation, transit agencies may successfully boost ridership by encouraging infrequent riders to increase and diversify their use of transit services. Indeed, there is a growing body of evidence suggesting that infrequent riders may be a critical market for building transit ridership and revenue. Given the conventional wisdom and standard practices within the transit industry, these findings are surprising, and suggest the need for new directions in transit marketing and pricing strategies.

Overall, the data analyzed for this effort indicate that the attitudes of infrequent users regarding transit are relatively positive, and most are not eager to switch to driving. These findings suggest that most of the infrequent riders have chosen to use transit for a certain portion of their travel needs and are relatively satisfied with it. However, as mentioned previously, marketing research has shown that a high number of users are likely to switch (i.e., stop using a product of service) because of failed service encounters. As such, emphasis on customer service, particularly among bus operators, is essential.

\section{Further Research}

While this project sought to comprehensively analyze and synthesize the relationships among transit ridership, reliability, and retention, the effort uncovered the need for even further research in these areas. Transit agencies do not generally collect significant amounts of data and information from their users, aside from what can be generalized from on-board surveys or other household surveys. While many providers of typical goods and services can track individual use of their offerings, locating infrequent users or ex-users of a public transit service in order to obtain additional information is difficult. This lack of information also prevents an even deeper understanding of the behavior of these rider (and ex-rider) segments. Additional market segmentation research of other transit user groups and their regional differences can further uncover user preferences.

Also, the precise relationship between travel time reliability and transit ridership, while certainly significant, remains somewhat elusive. Transit agencies should continue moving toward customer-oriented measures of reliability and satisfaction. Even if this research had determined and used a particular definition for reliability, or on-time performance, the meaning of any result might be obscured because of the varying subjective values that 
transit users and non-users place on mode reliability and travel time (as well as other mode characteristics). It is possible that the values placed on reliability and travel time might vary not only based on individual characteristics but also on regional characteristics, and this value of time is an area requiring additional research. 


\section{TABLE OF CONTENTS}

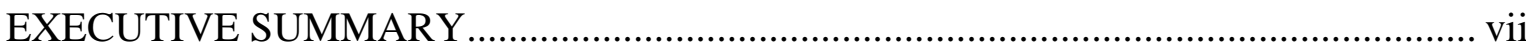

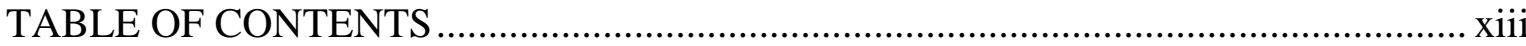

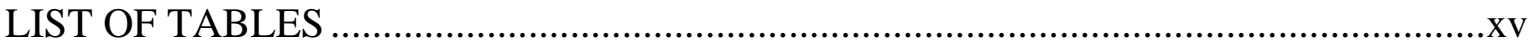

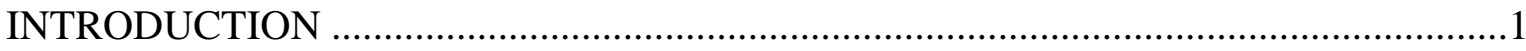

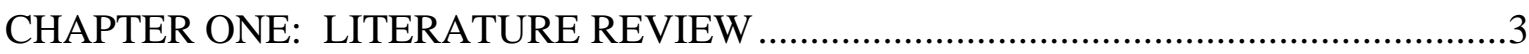

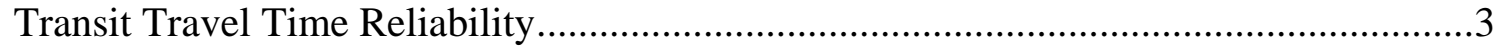

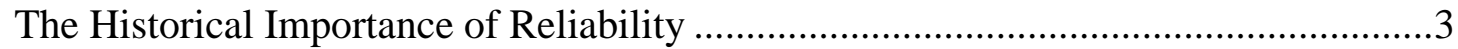

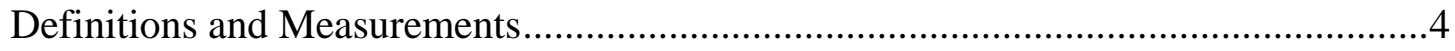

Perceptions, Behaviors, and Values Regarding Time .............................................

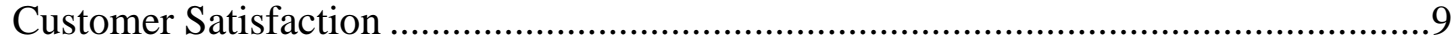

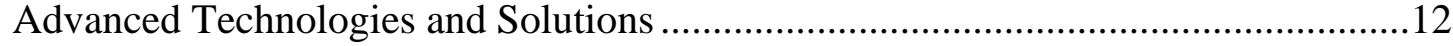

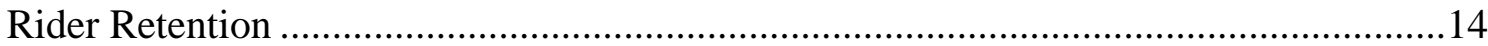

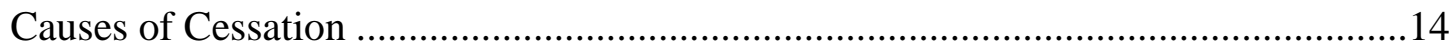

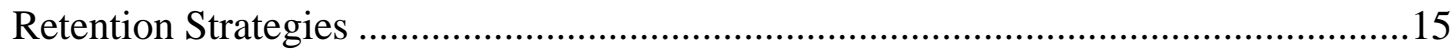

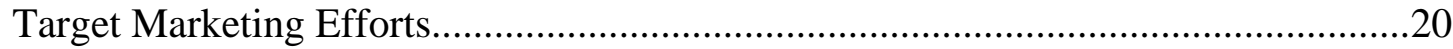

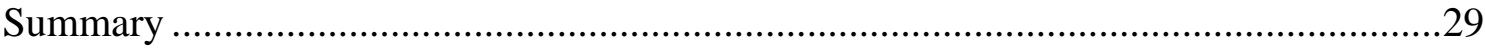

CHAPTER TWO: SYNTHESIS AND ANALYSIS OF EXISTING DATA.....................31

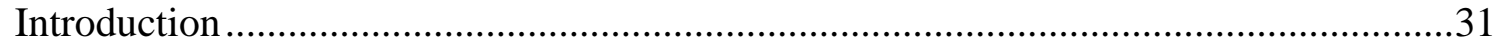

Puget Sound Transportation Panel Data Set ....................................................... 31

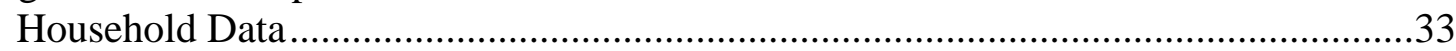

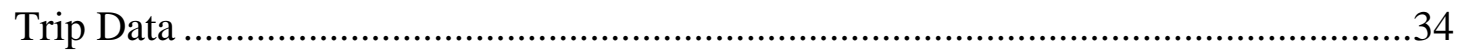

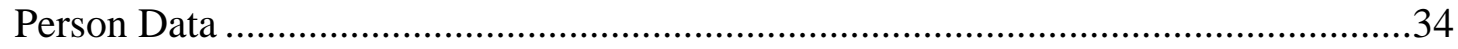

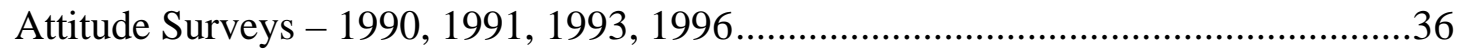

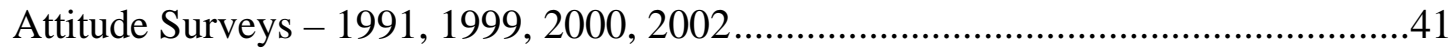

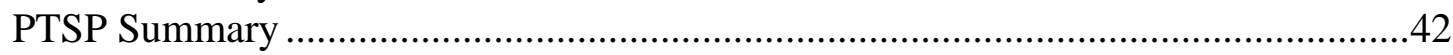

APTA Transit Performance Monitoring System (TPMS) ..........................................42

APTA - A Profile of Public Transportation Passenger Demographics and Travel

Characteristics Reported in On-Board Surveys ......................................................44

Florida On-Board Survey Database ...................................................................46

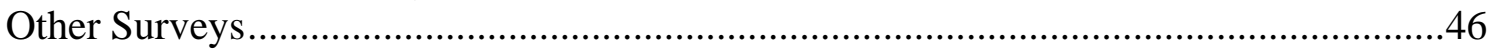

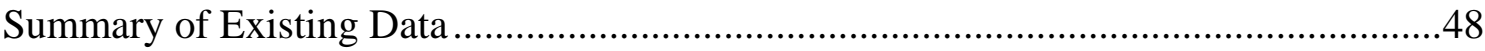

CHAPTER THREE: TRANSIT RELIABILITY AND RIDERSHIP .............................51

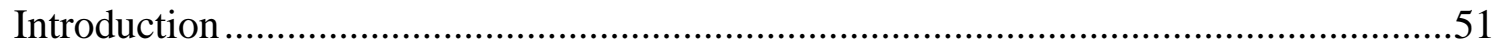

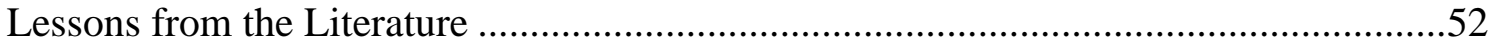

Observations on Reliability Revealed by On-Board Surveys \&

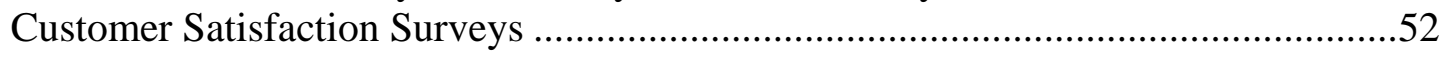

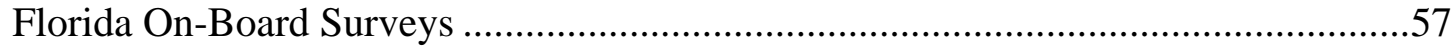


Attitudes on Reliability Revealed by the Puget Sound Transportation Panel Surveys....68

Impacts of Transit Travel Time Reliability on Ridership: Agency Experiences ............82 Evidence from Transit Agency Experience with Improvements to

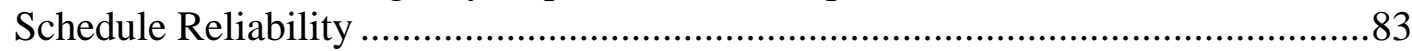

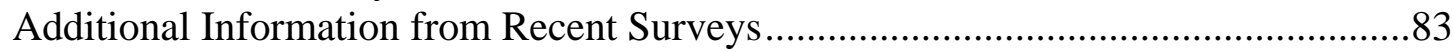

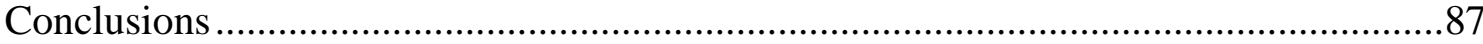

CHAPTER FOUR: CESSATION OF TRANSIT USE ….............................................91

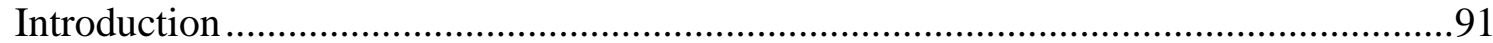

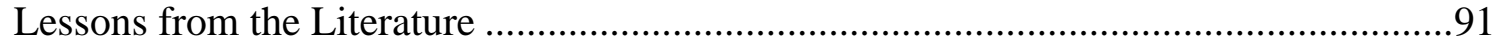

Characteristics Revealed by Household Travel Surveys ...........................................92

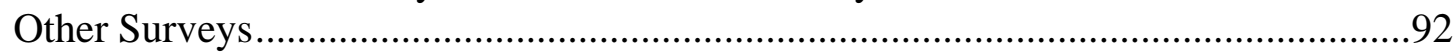

Puget Sound Transportation Panel ........................................................................95

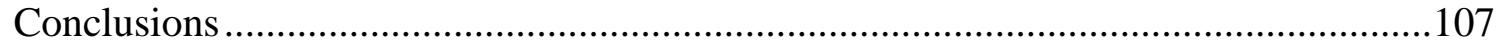

CHAPTER FIVE: CHARACTERISTICS OF INFREQUENT RIDERS.......................111

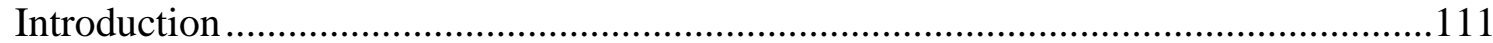

Lessons from the Literature .................................................................................112

Characteristics Revealed by On-Board Surveys .........................................................112

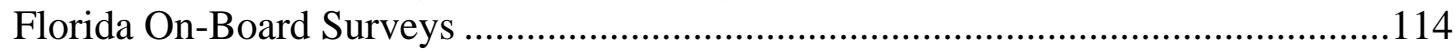

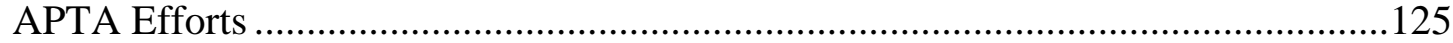

Characteristics Revealed by Household Travel Surveys .........................................126

Puget Sound Transportation Panel ...........................................................................126

Pinellas County, Florida, Household Travel Survey.............................................139

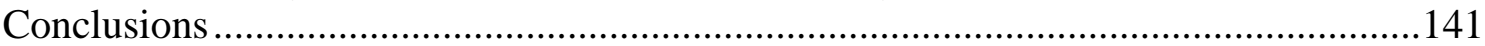

CHAPTER SIX: OVERALL FINDINGS AND CONCLUSIONS ...............................145

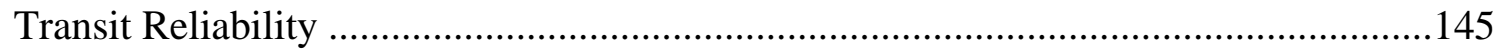

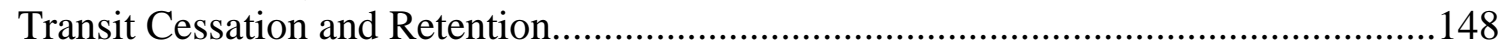

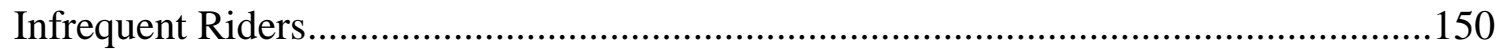

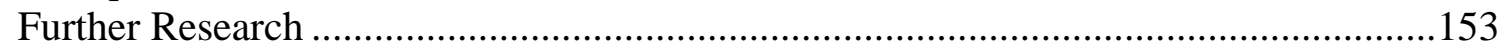

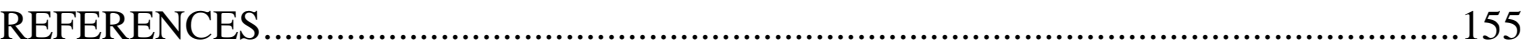




\section{LIST OF TABLES}

Table 2-1: Primary Work Mode - Puget Sound Transportation Panel ...............................32

Table 3-1: On-Board Surveys Used to Analyze Reliability...........................................58

Table 3-2: Satisfaction with Schedule Reliability - Florida On-Board Surveys ................59

Table 3-3: Work Trip Purpose - Florida On-Board Surveys...........................................60

Table 3-4: School Trip Purpose - Florida On-Board Surveys ..........................................60

Table 3-5: Reason for Riding - Florida On-Board Surveys ..........................................61

Table 3-6: Alternative to Transit - Florida On-Board Surveys .......................................62

Table 3-7: Frequency of Transit Use - Florida On-Board Surveys ...................................63

Table 3-8: Length of Transit Use - Florida On-Board Surveys.......................................64

Table 3-9: Age Groups - Florida On-Board Surveys .................................................65

Table 3-10: Annual Income - Florida On-Board Surveys .............................................66

Table 3-11: Vehicle Availability - Florida On-Board Surveys .......................................67

Table 3-12: Primary Work Mode - Puget Sound Transportation Panel ............................69

Table 3-13: Importance of the Ability to Arrive on Time -

Puget Sound Transportation Panel Attitude Surveys (1990-1996) .......................70

Table 3-14: Select Household Characteristics of Those Rating the Ability to Arrive on

Time as "Extremely Important"-Puget Sound Transportation Panel Attitude

Surveys $(1990$-1996) ................................................................................... 71

Table 3-15: The Ability to Arrive on Time as "Extremely Important"

by Frequency of Transit Use -

Puget Sound Transportation Panel Attitude Surveys (1990-1993) ......................72

Table 3-16: The Ability to Arrive on Time as “Extremely Important”_by Share of

Respondents Rating Other Characteristics as “Extremely Important”*__Puget

Sound Transportation Panel Attitude Surveys (1990-1996) ................................72

Table 3-17: The Ability to Arrive on Time as "Extremely Important” by Select

Agreement/Disagreement Statements* _Puget Sound Transportation Panel

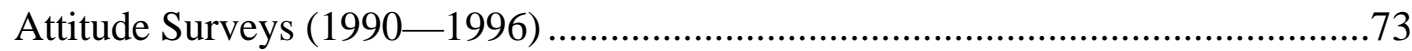

Table 3-18: The Ability to Arrive on Time as "Extremely Important"

by the Perceived Ability to Arrive On Time by Mode -

Puget Sound Transportation Panel Attitude Surveys (1990-1996) ........................74

Table 3-19: "I Get Annoyed Easily When My Travel is Delayed” -

Puget Sound Transportation Panel Attitude Surveys (1997) .................................75

Table 3-20: Agreement/Disagreement Statements*, Those Who Most Often

Travel by Bus -_Puget Sound Transportation Panel Attitude

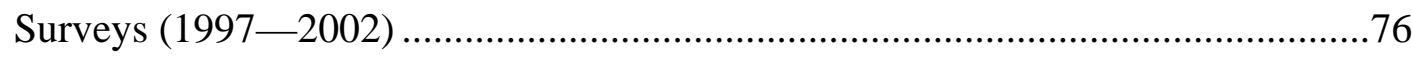

Table 3-21: Agreement/Disagreement Statements*, Those Who Indicate That They

"Would Like to Switch to Driving to and from Work/School as Soon as

Possible”-Puget Sound Transportation Panel Attitude Surveys

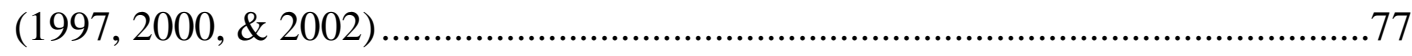


Table 3-22: Agreement/Disagreement Statements*, by Age Group __Puget Sound

Transportation Panel Attitude Surveys (1996 \& 2002)...........................................78

Table 3-23: Agreement/Disagreement Statements*, Transit Users by Age Group -

Puget Sound Transportation Panel Attitude Surveys (1996 \& 2002) ......................79

Table 3-24: “I Get Annoyed Easily When My Travel is Delayed*” by Flexibility

in Work Hours-Puget Sound Transportation Panel Attitude Surveys (1997) .........80

Table 3-25: “I Worry a Lot About Being Late*” by Flexibility in Work Hours -Puget

Sound Transportation Panel Attitude Surveys (1997, 2000, \& 2002) ....................80

Table 3-26: Mode Choice, by Flexibility in Work Hours -Puget Sound Transportation

Panel Attitude Surveys (1997-2002) ...............................................................81

Table 3-27: Southern California Regional Rail Authority Survey Results ........................86

Table 4-1: Primary Work Mode - Puget Sound Transportation Panel ...............................96

Table 4-2: Additional Characteristics of the SOV User-Puget Sound

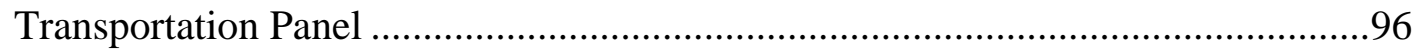

Table 4-3: Work Mode Switches* Over 10 Survey Waves -Puget Sound

Transportation Panel

Table 4-4: Those Switching To or From Transit*, by Age -_Puget Sound

Transportation Panel .98

Table 4-5: Occupation and Workplace Changes* - Puget Sound Transportation Panel.....98

Table 4-6: Car Required for Work or Children* - Puget Sound Transportation Panel.......99

Table 4-7: Importance Ratings for Deciding Travel Mode* __Puget Sound

Transportation Panel Attitude Surveys (1990-1996)........................................100

Table 4-8: Performance Ratings for the Bus Mode* _Puget Sound Transportation

Panel Attitude Surveys $(1990$-1996) ...............................................................102

Table 4-9: Agreement/Disagreement Statements* _Puget Sound Transportation

Panel Attitude Surveys $(1990$-1996) ..............................................................104

Table 4-10: Agreement/Disagreement Statements* _Puget Sound Transportation

Panel Attitude Surveys (1997-2000) ..............................................................106

Table 5-1: On-Board Surveys Used to Analyze Infrequent Riders...................................115

Table 5-2: Frequency of Use - Florida On-Board Surveys ...........................................116

Table 5-3: Work Trip Purpose for Infrequent Users - Florida On-Board Surveys ...........117

Table 5-4: School Trip Purpose for Infrequent Users - Florida On-Board Surveys .........117

Table 5-5: Reason for Riding for Infrequent Users - Florida On-Board Surveys .............118

Table 5-6: Alternative to Transit for Infrequent Users - Florida On-Board Surveys ........119

Table 5-7: Length of Transit Use for Infrequent Users - Florida On-Board Surveys .......120

Table 5-8: Annual Income of Infrequent Users - Florida On-Board Surveys ...................121

Table 5-9: Vehicle Availability of Infrequent Users - Florida On-Board Surveys ...........122

Table 5-10: Satisfaction with Transit Reliability among Infrequent Users -

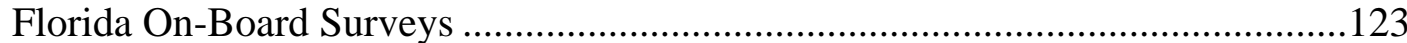

Table 5-11: Relative Importance of Transit Reliability Among Infrequent Users -

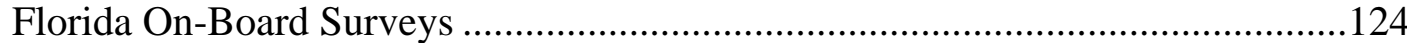

Table 5-12: Primary Work Mode - Puget Sound Transportation Panel ...........................127 
Table 5-13: Additional Characteristics of the SOV User-Puget Sound

Transportation Panel

Table 5-14: Frequency of Bus Use per Week- Puget Sound Transportation Panel

Table 5-15: Select Household Characteristics of the Infrequent Transit User-

Puget Sound Transportation Panel

Table 5-16: Importance Ratings for Deciding Travel Mode:_Share of Riders Rating

Characteristics as "Extremely Important”*__Puget Sound Transportation

Panel Attitude Surveys (1990-1993) .

Table 5-17: Performance Ratings by Mode:_Share of Infrequent Riders Rating Mode

as Performing "Extremely Well"* -Puget Sound Transportation Panel

Attitude Surveys (1990—1993)

Table 5-18: Agreement/Disagreement Statements*, Infrequent Riders _-Puget Sound

Transportation Panel Attitude Surveys (1990_1993)..........................................135

Table 5-19: Agreement/Disagreement Statements*, Infrequent Riders -Puget Sound

Transportation Panel Attitude Surveys (2002)......................................................137

Table 5-20: Select Household Characteristics of Transit Users -Pinellas County

Household Travel Survey (2007) ...........................................................................140

Table 5-21: Trip Purposes of Transit Users -_Pinellas County Household Travel

Survey (2007). 


\section{INTRODUCTION}

This research project seeks to explore three major components that affect transit ridership: travel time reliability, rider cessation, and the characteristics of infrequent riders. It has been recognized that transit travel time reliability may have a significant impact on attractiveness of transit to many current and prospective riders. There is a need to determine to what level a correlation between travel time reliability and transit ridership might exist. In addition, transit agencies are constantly attempting to keep the riders they have and attract new riders to their service. Increased rider retention may be a more realistic approach to building ridership than attracting new riders. Finally, increasing trip making by infrequent riders also represents a promising potential growth market.

Accuracy of predictions of transit ridership based on transit travel time reliability is becoming increasingly important. Knowledge of what transit improvements the potential transit customer responds to will help transit agencies to provide better services.

Regarding rider retention, much of the literature focuses on existing users or non-users, but little is known about ex-users. Transit on-board surveys across the country consistently show a high percentage of new riders over time. Given relatively stable total ridership, the constant existence of these new riders suggests a sizable degree of cessation of transit use. Little is known about people who stop using transit. In fact, the joint national effort between the Federal Transit Administration and the American Public Transportation Association called the Transit Performance Monitoring System (TPMS) recently identified high user turnover as a key research need. Who are these individuals? A good understanding of these riders is necessary to develop and implement strategies for retaining them.

There is very little information about the patterns of transit use by individuals over time. Who stops using transit, who remains loyal to transit, and who begins using transit? What are the triggering events or changes in demographic and socio-economic characteristics that bring about mode shifts to and away from transit? Panel survey data (measurement of travel characteristics over time for the same sample of individuals) is required to answer such critically important questions.

Finally, while infrequent riders can represent a majority of the rider population (based on onboard survey results examined for this project), they represent a relatively small share of total 
transit trips and have the potential to become a much larger market. Because infrequent riders have already made the first, often intimidating, step to try transit, it is potentially easier to induce them to use transit more than to attract new riders. Infrequent riders have implications to several areas of transit operations and planning, including fare media, modeling, and benefit analysis. More important, transit agencies across the country have used a variety of strategies to increase the frequency of usage by infrequent riders. These strategies fall into a number of categories, including marketing, fare structure, network structure, and passenger information systems.

This report comprises six chapters. The first chapter summarizes existing literature regarding transit ridership, reliability, and retention. Chapter 2 presents a synthesis and analysis of existing data which are further explored in later chapters. The data include on-board surveys, customer satisfaction surveys, household travel surveys, and the comprehensive Puget Sound Transportation Panel, a longitudinal study encompassing 10 survey waves and 8 related attitude surveys. Chapter 3 focuses on transit reliability and ridership. In addition to comprehensive analysis of existing data, some agency experiences with transit service reliability improvements are shared. Cessation of transit usage is the focus of the fourth chapter, although factors contributing to the start of transit use are also explored. Chapter 5 addresses characteristics of infrequent transit riders, a little understood segment of transit ridership. Finally, Chapter 6 presents the major conclusions derived from each of the preceding chapters, essentially tying together all the elements to better understand transit ridership, reliability, and retention. 


\section{CHAPTER ONE: LITERATURE REVIEW}

The literature review comprises two key sections, as outlined below:

- Transit travel time reliability

- Ridership retention

\section{Transit Travel Time Reliability}

\section{The Historical Importance of Reliability}

Transit service reliability- where vehicles run on time and adhere to schedules- has been a basic service objective throughout the history of the industry. Reliable transit service is essential to attracting and retaining riders, particularly in modern times when many transportation options are available (Levinson 2005). However, the provision of reliable service has become increasingly difficult over the past 60 years. In addition to the longstanding challenges of severe weather, equipment failure, emergencies, and demand variation, transit agencies now confront more recent trends toward longer commutes and increasing traffic congestion. These combined factors all too easily lead to service disruptions, vehicle crowding, delays, and an overall poor reputation for transit. The added travel cost of unreliable service eventually influences mode choice decisions, resulting in patronage declines over time and an increase in the amount of public funds required to support public transit services. Efficient scheduling and utilization of vehicle capacity, which provides significant benefits to transit agencies and passengers alike, can be achieved through more reliable transit service (Kimpel, 2001). In addition to containing operating costs, improved reliability lowers average passenger wait times, reduces bus crowding, and ensures greater predictability. Transit service reliability is an important measure of service quality and has a direct influence on both passenger demand and level of service. Consequently, reliability is a growing priority for transit agencies struggling to provide service that is both highquality and cost-effective (Levinson).

Most research into travel time reliability has centered on day-to-day variations in travel time, which are considered to be independent of normal traffic conditions such as congestion and traffic signalization. The most important traffic-related issue influencing bus performance is non-recurring traffic congestion (Kimpel). It is generally accepted that this congestion stems mainly from road capacity reductions caused by random events such as emergencies, 
breakdowns, and passenger or driver behavior, as well as fluctuations in day-to-day travel demand. In addition, reduced capacity during peak travel times may potentially result in greater variation in travel times (Nam, et al 2005; Noland and Polak). Because congestion typically occurs in stable daily patterns that come to be expected, it can be dealt with through effective transit scheduling techniques. However, nonrecurring problems such as traffic accidents and vehicle breakdowns introduce the element of uncertainty, making it far more complex to manage the system in real time (Kimpel). Other variables that have been found to adversely affect reliability include the number of alighting passengers, size of the scheduled headway, a time point's position in the sequence of time points, presence of a part-time driver, and new sign-up period. In addition, several studies have noted that service reliability tends to deteriorate with increases in transit route features such as scheduled distance, number of scheduled stops, number of signalized intersections, and on-street parking. Finally, driver behaviors such as not departing from the terminal on time, making unscheduled stops, or spending excess dwell time at stops may also adversely affect service reliability.

It should be noted that although most theoretical contributions regarding travel time reliability assume a continuous choice of departure times, public transit service is necessarily provided at fixed intervals. Because transit patrons must choose discrete departure times, the likelihood that a given service will correspond to the desired arrival time is reduced. Thus, regardless of variability, most transit users will arrive either earlier or later than their target arrival time. Naturally, travel planning becomes even more problematic for transit users if service is unreliable, especially considering that variability can be introduced at several points along a given journey by transit. For instance, on-time arrival, late arrival, early arrival, on-time departure, late departure, and (worst of all) early departure, can combine in any number of pair combinations to form many possible trip scenarios. Matters are complicated further when travelers must transfer to a second service. Variation in travel times during the first part of a trip increases the risk of missing a connection. Therefore, reliability is in part a function of the variability of each leg of the trip, the headway of the second leg, and the time needed to make the transfer (Noland and Polak).

\section{Definitions and Measurements}

Transit service reliability is complex in that there is no single measure that can comprehensively gauge service quality. The most common measures of service reliability generally relate to schedule adherence, running times, and headways. The relevance of each measure depends 
largely on frequency of service, whether or not timed transfers are involved, and functional purpose (e.g., scheduling or performance monitoring) (Kimpel). Schedule adherence is the most important measure of reliability for occasional users, timed transfers, and routes characterized by infrequent service. When vehicles conform to schedule, passengers are better able to coordinate their arrivals with those of the bus, resulting in average wait times that are less than one-half the scheduled headway. For high-frequency service, typically defined as service operating at headways of 10 minutes or less, headway delay is the most important indicator of reliability. Headway delay uses actual headway minus scheduled headway to measure the spacing between buses. Extreme variation in headway delay results in bus bunching, which tends to propagate as vehicles travel along a route. The uneven passenger loading associated with bunching causes additional delay and requires the use of more vehicles to serve the same number of passengers. When buses are evenly spaced, passenger loading is more uniform and cumulative passenger wait times are reduced.

TCRP Report 100, the second edition of the Transit Capacity and Quality of Service Manual (2003), is intended to provide a consistent set of methodologies for evaluating the quality of service and capacity of transit service, facilities, and systems. It is known as the primary document that incorporates research findings on transit capacity and quality of service. A set of fixed-route transit service measures is provided to assist with the measurement of transit availability and comfort/convenience at the stop-level, route segment-level, and system-level. One of the six measures is on-time performance. The manual indicates that on-time performance should be measured at locations of interest to transit riders. The six measures are presented as level of service (LOS) grades from A to F (analogous to the highway LOS measures). The ontime performance LOS defines "on time” as zero to five minutes late. For LOS A, the on-time percentage is 95 to 100 percent or, from the perspective of the passenger, approximately one late transit vehicle every two weeks (not including transfers). For LOS F, the on-time percentage is less than 75 percent or, from the passengers' perspective, at least one late transit vehicle on a daily basis (also not including transfers).

As if the measurement of reliability were not complex enough, there are also notable distinctions between passengers and agencies in their perceptions of service quality. For instance, while passengers are primarily concerned with day-to-day consistency in bus performance, transit planners and schedulers tend to evaluate reliability over longer periods of time. Also, while agencies typically monitor schedule adherence at peak load points or evenly spaced intervals such as time points, passengers are primarily affected by reliability at their particular stop. Passengers and transit agencies also differ in their conceptions of schedule adherence. On-time 
performance (OTP) is the conventional measure used by transit agencies to assess schedule adherence. OTP is expressed as the percentage of buses that depart a certain location within a predetermined range of time, generally no more than one minute early or five minutes late. Although a discrete on-time window may be practical for evaluating system reliability from a transit agency's standpoint, a continuous measure such as departure delay is more relevant to a passenger's experience of delay. Another limitation of OTP from the passenger's perspective is that it assumes that all early and late departures are of equal consequence, regardless of the delay's severity or the time of day (Kimpel).

Clearly, variations in travel time impose an added scheduling cost to travelers, due to the extra time that must be budgeted for a trip due to its uncertainty. Furthermore, customer perceptions of transit service quality are affected by waiting time, and in particular by uncertainty in time spent waiting (Reed 1995). Research by Bowman and Turnquist (1981) indicates that wait time at stops is much more sensitive to schedule reliability than service frequency, a finding that underscores the importance of reliability in determining customer satisfaction. Fluctuations in transit waiting and travel time are an inconvenience that may decrease user confidence and eventually result in the selection of a different mode (Chen, et al). Researchers hypothesize that reducing the uncertainty of the length of time spent waiting for public transit will enhance its utility to customers, fostering a larger, more satisfied customer base. Although mode choice models have shown that travel time is the most influential factor in the decision to use transit (Handy and Clifton), reliability is also an important consideration in mode choice behavior (Nam, et al). Yet until recently, the influence of reliability on mode choice has largely gone unnoticed, and empirical advances in this area have not been incorporated into standard travel demand modeling software (Noland, 2002). There are, however, some long-established principles that have been verified by models of service reliability (Levinson):

- Long, heavily-used bus lines on congested roadways are likely to have poor schedule reliability;

- When a bus experiences delays early along a bus line, delays are propagated along the route;

- For routes with long headways, schedule adherence is crucial, while for routes with short headways, uniform spacing is important (Kimpel, Levinson; Strathman, et al); and

- Reducing the number and duration of bus stops and traffic congestion along a bus route can improve both speed and reliability. 


\section{Perceptions, Behaviors, and Values Regarding Time}

In addition to exploring the factors affecting travel time reliability, a thorough study of reliability should also include the values and perceptions of travelers. Currently, very little is known about how people perceive and process information on travel time reliability, or how these perceptions change over time. Insight into how travelers apply their perceptions of reliability to the decisionmaking process may help determine the relationship between perceived values and objective measures of reliability. Such knowledge, which has yet to be integrated into standard travel demand modeling software, may lead to more accurate measures and predictors of behavioral responses and, as a result, improved cost-benefit evaluations of transportation projects (Noland and Polak).

Studies of how people learn about travel conditions over time provide insight into how they perceive travel time reliability. Simulation tests of how travelers adapt in reaction to prior experiences indicate that the most recent experience, i.e. the previous trip's travel time and schedule deviation (either early or late), is the key component in adjustment to the next trip's departure time choice. An analysis of route choice adjustments over time also suggests that more recent travel experience is more significant than less recent experience, although some people are not likely to switch routes, regardless of their experiences. Nam, et al speculate that because travelers estimate expected travel time from situations they encounter most often, they may perceive travel time in terms of mode more than mean. Other studies have concluded that experience and credible information are important factors in the learning process that may contribute to improved predictions of travel time. Not surprisingly, extreme variation in travel times may have a negative effect on learning (Chang and Mahmassani; Iida, et al.; Fujii and Kitamura; and Polak and Oladeinde; all sited by Noland and Polak).

Regarding traveler values, research has shown that people value both travel time and its reliability. Studies of travel behavior suggest that, from the traveler's point-of-view, the cost of (un)reliability may in fact be greater than the cost of expected travel time (Chen). For example, in a study of travel time variability in California, the Transportation Research Board estimated a value of $\$ 12.60$ per hour of standard deviation in travel time, compared with a value of only \$5.30 per hour for regular travel time (Key Transportation Indicators: Summary of a Workshop 2002). The values of travel time and reliability were found to be nonlinear in an analysis using data from the Austin Commuter Stated Preference Survey (Pinjari and Bhat). It was found that in the first 15 minutes, commuters place a relatively small value on travel time, and a very high value on travel time reliability. Beyond 15 minutes, however, the value of travel time increases 
rapidly, while that of travel time reliability declines. These findings are supported by a study analyzing the influence of trip length on route choice, which also indicated that the importance of travel time increases with the length of a trip (Conlon, et al). The nonlinearity of the value of travel time reliability was also revealed by a modeling study of early arrival, which found a benefit to the arrival of a transit vehicle up to about three minutes early, but a strong disbenefit for arrivals greater than three minutes early (Small et al, 1999). Additional research shows that longer waiting times are perceived as more onerous than shorter waits and that out-of-vehicle waiting time is perceived to pass more slowly than an equal amount of in-vehicle travel time (Handy and Clifton, Reed). More specifically, the value of waiting time has been estimated to be roughly two to three times, and in some studies, as much as twelve times that of travel time (Mohring, et al 1987, Reed 1995), a finding that reflects the burden of both uncertainly and exposure of the transit patron to the elements (Handy and Clifton).

However, because of the wide variation in the findings of studies that have attempted to assign a dollar value to travel time reliability, it may be more useful to examine how people make decisions related to time. In other words, do consumers really behave according to the old saying "time is money," or are decisions that involve waiting governed by a different set of conditions? In many approaches to the study of time, there is an underlying assumption that the value of time is equal to its opportunity cost, usually defined as the wage rate. This line of thinking has supported the notion that time is a resource equivalent to money, capable of being bought and spent, as well as saved and wasted (Leclerc, et al 2005). Yet behavioral decision research suggested that although most behaviors relating to time and money were comparable, the behaviors differed for all situations involving risk. The study indicated that, as with money, the value of time is highly dependent on context. For example, time was found to have a higher value in the context of a short wait rather than a long one, as well as when waiting was associated with a good or service of high monetary value rather than a low value. It was also found that subjects were inclined to avoid risk for time decisions and were significantly more risk averse for decisions concerning time than for those involving money. Most of the riskaverse subjects cited the importance of being able to make better plans as the justification for their preference. The authors believe that the introduction of uncertainty in matters concerning time creates special problems because losses or savings of time cannot be recouped or stored as can outcomes of money. Therefore, planning is even more important for time than for money, and because uncertainty makes planning more difficult, uncertainty is especially burdensome as it relates to time (Leclerc, et al). 
Given the value of travel time reliability, it should come as no surprise that it influences decisions of mode choice. In a report investigating the importance of travel time reliability and the value of travel time to transportation users, Nam, et al developed Multinomial and Nested Logit (MNL) model structures in order to obtain the model best representing trip behavior. When comparing between two models, it was found that the model that included reliability (expressed in terms of maximum delay and standard deviation of travel time) was a better predictor of mode choice. The report found values of reliability to be greater than values of time, leading the authors to conclude that, at the same level of improvement, policies designed to increase reliability may be more beneficial than policies designed to reduce travel time. Schaller (2005) also studied methodologies to gauge the relative importance of reliability as well as other transit characteristics.

\section{Customer Satisfaction}

Travel time, waiting time, and the uncertainties associated with both have been shown to affect customer perceptions of transit service quality (Reed 1995). To improve service quality from the customer's viewpoint, transit agencies should focus their efforts on reducing the inconsistency in bus performance over time (Kimpel). For instance, if a bus is consistently two minutes late, passengers merely learn to coordinate their arrival with that of the bus, whereas extreme variability forces passengers to arrive at stops much earlier in order to offset the high level of uncertainty. Hence, it should be emphasized that passengers will consider the bus reliable if it operates in a predictable manner, even if it is predictably late. The following studies illustrate the importance of the role that reliability plays in determining customer satisfaction and mode choice.

Statistical analysis of data from two on-board surveys of bus rapid transit (BRT) systems in Miami and Orlando, Florida suggest that reliability is one of the service characteristics most important to transit customers (Baltes 2003). In order to derive the correlation of various service attributes to overall customer satisfaction, the analysis employed STEPWISE regression, with the r-squared values of each attribute assigned as proxies for customer satisfaction. Attributes with the strongest ability to increase the predictive power of the regression equation were understood to be of greater relative importance to a positive customer experience. The results of the analysis indicate that customers put a premium on comfort, travel time, frequency, and reliability. 
Dramatic ridership gains have taken place following the implementation of Miami’s Busway and Orlando's LYMMO, as well as many other BRT and enhanced bus systems that provide improved travel time reliability (Baltes, Meagher). However, while ridership in the year following inception for both the Busway and LYMMO averaged about twice that of the previous service, it is difficult to determine how much of the increase is due to improved travel time reliability. Thus, the nature of the relationship between reliability and ridership growth remains unquantified. For instance, in addition to travel time reliability and high frequency service, the ridership gains of the Busway and LYMMO may also be attributable to new and existing factors that coincided with their implementation. These include increases in service provided (both revenue miles and revenue hours), aggressive marketing campaigns, real or perceived travel time savings, comfortable seating, and improved safety at stations and on vehicles. This suggests that, perhaps more than any single factor, it is the right combination of a wide range of quality service elements that will cultivate a growing clientele.

A second study also demonstrates the importance of reliability for achieving customer satisfaction. Conlon, et al. (2001) analyze before-and-after data to evaluate the success of the Chicago Transit Authority (CTA) experimental X49 Western Avenue bus route. The X49 was introduced in 1998 as the first route of CTA's Neighborhood Express Bus Route (NEBR) system, a BRT-like system of routes designed to stop only at major arterial cross streets, eliminating nearly $75 \%$ of bus stops associated with local routes. The limited-stop X49 route, which operates as an overlay onto the existing local route 49, was one of CTA's first attempts to actively encourage customer satisfaction and ridership growth at the route level. While the local 49 follows CTA's standard 1/8 mile stop spacing pattern, the X49 stops are located only at major intersections and transfer points, approximately $1 / 2$ to 1 mile apart. By serving only high-volume stops, boarding on the X49 is more efficient and travel speeds are approximately 25 percent faster than the local 49 . The researchers found that, since the inception of route X49, ridership along the Western Avenue corridor had grown by 17 percent and customer loyalty nearly doubled.

Respondents to a before-and-after survey were asked to rate the importance of, and satisfaction with, eleven individual attributes of bus service. Ratings were measured on a five-point scale, with a mean score of 4 or greater falling into CTA's target range for improved customer satisfaction. X49 riders gave the highest ratings, with six out of 10 attributes falling into the target range. Although not all scores were on target, passengers on route X49 reported much higher satisfaction on four factors known to be vital to bus customer satisfaction. It should be noted that these four factors all relate to reliability to some degree. They are: 
- On-time performance

-Wait time at stop

- Travel time to destination

- Route dependability

For a better understanding of the extent to which customer satisfaction and loyalty were improved by introducing route X49, and if such improvements contributed to ridership growth, the authors also examined customer survey responses that rated three components: overall satisfaction, likelihood of continued riding, and willingness to recommend the service to others. The more reliable X49 route had the highest overall satisfaction rating of any of the routes. The percentage of riders who were very satisfied increased from approximately thirty percent to approximately 50 percent after the changes. The second component of the survey demonstrated that riders went, on average, from "somewhat likely to continue riding" to "very likely to continue riding." Additionally, the survey showed that riders changed from "willing to recommend service" to "very willing to recommend." Finally, the authors of the study combined these three survey components to create a customer loyalty index. Riders were considered "secure" if they were very satisfied, very likely to continue riding, and very willing to recommend the route to others. While the portion of X49 customers considered secure increased from less than one-third in 1998 to more than one-half in 1999, there was no significant change for local 49 riders. These findings, along with the fact that the X49 generated higher ratings for service attributes associated with reliability, suggest that BRT or limited-stop "BRT-like” service design can result in improved reliability and, as a consequence, greater customer satisfaction.

Another example of improved reliability resulting in an impressive mode shift from cars to buses is the case of Dublin, Ireland's Quality Bus Corridor (QBC). The QBC system was implemented in the 1990s with the hope of reversing a perpetuating cycle of declining bus ridership, increasing use of private automobiles, slower bus speeds, and escalating congestion. The most prominent features of the QBCs are exclusive rights of way, high speeds, and vastly improved reliability. According to Meagher (2005), if buses are afforded the necessary frequency, priority, and investment, they can be a very acceptable alternative to private transport. Dublin's QBCs have been credited with reducing the annual number of vehicles entering Dublin proper by 21 percent. This decrease in private vehicles has been accompanied by a 32 percent increase in buses crossing into Dublin. In addition, QBCs have had a dramatic effect on mode split. On one of the most successful lines, the share of bus transit increased from 20 percent to 53 percent during the period from 1997 to 2004. Travel time reliability was increased by allowing access to 
QBC lanes only to dedicated QBC buses, provincial bus services, city taxis, and emergency and police vehicles. Dublin's transport agencies, public transport experts, and the public cite frequency, reliability, and speed as the three key factors contributing to the mode shift from cars to buses.

\section{Advanced Technologies and Solutions}

Effective service monitoring is crucial to managing random factors and unforeseen events that may disrupt normal service. Transit agencies are putting forth considerable effort to implement intelligent transportation systems (ITS) technologies in order to improve transit service reliability. These advanced technologies provide more streamlined methods for executing the techniques used to monitor transit service and improve its reliability (Levinson; Chen, et al). For instance, transit signal priority (TSP) can improve schedule adherence, reliability, and speed by extending or advancing green light times to allow late buses to get back on schedule. Another example is automatic vehicle location and control (AVLC) systems, which monitor schedule adherence in real time, enabling instantaneous service adjustments. Most of these adjustments involve the need to space service to produce uniform headways, which may entail adding an extra vehicle, filling runs from other routes, adjusting speeds, using standby drivers, running extra trips, or decreasing layover times (Levinson).

Automated service control methods, such as Portland's Bus Dispatching System (BDS), which is based upon the integration of several technologies, have shown evidence of improved service reliability. The BDS uses a computer-aided dispatch (CAD) and control center, automatic passenger counting (APC) systems, a two-way radio system enabling voice and data communication between drivers and dispatchers, and AVLC in tandem with global positioning system (GPS) technology to track buses in space and time. A study comparing OTP before and after BDS implementation demonstrated considerable improvements in OTP merely by providing schedule adherence information to operators in real time (Kimpel). Such systems also provide a wealth of information for service planning and operational improvements by recording real-time operating data at the stop level, thereby promoting more effective system design. In addition to real-time operations control, BDS data is archived and used for more long-term adjustments such as performance monitoring, service planning, scheduling, and administrative changes (Kimpel, Levinson). Furthermore, advanced data collection and communication technologies also encourage the use of more sophisticated modeling techniques, which in the past have relied on rather simplistic specifications due to the limitations of costly and time- 
consuming manual data collection. Unlike manual data collection, technologies such as the BDS collect information on a continuous basis and at much finer resolutions of space and time. Vast amounts of such detailed data provide new opportunities for analyzing transit service reliability in a more thorough and comprehensive manner than previously possible (Kimpel).

Advances in automated technologies may also cut annual operating costs by reducing the need for street supervision. By merging control of schedules, services, and operations into a single function, one central supervisor is able to "see" 50 to 100 buses, allowing street supervisors to concentrate largely on emergencies, incidents, and vehicle inspections (Levinson). However, the primary role of new technologies will likely be to improve reliability rather than contain monitoring costs, which generally account for only a small portion of a transit agency's operating costs. By 2001, more than 50 bus systems were equipped with AVLC, and many more were under contract or in the planning phase.

In addition to supplying transit operators with on-the-spot information, emerging technologies such as AVLC may decrease the anxiety of waiting by providing real-time schedule information to customers. Assuming that most waits for transit result from uncertainty regarding vehicle arrival, greater certainty of when the vehicle will arrive should allow travelers to reduce waiting times. This hypothesis was examined through conjoint analysis, a method that has been widely used to study and predict individual preferences (Reed). The analysis, in which respondents were asked to rate a series of scenarios, has shown that a higher degree of certainty regarding the duration of a wait will reduce a traveler's burden of waiting. In fact, the opinions of the study respondents indicate that real-time arrival information is about three times as important as reliability. This suggests that for customers, real-time information may have the ability to act as a surrogate for reliability. Informing riders of when vehicles will actually arrive allows them to plan their arrival to meet with that of the vehicle. Thus, real-time information shows promise not only for reducing the hardship of uncertainty while waiting, but also for reducing the length of the wait.

Of course, adequate fleet maintenance and practical route and schedule design are also essential for achieving reliable bus service (Levinson). Without sensible service planning and management policies, even the most advanced technologies and effective supervision will be of little use. Planning actions and policies that may improve reliability include using restricted parking to ease traffic congestion, operating on less congested streets, prohibiting left turns, simplifying route structures and avoiding long routes, reducing the number of stops and duration 
of dwell times, giving signal priority to transit vehicles, designating transit-only lanes, and, where necessary, building subways in congested areas (Levinson).

\section{Rider Retention}

Shifting market characteristics and changing travel patterns pose a formidable challenge to public transit today. As discussed below, the concepts of transit dependency and the captive rider are not as relevant as they once were to the public transit market in the U.S., which is now

for the most part a discretionary market (Cronin, Hightower, and Brady, 2000; Oram and Stark, 1996). Therefore, the transit industry cannot afford to be complacent. It is up to the industry to take a proactive role in achieving sustained ridership growth in a dynamic new market characterized by changing trip frequencies, occasional riders, and high turnover. The following section will discuss reasons for rider cessation and strategies for retention, with a particular focus on marketing efforts and the importance of the infrequent rider.

\section{Causes of Cessation}

Although there was a time when public transit was the only means of mobility for a significant number of U.S. consumers, most Americans now have options when it comes to transportation. Ridership, at least in the U.S. context, seems today to be a phase phenomenon related to demographics such as age and socioeconomic advancement (Barlow and Clark, 2006). In other words, although many people go through a stage of using transit, few will use it for a lifetime. Nationally, most bus riders tend to be young people who use transit intensively when they are students or new to their careers (CJI Research, 2003). As their incomes rise and lifestyles change, many stop using transit because they are able to afford a car. It appears that as people marry, raise families, and relocate, the mobility and convenience of the automobile often outweigh the benefits of transit (Bush, 2000). Thus, public transportation systems in the U.S. experience a high degree and rapid rate of ridership turnover. This is due in part to the phasic nature of transit ridership, coupled with the economically and geographically mobile society of the U.S. Because people are continually entering new life stages, the social composition of the ridership population is in a constant state of flux, meaning that at any given time, a significant portion of riders are new to transit (Barlow and Clark, Bush, CJI Research).

Rapid rider turnover yields the following two implications for achieving ridership growth (Barlow and Clark; Business, Transportation and Housing Agency, California Department of 
Transportation, 2003). First, because even a small reduction in turnover would add significantly to the growth of the transit market, strategies designed to increase ridership should focus as much on retaining current riders as on attracting new ones. Second, effective transit marketing is critical in order to provide a steady stream of information to a constantly renewing consumer base. In light of these two objectives, the industry must acknowledge that a new transportation market has emerged, make a concerted effort to determine the changing needs of that market, and redirect its product offerings accordingly. Such efforts will require a better understanding of (1) the factors that hinder or encourage transit use, and (2) the determinants of service quality perceptions and customer loyalty. This knowledge must then be effectively applied to transit service improvements and marketing strategies.

\section{Retention Strategies}

Clearly, maintaining the current rider base is crucial to sustained ridership growth, yet cessation will undoubtedly persist as people continue to age, finish school, gain employment, earn more money, buy cars, relocate, and start families. Since the transit industry cannot exactly prevent the causes of cessation, rider retention efforts should instead seek to prolong the ridership lifecycle by increasing the time period during which people are both able and willing to use transit (CJI Research). This means that a portion of riders who are currently transit dependent must eventually become riders who choose transit as a viable alternative to the car (Business, Housing, and Transportation Agency; Foote, Stuart, and Elmore-Yalch, 2001; Huffer, 1997). As discussed above, the reasons why people make the decision to stop using transit are fairly straightforward. However, factors that motivate transit use, as well as those that deter or prevent it altogether, are not as clear. Although these are complex issues that will be difficult to unravel, they must be understood in order to cultivate choice riders and stabilize today's volatile transit market.

For people who are transit dependent or share a vehicle, the most important reason for using transit is often lack of access to a private vehicle. Yet there is little information on the motivations of people who use transit by choice rather than necessity. Demographic data has shown that a significant number of transit users, particularly those commuting from suburban areas to high-density urban employment centers, have access to an automobile (Business, Housing, and Transportation Agency). If we can understand why these riders decide to use transit instead of driving, this insight might be applied to service and marketing strategies in order to retain riders, as well as attract them, in larger numbers. 
For the rider who has the option of driving, the decision to use transit appears to be a matter of trade-offs. In most urban transit systems, a trip by bus will usually take more time by far than the same trip by private automobile. What, then, makes the burden of this added time tolerable for discretionary riders? An analysis of an on-board survey of riders who use Wheels, a public transit system serving several communities near San Francisco (CJI Research), provides some insight into these questions. When asked to rate the relative importance of various reasons for using transit service, choice riders gave helping the environment, avoiding traffic, and saving money higher ratings than saving time. Apparently, choice riders consider these benefits valuable enough to offset the additional time required for travel by transit. According to the authors of the analysis, the acceptable trade-offs take place in the range of fifteen to twenty minutes of extra travel time, while the ratio of bus travel time to car travel time usually must be less than 2:1 to retain the rider by choice. It is also worth noting that when asked to rate various service components on a scale of one to ten, choice riders were less likely than others to be satisfied with coordination of transfers, bus-operator courtesy, reliability, and overall convenience. This suggests that for choice riders, disincentives associated with driving, such as traffic congestion and parking costs, may be more important in the decision to use transit than positive motivators such as convenience or reliability.

Although it may seem strange at first that this study did not identify the cost of fuel as a disincentive, it is important to remember that during the time the study was conducted, the average fuel price in the Wheels service area was $\$ 2.02$ per gallon. It has not been uncommon in recent times for the price of fuel in the area (and nationwide) to rise well above $\$ 4.00$ per gallon; during the summer of 2008, prices rose to more than $\$ 5.25$ in the Wheels service area. According to a 2008 ridership report by the American Public Transportation Association, the disincentive of high gas prices is indeed a strong factor in the motivation to use transit (http://www.apta.com).

\section{Attitudes of Non-Riders}

Because the majority of research on transit consumer satisfaction is based on surveys of existing riders (Business, Housing, and Transportation Agency), transit operators have very limited knowledge about the attributes of non-riders and ex-riders. Consequently, services are designed to accommodate the needs of current riders who typically have low incomes and few mobility options, while little effort is spent investigating service initiatives that might retain riders over 
time. As mentioned previously, riders tend to cease using transit when their incomes rise and lifestyles change to the degree that transit is no longer sufficient and driving becomes a viable option. If these potential ex-riders are able to avoid or delay the transition to driving, higher rates of retention and subsequent ridership gains would likely result. Insight into why non-riders do not currently use transit may shed some light on why current riders might stop using transit in the future. Thus, information gleaned from the non-rider perspective may prove quite useful in devising rider retention strategies.

It is interesting to note that non-riders questioned in a California statewide household travel survey consistently indicated a desire for the same travel benefits as transit riders: reliability, convenience, safety, and comfort (Business, Housing, and Transportation Agency). However, non-riders appear to have stricter standards for each service category and are less likely to commit to using transit, even if their higher expectations are met. When asked which of several specific service improvements would entice them to use transit regularly, roughly 15 percent of non-riders in the California household travel survey claimed they would ride regularly if routes "were closer to home, if buses ran more often, and if service were faster or more direct" $(5,6)$. Nearly one third of respondents indicated that they would ride more often if the bus were on time. These same respondents also most frequently ranked reliability as the most important criterion for using transit service. Of course, a hypothetical claim by a large portion of respondents is no guarantee that all of them would follow through and actually increase their use of transit. However, if even a fraction were to do so, a substantial increase in ridership would occur.

The California survey asked non-riders to state their reasons for not using transit, as well as the types and degree of service adjustments that would be required to persuade them to use transit services. Not surprisingly, the results suggest that the primary reason people choose not to use transit is that it does not meet their specific travel needs. Survey participants identified one or more of the following conditions as obstacles to transit use.

- Current routes and stops are not convenient to desired origins and destinations.

- Transit frequency and/or service span are inadequate to accommodate travel schedules.

- Transit lacks the flexibility needed to run errands or make other necessary trips.

- Transit lacks sufficient security in and around facilities and stops.

- Transit travel time is too long.

- Trips by transit often require at least one transfer. 
- There is a need for more information regarding which services are available and how to access them.

According to the authors of the analysis, "These service-related issues are at the heart of why people do not or cannot choose transit as a travel option" (6). However, in addition to service enhancements that make transit a more feasible option, the authors stress that improvements in perception will also be necessary for sustained rider retention.

\section{Customer Satisfaction and Loyalty}

With the increasing realization that customer satisfaction is a challenge for transit, there has been a shift in recent years toward more customer-oriented service strategies. Great strides have been made in market research and the development of customer-defined measures of service quality, such as driver courtesy, reliability, or smoothness of ride. However, in an analysis of a Chicago Transit Authority (CTA) customer survey, Foote, Stuart, and Elmore-Yalch (2001) find that customer loyalty may also be an important transit performance measure. The authors point out that (1) only a truly satisfied customer will be a truly loyal customer, while those who are not highly pleased are very likely to switch between brands or service providers, and (2) transit ridership in the U.S. today is strongly linked to increasing the number of choice riders- people who have the option to switch to another mode if they choose. Based on these principles, they argue that customer satisfaction and loyalty are the fundamental ingredients for achieving growth in urban transit use. When considering the significance of rider retention as discussed above, customer loyalty may indeed be a good indicator of public transit's ability to increase ridership.

In keeping with the focus on "customer-driven" service, CTA conducted customer satisfaction surveys in the fall of 1995, 1997, and 1999, to measure perceptions of CTA management style, performance in various customer-defined service quality attributes, and overall satisfaction and loyalty. The specific goals of the survey program were to:

- Identify market segments most likely to be influenced by enhanced service quality,

- Determine which performance attributes are most vital to customer satisfaction and loyalty,

- Assess overall agency performance, and

- Identify actions that increase satisfaction and loyalty 
The survey analysis revealed significant shifts in household travel market share, customer travel frequencies, and the share of choice riders among CTA's customers. For instance, the proportion of infrequent riders increased considerably, from 37 percent in 1995 to 49 percent in 1999, resulting in a much broader market base among a larger number of households. There was also a significant increase in the proportion of choice riders who own a car but prefer to use transit for at least some trips, from 40 percent in 1997 to 47 percent by 1999. In 1999, an additional 13 percent chose to forego owning a car altogether in favor of using public transportation, bringing the grand total of choice riders on CTA to an impressive 60 percent. The increase in choice riders is consistent with the higher proportion of infrequent riders, who generally tend to have other mode options available, and are therefore more selective when it comes to travel choices.

To help determine what is necessary for choice transit riders to become very satisfied customers, CTA developed a three-part customer loyalty index based on three questions that were posed to survey respondents:

1. “How satisfied are you overall with CTA service?"

2. "How likely are you to continue riding CTA service?"

3. "How willing are you to recommend CTA service to a friend, family or co-worker?"

These three questions, each worth between one and five points, are the foundation of CTA's customer loyalty index. This index is based on achieving the very highest rating for two out of the three measures. Hence, out of a range of three to 15 possible points, the target zone for customer loyalty was set at between 14 and 15. This seemingly unrealistic target is justified by one of the most general principles of market research: consumers who are not completely satisfied with a product or service are likely to leave at the first opportunity and should be considered vulnerable to market competition. Applying this maxim to transit would mean that only truly satisfied customers will be retained long enough to offer transit agencies the possibility of increased ridership and greater farebox return. The proportion of riders within the target range increased from only 27 percent in 1995 to 46 percent in 1999.

Customer-derived measures of loyalty and satisfaction were responsible in large part for the increase in loyal customers and the higher ratings for specific performance attributes. During the two-year period from 1997 to 1999, ridership growth occurred in tandem with the most dramatic increases in customer satisfaction and loyalty, suggesting that the loyalty index could be a useful measure of public transit's ability to attract additional choice riders. The researchers emphasize 
that, in order for CTA to sustain its impressive level of customer loyalty and continue to attract new choice riders, the agency must persist in improving the service quality features that matter most to customers. This can be achieved through ongoing market research on the service attributes that have the greatest influence on customer satisfaction and loyalty. The authors also note that when no major increases are observed in specific performance attributes and service quality is perceived to stabilize, it will be difficult to attract new choice riders. However, this may be possible to some extent through expanded marketing and promotion efforts emphasizing the positive transit performance measures that are most attractive to choice riders. Several transit agencies have used the market segmentation approach with great success to identify key characteristics and travel needs of existing and potential rider groups. Of particular interest is the growing body of evidence suggesting that infrequent riders may be critical to growth in transit ridership.

\section{Target Marketing Efforts}

\section{Infrequent Riders}

In addition to its preoccupation with the captive rider market, the standard practice of the transit industry has been to cater to regular riders who make large numbers of daily commuting trips. However, the emphasis on these conventional market segments reinforces outmoded assumptions regarding transit users and may actually result in overlooking a bigger market opportunity. Along with postponing rider cessation, transit agencies may successfully boost ridership by encouraging infrequent riders to increase and diversify their use of transit services (Cronin, Hightower, and Brady). Results from research of on-board surveys, fare structure changes, and fare subsidy plans support the idea that infrequent riders may in fact be a critical market for building transit ridership and revenues (Oram and Stark, 1996). Considering the industry's traditional focus on daily commuters, these findings are surprising and suggest the need for new directions in transit marketing and pricing strategies.

In order to remove frequency bias and the resulting erroneous data interpretations, the researchers weighted raw survey data according to the assumption that a rider's chance of being surveyed is directly linked to the number of trips a rider takes. The frequency-corrected data revealed that infrequent riders (those using transit twice a week or less) represented the majority of total transit users and also accounted for a large share of total trips taken. Thus, at least on a frequency basis, most people who use transit cannot be considered transit dependent. In further 
support of the idea that transit dependency may be an archaic market concept, cross tabulations of the frequency-corrected data show that new riders are disproportionate as infrequent riders, very likely to stop riding, and tend to be younger and more affluent than longer-term riders. Turnover and low frequency more accurately describe transit use. According to the authors, getting infrequent riders to use transit at least a little more is "a reasonable and perhaps easily achieved goal. A less reasonable goal is to fully convert these riders...to regular or daily use” (37).

Insights regarding transit user characteristics and the transit rider lifecycle have also emerged from this research. In regard to their inclination toward infrequent use, new riders are more likely to use transit for occasional work trips rather than off-peak or non-work trips. Their trip rates appear to increase with their duration of riding, possibly expanding into off-peak use with continued riding, although this is unlikely considering the high rates of turnover observed. In addition, cash-paying riders are disproportionately seen to be infrequent users and new riders, which in turn suggests that they are more likely to stop riding. All of these findings emphasize the importance of cultivating the commitment of new and infrequent riders through outreach, distribution of information, promotional programs, and pricing strategies. The authors cite new evidence from one obvious approach, the deep discount fare strategy, as further substantiating the importance of infrequent riders.

As mentioned earlier, survey data revealed a correlation between fare payment methods and trip frequency, turnover, and ridership stability. While infrequent riders, new users, and riders with shifting trip frequencies tend to pay cash, fare prepayment correlates with more trips, stable trip rates, and longer periods of ridership. The deep discount fare strategy, which assumes that prepayment correlates with greater frequency, duration, and stability of ridership, uses prepayment incentives to get more riders to display these favorable ridership behaviors. By raising cash fares while leaving the price of multi-ride tickets unchanged, deep discount strategies are designed to offer at least a 25 percent discount to riders who switch from cash to tickets. By giving riders the choice either to avoid higher fares by buying multi-ride tickets or to pay the higher fare, deep discounting separates the infrequent rider market into fare-sensitive and fare-insensitive segments. Deep discounting has been shown to raise ridership by a small percentage and offset ridership loss during fare increases, as well as raising revenue by 15 to 20 percent without losing riders.

According to the researchers, the fact that fare increases can result in ridership and revenue growth shows that "some powerful marketing factors other than price are being activated" (39). 
First, fare prepayment and the perception of a discount have been shown to build ridership. This is supported by the fact that infrequent users in the study who bought ten-ride tickets tended to ride more than when paying the cash fare. The other factor at play is that many infrequent riders are fare-insensitive and readily pay more without changing their riding habits. The authors argue that the importance of infrequent riders is validated by the success of the deep discount plan, which is "perhaps the most broadly applicable single action for making the frequency, turnover, and related characteristics of the transit market better serve transit agency goals” (39).

The authors found "the most interesting" findings regarding the importance of infrequent riders from survey data on the effect of the Commuter Check fare subsidy program in the San Francisco Bay Area. The Commuter Check program offers two denominations, \$20 and \$30 Commuter Checks, that are bought by employers and given to employees as a tax-free benefit. The survey found that 33.9 percent of the respondents increased their use of transit for commuting. The average reported increase was 3.24 trips per week per recipient. However, one aspect of the analysis was counterintuitive: no correlation was found between the increases in transit work trips and the value of the Commuter Check received. Logically, one would expect that $\$ 30$ subsidies would result in more new trips than $\$ 20$ subsidies, but this was not observed. Generally the same impact was seen for both denominations; in fact, more trips were induced for recipients of \$20 Commuter Checks. After ruling out employer location as an explanation for the contradiction, it was discovered that trip frequency was the deciding factor. It was seen that most users induced to take additional transit trips were occasional riders. Logically, those already riding frequently could not add more trips. Hypothetically, those riding occasionally or previously not at all would shift some, but not all, of their trips to transit, and would only use a fraction of the full one-month subsidy for taking daily transit trips. This hypothesis is supported by the data. Not only were most induced trips from previous infrequent riders, but most of the increases were light- just one to two, three to four, or five to six new trips per week. Formerly infrequent riders who are still not regular riders make up the largest single group of induced riders, which further confirms the role of infrequent users as a new rider market.

\section{Niche Services}

In spite of the need for innovative marketing solutions, comparatively little attention has been directed toward developing a better understanding of how consumer marketing approaches might be utilized by public transit agencies. According to Cronin, Hightower, and Brady (2000), special-purpose, or “niche,” marketing efforts are an effective strategy that should be employed 
in order to attract and retain riders in order to offset the prolonged decrease in transit's market share. Key assumptions that underlie the use of niche marketing strategies are that they can help transit agencies attract and retain users by influencing riders to expand their service usage. Yet, according to the authors, because public transit agencies tend to offer niche services merely as a “convenience” or "public service,” the potential of these efforts as a marketing tool has been largely unrealized (65). Rather than a decaying market for transit services, the authors argue that declining transit patronage reflects a need for new directions in product planning, guided by a better understanding of the factors that motivate individual transit choices.

Organizations experiencing a small and declining market typically respond with marketing efforts aimed at increasing product awareness and encouraging trial use. For consumer products, trial use is usually promoted via sampling of the product by potential customers. In the case of public transit, sampling as a marketing strategy is obviously more of a challenge. However, there is a lesson to be learned from the consumer marketing tactic of bringing a product to a central location, such as a local mall, where large numbers of consumers can sample it. The nearest counterpart to the sampling approach within the transit industry is the niche market strategy, defined as "one-time, or infrequently occurring, transit services designed to offer access to a unique event or activity” (65). Typical examples include sporting events, holiday celebrations, parades, seasonal festivals, and similar events. The aim of niche marketing is to identify events that attract large numbers of people (non-transit users in particular), and where transit service is a visible, attractive, and feasible transportation alternative. When given the opportunity to avoid traffic jams, stressful searches for parking, possible theft or damage to their vehicles, and other inconveniences, consumers will supposedly be enticed to sample transit services.

To better understand the implications of niche marketing strategies, the authors studied data from personal intercept surveys. Data were collected in four metropolitan areas of varying sizes and in different regions of the country, each with a well-established public transit agency. Niche services in the four sites included a college football shuttle, professional football shuttle, summer metropolitan park shuttle, and an employee subscription vanpool service. Analysis of the data revealed that, of the niche services in question, approximately 65 percent of riders represented new or infrequent riders; furthermore, after using the niche service, over 62 percent indicated that they would be willing to use other public transit services. These findings support the idea that niche marketing can be used as a means of attracting and retaining new or infrequent transit users, thus increasing overall transit ridership. To explore niche marketing strategies in more detail and determine their optimal use, the analysis focused specifically on: 
- Whether the users of such services are likely to be non- or infrequent public transit users, and if so,

- Whether the use of niche services is likely to result in an increase of their overall transit use, and

- What determines the service quality perceptions and satisfaction levels of niche transit customers

In terms of service quality and customer satisfaction, the authors stress that the success of niche marketing depends on its ability to influence customers to (1) reuse the niche service, (2) use other transit services, and (3) recommend public transit to other consumers. Survey responses regarding all three behaviors reveal that riders are inclined to react to niche strategies in a manner beneficial to the transit agency. Also, though not surprising, analyses of the survey data validate a strong correlation between service quality and customer satisfaction. The results show that service quality perceptions and customer satisfaction have a "consistently strong, positive, and statistically significant influence" (71) on the willingness of consumers to engage in the desired behaviors. Additionally, since most of the customers who used the services investigated were not regular transit customers, their willingness to use the service again indicates that such services have the ability to retain, as well as attract, new riders. These findings suggest that if transit agencies want to use niche marketing strategies to increase ridership on their traditional services, they must not only deliver service excellence, but promote it as well, using the best operators and equipment available. Survey respondents identified the following as important elements of service quality:

- Safety,

- Convenience,

- Organization,

- Fast travel time,

- Reasonable wait time,

- Information availability,

- Smooth, uncrowded ride,

-Vehicle comfort,

-Vehicle cleanliness,

- Ease of ticket purchasing,

- Staff courtesy, 
- Convenient parking

- Convenient stops, and

- Linkage to the local transit system.

Of all these elements, the analysis revealed that consumers are most likely to reuse, expand, and recommend transit services that they perceive as safe, well-organized, and more convenient than driving. This finding suggests that promoting these three aspects of service may allow transit agencies to most effectively leverage their investments in niche marketing.

Overall, the researchers conclude that niche strategies, when they are properly planned and executed as a promotional tactic rather than as a public service, can be an effective means to attract and retain new transit customers. By using entertainment-based venues to promote the quality of their services, transit agencies have an opportunity to provide a level of satisfaction that will encourage infrequent or first-time riders to consider public transit as an option for their daily travel needs. Moreover, these services do not have to be given away. Sponsors of events or the riders themselves are often perfectly happy to pay for the convenience of using such services. Thus, niche marketing strategies are not only one of the most effective investments for reaching new markets; they are often profitable in their own right.

\section{Advertising and Promotion}

A good example of successful advertising and promotion of niche services can be found in the St. Louis Metropolitan region's public transportation system, Metro, which has targeted specific destinations and audiences to bring millions of new riders to the system over the years. Huffer (1997) claims that advertising and marketing such services can be extremely effective when the service "is designed to be fun, convenient, and interesting." The service delivery concept at Metro consciously pursues the destination and special events market as a segment that is crucial to attracting first-time customers. In addition to new riders, this market provides Metro with a steady stream of revenue during non-peak hours.

MetroLink, the region's light rail system, directly serves attractions such as Lambert International Airport, local universities and colleges, a special events arena, sports stadiums, a convention center, the central business district, and two casinos. Because it serves so many popular activity centers, destination advertising lends itself to this system and has been a very effective media. Many of the businesses along its alignment promote MetroLink as the best way 
to get to local attractions, and the local media actively encourage locals to use MetroLink as a way of avoiding and easing traffic congestion during special events. In addition, Metro has cultivated a close rapport with the Convention and Visitors Commission, which advertises MetroLink in order to promote St. Louis as an attractive convention site. According to Huffer, MetroLink service helped reverse a decade-long decline in ridership and was essential to improving public opinion of local transit service. This shift in opinion is all the more significant in light of the fact that many of the millions of yearly riders drawn to the above local attractions are new to public transit.

Huffer asserts that people became more amenable to using bus services due in large part to the success of the MetroLink light rail system. Metro used this newfound public support as an opportunity to develop and market new services designed around special destinations or events. These services are advertised by using unique names and paint schemes, as seen on the two popular "insect” routes that attract over a half million riders per year. The Forest Park ShuttleBug is painted red with black dots to resemble a ladybug, while the Clayton ShuttleBee is painted like a giant bumble bee. Both routes feature highly visible, specially designed "bug stop” signs. The ShuttleBug connects MetroLink with various cultural institutions, upscale restaurants, and the Washington University Medical Center. The cultural institutions along the route heavily promote the ShuttleBug, and over the years have provided Metro with a special grant to be used solely for the marketing of the service. The ShuttleBee, which provides high frequency service between MetroLink and the nearby commercial and residential district of Clayton, is promoted by Clayton hotels and businesses, as well as the St. Louis Convention and Visitors Commission. Also, in exchange for painting their logo on the side of the bus, the St. Louis Post Dispatch offers a major sponsorship of the route in the form of free Metro advertising in its special entertainment section. Although the ShuttleBee previously existed as the 55 Clayton Shuttle, it experienced a 35 percent increase in riders within six months of transitioning to the ShuttleBee. Similarly, ridership on the ShuttleBug route increased each year compared to the previous year since its inception, which, at the time of Huffer's article, was four years.

In addition to the niche marketing opportunities offered by the popular insect routes, Metro provides other niche services that play a central role in attracting customers to both rail and bus. These services, advertised by Metro as fun runs, are designed to serve local sporting events and festivities such as $4^{\text {th }}$ of July weekend, the Mardi Gras and St. Patrick's Day parades, the annual First Night celebration, and the events at the outdoor Municipal Opera. Service to St. Louis Rams games has given Metro a transit market share of almost 20 percent, among the highest of all NFL cities. To promote the service, MetroLink rail cars were decorated with Rams logos and 
colors, and giant Rams helmets were used as markers for Park-and-Ride lots for both rail and bus. A vigorous advertising campaign during the team's first year in St. Louis resulted in exceptional ridership that year, as well as sustained ridership in the following years; in its first two seasons alone, the service drew 500,000 riders to Metro. Metro also plays a major role in transporting people to and from the three-day long Fair St. Louis, one of the largest $4^{\text {th }}$ of July celebrations in the U.S. Every year, the $4^{\text {th }}$ of July is the highest ridership day of the year on MetroLink, attracting more than triple the normal daily average. Because Metro provides extra service for the Fair, it is considered a major corporate sponsor and receives plenty of free advertising, as well as being advertised by the news media as the best way to get to the fair. Because fun run brochures contain details about other public transit services, all of Metro's services are marketed during special events, which helps to keep audiences interested and informed nearly all year long.

\section{Direct Mail Promotion}

Another marketing approach for building transit ridership, the direct mail promotion, was used by the Wisconsin Department of Transportation (WisDOT) to great success in persuading nonriders to trial use and increasing the riding frequency of existing customers (Bush, 2000). With the goal of building and sustaining long-term transit ridership in targeted areas, WisDOT partnered with four transit agencies in southeastern Wisconsin to develop a direct mail campaign that occurred over a three-month period in the fall of 1998. The campaign also tracked shortterm rider activity for the purpose of guiding future targeted marketing efforts. In addition, the mail promotion and local newspaper and radio provided messages to emphasize the benefits of riding the bus and to strengthen the image of the transit industry. The goal of the mail promotion was to catch the reader's attention at the mailbox, provide useful information on transit service, and induce the reader to take action on the direct mail offer. The mailer, which was geared toward under-performing portions of existing transit service areas, encouraged trial use of the transit system by offering 10 free rides (a value of $\$ 10.00$ - \$13.50 depending on the specific system). To ensure a positive customer experience, only areas with adequate levels of service were selected to receive the mailers.

After receiving a mailer, interested parties were required to fill out a business reply card (requesting the person's name, address, and daytime and home phone number) and mail it back in order to receive the free rides. This enabled the development of a database of program participants. Upon receipt of the completed card, 10 free-ride tickets were sent to the program 
participants, along with a welcome letter, route map, and schedule. The free tickets also contained a serial number so that coupons could be tracked according to individual rider activity.

Of the 58,156 households that received the mailer, almost nine percent (approximately triple the transit mode share for the region) requested the 10 free-ride tickets. The direct mail campaign enjoyed a high redemption rate of 53 percent of tickets that were distributed, providing over 27,000 free rides. To better understand the transit riding habits of program participants before, during, and after the direct mail offer, people who redeemed free ride tickets during the promotion were randomly surveyed by telephone. Survey responses were grouped according to the respondent's travel behavior before the promotion. Sixty-three percent of participants were identified as "regular riders," (defined as those who usually rode the bus more than once a week) while "infrequent riders" (defined as those who generally took the bus from a few times per year to twice a month) were found to account for 23 percent of the survey respondents. Non-riders represented 14 percent of those surveyed.

As expected, the survey found that regular riders, who redeemed an average of 8 tickets, used more free tickets than infrequent or non-riders. However, the results also indicate that the promotion was successful in persuading non-riders to trial use and encouraging infrequent riders to significantly increase their trip-making frequency during the incentive period. Non-riders redeemed an average of 3.6 tickets per person during the promotion, and 14 percent of non-riders used all 10 tickets. Furthermore, thirty percent of the people who were non-riders prior to the promotion reported paying to ride the bus after the free tickets had expired. The campaign also significantly increased the riding habits of infrequent riders, who redeemed an average of five tickets during the campaign, with 19 percent using all 10 tickets. Like the non-riders, these occasional customers also increased their use of paid transit trips after the end of the promotion. At an average rate of 3.3 one-way trips per month, 59 percent of the infrequent riders increased their transit trips after the promotion had ended. Overall, more than two-thirds of people who were surveyed reported riding the bus after the end of the promotion.

The survey also queried respondents about their likelihood of continuing transit use in the future and the possibility of recommending the service to other people. Fifty-eight percent of survey respondents reported that they were "very likely" to continue riding the bus in the next year, while an additional 31 percent indicated that they were "somewhat likely" to ride in the next year. Fifty-five percent said they "definitely would" recommend the transit service to friends, family, or co-workers, while an additional 37 percent indicated that they "probably would" recommend transit service to others. On the whole, over 90 percent of survey respondents 
definitely or probably would recommend the service to other people. Those who continued to use transit after the end of the promotion were more apt than those who did not continue riding to say they definitely would recommend the transit service to others.

It should be emphasized that the willingness of customers to sustain their ridership patterns and recommend transit service to other people depends largely on the service quality they encounter early on in their experience of transit. Despite the success of the direct mail promotion in Wisconsin, the author cautions that if the goal of such efforts is to attract new riders or increase the use of public transportation by infrequent riders, the importance of selecting areas with good service quality cannot be overstated.

\section{Summary}

This review of current literature encompasses two areas: transit travel time reliability and transit rider retention. The literature reveals the current state of thinking in these two areas and also identifies areas that need further research. The information from this literature review will be used as the basis for the subsequent tasks of this research project on transit ridership, reliability, and retention. 


\section{CHAPTER TWO: SYNTHESIS AND ANALYSIS OF EXISTING DATA}

\section{Introduction}

The objective of this task of the project, and the subject of this section of the technical memorandum, is to identify and synthesize existing data sources that will be utilized in later tasks. Such sources include the Puget Sound Transportation Panel (PSTP) data set, APTA's Transit Performance Monitoring System (TPMS), CUTR’s extensive database of on-board survey results from transit agencies in the state, and other surveys available from across the United States.

The PSTP data set covers a sample of more than 3,000 persons and includes data collected in 10 waves (survey contacts) over a 12-year period. In addition, the sampling scheme adopted in the survey constituted a choice-based sampling scheme where transit users were over sampled in each survey wave. The data set includes detailed household and person demographic and socioeconomic data, personal attitudes, values, and perceptions, and personal activity and travel characteristics.

The TPMS is a joint national effort between the Federal Transit Administration and the American Public Transportation Association which consists of a nationwide on-board survey database. The surveys in this database all share a set of common questions.

\section{Puget Sound Transportation Panel Data Set}

According to documentation on the Puget Sound Transportation Panel (PSTP), it was the first general-purpose travel panel survey conducted in an urban area of the United States. The PTSP originated in 1989 by the Puget Sound Council of Governments (now known as the Puget Sound Regional Council). The information acquired from the panel survey results assist the Puget Sound Regional Council in long-range transportation planning and analysis for decisions such as highway and road construction, transit development, and policies for carpooling and parking.

The panel comprises approximately 1,700 households across the four-county Puget Sound region (the four counties are King, Kitsap, Pierce, and Snohomish), and specifically includes households that contain at least one member who regularly uses transit and households with at 
least one member who carpools regularly. Other households with members who drive alone for most of their trips are also included. Table 2-1 provides the primary work mode as reported by the participants in each wave of the survey. The household members recorded all of their trip activity for a two-day period in each wave. In addition, a sample of the household members was asked to complete a separate survey on their attitudes and perceptions of various modes of transportation. The trip activity data as well as the attitude survey results are both quite useful for the purposes of this project.

Table 2-1: Primary Work Mode - Puget Sound Transportation Panel

\begin{tabular}{|c|c|c|c|c|c|c|c|c|c|c|c|}
\hline & $\begin{array}{c}\text { Wave } 1 \\
\text { (1989) }\end{array}$ & $\begin{array}{c}\text { Wave } 2 \\
(1990)\end{array}$ & $\begin{array}{l}\text { Wave } 3 \\
\text { (1992) }\end{array}$ & $\begin{array}{c}\text { Wave } 4 \\
\text { (1993) }\end{array}$ & $\begin{array}{c}\text { Wave } 5 \\
\text { (1994) }\end{array}$ & $\begin{array}{c}\text { Wave } 6 \\
\text { (1996) }\end{array}$ & $\begin{array}{c}\text { Wave } 7 \\
\text { (1997) }\end{array}$ & $\begin{array}{c}\text { Wave } 8 \\
\text { (1999) }\end{array}$ & $\begin{array}{c}\text { Wave } 9 \\
(2000)\end{array}$ & $\begin{array}{c}\text { Wave } \\
10 \\
(2002)\end{array}$ & Avg. \\
\hline SOV & $69.0 \%$ & $68.9 \%$ & $62.4 \%$ & $68.1 \%$ & $69.4 \%$ & $68.7 \%$ & $67.3 \%$ & $66.0 \%$ & $63.3 \%$ & $67.0 \%$ & $67.0 \%$ \\
\hline Transit & $13.2 \%$ & $10.5 \%$ & $4.7 \%$ & $6.3 \%$ & $6.7 \%$ & $8.1 \%$ & $7.5 \%$ & $9.4 \%$ & $10.0 \%$ & $7.1 \%$ & $8.4 \%$ \\
\hline Car/Bus Combination & $4.5 \%$ & $5.0 \%$ & $3.1 \%$ & $4.6 \%$ & $3.9 \%$ & $4.8 \%$ & $4.4 \%$ & $3.2 \%$ & $0.9 \%$ & $2.2 \%$ & $3.7 \%$ \\
\hline Carpool & $12.2 \%$ & $12.0 \%$ & $20.4 \%$ & $13.5 \%$ & $12.8 \%$ & $9.4 \%$ & $14.1 \%$ & $14.6 \%$ & $15.9 \%$ & $12.1 \%$ & $13.7 \%$ \\
\hline
\end{tabular}

NOTE: Percentages do not add to 100 due to rounding and the exclusion of other modes/responses (walk/bike, ferry, other, refused, work at home).

In the fall of 1989, the first wave of the PSTP was conducted, and was followed by the first attitude survey in early 1990. The second wave occurred in the fall of 1990 and was again followed by an attitude survey in the fall of 1991. Successive waves took place in 1992, 1993, 1994, 1996, 1997, 1999, 2000, and 2002. Attitude surveys were administered along with the 1990, 1991, 1993, 1996, 1997, 1999, 2000, and 2002 waves.

The PSTP began with 1,712 participating households in 1989 and has been maintained at between 1,700 and 1,900 over the years. For each wave, approximately 20 percent of the households need to be replaced, mainly due to households relocating.

A panel survey is defined as a longitudinal survey for which similar measurements are made on the same sample over different points in time. Advantages of panel data include direct measurement of changes in individual attributes, smaller sample size requirements, and the ability to analyze causality about the effects of changes in one or more of the variables that influence travel behavior. However, there are some disadvantages to panel data sets such as higher initial costs, higher non-participation rates, and attrition/replacement of panel members. 
The PSTP data are analyzed extensively for this study. Comprehensive frequency analysis and crosstabulations will be conducted, as well as other statistical techniques (using methods specifically for panel data) will be applied to better understand mode choices and attitudes about transportation over time. Data from the trip diaries from each wave, including mode choice and residential and work location, are of great interest, as are the data from the attitude surveys which cover a wide array of opinions and perceptions about different transportation modes. The PSTP is quite important to the three focus areas of this project, transit reliability, frequency of use, and cessation of use. While the PSTP data are analyzed more thoroughly in later tasks of this project, some relevant findings are summarized here.

Each wave of the survey is categorized into three separate data sets. One data set contains characteristics of the participating households. Relevant household characteristics for the purposes of this project include lifecycle information (number of persons/children in the household), income ranges, and number of household vehicles.

\section{Household Data}

Lifecycle information for a household can give insight into mode choices for work trips, the selection of a particular mode due to the need to pick up or drop off children from school, daycare, or other activities, as well as general attitudes and perceptions about transportation modes. In the PSTP, the largest category of households is those with children up to age 17. Households with any number of children comprise approximately one third of the participating households for each wave. The next largest group is households with two adult members age 35 to 64. The percentages for each lifecycle group have remained relatively stable over the 10 survey waves. The households with children decreased from a high of nearly 38 percent in the second wave (1990) to closer to 30 percent over the last four waves $(1997,1999,2000$, and 2002). One-adult households have increased over the 10 waves, with households with one adult age 35 to 64 increasing from 9 percent in the first wave (1989) to more than 12 percent in the $10^{\text {th }}$ wave (2002), and households with one adult age 65 or over increasing from 4 percent in the first wave to 8 percent in the $10^{\text {th }}$ wave.

Information on a household's annual income can also provide insight into mode choice, as well as attitudes and perceptions about different transportation modes such as public transit. Households could respond to a query about their income in two different ways. Income could be reported in $\$ 10,000$ ranges, or a household could simply report that the income was above or 
below $\$ 35,000$. Most reported in income ranges, and it appears that the household incomes of the PSTP participants have increased over the 10 waves of the survey. In the first three waves of the survey, the largest income category was between $\$ 45,000$ and $\$ 55,000$. In waves four and five, the largest proportion was between $\$ 55,000$ and $\$ 75,000$. In the last five waves of the survey (between 1996 and 2002), the largest proportion was $\$ 75,000$ or more. In the $10^{\text {th }}$ wave (2002), nearly 27 percent of the households reported annual incomes in this category. The income categories that comprise household income below $\$ 35,000$ have declined from a sum of approximately 26 percent in the $6^{\text {th }}$ wave (1996) to 19 percent in the $10^{\text {th }}$ wave (2002). One explanation for a part of these variations could be inflationary changes, but other factors are likely also involved.

The number of vehicles available to members of a household clearly influences their travel mode choice. Typically, those with fewer vehicles available are more likely to take public transit, and those with more vehicles are less likely, all else equal. More than 80 percent of the households in the PSTP reported having one, two, or three vehicles in all 10 waves of the survey. The largest proportion of households in each wave had two vehicles (the percentage ranges from 40 percent to 45 percent over the waves). The proportion of households with no vehicles available remained relatively stable over the 10 waves at approximately three percent.

\section{Trip Data}

The information from the two-day trip diaries is included in a separate data set. Information relevant to this project includes trip purpose, trip mode, and travel distance. Trip purposes are categorized into work, shopping, school, visiting, free time, personal, appointments, home, and college. As is often seen in similar surveys that inquire about trip purpose, approximately 45 percent of the trips in each wave were reported as "home" trips. This is followed by work trips, personal trips, and shopping trips. Most trips are a distance of less than 10 miles. A majority of trips in each wave were taken by car, and bus transit was used for a high of 4.2 percent of trips in the first wave (1989) to a low of 3.2 percent of trips in the $10^{\text {th }}$ wave (2002).

\section{Person Data}

In addition to the household-specific data and the trip diaries, each individual household member provided additional information, as well. Some variables of interest are work travel mode, mode combinations (such as car to bus), whether a car is required for work or for transporting children, whether one has a valid driver's license or transit pass, whether the individual has taken the bus in the past six months, and how often the bus is used per week. 
Over the 10 waves, between 62 percent and 69 percent of participating individuals reported that a single-occupant-vehicle (SOV) was the primary work travel mode. Between 5 percent and 13 percent reported that transit was the primary mode (the 13 percent was reported in the first wave in 1989). By the $10^{\text {th }}$ wave in 2002, 7 percent reported that the primary work travel mode was transit. Recognizing that many people use more than one mode for the work trip, individuals were also asked about all modes they use for going to work. A majority reported that they use only the SOV for the work trip; more than 80 percent in each of the first seven waves. Waves 8 and 10 have this figure closer to 80 percent. Between four and five percent of respondents indicated that they use some combination of car and bus for the work travel mode over the first 8 waves, perhaps driving to a park-and-ride location or being dropped off at a bus stop. However, this percentage declined beginning with the $9^{\text {th }}$ wave in 2000, settling at 1.4 percent for the $10^{\text {th }}$ wave in 2002.

Individuals were also asked about their frequency of use of available bus service, from zero trips per week, to more than 20 trips per week. Between approximately four and eight percent of responding individuals indicated they took bus trips between one and five times per week. The three most recent waves of the survey (in 1999, 2000, and 2002) had the highest percentages in this category, at approximately eight percent. Between seven and nine percent of the responding individuals indicated they took between six and 10 bus trips per week. The nine percent was reported in the first wave in 1989. The three most recent waves ranged between seven and eight percent. It should be noted that this particular question was not included in waves 6 and 7 (1996 and 1997). Crosstabulations with other household and individual characteristics can be used to learn more about the less frequent transit users. It would have been interesting if the question had provided additional responses, such as a certain number per month or per year; however, for this survey, if a respondent used the bus less than one time per week, they likely responded that they use it zero times per week.

An additional question of interest is if an individual had taken the bus at all in the past six months. Responses to this question varied quite widely over the 10 waves of the survey, from a low of 2.5 percent in 1999 (wave 8) to a high of 16.8 percent in 1996 (wave 6). For the most recent wave in 2002, 14.6 percent of the responding individuals indicated that they had taken the bus at least one time in the previous six months.

According to the survey results, a majority of respondents need a car at work. In 1989, 60 percent of respondents indicated that a car was required at work. This proportion fluctuated 
slightly over the 10 waves and, in 2002, was 74 percent. Certainly, the requirement of a car at work will impact a worker's mode choice. Closer examination of this variable will be useful in the tasks on frequency of transit use and cessation of transit use.

Similarly, survey respondents were asked if they needed a car for transporting children. Again, this variable would impact an individual's mode choices. Throughout all 10 waves of the panel survey, the proportion of respondents indicating that they needed a car to transport children remained relatively stable at 80 percent.

To obtain more information on transit use as an option for the individuals in this panel survey, respondents were asked if they had a valid driver's license. In the first and last years of the survey, the proportion of those reporting that they had a valid driver's license was approximately 93 percent. This percentage dropped slightly in the middle years of the survey to between 84 and 88 percent. It should be noted that those aged 15 years and older in the selected households were asked to fill out the person data questionnaires; as such, those reporting that they did not have a valid driver's license were not under the age of 15.

Respondents were also asked if they had a transit pass. This question was not asked in the first wave, but for the second wave, in 1990, six percent of respondents indicated that they did have a transit pass. This proportion increased steadily over the survey waves, peaking at 15 percent in both 1999 and 2000. However, in 2002, only eight percent reported having a transit pass.

\section{Attitude Surveys - 1990, 1991, 1993, 1996}

As mentioned previously, a sample of the household members participating in the PSTP was asked to complete a separate survey on their attitudes and perceptions of various modes of transportation. While the household, trip, and person data described above can help provide more concrete reasons for mode choices (based on characteristics such as lifecycle, vehicle availability, occupation, etc.), data compiled from the attitude surveys provide more insight into these choices based on individual perceptions of various mode qualities.

The first attitude survey was conducted along with the second panel wave, in 1990. In the first four attitude surveys conducted (in 1990, 1991, 1993, and 1996), respondents were asked their current work or school status (as in full-time, part-time, etc.) and whether they were a homemaker, retired, or unemployed. Only those who answered that they worked or went to 
school, either full- or part-time, were asked to complete the remainder of the attitude survey. In the more recent waves of the survey, this question changed to a simple yes or no format asking whether the respondent works or goes to school three hours per week or more. In 2002, 61 percent of the respondents indicated that they did go to work or school three or more hours per week. This proportion is smaller than the combined proportion of 70 percent that, in 1996, under the previous questioning scheme, answered that they worked or were students, either full- or part-time. In the first attitude survey in 1990, this proportion was 80 percent. Certainly, some of the significant differences in these percentages are due to the change in the question. However, one might expect the percentages to be somewhat more similar over time. Nonetheless, between 1990 and 2002, there appears to be a decline in the number of respondents who work or go to school, either full- or part-time.

In the 1997, 1999, and 2000 attitude surveys, respondents were asked about the flexibility of their working hours. The responses are not terribly consistent over these three waves. In 2000, however, nearly one-half reported that they had no flexibility in working hours (47 percent). Approximately 28 percent reported that they could start or finish work with a 30-minute flexibility, and 25 percent indicated that they were flexible (flexibility was not further defined). It can be hypothesized that those with less flexibility in their working schedules would place more weight on mode characteristics such as reliability in making travel decisions. This is further explored in the next task of this project.

As discussed previously, a total of eight attitude surveys have been conducted between 1990 and 2002. The structure of these surveys was altered in the later years of the survey. For the first four attitude surveys (1990, 1991, 1993, and 1996), were each divided into four sections: importance ratings, performance ratings, agreement/disagreement statements, and commute information. Results relevant to this project are discussed in the following sections.

\section{Importance Ratings}

In this section of the survey, respondents were asked to rate the importance of several items in deciding how to travel to work (or school). Ratings were made on a scale of 1 to 7 , with " 1 " indicating the item was "not important at all" and "7" indicating the item was "extremely important." 
The first item is "ability to arrive on time." Clearly, examination of responses to this item is essential for the reliability portion of this project. As might be expected, a majority of respondents rated this item as "extremely important." The highest percentage was in 1990, with 73 percent rating this item as “extremely important." The percentage actually declined, however, settling at 62 percent in 1996. If the percentages for a rating of " 6 " and a rating of " 7 " are summed, however, the total is 87 percent in 1990 and 82 percent in 1996.

Another important item in examining the importance of reliability is the ability to predict arrival times reliably. This item was only specifically included in the 1997 attitude survey. The question was posed as an agreement/disagreement statement, as "I like to be able to predict just how long a trip will take." The scale was 0 to 10, with " 0 ” indicating “disagree completely” and “10” indicating “agree completely.” Eighteen percent responded “agree completely.” A total of 77 percent agreed with the statement to some degree (rated the item above "neutral”).

Another item relating to the importance of reliability only found in the 1997 survey is "I get annoyed easily when my trip is delayed." Twenty percent indicated they were neutral on this item. However, a total of 58 percent agreed with the statement (rated it above “neutral”).

Returning to the importance scale, there are several other items in this section that can be used to gain insight into the frequency of transit use and the cessation of transit use. A selection of these includes:

- Ability to travel without changing vehicles

- Not having to deal with traffic congestion

- Short travel time

- Short wait time

- Flexibility to change plans

- Parking availability

- Freedom from threats to personal safety

- Avoiding stress

For each of the above, a majority of respondents provided a rating of " 5 ” or greater, indicating that the items were important in deciding how to travel. In looking just at the ratings of " 6 " or “7”, however, respondents rated personal safety the most important out of those items listed above, with 83 percent responding with a “6” or “7” in 1990 and 80 percent responding similarly 
in 1996. Other items rated as highly important relative to the others listed include a short wait time, the flexibility to change plans, parking availability, and avoiding stress. Interestingly, for each of the items above, the proportion of respondents rating the item "6" or "7" (extremely important) declined slightly from 1990 to 1996. For the later tasks, these results are crosstabulated with other household and person characteristics and otherwise further analyzed.

\section{Performance Ratings}

In this section, survey respondents were asked to rate how the drive-alone mode, bus mode, and carpool mode perform according to each of the items from the importance ratings section (listed previously). The rating scale was from 1 to 7 , with “ 1 ” indicating “extremely” poor performance and “7” indicating “extremely” good performance. Respondents were asked to rate each mode, even if they did not personally use it. So, for modes that respondents did not use, they were providing their perceptions of the mode's performance. A few selected results are discussed in this section. Because this project addresses transit ridership, reliability, and rider retention, the discussion focuses on the drive-alone and bus modes only.

Regarding the ability to arrive on time, it is not surprising that respondents rated the drive-alone mode significantly more favorably. In the 1990, 1991, and 1993 surveys between 87 and 88 percent of the respondents rated the drive-alone mode's performance in arriving on time as a "6" or “7” (extremely good). In 1996, however, the percentage dropped to 80 percent (perhaps as a result of increasing congestion). For the bus mode, 32 percent rated its performance at arriving on time as a "6" or “7” (extremely good) in 1990, compared with 29 percent in 1996. Also in 1996, 8 percent reported the bus mode as "extremely" poor (“1”) in arriving on time, compared to 1 percent for the drive-alone mode. For the drive-alone mode, a majority of respondents rated the on-time performance as "7”, while for the bus mode (in each survey between 1990 and 1996), the largest percentage of respondents rated on-time performance as a " 5 ” on the scale of 1 to 7.

\section{Agreement/Disagreement Statements}

For the attitude surveys conducted in 1990, 1991, 1993, and 1996, respondents were provided with a list of 23 statements and asked to rate them on a scale of 1 to 7 , with " 1 " indicating they "very strongly disagree” and “7” indicating they "very strongly agree.” A rating of “4” indicates "neutral." Several statements relate to the mode choice between driving alone and bus transit. 
Regarding whether riding the bus is a relaxing experience, the largest proportion of responses across all four surveys was in the "neutral" to "somewhat agree" categories, with nearly a third of all responses. Between 21 and 25 percent "strongly" agreed or "very strongly" agreed that the bus is relaxing. Over the first four attitude surveys, the proportion of respondents indicating that the bus is an enjoyable way to travel ranged from 41 percent in 1990 to 32 percent in 1996 . The percentage of respondents indicating that they agreed with the statement that driving a car is a relaxing way to commute decreased from 40 percent in 1990 to 29 percent in 1996.

As to whether driving is enjoyable, even in traffic, the proportion of respondents agreeing with this statement to any degree declined from a high of 62 percent in 1990 to 42 percent in 1996 . In 1990, 87 percent of respondents agreed that they like the freedom of driving a car. This percentage decreased to 75 percent, still a significant majority, in 1996. These results could indicate a decreased tolerance for driving in congested conditions.

Participants were asked to respond to the statement, "If gas prices get much higher, I'll be less likely to drive to work.” In 1990, 1991, and 1993, approximately 50 percent of respondents indicated that they "strongly" disagreed or "very strongly" disagreed with this statement. The proportion responding in this fashion decreased to 39 percent in 1996.

Approximately one-half of the respondents agreed with the statement, “Taking the bus doesn't fit my lifestyle.” This proportion declined, however, from 54 percent in 1990 to 48 percent in 1996. As might be expected, a majority of respondents agreed that they "hate" the idea of bus transfers. However, this proportion also declined from 71 percent in 1990 to 59 percent in 1996.

Approximately 62 percent of respondents indicated in 1990 that taking the bus is a "hassle." In 1996, 51 percent responded this way, still about one-half of all respondents. Over the course of the first four attitude surveys, a little less than one-third of respondents agreed that "people only ride the bus if they have to.” For this statement, a larger percentage of respondents were neutral or "somewhat" disagreed.

In 1990, 88 percent of the respondents agreed that riding the bus helps to reduce traffic congestion. In 1996, this proportion decreased to 74 percent, still a significant majority of responses. 


\section{Attitude Surveys - 1991, 1999, 2000, 2002}

The four most recent attitude surveys analyzed for this project were constructed differently than the previous four. Many of the questions were similar, but there were notable differences. When possible, the responses from this set of surveys are compared with the responses from the previous set. Otherwise, the responses will be evaluated separately. In addition to their attitudes and perceptions about their commutes and mode choices, respondents were also asked additional questions about their mode of travel for work or school, as well as other characteristics. In later tasks of this project, responses to these additional questions are used in crosstabulations and other statistical analyses to provide further insight into traveler attitudes regarding various commute characteristics.

These more recent attitude surveys reveal that, as expected, over the four surveys, a majority of travelers use a private vehicle (drive alone or carpool) for commuting to work or school. The percentage using bus declined from 10 percent in 1997 to 8 percent in 2002.

No matter the mode of travel, survey respondents were asked if they agreed or disagreed with the statement that there were unexpected delays on their route at least twice per week. The scale is from 0 to 10, with " 0 ” representing “disagree completely” and “ 10 ” representing "agree completely.” Responses are only able to be analyzed for the 2000 and 2002 surveys, and they are relatively stable between the two years. Approximately 20 percent disagreed completely with the statement, approximately 10 percent were neutral, and approximately 10 percent agreed completely (other responses were in between these categories). In 1999, this question was posed in yes-or-no format, and 60 percent responded that they did not encounter an unexpected delay on their route at least two times per week. Responses to this question can give insight as to the importance of reliability in making a mode decision.

Survey participants were asked to respond to a statement that, within the past three years, they have seriously considered changing their job or residential location to reduce the amount of time spent commuting. In 2000, 43 percent disagreed completely with the statement, while 25 percent agreed to some degree. In 2002, the question was separated into changing the work location and changing the residence location. In 2002, between 50 and 55 percent disagreed completely that they had considered changing either their work or place of residence in order to reduce commute times. Eighteen percent agreed to some degree that they had considered changing their work location to reduce commute times, and 14 percent agreed to some degree that they had considered changing their residential location for the same reason. In 2000 and 2002, a slight 
majority (55 percent and 58 percent, respectively) indicated that they were satisfied, at least to some degree, with their commutes.

Those who travel to work or school by bus (or ferry) were asked to respond to an additional set of questions. Regarding the statement, “When I'm waiting for a bus, I'm happier if I know when it will arrive,” 86 percent and 74 percent agreed at some level (above neutral) in 2000 and 2002, respectively. A similar statement, "I don't mind the delays so much if I can forecast accurately when I'm going to get there,” resulted in 34 percent of respondents agreeing to some degree in 1999, increasing to 42 percent in 2002.

In 2000, 37 percent of respondents who take the bus or ferry to work or school agreed (above neutral) that they sometimes miss a connection because a bus or ferry is late. In 2002, this percentage dropped to 20 percent. When asked to respond to a statement indicating that they want to switch to driving to work or school as soon as possible, 40 percent disagreed completely in 2000 and 30 percent disagreed completely in 2002. Only approximately 20 percent agreed to some degree with that statement in both 2000 and 2002.

\section{PTSP Summary}

The Puget Sound Transportation Panel (PTSP) data set provides a voluminous amount of information that can be used to further explore transit ridership, reliability, and retention. In addition to having conducted comprehensive attitude surveys along with the typical household travel survey information, the surveys have been conducted in 10 waves covering a period of 13 years and following, to the extent possible, the same households. It is the longitudinal nature of these surveys that will provide additional insight into what factors influence mode choices over time, and the relative importance of such characteristics as transit reliability.

\section{APTA Transit Performance Monitoring System (TPMS)}

The Transit Performance Monitoring System (TPMS) was designed to collect data on transit customers via on-board surveys. The goal is to provide a basic yet comprehensive analysis of the benefits and performance of transit services. The TPMS project was sponsored jointly by the Federal Transit Administration (FTA) and the American Public Transportation Association (APTA). The project aimed to develop an approach that local transit agencies could use to evaluate performance and identify the benefits of their transit services. 
The TPMS project was conducted in three phases. The first phase was conducted between 1996 and 1998 and included surveys at nine transit agencies. For the second phase, in 2000, the surveys were conducted at 11 transit agencies. In both phases, assistance was provided to the individual agencies in designing and printing the surveys (to include a set of common questions), and in processing the results. For the third phase, conducted in 2002 and 2003, a voluntary approach was employed in which no assistance was provided to the 30 participating agencies.

Common survey questions included the following:

- Gender

- Age

- Household income

- Household size

- Trip frequency

- Duration of transit use

- Trip purpose

- Vehicle availability

- Access/egress mode at the home end

- Access/egress mode at the non-home end

- Trip alternatives

The surveys were not designed to capture such customer satisfaction items as reliability of service. However, they do provide a significant amount of information on transit user characteristics, including some of the factors that do influence their ridership, as well as information on frequency of use. As such, the results of the three phases of the TPMS are useful in the task of this project that addresses frequency of transit use.

The results appear to be relatively consistent over the three phases. Some key findings from the third phase that are relevant to this project are summarized herein. Approximately two-thirds of the transit users were of "working age" between the ages of 25 and 64. Most transit trips were made by people living in low-income households. Further, most transit trips (approximately two-thirds) were made by people living in households of three persons or less. 
Regarding frequency of transit use, approximately 70 percent of trips at participating agencies were made by users who ride the system at least five days per week. And, as seen in many surveys, most trips are made by relatively new riders, providing evidence of the high turnover in the transit customer base that was discussed previously.

The largest proportion of trips (just over 50 percent) were made for work purposes, but work trips account for a larger percentage of trips in medium and large systems that in smaller systems. Approximately one-half of those surveyed indicated that if the transit service was not available, they would have made the trip by automobile, either as a passenger or a driver. However, approximately 20 percent indicated that they had no alternative, thus suggesting that transit provides basic mobility for a segment of users.

On average, among those transit systems included in the TPMS, approximately one-third of transit trips were made by choice riders, as defined by having a vehicle available for

making the trip. As expected, trips by choice riders are higher at medium, large, and large suburban systems than at smaller systems.

\section{APTA - A Profile of Public Transportation Passenger Demographics and Travel Characteristics Reported in On-Board Surveys}

For this effort, described as the largest on-board survey study about the public transportation industry, data from 150 on-board surveys conducted by public transportation agencies from 2000 through 2005 were compiled. The surveys summarized results based on more than 496,000 sampled transit riders from systems that carry more than 60 percent of all transit trips in the United States.

As stated in the title of the work, the compiled information is restricted to rider demographics and travel characteristics, with the goal of obtaining a profile of people who take public transportation trips. No customer satisfaction items are included, such as transit reliability.

The demographic and travel characteristics summarized are similar to the TPMS project and include the following: 
- Age

- Gender

- Ethnicity

- Household income

- Household size

- Occupation

- Vehicle availability for trip

- Vehicles owned

- Access/egress mode

- Alternative mode of travel

- Duration of transit riding

- Frequency of transit travel

- Transfer frequency

- Trip purpose

The results are very similar to those from the TPMS project described above. Approximately 60 percent of the surveyed trips were taken by persons between 25 and 54 years of age, who come from relatively small, low-income households (26 percent had households consisting of two persons).

Most riders use transit for the work trip, and approximately 45 percent have a vehicle available when deciding to make a trip. Without the available transit service, 56 percent of riders would make the same trip via personal vehicle: 24 percent would drive themselves and 22 percent would ride with someone else. Approximately 22 percent would not be able to make their trips at all without the availability of transit service.

Most users (57 percent) have been riding public transit more than two years, while 30 percent of trips are taken by users who are in their first year of riding their system. Almost two-thirds of transit trips are taken by users who ride at least five days per week.

The results of the APTA study are useful to a certain extent in the task on frequency of transit use in this project. Further analysis of additional data, along with information presented in this section, is undertaken in the later task. 


\section{Florida On-Board Survey Database}

The Center for Urban Transportation Research (CUTR) at the University of South Florida (USF) has conducted, or has access to, an on-board survey for nearly every public transit system operating in the state. CUTR has conducted a majority of these. The transit systems represented include fixed-route systems operating less than 10 vehicles such as the Bay Town Trolley in Panama City, Key West Transit, and Collier Area Transit in Naples, and the large systems such as Miami-Dade Transit, Broward County Transit, and Jacksonville Transportation Authority. In total, 25 Florida transit agencies are represented, with the most recent surveys conducted between 1997 and 2005.

Only two Florida transit systems were represented in the APTA TPMS project, the Bay Town Trolley in Panama City and VOTRAN in Volusia County (Daytona Beach area). As such, a similar profile can be constructed for the Florida systems and compared to the TPMS results (and other APTA results).

Three characteristics of the Florida on-board survey database are of particular interest to this project. First, there is access to the raw data from most of the surveys, which allows for a deeper analysis of the results than that shown in basic summary information such as that presented in the APTA projects. Second, several agencies have more than one year of survey data available which allows for a degree of temporal analysis. Third, many of the Florida on-board surveys contain a section on customer satisfaction ratings, which typically include items such as transit reliability (or on-time performance), among other factors in customer satisfaction.

The Florida on-board survey database provides a rich source of data to use in two of the major tasks of this project that deal with transit reliability and frequency of transit use, respectively. Crosstabulations and other statistical techniques are employed to further analyze the data. These data are supplemented with other data described in this technical memorandum, along with additional data collected by CUTR staff.

\section{Other Surveys}

Through direct contact with agencies across the United States as well as Internet searches, additional surveys and survey data that are useful for this project have been collected and 
compiled. These studies include transit on-board surveys, customer satisfaction surveys, and other relevant surveys (including non-user surveys).

A total of 19 additional on-board survey data/results have been collected from transit agencies across the United States (and outside of Florida). Eleven of these 19 surveys include a customer satisfaction component that includes ratings on multiple factors (as opposed to a single rating of “overall” customer satisfaction). Results from seven additional transit customer satisfaction surveys have also been collected. These data are particularly helpful in the two tasks of this project that address transit reliability and frequency of transit use. While the additional on-board survey data are helpful, of primary usefulness in these additional surveys is the information on customer satisfaction, which is an input to the task on transit reliability.

Data on the cessation of transit use has proven difficult to obtain. While the Puget Sound Transportation Panel data sets are helpful in this regard, additional data are desirable. Non-user surveys are one method of capturing this information. An example of this type of survey used for this project is a telephone survey of bus non-riders that was conducted in 2000 for the Washington Metropolitan Area Transit Authority (WMATA) as part of a larger regional bus study. This non-user survey is briefly discussed herein.

For the WMATA bus non-user telephone survey, the sample of respondents was drawn from a population of residents of the Washington, D.C. metropolitan area who were at least 18 years of age and had not used public bus service in the previous 30 days. Of course, the survey results depended on the willingness of people to complete a telephone interview of approximately 12 minutes. Most actual survey respondents were 35 years or older, with no children in the household, and with annual household incomes of $\$ 50,000$ or more. Most respondents held valid driver's licenses and 73 percent were employed.

Nearly two-thirds (63 percent) of the respondents indicated that they would consider using bus transit for at least some of their transportation needs if bus services were improved. Generally, these potential riders were less likely to have a vehicle available than other respondent groups. The preferred improvements varied, but included more frequent bus service, stops closer to homes/destinations, faster/more direct service, and amenities such as more/better bus information and better shelters.

To participate in this non-user survey, respondents must not have used the public bus system in the past 30 days. They were asked how long it had been since they last rode the bus. More than 
46 percent responded that it had been more than one year. Approximately 32 percent indicated that they had never ridden the bus.

For those who had previously ridden the bus system, they were asked to what extent they relied on the bus for their transportation needs. Approximately 21 percent rode the bus four or more times per week, 32 percent rode less than once per week ("once in a while”), and 29 percent rode only one time.

Respondents were asked outright why they stopped riding the bus. By far the most common response, comprising more than 43 percent of all responses, was an increased access to a car for their transportation needs. The next most common response, with 17 percent of all responses, was a change in travel pattern (including a change in job location or residential location).

Many of the other responses about why current non-users who had once ridden the bus stopped riding included the typically cited complaints about transit service. These include the bus being too slow (six percent), too many transfers (two percent), service not frequent enough (three percent), bus did not go where needed (four percent), and the bus did not go when needed (two percent). Also of interest to this project, six percent of respondents in this non-user survey indicated that they stopped riding the bus because the bus was not "reliable enough," referring to the bus not being at the bus stop at the scheduled time.

Another interesting question posed to the telephone survey respondents asked about the "biggest drawback" to using the bus. Twenty-eight percent of respondents, the largest response category, indicated that the largest drawback is that the bus is not as convenient as a car. The travel time on the bus takes too long was the answer for 14 percent of respondents, while 12 percent indicated having to wait too long was the largest drawback. Five percent stated that too many transfers was the main drawback, and three percent indicated the biggest drawback is that the bus is not reliable enough. While it seems that components such as travel time, waiting, and transfers could be considered elements of convenience, this question was open-ended and the authors categorized the responses. Six percent indicated that there were no drawbacks.

\section{Summary of Existing Data}

This task comprised summaries of several types of existing data that can be used to further study transit ridership, reliability, and retention. While several on-board surveys and customer 
satisfaction surveys from across the United States have been collected, for the most part, this information serves to provide an understanding of how existing transit riders perceive reliability and what factors affect riders' use and frequency of use of transit. In those cases where raw data are available, additional insight can be gained regarding these issues through crosstabulations and other statistical analyses (undertaken in later tasks).

While much of the survey information serves to further confirm existing hypotheses about transit ridership, other data sets and non-user survey results serve to provide some missing pieces of information concerning transit users' and non-users' attitudes and perceptions about transit characteristics such as travel time reliability or on-time performance. In addition, from longitudinal data sets such as the Puget Sound Transportation Panel, more can be learned about commuters' travel patterns over time, including mode choices. These issues are fully explored in the remaining tasks of this project. 


\section{CHAPTER THREE: TRANSIT RELIABILITY AND RIDERSHIP}

\section{Introduction}

Accuracy of predictions of transit ridership based on transit travel time reliability is a topic of recent interest in the industry. Knowledge of what transit improvements the potential transit customer responds to will help transit agencies to provide better services.

Transit travel time reliability can be measured in terms of variation in arrival time at a particular scheduled transit stop as well as in terms of the variation in the total trip time for a given origin and destination. While these two terms are interrelated to some degree, the first term is concerned with passenger waiting time at a transit stop while the second term is concerned with delay in traffic. Variation in arrival time and delay in traffic could have different influences on transit ridership. Passenger perceptions of these two issues can differ in importance. Transit agency responses to these two issues could differ.

This chapter begins with a description of relevant findings from the literature regarding transit travel time reliability. Then, several data sources are fully explored to gain a better understanding of perceptions and attitudes regarding reliability as well as its impact on transit ridership. On-board survey data from across the country are used in this effort, with data from eight recent on-board surveys in Florida being examined in further detail. In addition, data from the Puget Sound Transportation Panel (discussed in Chapter 2), particularly from the attitude surveys, are also analyzed to determine the relative importance of reliability. In addition, a section is included detailing some further contact with several agencies that have recently implemented service changes or initiatives that included improved transit travel time reliability with the goal of establishing ridership impacts.

The findings from this chapter include a summary of relevant information from all of the survey data, transit agency data, and literature. In addition, the role of reliability in the frequency of transit use is discussed. Recommendations include a consideration of factors related to reliability that can impact transit ridership that have been found in the literature, from surveys of transit users and non-users, and additional transit agency experiences. 


\section{Lessons from the Literature}

Reliable transit service is essential to attracting and retaining riders, particularly in modern times when many transportation options are available. Transit service reliability is an important measure of service quality and has a direct influence on both level of service and passenger demand. Chapter 1 summarizes relevant literature related to transit service reliability. A lack of reliability often leads to disrupted service, delays, vehicle crowding, an overall negative image of transit, and ultimately, declining ridership. Improved reliability contains operating costs, lowers average passenger wait times, reduces bus crowding, and ensures greater predictability. Put simply, improved reliability results in more efficient use of transit agency resources and more satisfied customers.

Reliability plays a role in overall customer satisfaction and mode choice, yet standard travel demand models have failed to acknowledge the role of reliability, focusing instead on travel time. Interestingly, studies of travel behavior suggest that, depending on trip length and total travel time, the cost of unreliable service may actually be greater than the cost of travel time. Even under optimal running conditions, most transit patrons will not arrive at the time of their choosing, simply due to the fact that departure times must be chosen at predetermined intervals. When service is unreliable, planning a transit trip becomes exceedingly difficult, and more complicated still if transferring is necessary. From the customer's point of view (particularly the choice rider), the necessary time expenditures of unreliable service may be great enough to offset any monetary savings associated with transit travel. Over time, the inconvenience, uncertainty, and added time costs of unreliable service diminish user confidence and may result in ridership declines. Thus, improving the consistency of transit waiting and travel time might foster a larger, more satisfied base of customers. A fuller discussion of these issues is found in Chapter 1.

\section{Observations on Reliability Revealed by On-Board Surveys \& Customer Satisfaction Surveys}

Transit on-board surveys can include a section on customer satisfaction, where respondents are be able to indicate their level of satisfaction with a variety of transit service attributes. When attributes such as on-time performance, wait time, and travel time are included in transit surveys, the related results can be analyzed to determine user attitudes toward these characteristics and how they affect user behavior, including the frequency of riding. 
Data and results from several on-board surveys were used in the analysis conducted for this chapter. The results from a total of 19 on-board surveys, 5 customer satisfaction surveys, and 1 non-user survey from around the country were collected and found to be useful for this study. For further detailed analysis, raw data sets from eight recent on-board surveys conducted in Florida were obtained. This section begins with a synthesis of the results of 11 recent on-board surveys and 5 customer satisfaction surveys conducted outside Florida.

The 11 on-board surveys each contained an element measuring customer satisfaction (including reliability) and were conducted between 2001 and 2006. Results were obtained through direct contact with the agency or via online searches. The agencies represented are listed below:

- Alameda-Contra Costa Transit District (2003)

- City of Lawrence, Kansas (The T, 2006)

- Colorado Springs Transit (2005)

- Dallas Area Rapid Transit (2004)

- Elk Grove, California (2005)

- Greater Cleveland Regional Transit Authority (includes non-user survey results, 2001)

- Sacramento Regional Transit (bus and rail, 2006)

- Santa Clara Valley Transportation Authority (2005)

- Tucson Department of Transportation (2004)

- Valley Metro, Phoenix (2001)

- Washington Metropolitan Area Transit Authority (WMATA Regional Bus Study, 2001)

Additionally, the five customer satisfaction surveys were each conducted between 2003 and 2007. The WMATA non-user telephone survey was conducted in 2001. The agencies represented are listed below:

- Chicago Transit Authority (2003)

- Metro Transit - Minneapolis (Metropolitan Council, 2007)

- Southeastern Pennsylvania Transportation Authority - SEPTA (2005)

- Southeastern Pennsylvania Transportation Authority - SEPTA (includes non-user survey results, 2003) 
- Washington Metropolitan Area Transit Authority (WMATA Non-User Telephone Survey, 2001)

- York Region Transit (2006)

Some of these surveys simply asked respondents to rate their level of satisfaction with transit reliability and/or travel time without further questions or analysis in the results. Overall, how riders rate various attributes including reliability is specific to the operations at each transit agency. At some agencies, schedule reliability is rated very highly while, at other agencies, it has relatively lower ratings among the users. Some of the survey reports tracked customer satisfaction over time: at some agencies, schedule reliability improved over time and, at others, it was perceived to decline. At one agency, the perception of unreliable service was a large concern, mainly with respect to the possibility of losing choice riders. The most interesting insights from some of the survey results came from deeper analysis of the customer satisfaction ratings.

In the Dallas survey, respondents were first asked how often the bus picked them up and dropped them off on time, according to the system's pocket schedule. While a majority indicated "almost always" or "always," 29 percent indicated "sometimes" and 15 percent indicated "never." A follow-up question was targeted to those who answered "sometimes" or "rarely" and asked why the bus was not on-time. The largest category of responses, 34 percent, indicated that "people boarding" the vehicle resulted in delays. Other responses included "heavy traffic" (23 percent), "weather” (14 percent), "schedule needs more time” (11 percent), “routing” (8 percent), and "other" (18 percent). With service operated in mixed traffic, it is not unexpected that the buses will be a part of the "heavy traffic" that can cause delays. Initiatives such as bus rapid transit (BRT) operating in exclusive lanes along with technology such as signal priority can remedy the issue of buses getting caught in same traffic congestion as everyone else. However, there is evidence that actions taken to reduce dwell times at stops can help improve on-time performance, at least in the Dallas case.

Some agencies categorized the customer satisfaction ratings among various user groups. For example, in Colorado Springs, ratings were also examined separately for choice riders and transit-dependent riders (based on their definitions). Where rail modes are also operated, a few surveys also provided separate satisfaction ratings (as well as overall ratings). Typically, schedule reliability is rated better for rail modes than bus. 
For a better understanding of riders' perceptions regarding various service characteristics, three of the surveys combined satisfaction ratings of service attributes (sometimes referred to as "performance" or "quality") with the relative importance of the attributes. This is a technique also utilized in the Puget Sound Transportation Panel attitude surveys (discussed in Chapter 2 and later in this chapter). In the Cleveland survey, when the two rankings are combined, “arriving at stop as scheduled” was ranked fifth out of 22 attributes, while "reasonable travel time” was ranked sixth out of 22. In Cleveland it was found that the characteristics considered to be more important also received better performance scores.

In the analysis conducted for The $\mathrm{T}$, the relative importance of an attribute was related to performance using Pearson correlation coefficients, which were then used to compute an importance index. An index score of greater than 100 indicates a higher correlation with overall satisfaction, while those attributes with index scores less than 100 are less correlated. The analysis found that both on-time performance and travel time had scores very close to 100 (95 and 105, respectively).

In Sacramento, the buses and trains “running when schedule says” (on-time performance) ranked second in importance out of 29 attributes, but ranked $12^{\text {th }}$ in quality (or performance). “Total travel time for your trip” ranked fifth in the list of 29 attributes, and ranked tenth in quality. In addition, it was noted that 22 percent of respondents rated "running when schedule says" as excellent, while 24 percent rated travel time as excellent. While these ratings are good, it was also found that 20 percent of respondents reported having a problem with on-time performance during the previous month, while 9 percent experienced a problem with total travel time during the same period. The Sacramento surveys also computed impact scores, which are based on the premise that subjective ratings of service attributes should be qualified by the incidence of reported problems with those attributes. Interestingly, the on-time performance attribute had the second-worst impact score, which was based on it being rated second in importance yet with a high incidence of reported problems. Total trip travel time had the second-best impact score. More about the Sacramento experience is included later in this chapter.

Results from WMATA's on-board survey, conducted as part of its Regional Bus Study, showed that on-time arrival/reliability was the service feature that riders wanted improved the most (cited by nearly half the respondents). The bus service features identified for improvement varied little in relation to the time or day of the surveyed trip as well as most demographic characteristics. However, the youngest riders selected on-time arrival/reliability most often (66 percent of riders age 15 to 18 and 79 percent of riders under age 15). 
Finally, three agencies provided some results of non-user or potential-user surveys. In Cleveland, a telephone survey was conducted of those considered to be familiar with the transit authority but not regular users (these survey participants were considered potential users). The respondents were asked to rate the same service attributes as in the on-board survey. It was found that this group of infrequent users and non-users generally rated service attributes worse than regular riders, including schedule reliability and travel time.

The non-user element of the 2003 SEPTA customer satisfaction survey asked participants to rate characteristics of SEPTA service based on their perceptions. Schedule reliability was rated 7.2 on a scale of 1 to 10 and travel time was rated 7.1 on the same scale. Both of these ratings were improved over the 2002 non-user survey. Additionally, respondents were asked what they "view as the greatest obstacle to using public transit." Transit being "not reliable/not on time” comprised the smallest category, about five percent, of responses. The largest response category was “less convenient/I prefer my car” with 23 percent. "It takes too long” for 21 percent of respondents and "transit isn't close enough" to home or a destination for an additional 17 percent of respondents. Other categories were "it's too expensive” and "nothing specific.” At least in SEPTA's case, the schedule reliability is not a major factor in why non-users do not ride the system.

In WMATA's telephone survey of bus non-riders, respondents were asked to name the biggest drawback to using the bus. Only about three percent indicated that service being "not reliable" was the biggest drawback. The bus being “inconvenient” was cited by 31 percent of respondents. The next largest response, at 15 percent, was that the bus "takes too long." The respondents were also read a list of six specific improvements and asked to choose the one that would make them most willing to take the bus for at least some of their trips. The most common response was "nothing," with 18 percent. Of the six service improvements, service being "more reliable" was cited least often, comprising six percent of responses. "Stop closer to home/destination" was the most frequently named improvement, with 18 percent of responses. If the "service were faster" and if the "service were more frequent” were next, each with 16 percent of the responses.

Sixty-eight percent of the respondents in WMATA's non-rider survey indicated that they had used the bus in the past. These respondents were asked why they had stopped using the bus services. Over 43 percent indicated that they stopped using the bus because they gained access to a car. The next most-frequently cited response, at 17 percent, was a lifestyle change, such as a change in residence or work location. The bus service not being “reliable enough” was cited by 
only six percent of respondents. While the results of WMATA's on-board survey, discussed above, indicate that on-time arrival/reliability is the feature that current riders want improved the most, the results of this survey indicate that it is not a significant factor in why WMATA nonriders do not ride or ceased riding.

\section{Florida On-Board Surveys}

Raw data from eight recent Florida on-board ridership surveys were used to further analyze perceptions and impacts of reliability. Findings are determined from cross-tabulations of the survey questions regarding customer satisfaction with relevant attributes with several other questions about respondents' travel behavior, demographics, and satisfaction. Transit surveys in Florida typically contain nearly identical sets of questions, allowing for a relatively straightforward task of analyzing and aggregating results.

The Center for Urban Transportation Research (CUTR) has conducted most of the on-board surveys in the state of Florida. From a database of 25 surveys, 7 recent surveys were selected for this study. Care was taken to include agencies from across the geography of the state and to have small, medium, and larger agencies represented. Data from an eighth survey, in Pinellas County, were obtained from Tindale-Oliver \& Associates, Inc., in Tampa. The agencies with surveys represented in this section are listed below:

- Bay Town Trolley (Panama City)

- Collier Area Transit (Naples)

- Jacksonville Transportation Authority

- Lee County Transit (Fort Myers)

- Palm Tran (Palm Beach County)

- Pinellas Suncoast Transit Authority

- StarMetro (Tallahassee)

- VOTRAN (Volusia County)

Table 3-1 provides some recent information on these eight transit agencies. The year of the survey is shown, along with four indicators found in the 2006 National Transit Database: population, peak vehicles, revenue miles of service, and ridership (passenger trips). 
Table 3-1: On-Board Surveys Used to Analyze Reliability

\begin{tabular}{|l|c|c|c|c|c||}
\hline \multicolumn{1}{|c|}{ Agency } & $\begin{array}{c}\text { Year of } \\
\text { Survey }\end{array}$ & $\begin{array}{c}\text { Population } \\
\text { Served }\end{array}$ & $\begin{array}{c}\text { Peak } \\
\text { Vehicles* }\end{array}$ & $\begin{array}{c}\text { Revenue Miles } \\
\text { of Service* }\end{array}$ & Ridership* $^{*}$ \\
\hline Bay Town Trolley (Panama City) & 2006 & 85,458 & 8 & 420,927 & 309,232 \\
\hline Collier Area Transit (Naples) & 2005 & 317,788 & 13 & 870,424 & $1,052,536$ \\
\hline Jacksonville Transportation Authority & 2006 & 827,453 & 186 & $10,157,162$ & $11,125,128$ \\
\hline Lee County Transit (Fort Myers) & 2006 & 429,057 & 48 & $2,961,160$ & $2,891,968$ \\
\hline Palm Tran (Palm Beach County) & 2006 & 958,582 & 117 & $6,858,765$ & $9,310,413$ \\
\hline Pinellas Suncoast Transit Authority & 2007 & 881,705 & 165 & $8,609,598$ & $11,141,685$ \\
\hline StarMetro (Tallahassee) & 2005 & 162,310 & 56 & $1,749,960$ & $4,333,213$ \\
\hline VOTRAN (Volusia County) & 2006 & 468,670 & 48 & $2,636,071$ & $3,061,944$ \\
\hline
\end{tabular}

*From the 2006 National Transit Database.

Table 3-2 shows on-board survey respondents' level of satisfaction with their transit system's schedule reliability. On average, 59 percent are satisfied and approximately 18 percent are dissatisfied. The remainder are neutral. On all of the surveys except Pinellas, respondents were asked to select the top three service characteristics from the list used for the satisfaction ratings that, if improved, would benefit them the most. Table 3-2 also presents these results, which indicate that, on average, 17 percent selected schedule reliability as one of the top three most important service improvements. Among the individual agencies, higher percentages of those dissatisfied with reliability generally translated to higher percentages indicating a need for improved reliability. Because this research addresses how reliability might affect ridership, the following tables focus on the characteristics of those indicating a dissatisfaction with reliability, as this group of riders may be at risk of being lost. 
Table 3-2: Satisfaction with Schedule Reliability - Florida On-Board Surveys

\begin{tabular}{|c|c|c|c|c|}
\hline Agency & $\begin{array}{l}\text { Satisfied or } \\
\text { Very Satisfied }\end{array}$ & Neutral & $\begin{array}{l}\text { Dissatisfied } \\
\text { or Very } \\
\text { Dissatisfied }\end{array}$ & $\begin{array}{l}\text { In the Top } 3 \text { Most } \\
\text { Important Service } \\
\text { Improvements }\end{array}$ \\
\hline $\begin{array}{l}\text { Bay Town Trolley } \\
\text { (Panama City) }\end{array}$ & $70.0 \%$ & $20.0 \%$ & $10.0 \%$ & $6.4 \%$ \\
\hline $\begin{array}{l}\text { Collier Area Transit } \\
\text { (Naples) }\end{array}$ & $69.2 \%$ & $20.7 \%$ & $9.9 \%$ & $13.0 \%$ \\
\hline $\begin{array}{l}\text { Jacksonville } \\
\text { Transportation Authority }\end{array}$ & $41.1 \%$ & $26.0 \%$ & $33.0 \%$ & $19.8 \%$ \\
\hline $\begin{array}{l}\text { Lee County Transit } \\
\text { (Fort Myers) }\end{array}$ & $65.9 \%$ & $20.2 \%$ & $13.9 \%$ & $6.8 \%$ \\
\hline $\begin{array}{l}\text { Palm Tran } \\
\text { (Palm Beach County) }\end{array}$ & $55.0 \%$ & $20.6 \%$ & $24.3 \%$ & $20.3 \%$ \\
\hline $\begin{array}{l}\text { Pinellas Suncoast } \\
\text { Transit Authority* }\end{array}$ & $65.0 \%$ & $24.5 \%$ & $10.5 \%$ & $\mathrm{n} / \mathrm{a}$ \\
\hline StarMetro (Tallahassee) & $37.3 \%$ & $34.2 \%$ & $28.5 \%$ & $37.3 \%$ \\
\hline $\begin{array}{l}\text { VOTRAN } \\
\text { (Volusia County) }\end{array}$ & $70.3 \%$ & $17.9 \%$ & $11.8 \%$ & $13.8 \%$ \\
\hline Average & $59.2 \%$ & $23.0 \%$ & $17.7 \%$ & $16.8 \%$ \\
\hline
\end{tabular}

NOTE: Percentages may not add to 100 due to rounding.

*The survey instrument in Pinellas did not ask about service improvements.

In Tables 3-3 and 3-4, work and school trip purposes are compared between all riders and those indicating a level of dissatisfaction with schedule reliability. The information in Table 3-3 indicates that an average of 46 percent of responding riders reported that their surveyed trip was a work trip. Approximately 48 percent of the dissatisfied riders were taking a work trip; not a significant variation. For school trips, Table 3-4 indicates that approximately 19 percent of the rider sample average were going to or returning from school (grade school, high school, college, or technical school) while 24 percent of those dissatisfied with reliability were on a school trip. 
Table 3-3: Work Trip Purpose - Florida On-Board Surveys

\begin{tabular}{|l|r|r||}
\hline \multicolumn{1}{|c|}{ Agency } & All Riders & $\begin{array}{c}\text { Riders Dissatisfied with } \\
\text { Schedule Reliability }\end{array}$ \\
\hline Bay Town Trolley (Panama City) & $38.6 \%$ & $50.0 \%$ \\
\hline Collier Area Transit (Naples) & $53.1 \%$ & $50.6 \%$ \\
\hline Jacksonville Transportation Authority & $42.5 \%$ & $46.6 \%$ \\
\hline Lee County Transit (Fort Myers) & $52.4 \%$ & $49.2 \%$ \\
\hline Palm Tran (Palm Beach County) & $55.8 \%$ & $57.4 \%$ \\
\hline Pinellas Suncoast Transit Authority & $48.6 \%$ & $54.0 \%$ \\
\hline StarMetro (Tallahassee) & $24.1 \%$ & $25.7 \%$ \\
\hline VOTRAN (Volusia County) Average & $52.3 \%$ & $48.6 \%$ \\
\hline \multicolumn{2}{|c|}{$45.9 \%$} & $47.8 \%$ \\
\hline \hline
\end{tabular}

Table 3-4: School Trip Purpose - Florida On-Board Surveys

\begin{tabular}{|c|c|c|}
\hline Agency & All Riders & $\begin{array}{l}\text { Riders Dissatisfied with } \\
\text { Schedule Reliability }\end{array}$ \\
\hline Bay Town Trolley (Panama City) & $12.9 \%$ & $25.0 \%$ \\
\hline Collier Area Transit (Naples) & $14.2 \%$ & $18.0 \%$ \\
\hline Jacksonville Transportation Authority* & $\mathrm{n} / \mathrm{a}$ & $\mathrm{n} / \mathrm{a}$ \\
\hline Lee County Transit (Fort Myers) & $9.5 \%$ & $11.0 \%$ \\
\hline Palm Tran (Palm Beach County) & $18.4 \%$ & $19.1 \%$ \\
\hline Pinellas Suncoast Transit Authority & $6.1 \%$ & $4.0 \%$ \\
\hline StarMetro (Tallahassee) & $53.2 \%$ & $66.2 \%$ \\
\hline VOTRAN (Volusia County) & $15.6 \%$ & $26.1 \%$ \\
\hline Average & $18.6 \%$ & $24.2 \%$ \\
\hline
\end{tabular}

*The survey instrument in Jacksonville did not have an option for school trip purpose. 
Table 3-5: Reason for Riding - Florida On-Board Surveys

\begin{tabular}{|c|c|c|c|c|c|c|c|c|}
\hline \multirow[b]{2}{*}{ Agency } & \multicolumn{2}{|c|}{ I Don't Drive } & \multicolumn{2}{|c|}{ No Car is Available } & \multicolumn{2}{|c|}{$\begin{array}{l}\text { Parking/Traffic is } \\
\text { Too Difficult }\end{array}$} & \multicolumn{2}{|c|}{$\begin{array}{c}\text { Bus is More } \\
\text { Economical/Convenient }\end{array}$} \\
\hline & $\begin{array}{c}\text { All } \\
\text { Riders }\end{array}$ & $\begin{array}{c}\text { Riders } \\
\text { Dissatisfied } \\
\text { with Reliability }\end{array}$ & $\begin{array}{c}\text { All } \\
\text { Riders }\end{array}$ & $\begin{array}{c}\text { Riders } \\
\text { Dissatisfied } \\
\text { with Reliability }\end{array}$ & $\begin{array}{c}\text { All } \\
\text { Riders }\end{array}$ & $\begin{array}{c}\text { Riders } \\
\text { Dissatisfied } \\
\text { with Reliability }\end{array}$ & $\begin{array}{c}\text { All } \\
\text { Riders }\end{array}$ & $\begin{array}{c}\text { Riders } \\
\text { Dissatisfied } \\
\text { with Reliability }\end{array}$ \\
\hline $\begin{array}{l}\text { Bay Town Trolley } \\
\text { (Panama City) }\end{array}$ & $41.3 \%$ & $62.5 \%$ & $42.4 \%$ & $25.0 \%$ & $0.0 \%$ & $0.0 \%$ & $16.3 \%$ & $12.5 \%$ \\
\hline $\begin{array}{l}\text { Collier Area Transit } \\
\text { (Naples) }\end{array}$ & $52.1 \%$ & $51.2 \%$ & $23.1 \%$ & $31.4 \%$ & $2.2 \%$ & $0.0 \%$ & $19.0 \%$ & $12.8 \%$ \\
\hline $\begin{array}{l}\text { Jacksonville } \\
\text { Transportation } \\
\text { Authority }\end{array}$ & $20.1 \%$ & $23.2 \%$ & $42.2 \%$ & $48.0 \%$ & $5.1 \%$ & $5.2 \%$ & $27.9 \%$ & $18.2 \%$ \\
\hline $\begin{array}{l}\text { Lee County Transit } \\
\text { (Fort Myers) }\end{array}$ & $19.0 \%$ & $15.6 \%$ & $47.0 \%$ & $62.8 \%$ & $4.4 \%$ & $2.5 \%$ & $27.6 \%$ & $17.1 \%$ \\
\hline $\begin{array}{l}\text { Palm Tran } \\
\text { (Palm Beach County) }\end{array}$ & $34.2 \%$ & $32.8 \%$ & $39.2 \%$ & $48.0 \%$ & $4.3 \%$ & $3.3 \%$ & $18.6 \%$ & $11.1 \%$ \\
\hline $\begin{array}{l}\text { Pinellas Suncoast } \\
\text { Transit Authority }\end{array}$ & $18.5 \%$ & $15.2 \%$ & $48.1 \%$ & $57.6 \%$ & $2.7 \%$ & $4.0 \%$ & $26.3 \%$ & $17.9 \%$ \\
\hline $\begin{array}{l}\text { StarMetro } \\
\text { (Tallahassee) }\end{array}$ & $29.8 \%$ & $28.1 \%$ & $40.8 \%$ & $46.8 \%$ & $16.1 \%$ & $11.6 \%$ & $13.3 \%$ & $10.5 \%$ \\
\hline $\begin{array}{l}\text { VOTRAN } \\
\text { (Volusia County) }\end{array}$ & $52.5 \%$ & $52.3 \%$ & $29.8 \%$ & $36.0 \%$ & $1.0 \%$ & $0.9 \%$ & $12.6 \%$ & $3.6 \%$ \\
\hline Average & $33.4 \%$ & $35.1 \%$ & $39.1 \%$ & $44.5 \%$ & $4.5 \%$ & $3.4 \%$ & $20.2 \%$ & $13.0 \%$ \\
\hline
\end{tabular}

NOTE: Percentages may not add to 100 due to rounding and the exclusion of the "other" category.

Table 3-5 above summarizes the primary reasons for riding transit for those indicating dissatisfaction with schedule reliability and the sample rider population as a whole. For each of the surveys, all potential responses to this question were placed into one of the four categories in the table: I don’t drive, no car is available, parking/traffic is too difficult, and the bus is more economical/convenient. Responses in the “other” category generally represent a very small percentage of all responses and are not included here.

Highlights from the information in Table 3-5 include that, on average, riders dissatisfied with reliability are more likely than the rider sample as a whole to not have a car available for their trip. Also, these dissatisfied riders are less likely than all riders, on average, to take the bus primarily because they consider it more economical or convenient. These data suggest that this segment of dissatisfied riders tends to be more dependent on transit, at least for the surveyed trip. 
Table 3-6: Alternative to Transit - Florida On-Board Surveys

\begin{tabular}{|c|c|c|c|c|c|c|c|c|}
\hline \multirow[b]{2}{*}{ Agency } & \multicolumn{2}{|r|}{ Drive } & \multicolumn{2}{|c|}{ Ride with Someone } & \multicolumn{2}{|c|}{ Bike/Walk/Taxi } & \multicolumn{2}{|c|}{ Wouldn't Make Trip } \\
\hline & $\begin{array}{c}\text { All } \\
\text { Riders }\end{array}$ & $\begin{array}{c}\text { Riders } \\
\text { Dissatisfied } \\
\text { with Reliability }\end{array}$ & $\begin{array}{c}\text { All } \\
\text { Riders }\end{array}$ & $\begin{array}{c}\text { Riders } \\
\text { Dissatisfied } \\
\text { with Reliability }\end{array}$ & $\begin{array}{c}\text { All } \\
\text { Riders }\end{array}$ & $\begin{array}{c}\text { Riders } \\
\text { Dissatisfied } \\
\text { with Reliability }\end{array}$ & $\begin{array}{c}\text { All } \\
\text { Riders }\end{array}$ & $\begin{array}{c}\text { Riders } \\
\text { Dissatisfied } \\
\text { with Reliability }\end{array}$ \\
\hline $\begin{array}{l}\text { Bay Town Trolley } \\
\text { (Panama City) }\end{array}$ & $6.6 \%$ & $0.0 \%$ & $31.9 \%$ & $50.0 \%$ & $37.4 \%$ & $50.0 \%$ & $24.2 \%$ & $0.0 \%$ \\
\hline $\begin{array}{l}\text { Collier Area Transit } \\
\text { (Naples)* }^{\star}\end{array}$ & $\mathrm{n} / \mathrm{a}$ & $\mathrm{n} / \mathrm{a}$ & $\mathrm{n} / \mathrm{a}$ & $\mathrm{n} / \mathrm{a}$ & $\mathrm{n} / \mathrm{a}$ & $\mathrm{n} / \mathrm{a}$ & $\mathrm{n} / \mathrm{a}$ & $\mathrm{n} / \mathrm{a}$ \\
\hline $\begin{array}{l}\text { Jacksonville } \\
\text { Transportation } \\
\text { Authority }\end{array}$ & $14.8 \%$ & $11.4 \%$ & $36.2 \%$ & $35.8 \%$ & $31.7 \%$ & $30.8 \%$ & $17.2 \%$ & $21.9 \%$ \\
\hline $\begin{array}{l}\text { Lee County Transit } \\
\text { (Fort Myers) }\end{array}$ & $12.2 \%$ & $11.4 \%$ & $33.3 \%$ & $30.2 \%$ & $32.9 \%$ & $33.7 \%$ & $21.7 \%$ & $24.8 \%$ \\
\hline $\begin{array}{l}\text { Palm Tran } \\
\text { (Palm Beach County) }\end{array}$ & $10.0 \%$ & $6.7 \%$ & $33.1 \%$ & $33.0 \%$ & $40.5 \%$ & $38.4 \%$ & $16.4 \%$ & $21.9 \%$ \\
\hline $\begin{array}{l}\text { Pinellas Suncoast } \\
\text { Transit Authority }\end{array}$ & $8.9 \%$ & $11.8 \%$ & $25.8 \%$ & $22.4 \%$ & $37.9 \%$ & $41.4 \%$ & $27.4 \%$ & $24.3 \%$ \\
\hline $\begin{array}{l}\text { StarMetro } \\
\text { (Tallahassee) }\end{array}$ & $13.2 \%$ & $11.0 \%$ & $36.1 \%$ & $39.0 \%$ & $39.3 \%$ & $39.9 \%$ & $10.2 \%$ & $10.1 \%$ \\
\hline $\begin{array}{l}\text { VOTRAN } \\
\text { (Volusia County) }\end{array}$ & $10.1 \%$ & $10.8 \%$ & $26.5 \%$ & $30.6 \%$ & $48.7 \%$ & $46.8 \%$ & $14.7 \%$ & $11.7 \%$ \\
\hline Average & $10.8 \%$ & $9.0 \%$ & $31.8 \%$ & $34.4 \%$ & $38.3 \%$ & $40.1 \%$ & $18.8 \%$ & $16.4 \%$ \\
\hline
\end{tabular}

NOTE: Percentages may not add to 100 due to rounding and the exclusion of the "other" category.

*The survey for Collier Area Transit did not include this question.

Overall, the information presented in Table 3-6 does not show any major difference between riders dissatisfied with reliability and the rider sample population as a whole regarding alternatives to transit. If the bus service were not available, nine percent of the dissatisfied riders would be able to drive for their surveyed trip (compared to 11 percent for all riders). These dissatisfied riders are slightly more likely to be able to ride with someone to make their trip 34 percent versus 32 percent), and are slightly less likely to not be able to make the trip at all (15 percent versus 19 percent). 
In Table 3-7, data are presented on the frequency of transit use for those riders who indicating dissatisfaction with schedule reliability compared to the samples of all riders. While there is some variation among the individual agencies, on average, there does not appear to be a correlation between dissatisfaction with reliability and the frequency of transit use per week. Chapter 5 further explores the frequency of transit use.

Table 3-7: Frequency of Transit Use - Florida On-Board Surveys

\begin{tabular}{|c|c|c|c|c|c|c|}
\hline \multirow[b]{2}{*}{ Agency } & \multicolumn{2}{|c|}{4 to 7 Days/Week } & \multicolumn{2}{|c|}{1 to 3 Days/Week } & \multicolumn{2}{|c|}{ Less than 1 Day/Week } \\
\hline & $\begin{array}{c}\text { All } \\
\text { Riders }\end{array}$ & $\begin{array}{c}\text { Riders } \\
\text { Dissatisfied } \\
\text { with Reliability }\end{array}$ & $\begin{array}{c}\text { All } \\
\text { Riders }\end{array}$ & $\begin{array}{c}\text { Riders } \\
\text { Dissatisfied } \\
\text { with Reliability }\end{array}$ & $\begin{array}{c}\text { All } \\
\text { Riders }\end{array}$ & $\begin{array}{c}\text { Riders } \\
\text { Dissatisfied } \\
\text { with Reliability }\end{array}$ \\
\hline $\begin{array}{l}\text { Bay Town Trolley } \\
\text { (Panama City) }\end{array}$ & $56.1 \%$ & $76.1 \%$ & $31.9 \%$ & $19.3 \%$ & $12.0 \%$ & $4.5 \%$ \\
\hline $\begin{array}{l}\text { Collier Area Transit } \\
\text { (Naples) }\end{array}$ & $71.3 \%$ & $50.0 \%$ & $22.1 \%$ & $50.0 \%$ & $6.7 \%$ & $0.0 \%$ \\
\hline $\begin{array}{l}\text { Jacksonville } \\
\text { Transportation } \\
\text { Authority }\end{array}$ & $82.4 \%$ & $74.4 \%$ & $15.9 \%$ & $21.1 \%$ & $1.7 \%$ & $4.5 \%$ \\
\hline $\begin{array}{l}\text { Lee County Transit } \\
\text { (Fort Myers) }\end{array}$ & $72.2 \%$ & $76.6 \%$ & $23.2 \%$ & $18.0 \%$ & $4.6 \%$ & $5.4 \%$ \\
\hline $\begin{array}{l}\text { Palm Tran } \\
\text { (Palm Beach County) }\end{array}$ & $80.2 \%$ & $76.3 \%$ & $14.8 \%$ & $20.0 \%$ & $5.0 \%$ & $3.8 \%$ \\
\hline $\begin{array}{l}\text { Pinellas Suncoast } \\
\text { Transit Authority* }\end{array}$ & $78.1 \%$ & $84.5 \%$ & $21.9 \%$ & $12.4 \%$ & $\mathrm{n} / \mathrm{a}$ & $2.9 \%$ \\
\hline $\begin{array}{l}\text { StarMetro } \\
\text { (Tallahassee) }\end{array}$ & $73.1 \%$ & $80.4 \%$ & $21.8 \%$ & $19.6 \%$ & $5.1 \%$ & $\mathrm{n} / \mathrm{a}$ \\
\hline $\begin{array}{l}\text { VOTRAN } \\
\text { (Volusia County) }\end{array}$ & $79.3 \%$ & $90.7 \%$ & $16.2 \%$ & $9.1 \%$ & $4.4 \%$ & $0.2 \%$ \\
\hline Average & $74.1 \%$ & $76.1 \%$ & $21.0 \%$ & $21.2 \%$ & $5.6 \%$ & $3.0 \%$ \\
\hline
\end{tabular}

NOTE: Percentages may not add to 100 due to rounding.

*The survey instrument for Pinellas did not include an option for riding less than one day per week. 
Interestingly, regarding the length of transit use, Table 3-8 shows that riders who are dissatisfied with schedule reliability tend to be either very new riders (less than six months) or more longterm users (more than two years) when compared with the rider samples as a whole. A closer look reveals that whether these dissatisfied riders are more likely than all riders to be newer users or longer-term users varies by agency. The on-board surveys in Collier County and Pinellas County did not include a question on the length of transit use.

Table 3-8: Length of Transit Use - Florida On-Board Surveys

\begin{tabular}{|c|c|c|c|c|c|c|}
\hline Agency & $\begin{array}{c}\text { All } \\
\text { Riders }\end{array}$ & $\begin{array}{c}\text { Riders } \\
\text { Dissatisfied } \\
\text { with Reliability }\end{array}$ & $\begin{array}{c}\text { All } \\
\text { Riders }\end{array}$ & $\begin{array}{c}\text { Riders } \\
\text { Dissatisfied } \\
\text { with Reliability }\end{array}$ & $\begin{array}{c}\text { All } \\
\text { Riders }\end{array}$ & $\begin{array}{c}\text { Riders } \\
\text { Dissatisfied } \\
\text { with Reliability }\end{array}$ \\
\hline $\begin{array}{l}\text { Bay Town Trolley } \\
\text { (Panama City) }\end{array}$ & $42.9 \%$ & $75.0 \%$ & $30.8 \%$ & $0.0 \%$ & $26.4 \%$ & $25.0 \%$ \\
\hline $\begin{array}{l}\text { Collier Area Transit } \\
\text { (Naples)* }^{\star}\end{array}$ & $\mathrm{n} / \mathrm{a}$ & $\mathrm{n} / \mathrm{a}$ & $\mathrm{n} / \mathrm{a}$ & $\mathrm{n} / \mathrm{a}$ & $\mathrm{n} / \mathrm{a}$ & $\mathrm{n} / \mathrm{a}$ \\
\hline $\begin{array}{l}\text { Jacksonville } \\
\text { Transportation } \\
\text { Authority } \\
\end{array}$ & $19.5 \%$ & $16.3 \%$ & $28.6 \%$ & $32.5 \%$ & $51.8 \%$ & $51.2 \%$ \\
\hline $\begin{array}{l}\text { Palm Tran } \\
\text { (Palm Beach County) }\end{array}$ & $18.8 \%$ & $16.3 \%$ & $34.4 \%$ & $30.7 \%$ & $46.9 \%$ & $53.0 \%$ \\
\hline $\begin{array}{l}\text { Pinellas Suncoast } \\
\text { Transit Authority* }\end{array}$ & $\mathrm{n} / \mathrm{a}$ & $\mathrm{n} / \mathrm{a}$ & $\mathrm{n} / \mathrm{a}$ & $\mathrm{n} / \mathrm{a}$ & $\mathrm{n} / \mathrm{a}$ & $\mathrm{n} / \mathrm{a}$ \\
\hline $\begin{array}{l}\text { StarMetro } \\
\text { (Tallahassee) }\end{array}$ & $33.2 \%$ & $29.8 \%$ & $25.1 \%$ & $24.7 \%$ & $41.7 \%$ & $45.5 \%$ \\
\hline $\begin{array}{l}\text { VOTRAN } \\
\text { (Volusia County) }\end{array}$ & $23.2 \%$ & $24.3 \%$ & $25.9 \%$ & $19.8 \%$ & $50.9 \%$ & $55.9 \%$ \\
\hline
\end{tabular}

NOTE: Percentages may not add to 100 due to rounding.

*The survey instruments for Collier and Pinellas did not include this question. 
Table 3-9 presents the age groupings of riders indicating dissatisfaction with reliability compared to the rider samples as a whole. All of the age categories on the various on-board survey instruments were combined into four groups: ages 18 or less, ages 19 to 24, ages 25 to 49, and ages 50 and over. Most of the surveys utilized the same age groupings; although, in a few cases there were slight differences that sometimes did not match exactly the four categories shown in Table 3-9. These slight differences, however, did not affect the overall trends evident in the table. The table shows that, when compared with the rider samples as a whole, the youngest riders (age 18 or less) are be more dissatisfied with reliability while the oldest riders tend to be less concerned with reliability. These results are consistent with the findings of other on-board surveys, particularly the WMATA on-board survey results discussed previously.

Table 3-4 had shown that riders indicating dissatisfaction with reliability take more school trips when compared to all riders. This is consistent with the results in Table 3-9, given that students tend to represent younger age cohorts.

Table 3-9: Age Groups - Florida On-Board Surveys

\begin{tabular}{|c|c|c|c|c|c|c|c|c|}
\hline \multirow[b]{2}{*}{ Agency } & \multicolumn{2}{|c|}{18 or Younger } & \multicolumn{2}{|r|}{19 to 24} & \multicolumn{2}{|r|}{25 to 49} & \multicolumn{2}{|c|}{50 or Older } \\
\hline & $\begin{array}{c}\text { All } \\
\text { Riders }\end{array}$ & $\begin{array}{c}\text { Riders } \\
\text { Dissatisfied } \\
\text { with Reliability }\end{array}$ & $\begin{array}{c}\text { All } \\
\text { Riders }\end{array}$ & $\begin{array}{c}\text { Riders } \\
\text { Dissatisfied } \\
\text { with Reliability }\end{array}$ & $\begin{array}{c}\text { All } \\
\text { Riders }\end{array}$ & $\begin{array}{c}\text { Riders } \\
\text { Dissatisfied } \\
\text { with Reliability }\end{array}$ & $\begin{array}{c}\text { All } \\
\text { Riders }\end{array}$ & $\begin{array}{c}\text { Riders } \\
\text { Dissatisfied } \\
\text { with Reliability }\end{array}$ \\
\hline $\begin{array}{l}\text { Bay Town Trolley } \\
\text { (Panama City) }\end{array}$ & $7.4 \%$ & $35.2 \%$ & $59.8 \%$ & $18.7 \%$ & $29.3 \%$ & $40.7 \%$ & $3.4 \%$ & $5.5 \%$ \\
\hline $\begin{array}{l}\text { Collier Area Transit } \\
\text { (Naples) }\end{array}$ & $3.3 \%$ & $0.0 \%$ & $3.3 \%$ & $0.0 \%$ & $62.2 \%$ & $62.5 \%$ & $31.1 \%$ & $37.5 \%$ \\
\hline $\begin{array}{l}\text { Jacksonville } \\
\text { Transportation } \\
\text { Authority }\end{array}$ & $7.5 \%$ & $10.2 \%$ & $23.1 \%$ & $28.8 \%$ & $56.4 \%$ & $55.1 \%$ & $13.0 \%$ & $5.9 \%$ \\
\hline $\begin{array}{l}\text { Lee County Transit } \\
\text { (Fort Myers) }\end{array}$ & $16.8 \%$ & $27.1 \%$ & $13.5 \%$ & $18.7 \%$ & $45.9 \%$ & $42.1 \%$ & $23.8 \%$ & $12.1 \%$ \\
\hline $\begin{array}{l}\text { Palm Tran } \\
\text { (Palm Beach County) }\end{array}$ & $7.4 \%$ & $7.2 \%$ & $59.8 \%$ & $68.1 \%$ & $29.3 \%$ & $23.1 \%$ & $3.4 \%$ & $1.7 \%$ \\
\hline $\begin{array}{l}\text { Pinellas Suncoast } \\
\text { Transit Authority }\end{array}$ & $17.8 \%$ & $20.4 \%$ & $23.1 \%$ & $21.9 \%$ & $49.1 \%$ & $50.0 \%$ & $10.1 \%$ & $7.6 \%$ \\
\hline $\begin{array}{l}\text { StarMetro } \\
\text { (Tallahassee) }\end{array}$ & $4.5 \%$ & $7.0 \%$ & $15.1 \%$ & $23.1 \%$ & $61.3 \%$ & $57.3 \%$ & $19.2 \%$ & $12.6 \%$ \\
\hline $\begin{array}{l}\text { VOTRAN } \\
\text { (Volusia County) }\end{array}$ & $7.5 \%$ & $8.6 \%$ & $18.8 \%$ & $17.9 \%$ & $50.7 \%$ & $61.8 \%$ & $4.1 \%$ & $11.7 \%$ \\
\hline Average & $9.0 \%$ & $14.5 \%$ & $27.1 \%$ & $24.6 \%$ & $48.0 \%$ & $49.1 \%$ & $13.5 \%$ & $11.8 \%$ \\
\hline
\end{tabular}

NOTE: Percentages may not add to 100 due to rounding. 
For the results in Table 3-10, all of the annual household income categories from the various onboard survey instruments were combined into four groups: less than $\$ 20,000, \$ 20,000$ to $\$ 29,999, \$ 30,000$ to $\$ 50,000$, and greater than $\$ 50,000$. As with the age groupings, most of the surveys utilized the same income groups; although, again there were a few cases where there were slight differences. Again, as with the age groupings shown previously, these did not affect the overall trends depicted in Table 3-10. Results from the table do not show evidence of significant differences, on average, between riders dissatisfied with reliability and all riders among the four income categories. However, some of the agencies show more variation than others.

Table 3-10: Annual Income - Florida On-Board Surveys

\begin{tabular}{|c|c|c|c|c|c|c|c|c|}
\hline \multirow[b]{2}{*}{ Agency } & \multicolumn{2}{|c|}{ Less than $\$ 20,000$} & \multicolumn{2}{|c|}{$\$ 20,000$ to $\$ 29,999$} & \multicolumn{2}{|c|}{$\$ 30,000$ to $\$ 50,000$} & \multicolumn{2}{|c|}{ Greater than $\$ 50,000$} \\
\hline & $\begin{array}{c}\text { All } \\
\text { Riders }\end{array}$ & $\begin{array}{c}\text { Riders } \\
\text { Dissatisfied } \\
\text { with Reliability }\end{array}$ & $\begin{array}{c}\text { All } \\
\text { Riders }\end{array}$ & $\begin{array}{c}\text { Riders } \\
\text { Dissatisfied } \\
\text { with Reliability }\end{array}$ & $\begin{array}{c}\text { All } \\
\text { Riders }\end{array}$ & $\begin{array}{c}\text { Riders } \\
\text { Dissatisfied } \\
\text { with Reliability }\end{array}$ & $\begin{array}{c}\text { All } \\
\text { Riders }\end{array}$ & $\begin{array}{c}\text { Riders } \\
\text { Dissatisfied } \\
\text { with Reliability }\end{array}$ \\
\hline $\begin{array}{l}\text { Bay Town Trolley } \\
\text { (Panama City) }\end{array}$ & $75.3 \%$ & $100.0 \%$ & $6.8 \%$ & $0.0 \%$ & $12.4 \%$ & $0.0 \%$ & $5.5 \%$ & $0.0 \%$ \\
\hline $\begin{array}{l}\text { Collier Area Transit } \\
\text { (Naples)* }^{\star}\end{array}$ & $\mathrm{n} / \mathrm{a}$ & $\mathrm{n} / \mathrm{a}$ & $\mathrm{n} / \mathrm{a}$ & $\mathrm{n} / \mathrm{a}$ & $\mathrm{n} / \mathrm{a}$ & $\mathrm{n} / \mathrm{a}$ & $6.9 \%$ & $11.1 \%$ \\
\hline $\begin{array}{l}\text { Jacksonville } \\
\text { Transportation } \\
\text { Authority }\end{array}$ & $64.6 \%$ & $60.4 \%$ & $17.5 \%$ & $19.9 \%$ & $12.1 \%$ & $12.2 \%$ & $5.6 \%$ & $7.5 \%$ \\
\hline $\begin{array}{l}\text { Lee County Transit } \\
\text { (Fort Myers) }\end{array}$ & $62.4 \%$ & $65.3 \%$ & $19.2 \%$ & $18.6 \%$ & $12.6 \%$ & $13.8 \%$ & $5.8 \%$ & $2.4 \%$ \\
\hline $\begin{array}{l}\text { Palm Tran } \\
\text { (Palm Beach County) }\end{array}$ & $61.7 \%$ & $59.9 \%$ & $13.9 \%$ & $13.2 \%$ & $18.1 \%$ & $20.0 \%$ & $6.3 \%$ & $15.4 \%$ \\
\hline $\begin{array}{l}\text { Pinellas Suncoast } \\
\text { Transit Authority }\end{array}$ & $49.5 \%$ & $45.3 \%$ & $19.7 \%$ & $25.0 \%$ & $15.0 \%$ & $17.2 \%$ & $5.5 \%$ & $1.6 \%$ \\
\hline $\begin{array}{l}\text { StarMetro } \\
\text { (Tallahassee) }\end{array}$ & $69.9 \%$ & $74.3 \%$ & $10.0 \%$ & $7.6 \%$ & $10.7 \%$ & $9.5 \%$ & $9.4 \%$ & $8.6 \%$ \\
\hline $\begin{array}{l}\text { VOTRAN } \\
\text { (Volusia County) }\end{array}$ & $69.2 \%$ & $70.2 \%$ & $15.7 \%$ & $13.8 \%$ & $10.1 \%$ & $10.6 \%$ & $5.0 \%$ & $5.3 \%$ \\
\hline Average & $64.7 \%$ & $67.9 \%$ & $14.7 \%$ & $14.0 \%$ & $13.0 \%$ & $11.9 \%$ & $6.3 \%$ & $6.5 \%$ \\
\hline
\end{tabular}

NOTE: Percentages may not add to 100 due to rounding.

*The income categories on the Collier survey could not be matched with the others for responses under $\$ 50,000$. 
Table 3-11 provides information on household vehicle availability for riders dissatisfied with schedule reliability as compared to all riders sampled for each survey. While some results do vary by agency, on average, riders indicating dissatisfaction with reliability tend to have fewer cars available in their household. This is consistent with the findings in Tables 3-5 and 3-6 that show these dissatisfied riders tend to be somewhat more dependent on transit, on average, than riders as a whole.

Table 3-11: Vehicle Availability - Florida On-Board Surveys

\begin{tabular}{|c|c|c|c|c|c|c|c|c|}
\hline \multirow[b]{2}{*}{ Agency } & \multicolumn{2}{|r|}{ Zero } & \multicolumn{2}{|r|}{ One } & \multicolumn{2}{|r|}{ Two } & \multicolumn{2}{|c|}{ Three or More } \\
\hline & $\begin{array}{c}\text { All } \\
\text { Riders }\end{array}$ & $\begin{array}{c}\text { Riders } \\
\text { Dissatisfied } \\
\text { with Reliability }\end{array}$ & $\begin{array}{c}\text { All } \\
\text { Riders }\end{array}$ & $\begin{array}{c}\text { Riders } \\
\text { Dissatisfied } \\
\text { with Reliability }\end{array}$ & $\begin{array}{c}\text { All } \\
\text { Riders }\end{array}$ & $\begin{array}{c}\text { Riders } \\
\text { Dissatisfied } \\
\text { with Reliability }\end{array}$ & $\begin{array}{c}\text { All } \\
\text { Riders }\end{array}$ & $\begin{array}{c}\text { Riders } \\
\text { Dissatisfied } \\
\text { with Reliability }\end{array}$ \\
\hline $\begin{array}{l}\text { Bay Town Trolley } \\
\text { (Panama City) }\end{array}$ & $65.1 \%$ & $100.0 \%$ & $25.3 \%$ & $0.0 \%$ & $4.8 \%$ & $0.0 \%$ & $4.8 \%$ & $0.0 \%$ \\
\hline $\begin{array}{l}\text { Collier Area Transit } \\
\text { (Naples)* }^{*}\end{array}$ & $\mathrm{n} / \mathrm{a}$ & $\mathrm{n} / \mathrm{a}$ & $\mathrm{n} / \mathrm{a}$ & $\mathrm{n} / \mathrm{a}$ & $\mathrm{n} / \mathrm{a}$ & $\mathrm{n} / \mathrm{a}$ & $\mathrm{n} / \mathrm{a}$ & $\mathrm{n} / \mathrm{a}$ \\
\hline $\begin{array}{l}\text { Jacksonville } \\
\text { Transportation } \\
\text { Authority }\end{array}$ & $49.3 \%$ & $52.0 \%$ & $31.0 \%$ & $31.8 \%$ & $13.5 \%$ & $10.7 \%$ & $6.2 \%$ & $5.4 \%$ \\
\hline $\begin{array}{l}\text { Lee County Transit } \\
\text { (Fort Myers) }\end{array}$ & $45.2 \%$ & $45.2 \%$ & $32.4 \%$ & $30.5 \%$ & $14.4 \%$ & $14.7 \%$ & $8.0 \%$ & $9.6 \%$ \\
\hline $\begin{array}{l}\text { Palm Tran } \\
\text { (Palm Beach County) }\end{array}$ & $41.7 \%$ & $41.4 \%$ & $33.5 \%$ & $34.2 \%$ & $16.8 \%$ & $17.4 \%$ & $7.8 \%$ & $7.0 \%$ \\
\hline $\begin{array}{l}\text { Pinellas Suncoast } \\
\text { Transit Authority* }\end{array}$ & $\mathrm{n} / \mathrm{a}$ & $\mathrm{n} / \mathrm{a}$ & $\mathrm{n} / \mathrm{a}$ & $\mathrm{n} / \mathrm{a}$ & $\mathrm{n} / \mathrm{a}$ & $\mathrm{n} / \mathrm{a}$ & $\mathrm{n} / \mathrm{a}$ & $\mathrm{n} / \mathrm{a}$ \\
\hline $\begin{array}{l}\text { StarMetro } \\
\text { (Tallahassee) }\end{array}$ & $42.4 \%$ & $46.1 \%$ & $30.1 \%$ & $28.8 \%$ & $15.8 \%$ & $15.4 \%$ & $11.7 \%$ & $9.7 \%$ \\
\hline $\begin{array}{l}\text { VOTRAN } \\
\text { (Volusia County) }\end{array}$ & $51.3 \%$ & $52.7 \%$ & $29.0 \%$ & $18.8 \%$ & $12.9 \%$ & $16.1 \%$ & $6.8 \%$ & $12.5 \%$ \\
\hline Average & $49.2 \%$ & $56.2 \%$ & $30.2 \%$ & $24.0 \%$ & $13.0 \%$ & $12.4 \%$ & $7.6 \%$ & $7.4 \%$ \\
\hline
\end{tabular}

NOTE: Percentages may not add to 100 due to rounding and the exclusion of the "other" category.

*The survey instruments for Collier and Pinellas did not include this question.

Overall, this analysis of Florida on-board surveys showed that, on average, 59 percent of respondents are satisfied with schedule reliability, 23 percent are neutral, and 18 percent are dissatisfied. In addition, approximately 17 percent included reliability as one of the top three most important service improvements that can be made at their transit agency. The characteristics of the dissatisfied riders were further explored in this section, as transit agencies do not want to lose a segment of riders due to such dissatisfaction. It was found that, in general, there is little variation between this segment of dissatisfied riders and the rider samples as a whole, other than they tend to be somewhat younger and more transit-dependent. These findings 
are consistent with those found in the earlier analysis of other on-board and customer satisfaction surveys from across the country.

\section{Attitudes on Reliability Revealed by the Puget Sound Transportation Panel Surveys}

This section includes an analysis of the Puget Sound Transportation Panel (PSTP) data sets discussed previously and in detail in Chapter 2. According to documentation on the PSTP, it was the first general-purpose travel panel survey conducted in an urban area of the United States. It originated in 1989 by the entity now known as the Puget Sound Regional Council. The information acquired from the panel survey results assists the Puget Sound Regional Council in long-range transportation planning and analysis for decisions such as highway and road construction, transit development, and policies for carpooling and parking.

The panel comprises approximately 1,700 households across the four-county Puget Sound region (King, Kitsap, Pierce, and Snohomish Counties), and specifically includes households that contain at least one member who regularly uses transit and households with at least one member who carpools regularly. Other households with members who drive alone for most of their trips are also included. The household members recorded all of their trip activity for a two-day period in each wave. In addition, a sample of the household members was asked to complete a separate survey on their attitudes and perceptions of various modes of transportation.

The first wave of the PSTP was conducted in 1989, and was followed by the first attitude survey in early 1990. The second wave occurred later in 1990 and was again followed by an attitude survey in 1991. Successive waves took place in 1992, 1993, 1994, 1996, 1997, 1999, 2000, and 2002. Attitude surveys were administered along with the 1990, 1991, 1993, 1996, 1997, 1999, 2000, and 2002 waves.

The PSTP began with 1,712 participating households in 1989 and was maintained at between 1,700 and 1,900 over the 10 waves. For each wave, approximately 20 percent of the households needed to be replaced, mainly due to households relocating. This rate of attrition should be considered when looking at differences among the individual survey years.

Table 3-12 presents the share of those using the single-occupant vehicle (SOV), transit, or a combination of a car and transit as the primary work mode. On average, over the 10 survey 
waves, 67 percent of PSTP participants reported the SOV as their primary work mode. More than eight percent of PSTP participants used transit as the primary work mode and an additional four percent used a combination of a car and bus.

Table 3-12: Primary Work Mode - Puget Sound Transportation Panel

\begin{tabular}{|c|c|c|c|c|c|c|c|c|c|c|c|}
\hline & $\begin{array}{c}\text { Wave } 1 \\
\text { (1989) }\end{array}$ & $\begin{array}{c}\text { Wave } 2 \\
(1990)\end{array}$ & $\begin{array}{c}\text { Wave } 3 \\
\text { (1992) }\end{array}$ & $\begin{array}{c}\text { Wave } 4 \\
\text { (1993) }\end{array}$ & $\begin{array}{c}\text { Wave } 5 \\
\text { (1994) }\end{array}$ & $\begin{array}{c}\text { Wave } 6 \\
\text { (1996) }\end{array}$ & $\begin{array}{c}\text { Wave } 7 \\
\text { (1997) }\end{array}$ & $\begin{array}{c}\text { Wave } 8 \\
\text { (1999) }\end{array}$ & $\begin{array}{c}\text { Wave } 9 \\
(2000)\end{array}$ & $\begin{array}{c}\text { Wave } \\
10 \\
(2002)\end{array}$ & Avg. \\
\hline Transit & $13.2 \%$ & $10.5 \%$ & $4.7 \%$ & $6.3 \%$ & $6.7 \%$ & $8.1 \%$ & $7.5 \%$ & $9.4 \%$ & $10.0 \%$ & $7.1 \%$ & $8.4 \%$ \\
\hline Carpool & $12.2 \%$ & $12.0 \%$ & $20.4 \%$ & $13.5 \%$ & $12.8 \%$ & $9.4 \%$ & $14.1 \%$ & $14.6 \%$ & $15.9 \%$ & $12.1 \%$ & $13.7 \%$ \\
\hline
\end{tabular}

NOTE: Percentages do not add to 100 due to rounding and the exclusion of other modes/responses (walk/bike, ferry, other, refused, work at home).

As discussed in Chapter 2, a series of attitude surveys was conducted as part of the Puget Sound Transportation Panel. The results of these surveys provide insight into participants' opinions and perceptions of various characteristics and modes of travel. The first four attitude surveys (conducted in 1990, 1991, 1993, and 1996), were different in structure than the later surveys (conducted in 1997, 1999, 2000, and 2002). Thus, the two groups of surveys are analyzed separately.

Relevant results from the earlier attitude surveys are presented first. The attitude surveys provide good information on both users' and non-users’ perceptions and opinions about reliability and on-time performance in general. Cross-tabulations of select questions or statements from the attitude surveys relating to reliability against other pertinent questions/statements and some demographic information were used to compile the information that follows. To accomplish this, the attitude survey data sets were merged with data sets containing variables relating to individual person or household characteristics. A unique person identifier number was contained (or was easily computed using other identifiers consistent among the data sets) in the data sets being merged to ensure the information among the data sets could be matched with the correct individual responses. However, not all information is available for all survey years. Analysis and discussion of some attitudes and other characteristics is limited to a few or just one survey year, as noted in the appropriate tables and paragraphs below. 
In these early attitude surveys, participants were provided with a list of several travel mode characteristics and were asked to rate them in importance in deciding how to get to work or school (i.e., how important they are in mode choice). Table 3-13 shows how respondents rated the importance of a mode's ability to arrive on time. Not surprisingly, most consider arriving on time an important attribute; in total, 93 percent consider it to be important, with nearly 69 percent rating it as "extremely important." Interestingly, the share rating it as "extremely important fell from approximately 72 percent to 62 percent between 1990 and 1996; although, the share rating it "relatively important” increased during that time.

Table 3-13: Importance of the Ability to Arrive on Time Puget Sound Transportation Panel Attitude Surveys (1990_1996)

\begin{tabular}{||l|r|r|r|r|r||}
\hline \multicolumn{1}{|c|}{ Importance Rating } & \multicolumn{1}{c|}{1990} & \multicolumn{1}{c|}{1991} & \multicolumn{1}{c|}{1993} & \multicolumn{1}{c|}{1996} & Average \\
\hline Extremely Important & $72.5 \%$ & $72.3 \%$ & $67.5 \%$ & $62.3 \%$ & $68.7 \%$ \\
\hline Relatively Important & $22.1 \%$ & $23.0 \%$ & $26.1 \%$ & $27.6 \%$ & $24.7 \%$ \\
\hline Neutral & $2.6 \%$ & $2.6 \%$ & $3.5 \%$ & $3.5 \%$ & $3.1 \%$ \\
\hline Relatively Unimportant & $1.7 \%$ & $1.0 \%$ & $2.0 \%$ & $1.6 \%$ & $1.6 \%$ \\
\hline Not at All Important & $1.1 \%$ & $0.9 \%$ & $0.9 \%$ & $0.7 \%$ & $0.9 \%$ \\
\hline
\end{tabular}

NOTE: Percentages may not sum to 100 due to rounding.

In Table 3-14, a few household characteristics of the respondents rating the ability to arrive on time as "extremely important” are presented. The averages are also compared to the same characteristics for all the respondents. As the table indicates, those rating the ability to arrive on time as "extremely important" have similar lifecycle characteristics as the respondent population as a whole, with the two largest lifecycle categories being households with children and households with two or more adults age 35 to 64 with no children. Those rating the ability to arrive on time as "extremely important" do tend to have higher incomes, as indicated in Table 314. While an average of nearly 20 percent have annual incomes of $\$ 25,000$ or less, only 14 percent of those rating the ability to arrive on time as "extremely important" reported incomes in this category. Similarly, at the higher end of the income scale, 15 percent of those indicating that the ability to arrive on time is "extremely important” reported annual incomes greater than $\$ 75,000$, compared to 11 percent for all respondents. In addition, Table 3-14 shows that the respondents rating ability to arrive on time as “extremely important” tend to have more vehicles 
available in their households than the respondent population as a whole. For example, the table shows that 36 percent have three or more vehicles compared to 28 percent for all respondents.

Table 3-14: Select Household Characteristics of Those Rating the Ability to Arrive on Time as "Extremely Important"-

Puget Sound Transportation Panel Attitude Surveys (1990 - 1996)

\begin{tabular}{|c|c|c|c|c|c|c|}
\hline & 1990 & 1991 & 1993 & 1996 & Average & $\begin{array}{l}\text { Average of All } \\
\text { Respondents }\end{array}$ \\
\hline \multicolumn{7}{|c|}{ Lifecycle } \\
\hline Children < Age 18 & $42.2 \%$ & $44.9 \%$ & $42.5 \%$ & $36.8 \%$ & $41.6 \%$ & $36.1 \%$ \\
\hline 1 Adult < Age 35 & $3.3 \%$ & $1.6 \%$ & $4.3 \%$ & $1.4 \%$ & $2.6 \%$ & $4.0 \%$ \\
\hline 1 Adult Age 35-64 & $6.6 \%$ & $7.3 \%$ & $5.8 \%$ & $6.2 \%$ & $6.5 \%$ & $9.6 \%$ \\
\hline 1 Adult Age 65+ & $0.2 \%$ & $0.3 \%$ & $0.4 \%$ & $3.2 \%$ & $1.0 \%$ & $4.9 \%$ \\
\hline $2+$ Adults $<$ Age 35 & $8.5 \%$ & $7.5 \%$ & $11.3 \%$ & $5.4 \%$ & $8.2 \%$ & $6.8 \%$ \\
\hline 2+ Adults Age 35-64 & $36.3 \%$ & $35.4 \%$ & $31.2 \%$ & $31.3 \%$ & $33.6 \%$ & $26.2 \%$ \\
\hline $2+$ Adults Age $65+$ & $2.9 \%$ & $3.0 \%$ & $4.5 \%$ & $15.8 \%$ & $6.5 \%$ & $12.4 \%$ \\
\hline \multicolumn{7}{|c|}{ Annual Household Income } \\
\hline$<=\$ 25,000$ & $17.4 \%$ & $11.4 \%$ & $14.0 \%$ & $11.3 \%$ & $13.5 \%$ & $19.8 \%$ \\
\hline$\$ 25,000-\$ 35,000$ & $8.8 \%$ & $5.4 \%$ & $11.6 \%$ & $12.1 \%$ & $9.5 \%$ & $10.9 \%$ \\
\hline$\$ 35,000-\$ 45,000$ & $14.3 \%$ & $10.0 \%$ & $18.6 \%$ & $19.6 \%$ & $15.6 \%$ & $14.2 \%$ \\
\hline$\$ 45,000-\$ 55,000$ & $30.5 \%$ & $30.1 \%$ & $17.3 \%$ & $15.9 \%$ & $23.5 \%$ & $18.6 \%$ \\
\hline$\$ 55,000-\$ 75,000$ & $15.9 \%$ & $22.5 \%$ & $21.2 \%$ & $19.3 \%$ & $19.7 \%$ & $15.3 \%$ \\
\hline$>\$ 75,000$ & $9.0 \%$ & $13.2 \%$ & $17.2 \%$ & $21.8 \%$ & $15.3 \%$ & $11.3 \%$ \\
\hline \multicolumn{7}{|c|}{ Number of Household Vehicles } \\
\hline Zero & $2.0 \%$ & $1.2 \%$ & $1.6 \%$ & $1.9 \%$ & $1.7 \%$ & $3.5 \%$ \\
\hline One & $16.1 \%$ & $15.3 \%$ & $18.2 \%$ & $17.2 \%$ & $16.7 \%$ & $24.6 \%$ \\
\hline Two & $43.8 \%$ & $46.7 \%$ & $42.8 \%$ & $47.9 \%$ & $45.3 \%$ & $43.7 \%$ \\
\hline Three or More & $38.2 \%$ & $36.8 \%$ & $37.4 \%$ & $33.0 \%$ & $36.3 \%$ & $28.2 \%$ \\
\hline
\end{tabular}

NOTE: Percentages may not sum to 100 due to rounding and the exclusion of "refused" responses. 
For those using transit as a primary work mode, the importance rating of the ability to arrive on time was cross-tabulated by frequency of transit use. As Table 3-15 indicates, the majority of those who rate the ability to arrive on time as "extremely important” are frequent transit users, riding four to seven days per week. On average, 64 percent are frequent users and 36 percent are less frequent users, riding one to three days per week. Interestingly, the share of frequent users rating the ability to arrive on time as "extremely important” declined from 1990 to 1993. It should be noted that the 1996 surveys did not include a question on frequency of transit use.

\section{Table 3-15: The Ability to Arrive on Time as “Extremely Important” by Frequency of Transit Use - Puget Sound Transportation Panel Attitude Surveys (1990_1993)}

\begin{tabular}{||c|r|r|r|r||}
\hline Frequency of Transit Use & \multicolumn{1}{|l|}{1990} & \multicolumn{1}{l|}{1991} & \multicolumn{1}{l|}{1993} & Average \\
\hline 4 to 7 Days per Week & $70.1 \%$ & $62.6 \%$ & $60.4 \%$ & $64.4 \%$ \\
\hline 1 to 3 Days per Week & $29.9 \%$ & $37.4 \%$ & $39.6 \%$ & $35.6 \%$ \\
\hline
\end{tabular}

NOTE: Responses include transit users only.

The importance ratings for the ability to arrive on time were cross-tabulated with the ratings for some other attributes. Table 3-16 shows that, of those rating ability to arrive on time as “extremely important,” a majority also rated "not having to deal with traffic congestion," "short travel time," "short wait time,” and “avoiding stress” as “extremely important.” On average, two-thirds of those rating the ability to arrive on time as "extremely important" also rated the ability to avoid stress as “extremely important.”

Table 3-16: The Ability to Arrive on Time as "Extremely Important" by Share of Respondents Rating Other Characteristics as “Extremely Important”* Puget Sound Transportation Panel Attitude Surveys (1990-1996)

\begin{tabular}{|l|r|r|r|r|r||}
\hline $\begin{array}{c}\text { Attributes Rated } \\
\text { "Extremely Important" }\end{array}$ & \multicolumn{1}{c|}{1990} & \multicolumn{1}{c|}{1991} & \multicolumn{1}{c|}{1993} & \multicolumn{1}{c|}{1996} & \multicolumn{1}{c|}{ Average } \\
\hline $\begin{array}{l}\text { Not Having to Deal with Traffic } \\
\text { Congestion }\end{array}$ & $64.0 \%$ & $61.8 \%$ & $58.3 \%$ & $57.2 \%$ & $61.3 \%$ \\
\hline Short Travel Time & $59.1 \%$ & $61.6 \%$ & $59.1 \%$ & $51.7 \%$ & $59.9 \%$ \\
\hline Short Wait Time & $68.8 \%$ & $50.3 \%$ & $68.3 \%$ & $62.8 \%$ & $62.5 \%$ \\
\hline Avoiding Stress & $68.3 \%$ & $66.5 \%$ & $65.0 \%$ & $62.6 \%$ & $66.6 \%$ \\
\hline
\end{tabular}

*Characteristics rated as a 6 or 7 on a scale of 1 to 7 , with 1 being "not at all important” 
The attitude surveys also had a section of statements for which the respondents could indicate their agreement or disagreement on a numeric scale. Table 3-17 shows the share of those rating the ability to arrive on time as "extremely important" which agree with a selection of these statements. The purpose is to gain insight into how those who place heavy importance on arriving on time view riding the bus; as relaxing and/or enjoyable, or as a hassle. Similar shares agree that riding a bus is relaxing and agree that taking the bus is a hassle (40 percent and 43 percent, respectively). However, only an additional 8 percent "strongly agree" that the bus is a relaxing way to commute while an additional 19 percent "strongly agree" that the bus is a hassle. A little more than one-third agree or "strongly" agree that taking the bus is "enjoyable."

Table 3-17: The Ability to Arrive on Time as “Extremely Important” by Select Agreement/Disagreement Statements* -

Puget Sound Transportation Panel Attitude Surveys (1990-1996)

\begin{tabular}{|c|c|c|c|c|c|}
\hline & 1990 & 1991 & 1993 & 1996 & Average \\
\hline \multicolumn{6}{|c|}{ Riding a Bus is a Relaxing Way to Commute } \\
\hline Agree & $46.5 \%$ & $44.5 \%$ & $29.1 \%$ & $32.7 \%$ & $40.0 \%$ \\
\hline Strongly Agree & $8.6 \%$ & $6.6 \%$ & $8.4 \%$ & $11.2 \%$ & $7.9 \%$ \\
\hline \multicolumn{6}{|c|}{ Taking the Bus is an Enjoyable Way to Travel } \\
\hline Agree & $34.7 \%$ & $33.2 \%$ & $25.5 \%$ & $26.3 \%$ & $31.1 \%$ \\
\hline Strongly Agree & $5.7 \%$ & $5.1 \%$ & $7.3 \%$ & $6.3 \%$ & $6.0 \%$ \\
\hline \multicolumn{6}{|c|}{ It's a Hassle to Take the Bus } \\
\hline Agree & $46.1 \%$ & $46.0 \%$ & $36.7 \%$ & $32.7 \%$ & $42.9 \%$ \\
\hline Strongly Agree & $16.2 \%$ & $15.9 \%$ & $23.4 \%$ & $21.2 \%$ & $18.5 \%$ \\
\hline
\end{tabular}

*Statements rated on a scale of 1 to 7 , with 1 being "strongly disagree" and 7 being

"strongly agree." A rating of 5 or 6 represents "agree” in this

Another section of the attitude surveys asked respondents to rate the performance of the singleoccupant vehicle (SOV), transit, and carpooling with respect to the same attributes from the importance ratings section. For this study, the focus was on the performance of only the SOV and transit modes. Table 3-18 presents the share of those who consider the ability to arrive on time as "extremely important" rating the performance of these modes highly with respect to the given attributes. As expected, nearly all (90 percent), rate the SOV “extremely well” in its ability to arrive on time. For the bus mode, approximately 31 percent rate its ability to arrive on 
time "extremely well." However, 43 percent rate it "somewhat well” and 26 percent rate the bus mode's ability to arrive on time as poor or extremely poor.

\section{Table 3-18: The Ability to Arrive on Time as "Extremely Important" by the Perceived Ability to Arrive On Time by Mode - Puget Sound Transportation Panel Attitude Surveys (1990-1996)}

\begin{tabular}{|c|c|c|c|c|c|}
\hline $\begin{array}{l}\text { Ability to Arrive On Time - } \\
\text { Performance Rating* }\end{array}$ & 1990 & 1991 & 1993 & 1996 & Average \\
\hline \multicolumn{6}{|c|}{ sov } \\
\hline Extremely Well & $89.3 \%$ & $90.4 \%$ & $89.2 \%$ & $90.4 \%$ & $89.8 \%$ \\
\hline Somewhat Well & $8.7 \%$ & $7.8 \%$ & $7.9 \%$ & $7.1 \%$ & $7.9 \%$ \\
\hline Poorly/Extremely Poorly & $2.0 \%$ & $1.8 \%$ & $1.6 \%$ & $2.5 \%$ & $2.0 \%$ \\
\hline \multicolumn{6}{|c|}{ Bus Transit } \\
\hline Extremely Well & $33.3 \%$ & $28.5 \%$ & $28.0 \%$ & $33.8 \%$ & $30.9 \%$ \\
\hline Somewhat Well & $43.9 \%$ & $46.0 \%$ & $40.9 \%$ & $41.5 \%$ & $43.1 \%$ \\
\hline Poorly/Extremely Poorly & $22.7 \%$ & $25.4 \%$ & $31.1 \%$ & $24.6 \%$ & $26.0 \%$ \\
\hline
\end{tabular}

NOTE: Percentages may not sum to 100 due to rounding.

The attitude surveys conducted in 1997, 1999, 2000, and 2002 were constructed differently than those previously discussed and so were analyzed separately. While much could be learned from analysis within the individual attitude survey data sets, some additional analysis required the merging of two or more data sets from the same survey year so that the attitudes and perceptions regarding reliability (or on-time performance) of travel could be further examined.

In these four most recent attitude surveys, respondents were asked to indicate to what extent they agree/disagree with statements regarding their work or school travel. The scale is from 0 to 10 , with 0 being “disagree completely” and 10 being "agree completely.”

In the 1997 attitude survey only, participants were asked to respond to the statement, "I get annoyed easily when my travel is delayed.” Responses are categorized by those who, according to the survey results, most often travel by personal vehicle and most often travel by bus. Both sets of responses are compared to all responses. As Table 3-19 shows, the responses do not vary significantly among the private vehicle users, the bus users, and the respondent population as a whole. In all cases, a majority agree, to some extent, that they are easily annoyed when travel is delayed. These results can imply that, no matter the mode, people tend to be easily annoyed by unreliability. 
Table 3-19: "I Get Annoyed Easily When My Travel is Delayed” Puget Sound Transportation Panel Attitude Surveys (1997)

\begin{tabular}{||c|r|r|r||}
\hline & $\begin{array}{c}\text { Most Often Travel by } \\
\text { Private Vehicle }\end{array}$ & $\begin{array}{c}\text { Most Often Travel by } \\
\text { Bus }\end{array}$ & \multicolumn{1}{c|}{ All Responses } \\
\hline Agree Completely & $11.5 \%$ & $11.9 \%$ & $4.8 \%$ \\
\hline Agree & $53.3 \%$ & $49.0 \%$ & $20.2 \%$ \\
\hline Neutral & $17.4 \%$ & $15.4 \%$ & $13.0 \%$ \\
\hline Disagree & $16.2 \%$ & $19.5 \%$ & $2.0 \%$ \\
\hline Disagree Completely & $1.6 \%$ & $2.8 \%$ & \\
\hline
\end{tabular}

NOTE: Percentages may not sum to 100 due to rounding.

Table 3-20 further examines the attitudes of those who travel most often by bus. The share of those who travel most often by bus who agree with a given statement are provided. An "n/a" indicates that the statement was not included in the survey for that year.

According to Table 3-20, an average of nearly one-third of those who most often travel by bus agree, to some extent, that they experience unexpected delays at least twice per week. In addition, a similar percentage agrees that they sometimes miss transit connections if their bus (or ferry) is late. As might be expected, most of the respondents who are bus users (87 percent) indicate that they are happier if they know when a bus will arrive. Approximately 45 percent indicate that they do not mind delays as much if they have some accurate information on when they will arrive at their destination. Thus, while unexpected delays in bus travel are common for at least one third of those who most often travel by bus, on average, nearly half would not mind the delays as much with an amenity such as real-time information on bus arrivals and departures.

An interesting result in Table 3-20 is that an average of only 12 percent of those who use the bus agree that they "would like to switch to driving to and from work/school.” In 2002, the most recent attitude survey year, this percentage was only eight percent. This result suggests that most bus users, at least in the Puget Sound region, are satisfied enough that they are not eager to stop riding. 
Table 3-20: Agreement/Disagreement Statements*, Those Who Most Often Travel by Bus Puget Sound Transportation Panel Attitude Surveys (1997-2002)

\begin{tabular}{|c|c|c|c|c|c|}
\hline & 1997 & 1999 & 2000 & 2002 & Average \\
\hline \multicolumn{6}{|c|}{ Unexpected Delay at Least Twice per Week } \\
\hline Agree & $22.6 \%$ & $\mathrm{n} / \mathrm{a}$ & $26.0 \%$ & $17.7 \%$ & $22.1 \%$ \\
\hline Agree Completely & $8.0 \%$ & $\mathrm{n} / \mathrm{a}$ & $10.4 \%$ & $4.8 \%$ & $7.7 \%$ \\
\hline \multicolumn{6}{|c|}{ Sometimes Miss Connections if Bus/Ferry is Late } \\
\hline Agree & $20.7 \%$ & $\mathrm{n} / \mathrm{a}$ & $26.6 \%$ & $20.8 \%$ & $22.7 \%$ \\
\hline Agree Completely & $12.3 \%$ & $\mathrm{n} / \mathrm{a}$ & $10.8 \%$ & $11.2 \%$ & $11.4 \%$ \\
\hline \multicolumn{6}{|c|}{ I'm Happier When I Know When the Bus Will Arrive } \\
\hline Agree & $31.4 \%$ & $\mathrm{n} / \mathrm{a}$ & $37.0 \%$ & $34.6 \%$ & $34.3 \%$ \\
\hline Agree Completely & $50.2 \%$ & $\mathrm{n} / \mathrm{a}$ & $50.4 \%$ & $55.9 \%$ & $52.2 \%$ \\
\hline \multicolumn{6}{|c|}{ I Don't Mind the Delays So Much if I Can Forecast Accurately When I Will Get There } \\
\hline Agree & $35.7 \%$ & $31.1 \%$ & $34.1 \%$ & $44.4 \%$ & $36.3 \%$ \\
\hline Agree Completely & $8.9 \%$ & $5.0 \%$ & $11.7 \%$ & $10.5 \%$ & $9.0 \%$ \\
\hline \multicolumn{6}{|c|}{ I Would Like to Switch to Driving to Work/School as Soon as Possible } \\
\hline Agree & $6.3 \%$ & $\mathrm{n} / \mathrm{a}$ & $4.2 \%$ & $4.0 \%$ & $4.8 \%$ \\
\hline Agree Completely & $5.1 \%$ & $\mathrm{n} / \mathrm{a}$ & $12.5 \%$ & $3.9 \%$ & $7.2 \%$ \\
\hline
\end{tabular}

*Statements rated on a scale of 0 to 10, with 0 being "disagree completely" and 10 being "agree completely."

Using other relevant statements from the surveys, Table 3-21 more closely examines the attitudes of the relatively small share of those who agree that they want to switch from using the bus to driving for the work or school trip. As the table shows, those who would like to switch from the bus to driving are only slightly more easily annoyed by delays than the bus users as a whole (65 percent in Table 3-21 versus 61 percent in Table 3-19). Also, when comparing results in Table 3-21 with those in Table 3-19, this segment of bus users experiences similar rates of unexpected delays and is also similarly happier if, when delayed, they can forecast accurately when they will reach their destination. However, the bus users who would like to switch from the bus to driving miss connections because of late transit vehicles at a higher rate than bus users overall. Table 321 indicates that 48 percent sometimes miss connections because of a late bus (or ferry), while Table 3-19 indicates that 34 percent of those who travel most often by bus sometimes miss 
connections. The surveys did not ask why users wanted to switch to driving; however, it is possible that this higher rate of missed connections due to late transit vehicles is a factor.

Table 3-21: Agreement/Disagreement Statements*, Those Who Indicate That They "Would Like to Switch to Driving to and from Work/School as Soon as Possible”Puget Sound Transportation Panel Attitude Surveys (1997, 2000, \& 2002)

\begin{tabular}{|c|c|c|c|c|}
\hline & 1997 & 2000 & 2002 & Average \\
\hline \multicolumn{5}{|c|}{ I Get Annoyed Easily When Travel is Delayed } \\
\hline Agree & $47.1 \%$ & $\mathrm{n} / \mathrm{a}$ & $\mathrm{n} / \mathrm{a}$ & $47.1 \%$ \\
\hline Agree Completely & $18.3 \%$ & $\mathrm{n} / \mathrm{a}$ & $\mathrm{n} / \mathrm{a}$ & $18.3 \%$ \\
\hline \multicolumn{5}{|c|}{ I Worry a Lot About Being Late } \\
\hline Agree & $42.3 \%$ & $39.4 \%$ & $39.2 \%$ & $40.9 \%$ \\
\hline Agree Completely & $26.0 \%$ & $12.7 \%$ & $22.6 \%$ & $19.3 \%$ \\
\hline \multicolumn{5}{|c|}{ At Least Twice per Week, There is an Unexpected Delay on my Route } \\
\hline Agree & $13.5 \%$ & $18.3 \%$ & $28.4 \%$ & $15.9 \%$ \\
\hline Agree Completely & $11.5 \%$ & $8.5 \%$ & $9.0 \%$ & $10.0 \%$ \\
\hline \multicolumn{5}{|c|}{ I Don't Mind the Delays So Much if I Can Forecast Accurately When I Will Get There } \\
\hline Agree & $40.4 \%$ & $25.4 \%$ & $32.8 \%$ & $32.9 \%$ \\
\hline Agree Completely & $21.2 \%$ & $9.9 \%$ & $6.7 \%$ & $15.5 \%$ \\
\hline \multicolumn{5}{|c|}{ I Sometimes Miss My Connections Because a Bus/Ferry is Late } \\
\hline Agree & $25.0 \%$ & $35.2 \%$ & $18.5 \%$ & $30.1 \%$ \\
\hline Agree Completely & $17.3 \%$ & $18.3 \%$ & $9.0 \%$ & $17.8 \%$ \\
\hline
\end{tabular}

*Statements rated on a scale of 0 to 10, with 0 being “disagree completely” and 10 being "agree completely."

The analysis of on-board surveys discussed earlier in this chapter indicated that younger riders seem to place the highest emphasis on schedule reliability when compared to other age groups. This idea is further explored by examining the age group distribution of those responding that they agree with statements related to the timeliness of travel from the attitude surveys. Results from two of the survey waves are shown in Table 3-22. Shown first is the age distribution for the importance of a mode's ability to arrive on time from the 1996 survey, and then two other related statements from the 2002 survey are shown: “I worry a lot about being late” and “I don’t mind the delays so much if I can forecast accurately when I will get there.” 
Table 3-22 also compares the age distribution of those who agree with the given statements with the age distribution of all the survey respondents for the given year. The table indicates that, when compared to the age distribution of all survey respondents, there is no discernible pattern in the age distribution of those who rate the ability to arrive on time as important or of those who worry about being late. However, for the statement, "I don’t mind the delays so much if I can forecast accurately when I will get there," the age distribution of those who agree is younger than the distribution of all respondents. For example, of those who agree completely with this statement, nearly nine percent are age 17 or under and 10 percent are age 18 to 24, compared with approximately six percent and eight percent, respectively, for the respondents as a whole. In addition, of those who agree completely with this statement, 26 percent are age 55 or over, compared to the respondent population which includes 34 percent age 55 and over.

Table 3-22: Agreement/Disagreement Statements*, by Age Group Puget Sound Transportation Panel Attitude Surveys (1996 \& 2002)

\begin{tabular}{|c|c|c|c|c|c|}
\hline & $\begin{array}{l}17 \text { or } \\
\text { Under }\end{array}$ & $18-24$ & $25-44$ & $45-54$ & $\begin{array}{c}55 \text { and } \\
\text { Over }\end{array}$ \\
\hline \multicolumn{6}{|c|}{ Ability to Arrive on Time (1996) } \\
\hline Important & $6.1 \%$ & $6.4 \%$ & $37.0 \%$ & $19.7 \%$ & $30.8 \%$ \\
\hline Extremely Important & $2.9 \%$ & $5.5 \%$ & $37.2 \%$ & $24.8 \%$ & $29.4 \%$ \\
\hline All Respondents (1996) & $5.1 \%$ & $7.3 \%$ & $39.4 \%$ & $21.8 \%$ & $26.2 \%$ \\
\hline \multicolumn{6}{|c|}{ I Worry a Lot About Being Late (2002) } \\
\hline Agree & $5.1 \%$ & $4.7 \%$ & $29.3 \%$ & $26.6 \%$ & $33.8 \%$ \\
\hline Agree Completely & $5.1 \%$ & $6.8 \%$ & $23.4 \%$ & $19.9 \%$ & $44.7 \%$ \\
\hline All Respondents (2002) & $5.5 \%$ & $7.8 \%$ & $29.0 \%$ & $23.0 \%$ & $33.8 \%$ \\
\hline \multicolumn{6}{|c|}{ I Don't Mind the Delays So Much if I Can Forecast Accurately When I Will Get There (2002) } \\
\hline Agree & $6.2 \%$ & $7.1 \%$ & $34.2 \%$ & $33.0 \%$ & $19.1 \%$ \\
\hline Agree Completely & $8.7 \%$ & $10.4 \%$ & $21.7 \%$ & $33.0 \%$ & $26.1 \%$ \\
\hline All Respondents (2002) & $5.5 \%$ & $7.8 \%$ & $29.0 \%$ & $23.0 \%$ & $33.8 \%$ \\
\hline
\end{tabular}

*Statements rated on a scale of 0 to 10, with 0 being “disagree completely" and 10 being "agree completely."

While no significant patterns were found in the results shown in Table 3-22, Table 3-23 presents the age distribution for these statements among transit users only. As the table illustrates, for all three statements, the percentages of those who agree or agree completely are higher for the younger age groups and lower for the older age groups when compared to the responses as a 
whole. Such a finding provides evidence that the younger age groups tend to be more concerned with timeliness while the older groups tend to be less concerned. This is consistent with the findings from the on-board survey results discussed earlier that indicate younger riders are more concerned with transit schedule reliability than older riders.

Table 3-23: Agreement/Disagreement Statements*, Transit Users by Age Group Puget Sound Transportation Panel Attitude Surveys (1996 \& 2002)

\begin{tabular}{|c|c|c|c|c|c|}
\hline & $\begin{array}{l}17 \text { or } \\
\text { Under }\end{array}$ & $18-24$ & $25-44$ & $45-54$ & $\begin{array}{c}55 \text { and } \\
\text { Over }\end{array}$ \\
\hline \multicolumn{6}{|c|}{ Ability to Arrive on Time (1996) } \\
\hline Important & $16.7 \%$ & $3.3 \%$ & $60.0 \%$ & $13.3 \%$ & $6.7 \%$ \\
\hline Extremely Important & $3.5 \%$ & $9.4 \%$ & $48.2 \%$ & $25.9 \%$ & $12.9 \%$ \\
\hline All Respondents (1996) & $5.1 \%$ & $7.3 \%$ & $39.4 \%$ & $21.8 \%$ & $26.2 \%$ \\
\hline \multicolumn{6}{|c|}{ I Worry a Lot About Being Late (2002) } \\
\hline Agree & $14.3 \%$ & $19.6 \%$ & $33.9 \%$ & $22.3 \%$ & $9.8 \%$ \\
\hline Agree Completely & $4.2 \%$ & $20.8 \%$ & $41.7 \%$ & $16.7 \%$ & $16.7 \%$ \\
\hline All Respondents (2002) & $5.5 \%$ & $7.8 \%$ & $29.0 \%$ & $23.0 \%$ & $33.8 \%$ \\
\hline \multicolumn{6}{|c|}{ I Don't Mind the Delays So Much if I Can Forecast Accurately When I Will Get There (2002) } \\
\hline Agree & $12.8 \%$ & $15.6 \%$ & $37.6 \%$ & $22.0 \%$ & $11.9 \%$ \\
\hline Agree Completely & $11.1 \%$ & $16.7 \%$ & $16.7 \%$ & $33.3 \%$ & $22.2 \%$ \\
\hline All Respondents (2002) & $5.5 \%$ & $7.8 \%$ & $29.0 \%$ & $23.0 \%$ & $33.8 \%$ \\
\hline
\end{tabular}

*Statements rated on a scale of 0 to 10, with 0 being "disagree completely" and 10 being "agree completely."

Finally, attitudes regarding travel time reliability are examined with respect to the flexibility of work hours. Table 3-24 indicates that those who agree completely with the statement, "I get annoyed easily when my travel is delayed” (regardless of mode) tend to have less flexibility in their work hours than the respondent population as a whole. 


\section{Table 3-24: “I Get Annoyed Easily When My Travel is Delayed*” by Flexibility in Work Hours- Puget Sound Transportation Panel Attitude Surveys (1997)}

\begin{tabular}{|c|c|c|c|}
\hline & No Flexibility & No More than 30 Minutes & Free to Adjust Time \\
\hline Agree & $44.8 \%$ & $28.9 \%$ & $26.3 \%$ \\
\hline $\begin{array}{l}\text { Agree } \\
\text { Completely }\end{array}$ & $53.6 \%$ & $24.7 \%$ & $21.7 \%$ \\
\hline All Responses & $46.8 \%$ & $28.0 \%$ & $25.2 \%$ \\
\hline
\end{tabular}

*Statements rated on a scale of 0 to 10, with 0 being “disagree completely” and 10 being “agree completely.”

Table 3-25 illustrates the reported flexibility of work hours for those who agree with the statement, "I worry a lot about being late.” Responses are shown for the three survey waves that this information was available: 1997, 2000, and 2002. Also shown are the distributions for all survey respondents in the given year. The data in the table show that those who agree completely with the statement tend to have less flexibility in their working hours than the respondent population as a whole. Comparisons are less clear for those who simply "agree."

Table 3-25: “I Worry a Lot About Being Late*” by Flexibility in Work Hours Puget Sound Transportation Panel Attitude Surveys (1997, 2000, \& 2002)

\begin{tabular}{|c|c|c|c|c|}
\hline & 1997 & 2000 & 2002 & Average \\
\hline \multicolumn{5}{|c|}{ No Flexibility } \\
\hline Agree & $46.5 \%$ & $44.3 \%$ & $46.8 \%$ & $45.9 \%$ \\
\hline Agree Completely & $59.0 \%$ & $60.9 \%$ & $62.6 \%$ & $60.8 \%$ \\
\hline All Responses & $46.8 \%$ & $46.6 \%$ & $47.2 \%$ & $46.9 \%$ \\
\hline \multicolumn{5}{|c|}{ No More than 30 Minutes } \\
\hline Agree & $28.1 \%$ & $28.9 \%$ & $31.5 \%$ & $29.5 \%$ \\
\hline Agree Completely & $20.5 \%$ & $21.8 \%$ & $23.7 \%$ & $22.0 \%$ \\
\hline All Responses & $28.0 \%$ & $28.3 \%$ & $30.4 \%$ & $28.9 \%$ \\
\hline \multicolumn{5}{|c|}{ Free to Adjust Time } \\
\hline Agree & $25.4 \%$ & $26.8 \%$ & $21.7 \%$ & $24.6 \%$ \\
\hline Agree Completely & $20.5 \%$ & $17.3 \%$ & $13.6 \%$ & $17.1 \%$ \\
\hline All Responses & $25.2 \%$ & $25.1 \%$ & $22.4 \%$ & $24.2 \%$ \\
\hline
\end{tabular}

*Statements rated on a scale of 0 to 10 , with 0 being “disagree completely" and 10 being "agree completely." 
Table 3-26 provides information on the flexibility of work hours for those who drive alone to work and those who take the bus. Results for four survey years are shown. When looking at the average of the four survey years, the results in the table indicate that those who drive alone to work tend to have less flexibility in their working hours than those who take bus transit. Those with less flexibility in their work times would likely be very concerned with the reliability or ontime performance of their travel mode.

Table 3-26: Mode Choice, by Flexibility in Work Hours Puget Sound Transportation Panel Attitude Surveys (1997-2002)

\begin{tabular}{|c|c|c|c|c|c|}
\hline & 1997 & 1999 & 2000 & 2002 & Average \\
\hline \multicolumn{6}{|c|}{ Drive Alone (SOV) } \\
\hline No Flexibility & $46.6 \%$ & $40.6 \%$ & $46.9 \%$ & $44.9 \%$ & $44.8 \%$ \\
\hline No More than 30 Minutes & $27.2 \%$ & $28.0 \%$ & $27.8 \%$ & $33.1 \%$ & $29.0 \%$ \\
\hline Free to Adjust Time & $25.5 \%$ & $29.1 \%$ & $25.3 \%$ & $21.9 \%$ & $25.5 \%$ \\
\hline \multicolumn{6}{|c|}{ Bus Transit } \\
\hline No Flexibility & $36.0 \%$ & $31.1 \%$ & $31.7 \%$ & $36.3 \%$ & $33.8 \%$ \\
\hline No More than 30 Minutes & $36.2 \%$ & $35.3 \%$ & $40.7 \%$ & $33.1 \%$ & $36.3 \%$ \\
\hline Free to Adjust Time & $26.8 \%$ & $31.9 \%$ & $27.6 \%$ & $30.6 \%$ & $29.2 \%$ \\
\hline
\end{tabular}

This analysis of the Puget Sound Transportation Panel data aimed to examine the attitudes regarding reliability and on-time performance in general and how mode choice might be affected. As might be expected, a majority of respondents rated the "ability to arrive on time" as "extremely important." Of those rating the ability to arrive on time so highly, approximately one-quarter viewed the on-time performance of bus transit as poor or extremely poor, compared with only two percent for the single-occupant vehicle. Those rating the ability to arrive on time as extremely important also tend to have higher incomes and more vehicles available than the respondents as a whole, indicating they may have more than one transportation option. Of those who use transit, however, those most concerned with the ability to arrive on time are frequent users and tend to not mind delays as much if they can find out, with accuracy, when they will arrive at their destination. A small share of bus users concerned with on-time arrival indicated a desire to switch to driving to work or school; however, this group had a much higher rate of 
missed connections due to late transit vehicles which may be affecting their decision to switch modes. Among the transit users concerned with reliability, most tend to be younger and have less flexibility in their working hours.

\section{Impacts of Transit Travel Time Reliability on Ridership: Agency Experiences}

The research team sent a request for information to approximately 100 transit agencies throughout the state of Florida and the nation, asking for information on the impact that schedule reliability has on transit ridership based on evidence they might be able to produce. In virtually all cases, transit agency representatives responded that they believe schedule reliability is a very important factor to passengers. However, they had little information in terms of data or examples of service interventions that would allow the clean analysis of the impact of improved schedule reliability. Transit systems rarely intentionally implement one particular intervention (e.g., better schedule adherence) in order to test for its impact. They are far more concerned with improving service to the riding public in every fashion possible. For instance, given changes to a particular route or corridor might not only address schedule adherence. As a transit agency might address on-time performance by adding running time for each bus on a route, they might very likely be increasing the frequency on that route. In other cases the transit agency might also be restructuring that route, improving the connections with other routes, extending the span of service on the route, etc. CUTR received some information on routes where running time was modified to improve schedule adherence, but they were routes that were only months old and were still trying to become established and attract their market.

Transit planners from dozens of transit agencies responded in much the same fashion. They noted that there are many variables that impact ridership, such as the overall economy, changes in fare structure, the price of gasoline, highway congestion, or the perceived overall quality of the service. All of these factors and more can influence ridership on a route, even as schedule adherence is being improved. A good example of the frustrations of attempting to quantify the impact of schedule adherence came from Sacramento, California, where the agency improved schedule adherence on a route and lost ridership.

It proved difficult for transit agencies to isolate the impact of schedule adherence while all these other dynamic forces were also occurring. The world simply does not stand still, nor does the transit agency limit itself to just one method of improving their service. In almost all cases, they could not screen out the confounding factors. It becomes very challenging to determine which of 
the various factors had the most significant impact on ridership. However, two agencies were able to provide information that they felt was as close as possible to an isolated review of the impact of improved schedule reliability.

\section{Evidence from Transit Agency Experience with Improvements to Schedule Reliability}

PACE, the suburban transit services provider in the Chicago area, was able to provide information that they believe helps establish the positive impact on ridership when schedule adherence is improved. Responding to complaints of irregular bus service on Route 350, in June 2006, PACE adjusted headways that added two additional trips to the route in the course of a day, but frequency of service remained mostly unchanged. Between June 2006 and June 2007, ridership on Route 350 increased by 21.9 percent, compared to a system-wide increase in ridership of 5.2 percent.

Sacramento Regional Transit (RT) in California provided information on its Route 30, the fifth most boarded route with approximately 2,200 boardings per day. The route travels along the two most congested streets in downtown Sacramento, and carries a very high proportion of elderly passengers. Route 30 also serves Sacramento State University. The service change occurred in September 2004; at the same time RT started using their Clever Devices stop announcement system to track on-time performance. The on-time performance of Route 30 now tracks between 85 percent and 90 percent on time. While the agency did not have the Clever Device equipment prior to 2004, their staff believes on-time performance for Route 30 had been in the range of 65 percent. RT added running time, and in this case a bus, because it ended up being more running time than the original number of buses could operate. Although an additional bus was added to the route, frequency of service before and after the change was constant at 15 minutes. Ridership on this route decreased over time in spite of the substantial improvement in schedule reliability. The transit agency did not have reliable data to compare the routes ridership performance with the system's overall ridership performance. Nonetheless, it does demonstrate the significance of other factors on ridership, even when reliability is substantially improved.

\section{Additional Information from Recent Surveys}

A common response received from transit planners during the course of this research is that the importance of service reliability is a "no-brainer." Every transit agency fully intends to provide service in accordance with their printed schedules, and they do the best they can in the face of 
road construction, accidents, and increasing traffic congestion to provide a reliable service. Nonetheless, when surveying customers, most transit agencies include questions that allow passengers to prioritize the importance of a variety of factors, including schedule reliability. Customers have the opportunity to rate the importance of factors such as service frequency, span of service, schedule reliability, customer information, fare simplicity, safety, security, and a host of other factors that help transit agencies respond to their customers more effectively and provide the type of service deemed most important to them.

Some recent survey results, as described below, demonstrate that schedule reliability is among the most important factors to transit passengers, especially frequent passengers. It is usually rated as more important than frequency of service. In addition to this feedback from passengers, transit agencies believe that they have found some other interesting subtleties regarding the importance of real time information denoting on-time performance.

Pierce Transit - Information in the following paragraphs comes from the 2007 Fixed Route Customer Satisfaction Results report from Pierce Transit, a mid-sized bus system operating in Tacoma, Washington. Gilmore Research conducted three Stepwise Multiple Regression analyses using 64 service quality elements. ${ }^{1}$ The purpose of the analyses was to determine which of the many items in the survey were most closely associated with overall satisfaction among light, moderate, and heavy transit users. In this procedure, variables are entered or removed from the regression formula one at a time until all the independent (uncorrelated) sources of variance are included in the equation. The most important predictors or "explainers" are identified and then listed in descending order of importance. If a respondent is very satisfied with all of the identified elements, it can be predicted that person's overall satisfaction would also be very high. Conversely, riders who are dissatisfied with the majority of elements identified are also likely to be dissatisfied with Pierce Transit service overall.

It is important to point out that the items included in the regression model are not necessarily the items that were rated best or worst in terms of satisfaction. These are the items that explain the variance in overall satisfaction ratings and are items to focus on to maintain or improve overall satisfaction among members of each group. For the 2007 survey, the maximum margin of error for the entire weighted sample $(n=614)$ is \pm 4.0 percentage points at the 95 percent confidence level.

\footnotetext{
${ }^{1}$ These include one item new to the 2007 survey: satisfaction with the availability of bus service supervisors.
} 
The survey analysis included a regression analysis that explained the variation in overall satisfaction ratings among infrequent, moderate, and very frequent passengers. The results demonstrate that the more a passenger uses the service, the more important schedule reliability becomes:

- The regression procedure identified six elements that together explain 46 percent of the variation in overall satisfaction ratings among infrequent users defined as Light Riders (fewer than 10 trips per month). The top three predictors for this group are:

o The number of transfers that have to be made

o How early the bus starts running in the mornings on Sundays

o The quality of information provided by the customer service staff

- The regression procedure identified nine elements that together explain 38 percent of the variation in overall satisfaction ratings among Moderate Riders (between 10 and 59 trips per month). The top three predictors for this group are:

o The ease of reaching a customer service representative

o Driver's driving ability

o Dependability of the bus not leaving the stop early

- The regression procedure identified seven elements that together explain 54 percent of the variation in overall satisfaction ratings among Very Frequent Riders (more than 60 trips per month). The top three predictors for this group are:

o The route getting to where you are going on time

o Cleanliness inside the bus

o How early the bus starts running in the mornings on weekday

Sacramento Regional Transit Authority - Providing a baseline for tracking customer satisfaction was one of the primary objectives of Findings of Customer Surveys Conducted for Sacramento Regional Transit. The survey asked riders to rate Regional Transit (RT) service overall on 17 specific attributes. Buses and trains running when the schedule says they will run was rated as one of the four most important factors in determining customer satisfaction. In fact, its quality ranking (2) among all factors was slightly greater than frequency of service on weekdays (4), though both receiving a rating of 4.6 in terms of "Importance." 
Southern California Regional Rail Authority (SCRRA) - Henning Eichler, Research Manager for the SCRRA, believed that his agency had a good deal of evidence for the importance of schedule reliability for Metrolink, the provider of commuter rail service in the greater Los Angeles area. The surveys conducted in 2006 showed that on-time performance was the second most important determinant of customer satisfaction, trailing only safe operations. It was considered slightly more important than the frequency of service during the peak hours of service and considerably more important than the frequency of service in the off-peak hours (see Table 3-27 below):

\section{Table 3-27: Southern California Regional Rail Authority Survey Results}

\begin{tabular}{|c|c|c|c|c|c|c|}
\hline & $\begin{array}{l}\text { IMPORTAN } \\
\text { CE }\end{array}$ & $\begin{array}{c}\text { SATISFAC } \\
\text { TION }\end{array}$ & $\begin{array}{c}\text { IMPORTANCE } \\
\text { SCORE } \\
\text { WITHOUT } \\
\text { PROBLEM } \\
\text { OCCURRENCE }\end{array}$ & $\begin{array}{c}\text { SATISFACTION } \\
\text { SCORE } \\
\text { WITHOUT } \\
\text { PROBLEM } \\
\text { OCCURRENCE }\end{array}$ & $\begin{array}{l}\text { IMPORTANCE } \\
\text { SCORE WITH } \\
\text { PROBLEM } \\
\text { OCCURRENCE }\end{array}$ & $\begin{array}{l}\text { SATISFACTION } \\
\text { SCORE WITH } \\
\text { PROBLEM } \\
\text { OCCURRENCE }\end{array}$ \\
\hline Q23-A: TRAVEL TIME & 4.4 & 4.1 & 4.4 & 4.2 & 4.5 & 3.3 \\
\hline Q23-B: ON-TIME & 4.7 & 4.0 & 4.7 & 4.3 & 4.8 & 3.3 \\
\hline Q23-C:CONNECTING TRANSIT & 3.8 & 3.9 & 3.8 & 4.0 & 4.6 & 2.7 \\
\hline Q23-D: PARKING & 4.3 & 3.9 & 4.2 & 4.1 & 4.7 & 2.2 \\
\hline Q23-E: AVAILABILITY OF SEATING ON THE TRAIN & 4.6 & 3.9 & 4.5 & 4.1 & 4.7 & 2.8 \\
\hline Q23-F: CLEANLINESS OF TRAIN INTERIOR & 4.6 & 4.3 & 4.6 & 4.3 & 4.7 & 3.1 \\
\hline Q23-G: SAFE OPERATION & 4.8 & 4.5 & 4.8 & 4.5 & 4.8 & 3.6 \\
\hline Q23-H: PERSONAL SECURITY ON THE TRAIN & 4.7 & 4.4 & 4.7 & 4.4 & 4.6 & 3.2 \\
\hline Q23-I: PERSONAL SECURITY AT THE STATION & 4.6 & 4.2 & 4.6 & 4.2 & 4.6 & 2.6 \\
\hline Q23-J: EASE OF PURCHASING TICKETS & 4.4 & 4.2 & 4.4 & 4.3 & 4.5 & 3.0 \\
\hline Q23-K: COST & 4.6 & 3.5 & 4.6 & 3.6 & 4.7 & 2.1 \\
\hline Q23-L: COURTESY OF METROLINK CONDUCTORS & 4.4 & 4.3 & 4.4 & 4.3 & 4.6 & 3.1 \\
\hline Q23-M: COMMUNICATION OF SCHEDULE CHANGES & 4.6 & 3.9 & 4.6 & 4.0 & 4.8 & 2.5 \\
\hline Q23-N: COMMUNICATION OF DELAYS & 4.6 & 3.5 & 4.6 & 3.7 & 4.8 & 2.3 \\
\hline Q23-O: SCHEDULES DURING PEAK & 4.6 & 3.7 & 4.6 & 3.7 & 4.8 & 2.3 \\
\hline Q23-P: SCHEDULES DURING OFF-PEAK & 3.9 & 3.5 & 3.9 & 3.6 & 4.5 & 2.2 \\
\hline Q23-Q: EASE OF GETTING INFORMATION AT 800-371-LINr & 4.0 & 3.8 & 4.0 & 3.9 & 4.4 & 2.5 \\
\hline Q23-R: DEPENDABILITY OF TRAIN & 4.6 & 4.1 & 4.6 & 4.2 & 4.7 & 3.1 \\
\hline Q23-S: EASE OF USING TICKET VENDING MACHINE & 4.3 & 4.1 & 4.3 & 4.2 & 4.6 & 2.9 \\
\hline Q23-T: INFORMATION AT METROLINKS.COM & 4.3 & 4.0 & 4.3 & 4.1 & 4.5 & 2.4 \\
\hline OVERALL SATISFACTION & & 4.2 & & & & \\
\hline MEAN & 4.4 & 4.0 & 4.4 & 4.1 & 4.6 & 2.8 \\
\hline
\end{tabular}

Source: Henning Eichler, Southern California Regional Rail Authority

SCRRA gained experience in evaluating the importance of on-time performance with its

Riverside Line due to service impacts from the freight railroads that were sharing the track. $\mathrm{Mr}$.

Eichler also offered the following observations:

"We have also found that new riders have the least tolerance for unreliable service. Our research also confirms the TCRP findings that schedule reliability 
ranks as more important than travel time, in other words: our riders prefer predictability over speed.

Interestingly, we have also found that the quality of delay communications to the passengers has an even bigger impact on rider satisfaction than the actual ontime performance. Improving communications (real time) may be better than improving actual on-time performance."

\section{Conclusions}

Although getting vehicles to run on time and conform to schedule may seem like the most basic service objective, the problem of reliability is complex and many-sided. As described in Chapter 1 , non-recurring congestion, which results primarily from random events such as accidents and vehicle breakdowns, is generally accepted as the traffic-related issue with the greatest influence on bus performance. Transit scheduling techniques can be used to effectively manage recurring daily patterns of congestion; random, non-recurring events, however, present a far greater challenge because they are unpredictable. In addition, numerous variables unrelated to traffic may adversely affect reliability. These factors can originate from a number of sources, including passenger demand, route configuration, schedule components, and driver behavior. Furthermore, there is no single measure that can comprehensively gauge transit service reliability, and unfortunately, what is practical for evaluating system reliability from a transit agency's standpoint may not be relevant to a passenger's experience.

There are, however, some generally accepted principles regarding service reliability. According to the literature, long, heavily-used bus routes on congested roads are likely to have poor schedule reliability; when a delay occurs early along a route, delays are propagated along the route; for routes with long headways, schedule adherence is crucial, while for routes with short headways, uniform spacing is more important; and reducing congestion, dwell times, and the number of stops along a route can improve both speed and reliability.

Information about customer perceptions, behaviors, and values relating to reliability, and how these apply to the decision-making process, may lead to more accurate measures and predictors of travel behavior. Clearly, people value both travel time and its reliability. Studies of travel behavior suggest that, from the traveler's point-of-view, the cost of unreliable service may in fact be greater than the cost of travel time. People tend to avoid risk when making decisions 
concerning time, often citing the importance of being able to make better plans. Because lost or saved time cannot be earned back or stored as money can be, planning may be even more important for time than for money, and because uncertainty makes planning more difficult, uncertainty in matters of time is especially taxing.

Additional attitudes and perceptions about travel time and reliability were analyzed among transit users and non-users. Data from on-board surveys and customer satisfaction surveys from within Florida and across the country were used to explore these attitudes among transit users, while data from non-user surveys were also used. Data from the Puget Sound Transportation Panel, while certainly most relevant in the Puget Sound region, provided insight into attitudes and perceptions regarding such things as trip delays and on-time arrivals, not just for transit, but for other modes and travel in general. The findings from the surveys were further enhanced by additional contact with many transit agencies across the country. Some of the most interesting experiences from these agencies are also shared in this chapter.

Among those who use transit, the survey information indicates that reliability is very important and is often among the most-requested service improvements. Riders dissatisfied with schedule reliability at their transit agency tend to have more characteristics that would describe them as being more transit-dependent (e.g., lower incomes, fewer household vehicles). It could be that, although they are dissatisfied, they may have fewer transportation options available. Transit users concerned with reliability also tend to be more frequent users, and younger users. The Puget Sound data indicate that only a small share of transit users want to switch to driving as soon as they can; although, that share of users also had a higher rate of incidences of missed connections due to late transit vehicles than users as a whole, which can have an impact on their travel choices. However, it should be noted that, in one non-user survey (WMATA), unreliable service was not a major factor in why people stopped using transit.

The data analyzed for this chapter indicate that those who do not use transit tend to have a somewhat negative perception of the ability of transit to provide reliable service. However, both transit users and non-users tend to agree that they do not mind delays as much when they have accurate information regarding when they will arrive at their destination. For transit, such information takes the form of real-time information on bus arrivals.

Travel time, waiting time, and particularly the uncertainties associated with both have been shown to affect customer perceptions of transit service quality. To improve service quality from the customer's viewpoint, transit agencies should focus their efforts on reducing inconsistencies 
in bus performance over time. Passengers will consider the bus reliable if it operates in a predictable manner, even if it is predictably late. Also, while experience and credible information are important factors in the learning process, unreliable service may have a negative effect on learning how to use the system, resulting in the perception that transit is not userfriendly. 


\section{CHAPTER FOUR: CESSATION OF TRANSIT USE}

\section{Introduction}

There is very little information about the patterns of transit use by individuals over time. What are the triggering events or changes in demographic and socio-economic characteristics that bring about mode shifts to and away from transit? Panel survey data (measurement of travel characteristics over time for the same sample of individuals) is required to answer such questions.

In this chapter, the primary source of information is the Puget Sound Transportation Panel (PSTP) data, previously described in Chapter 2. The PSTP is used to identify patterns of transit usage over time. The data sets are a rich source of information ideally suited to analyzing the factors that contribute to people leaving and joining transit. Other relevant survey data from Chapter 2 will also be used to assess this issue. Results from this chapter can be used in improving transit planning and marketing efforts.

This chapter begins with a summary of the relevant literature which was discussed in detail previously in Chapter 1. Next, pertinent results from two household travel surveys, one in the Washington D.C. area and one in Pinellas County, Florida, are discussed. These surveys specifically asked ex-transit users why they had stopped riding. The bulk of the chapter focuses on the PSTP data, particularly from the attitude surveys.

The findings from this chapter comprise a summary of relevant information from all of the survey data and literature. Recommendations include a consideration of strategies to address the attitudes and perceptions of those who are likely to switch to transit and those who are likely to cease riding. The results can be used in targeted marketing efforts to attracting and retaining such riders.

\section{Lessons from the Literature}

Public transportation systems in the U.S. experience a high degree and rapid rate of ridership turnover. This is partly because transit ridership has become a phase phenomenon related to demographics such as age and socioeconomic advancement. Although there was a time when 
public transit was the only means of mobility for a significant portion of the U.S. population, most Americans now have other alternatives. Today, people may go through a phase of intensive transit use when they are young or new to their careers; however, the majority will stop using transit when an automobile becomes affordable or transit no longer serves their needs. As their incomes rise and lifestyles change, many stop using transit because they are able to afford a car. It appears that, with rising incomes and lifestyle changes such as marriage, childrearing, and relocation, the mobility and convenience of the automobile often outweigh the benefits of transit.

Even a small reduction in rider turnover would significantly bolster the growth of the transit market; strategies designed to increase ridership should focus as much on retaining current riders as on attracting new ones. Also, rapid ridership turnover means there is always a significant portion of riders who are new to transit. Effective transit marketing is critical in order to provide a steady stream of information to this constantly renewing customer base. Knowledge acquired through market research must be effectively applied to transit service improvements and marketing strategies. The industry must acknowledge that a new transportation market has arrived and adapt to the needs of that new market.

\section{Characteristics Revealed by Household Travel Surveys}

This section includes an analysis of survey questions targeted at previous users of transit in the Washington, D.C. area and Pinellas County, Florida. In addition, the Puget Sound Transportation Panel (PSTP) data sets, discussed in detail in Chapter 2, are fully explored to determine the characteristics and attitudes of those who switched to transit and those who switched from transit.

\section{Other Surveys}

Data on the cessation of transit is difficult to obtain. While the Puget Sound Transportation Panel data sets are helpful in this regard, additional data can also be useful. Non-user surveys are one method of capturing this information. An example of this type of survey used for this project is a telephone survey of bus non-riders that was conducted in 2000 for the Washington Metropolitan Area Transit Authority (WMATA) as part of a larger regional bus study.

For the WMATA bus non-user telephone survey, the sample of respondents was drawn from a population of residents of the Washington, D.C. metropolitan area who were at least 18 years of 
age and had not used public bus service in the previous 30 days. The survey response rate depended on the willingness of people to complete a telephone interview of approximately 12 minutes. Most actual survey respondents were 35 years or older, with no children in the household, and with annual household incomes of $\$ 50,000$ or more. Most respondents held valid driver's licenses and 73 percent were employed.

Nearly two-thirds (63 percent) of the respondents indicated that they would consider using bus transit for at least some of their transportation needs if bus services were improved. Generally, these potential riders were less likely to have a vehicle available than other respondent groups. The preferred improvements varied, but included more frequent bus service, stops closer to homes/destinations, faster/more direct service, and amenities such as more/better bus information and better shelters.

To participate in this non-user survey, respondents must not have used the public bus system in the prior 30 days. They were asked how long it had been since they last rode the bus. More than 46 percent responded that it had been more than one year. Approximately 32 percent indicated that they had never ridden the bus.

For those who had previously ridden the bus system, they were asked to what extent they relied on the bus for their transportation needs. Approximately 21 percent rode the bus four or more times per week, 32 percent rode less than once per week (“once in a while”), and 29 percent rode only one time.

Respondents were asked outright why they stopped riding the bus. By far the most common response, comprising more than 43 percent of all responses, was an increased access to a car for their transportation needs. The next most common response, with 17 percent of all responses, was a change in travel pattern (including a change in job location or residential location).

Many of the other responses about why current non-users who had once ridden the bus stopped riding included the typically cited complaints about transit service. These include the bus being too slow (six percent), too many transfers (two percent), service not frequent enough (three percent), bus did not go where needed (four percent), and the bus did not go when needed (two percent). Also of interest to this project, six percent of respondents in this non-user survey indicated that they stopped riding the bus because the bus was not "reliable enough," referring to the bus not being at the bus stop at the scheduled time. 
Another interesting question posed to the telephone survey respondents asked about the "biggest drawback" to using the bus. Twenty-eight percent of respondents, the largest response category, indicated that the largest drawback is that the bus is not as convenient as a car. The travel time on the bus takes too long was the answer for 14 percent of respondents, while 12 percent indicated having to wait too long was the largest drawback. Five percent stated that too many transfers is the main drawback, and three percent indicated the biggest drawback is that the bus is not reliable enough. Six percent indicated that there were no drawbacks.

In 2007, Pinellas County, Florida, which contains the cities of St. Petersburg and Clearwater, conducted a household travel survey. Data from this survey can also provide insight into transit usage. Nine percent of the survey respondents define themselves as transit users, while 91 percent are transit non-users. Forty-six percent are employed, and an additional 42 percent classify themselves as retired. Of those who do work, 83 percent drive alone to their place of employment and 3 percent ride the bus.

Fifty percent of respondents indicate that, once per week or more, they are "seriously delayed" by traffic congestion. Thirty-six percent agree that "taking a bus one or two days a week while still owning a car would save enough money to be worth it.” In addition, 49 percent agree that if the price of gas were to rise to $\$ 4.00$ per gallon (which has actually happened recently in this area), they would "consider using the bus a few times per week instead of using (their) personal vehicle to commute to/from work." These findings suggest that, especially with still-rising fuel costs, the attraction of some new riders to the transit system is possible, and that these riders would most likely fall into the segment of infrequent users (frequency of transit use is explored more fully in Chapter 5).

A few additional findings of interest include that 52 percent of respondents agree that the Pinellas County Transit Authority (PSTA) is mostly a "social service” that provides transportation primarily for low-income individuals who do not have a car. However, 75 percent agree that PSTA provides transit service that is "good enough to use regularly."

The question asked on the Pinellas travel survey of most interest to this chapter was why transit ex-users stopped riding the bus. For 63 percent of respondents, the reason was simply that they gained access to a car. The remaining 37 percent responded in the "other" category and were asked to describe their reasons. Of those responding “other," 22 percent indicated that they had changed jobs or retired. Seventeen percent reported that they began receiving rides from family 
or friends. A few others reported that the travel time on the bus was too long, or that they became disabled.

\section{Puget Sound Transportation Panel}

According to documentation on the PSTP, it was the first general-purpose travel panel survey conducted in an urban area of the United States. It originated in 1989 by the entity now known as the Puget Sound Regional Council. The information acquired from the panel survey results assists the Puget Sound Regional Council in long-range transportation planning and analysis for decisions such as highway and road construction, transit development, and policies for carpooling and parking.

The panel comprises approximately 1,700 households across the four-county Puget Sound region (King, Kitsap, Pierce, and Snohomish Counties), and specifically includes households that contain at least one member who regularly uses transit and households with at least one member who carpools regularly. Other households with members who drive alone for most of their trips are also included. The household members recorded all of their trip activity for a two-day period in each wave. In addition, a sample of the household members was asked to complete a separate survey on their attitudes and perceptions of various modes of transportation.

The first wave of the PSTP was conducted in 1989, and was followed by the first attitude survey in early 1990. The second wave occurred later in 1990 and was again followed by an attitude survey in 1991. Successive waves took place in 1992, 1993, 1994, 1996, 1997, 1999, 2000, and 2002. Attitude surveys were administered along with the 1990, 1991, 1993, 1996, 1997, 1999, 2000, and 2002 waves.

The PSTP began with 1,712 participating households in 1989 and was maintained at between 1,700 and 1,900 over the 10 waves. For each wave, approximately 20 percent of the households needed to be replaced, mainly due to households relocating.

Table 4-1 presents the share of those using the single-occupant vehicle (SOV), transit, or a combination of a car and transit as the primary work mode. On average, over the 10 survey waves, 67 percent of PSTP participants reported the SOV as their primary work mode. More than eight percent of PSTP participants used transit as the primary work mode and an additional four percent used a combination of a car and bus. 
Table 4-1: Primary Work Mode - Puget Sound Transportation Panel

\begin{tabular}{|l|r|r|r|r|r|r|r|r|r|r|r|}
\hline \hline & $\begin{array}{c}\text { Wave 1 } \\
\mathbf{( 1 9 8 9 )}\end{array}$ & $\begin{array}{c}\text { Wave 2 } \\
\mathbf{( 1 9 9 0 )}\end{array}$ & $\begin{array}{c}\text { Wave 3 } \\
\mathbf{( 1 9 9 2 )}\end{array}$ & $\begin{array}{c}\text { Wave 4 } \\
\mathbf{( 1 9 9 3 )}\end{array}$ & $\begin{array}{c}\text { Wave 5 } \\
\mathbf{( 1 9 9 4 )}\end{array}$ & $\begin{array}{c}\text { Wave 6 } \\
\mathbf{( 1 9 9 6 )}\end{array}$ & $\begin{array}{c}\text { Wave 7 } \\
\mathbf{( 1 9 9 7 )}\end{array}$ & $\begin{array}{c}\text { Wave 8 } \\
\mathbf{( 1 9 9 9 )}\end{array}$ & $\begin{array}{c}\text { Wave 9 } \\
\mathbf{( 2 0 0 0 )} \\
\mathbf{( 2 0 0 2 )}\end{array}$ & $\begin{array}{c}\text { Wave } \\
\mathbf{1 0} \\
\text { Avg. }\end{array}$ \\
\hline SoV & $69.0 \%$ & $68.9 \%$ & $62.4 \%$ & $68.1 \%$ & $69.4 \%$ & $68.7 \%$ & $67.3 \%$ & $66.0 \%$ & $63.3 \%$ & $67.0 \%$ & $67.0 \%$ \\
\hline Car/Bus Combination & $13.2 \%$ & $10.5 \%$ & $4.7 \%$ & $6.3 \%$ & $6.7 \%$ & $8.1 \%$ & $7.5 \%$ & $9.4 \%$ & $10.0 \%$ & $7.1 \%$ & $8.4 \%$ \\
\hline Carpool & $4.5 \%$ & $5.0 \%$ & $3.1 \%$ & $4.6 \%$ & $3.9 \%$ & $4.8 \%$ & $4.4 \%$ & $3.2 \%$ & $0.9 \%$ & $2.2 \%$ & $3.7 \%$ \\
\hline
\end{tabular}

NOTE: Percentages do not add to 100 due to rounding and the exclusion of other modes/responses (walk/bike, ferry, other, refused, work at home).

Table 4-2 provides some additional information about those who use the SOV as the primary mode to work. Over the 10 waves, an average of four percent of those who use an SOV as the primary work mode had used the bus at least one time in the previous six months (interestingly, this percentage was particularly high in the sixth wave, at slightly more than 12 percent). For more than 36 percent of the SOV users, their car is required at work and, for nearly 21 percent, their car is required to transport children. For those using a combination of a car and bus, approximately 17 percent indicated that the car was required for transporting children. It should be noted that the relevant questions regarding this mode combination were worded differently enough in the first, eighth, and ninth waves so as not be comparable with the other waves.

Table 4-2: Additional Characteristics of the SOV User-Puget Sound Transportation Panel

\begin{tabular}{|c|c|c|c|c|c|c|c|c|c|c|c|}
\hline & $\begin{array}{l}\text { Wave } 1 \\
\text { (1989) }\end{array}$ & $\begin{array}{c}\text { Wave } 2 \\
(1990)\end{array}$ & $\begin{array}{l}\text { Wave } 3 \\
\text { (1992) }\end{array}$ & $\begin{array}{l}\text { Wave } 4 \\
\text { (1993) }\end{array}$ & $\begin{array}{l}\text { Wave } 5 \\
\text { (1994) }\end{array}$ & $\begin{array}{c}\text { Wave } 6 \\
\text { (1996) }\end{array}$ & $\begin{array}{l}\text { Wave } 7 \\
\text { (1997) }\end{array}$ & $\begin{array}{l}\text { Wave } 8 \\
\text { (1999) }\end{array}$ & $\begin{array}{l}\text { Wave } 9 \\
(2000)\end{array}$ & $\begin{array}{c}\text { Wave } \\
10 \\
(2002)\end{array}$ & Avg. \\
\hline $\begin{array}{l}\text { Used the Bus in the } \\
\text { Past } 6 \text { Months }\end{array}$ & $2.9 \%$ & $2.2 \%$ & $5.3 \%$ & $4.0 \%$ & $3.0 \%$ & $12.3 \%$ & $2.0 \%$ & $2.2 \%$ & $2.8 \%$ & $2.4 \%$ & $3.9 \%$ \\
\hline $\begin{array}{l}\text { Car is Required at } \\
\text { Work }\end{array}$ & $39.7 \%$ & $38.6 \%$ & $32.6 \%$ & $35.9 \%$ & $36.5 \%$ & $37.9 \%$ & $35.7 \%$ & $37.0 \%$ & $39.3 \%$ & $30.8 \%$ & $36.4 \%$ \\
\hline $\begin{array}{l}\text { Car is Required for } \\
\text { Children - SOV }\end{array}$ & $18.8 \%$ & $20.5 \%$ & $18.9 \%$ & $20.2 \%$ & $22.6 \%$ & $22.6 \%$ & $19.9 \%$ & $21.8 \%$ & $20.8 \%$ & $19.9 \%$ & $20.6 \%$ \\
\hline $\begin{array}{l}\text { Car is Required for } \\
\text { Children - Car/Bus }\end{array}$ & $n / a$ & $21.7 \%$ & $15.7 \%$ & $18.6 \%$ & $19.7 \%$ & $18.3 \%$ & $9.8 \%$ & $\mathrm{n} / \mathrm{a}$ & $\mathrm{n} / \mathrm{a}$ & $11.9 \%$ & $16.5 \%$ \\
\hline
\end{tabular}


Table 4-3 summarizes the work mode switches of participants in the Puget Sound Transportation Panel over the 10 survey waves (specifically, waves 2 through 10). Of primary interest for this chapter are those who have switched to transit from the single-occupant vehicle (SOV) and those who have switched from transit to driving alone (SOV). For purposes of this analysis, ferry and car/bus combination were included in the transit mode.

Table 4-3: Work Mode Switches* Over 10 Survey Waves -
Puget Sound Transportation Panel

\begin{tabular}{|c|c|c|c|c|c|c|c|c|}
\hline \multicolumn{9}{|c|}{ TO MODE: } \\
\hline & & sov & Transit & Carpool & Walk/Bike & Ferry & $\begin{array}{l}\text { Car/Bus } \\
\text { Combo }\end{array}$ & $\begin{array}{l}\text { Work at } \\
\text { Home }\end{array}$ \\
\hline \multirow{7}{*}{ 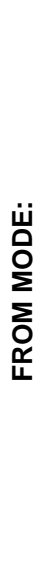 } & sov & $90.7 \%$ & $0.8 \%$ & $6.5 \%$ & $0.5 \%$ & $0.2 \%$ & $0.5 \%$ & $0.7 \%$ \\
\hline & Transit & $19.5 \%$ & $63.9 \%$ & $7.1 \%$ & $1.7 \%$ & $0.3 \%$ & $7.3 \%$ & $0.3 \%$ \\
\hline & Carpool & $43.4 \%$ & $3.1 \%$ & $48.7 \%$ & $1.5 \%$ & $0.3 \%$ & $1.5 \%$ & $1.5 \%$ \\
\hline & Walk/Bike & $25.7 \%$ & $7.4 \%$ & $5.9 \%$ & $58.4 \%$ & $0.0 \%$ & $1.0 \%$ & $1.5 \%$ \\
\hline & Ferry & $8.0 \%$ & $2.5 \%$ & $2.5 \%$ & $0.6 \%$ & $84.7 \%$ & $1.8 \%$ & $0.0 \%$ \\
\hline & Car/Bus Combo & $15.7 \%$ & $26.5 \%$ & $9.3 \%$ & $3.0 \%$ & $0.2 \%$ & $45.0 \%$ & $0.2 \%$ \\
\hline & Work at Home & $23.5 \%$ & $0.9 \%$ & $2.2 \%$ & $0.6 \%$ & $0.0 \%$ & $0.0 \%$ & $72.8 \%$ \\
\hline
\end{tabular}

*Data represent the aggregation of primary work mode changes over the 10 waves of the PSTP ("other" category not included).

As shown in Table 4-3, only 1.5 percent of SOV users switched to a transit mode over the 10 waves of the survey. During this time, 19.5 percent of transit users, 8 percent of ferry users, and 15.7 percent of those using a car/bus combination, switched to driving alone. The following tables and paragraphs further analyze those who made these work mode switches.

First, the age of those who switched modes is examined and compared to all SOV users and all transit users. In Table 4-4, the information shown represents the average over all the survey waves. The most interesting finding from these data is that those who switched to transit tend to be somewhat older than the transit users as a whole (as well as older than SOV users). Those switching from transit tend to be relatively younger, although the age distributions are not significantly different. 
Table 4-4: Those Switching To or From Transit*, by Age -
Puget Sound Transportation Panel

\begin{tabular}{||r|r|r|r|r||}
\hline Age Group & \multicolumn{1}{|c|}{ To Transit } & From Transit & \multicolumn{1}{c|}{$\begin{array}{c}\text { All SoV } \\
\text { Users* }\end{array}$} & \multicolumn{1}{c|}{$\begin{array}{c}\text { All Transit } \\
\text { Users* }\end{array}$} \\
\hline $15-17$ & $0.0 \%$ & $0.3 \%$ & $1.0 \%$ & $0.5 \%$ \\
\hline $18-24$ & $0.0 \%$ & $6.9 \%$ & $6.8 \%$ & $6.9 \%$ \\
\hline $25-34$ & $18.3 \%$ & $24.9 \%$ & $17.8 \%$ & $23.7 \%$ \\
\hline $35-44$ & $26.8 \%$ & $28.5 \%$ & $28.9 \%$ & $26.1 \%$ \\
\hline $45-54$ & $33.7 \%$ & $26.9 \%$ & $28.1 \%$ & $27.1 \%$ \\
\hline $55-64$ & $19.1 \%$ & $10.8 \%$ & $13.2 \%$ & $12.2 \%$ \\
\hline $65-98$ & $7.1 \%$ & $1.6 \%$ & $2.8 \%$ & $3.1 \%$ \\
\hline
\end{tabular}

*Average over the 10 survey waves.

One change that might occur over time which might necessitate a work mode switch is whether an individual's occupation has changed or whether the work location has changed. Table 4-5 summarizes this information for those who switched to and from transit over the survey waves. As the table indicates, the percentages are similar for both switching to and from transit. On average, approximately 29 percent experienced a change in occupation from the previous year, while approximately 45 percent had a change in workplace location from the previous year. It is expected that these types of changes might require a switch from transit to driving alone if a new occupation's hours or a job’s location no longer fit with existing transit schedules or routes. Alternately, such changes might allow someone to use transit when the previous workplace characteristics were not conducive. Clearly, however, changes in occupation and workplace location are a significant factor in the choice to switch work modes.

Table 4-5: Occupation and Workplace Changes* - Puget Sound Transportation Panel

\begin{tabular}{|l|r|r||}
\hline \multicolumn{1}{|c|}{ Change } & \multicolumn{1}{|c|}{ To Transit } & From Transit \\
\hline Occupation change since last year & $28.3 \%$ & $30.8 \%$ \\
\hline Workplace change since last year & $46.0 \%$ & $44.1 \%$ \\
\hline
\end{tabular}

*Average over survey waves 2 through 10. 
Another factor important in whether transit can be used for the work trip is whether a car is required either at work or to pick up children. As expected, Table 4-6 shows that, for those who switched to transit over the survey waves, no one required a car for such purposes. However, the table shows that 25 percent of those who switched from transit to the SOV needed a car at work. More than 17 percent of those who switched from transit were in need of a car in order to pick up children. Such requirements can explain some of the switching behavior observed over these survey waves.

\section{Table 4-6: Car Required for Work or Children* - Puget Sound Transportation Panel}

\begin{tabular}{|l|r|r|}
\hline \multicolumn{1}{|c|}{ Change } & \multicolumn{1}{|c|}{ To Transit } & From Transit \\
\hline Car required at work & $0.0 \%$ & $25.1 \%$ \\
\hline Car required to pick up children & $0.0 \%$ & $17.4 \%$ \\
\hline
\end{tabular}

*Average over the 10 survey waves.

While the information described in Tables 4-5 and 4-6 examine two factors that may necessitate a work mode switch, the next three tables provide information on the attitudes and perceptions of those who made switches based on results of the attitude surveys conducted as part of the PSTP. As described in Chapter 2 and earlier in this chapter, the first four attitude surveys conducted as part of the PSTP included different question formats than the later attitude surveys. Tables 4-7 through 4-9 address importance ratings, performance ratings, and agreement/disagreement statements from these first four attitude surveys. Attitudes are examined for the survey year prior to the switch, to gain insight into perceptions and opinions that precede or may trigger a mode switch.

Table 4-7 examines several statements which survey respondents had to rate in terms of importance in determining their mode of travel. The table focuses on those who rated the statements as "extremely important" for those switching to transit and from transit. These responses are also compared to all responses on average over the applicable survey waves.

Regarding the ability to arrive on time, Table 4-7 indicates that a relatively smaller percentage of those switching to transit from the SOV rated it as "extremely important" (73.7 percent) compared to those switching from transit (90.1 percent) and all responses (86.0 percent). As 
might be expected, the ability to arrive on time appears to be somewhat less important for those who switched to transit and somewhat more important for those who switched from transit. This indicates that the on-time performance of transit (real or perceived) likely has some influence on the decision to switch modes.

\section{Table 4-7: Importance Ratings for Deciding Travel Mode* - Puget Sound Transportation Panel Attitude Surveys (1990—1996)}

\begin{tabular}{||l|r|r|r||}
\hline \multicolumn{1}{|c|}{ Rated "Extremely Important"** } & \multicolumn{1}{c|}{ To Transit } & From Transit & All Responses"* \\
\hline Ability to Arrive on Time & $73.7 \%$ & $90.1 \%$ & $56.0 \%$ \\
\hline Not Having to Deal with Traffic Congestion & $51.0 \%$ & $59.9 \%$ & $55.2 \%$ \\
\hline Short Travel Time & $26.4 \%$ & $55.6 \%$ & $46.6 \%$ \\
\hline Day-to-Day Costs & $47.4 \%$ & $54.6 \%$ & $68.2 \%$ \\
\hline Flexibility to Change Plans & $52.6 \%$ & $66.7 \%$ & $64.3 \%$ \\
\hline Parking Availability & $68.4 \%$ & $64.2 \%$ & $83.1 \%$ \\
\hline Freedom from Threats to Personal Safety & $73.7 \%$ & $81.0 \%$ & $62.8 \%$ \\
\hline Avoiding Stress & $42.1 \%$ & $60.7 \%$ & 5 \\
\hline
\end{tabular}

* Average over survey waves 1 through 6 (1990 - 1996).

** Rated a 6 or 7 on a scale of 1 to 7 .

Another finding from Table 4-7 is that only approximately 26 percent of those switching from the SOV to transit rated a short travel time as "extremely important." This compares to approximately 55 percent for those switching from transit as well as for all the responses. Such a result is expected given that transit has generally longer travel times than the SOV. Similarly, those switching to transit generally rate the flexibility to change plans and freedom from threats to personal safety as less important than those who switched from transit as well as all respondents as a whole.

Interestingly, only 42 percent of those who switched to transit rated stress avoidance as “extremely important," compared to approximately 61 percent of those who switched from transit and approximately 63 percent for all respondents as a whole. It might be hypothesized that one reason for taking transit is to avoid stress; however, these data indicate there might be a 
certain level of stress associated with the use of transit (perhaps relating to ease of use or travel times).

In Table 4-8, the same statements that were rated in terms of importance are rated in terms of performance for the bus mode (except for parking availability, which is rated for the SOV mode). The performance ratings reflect the attitudes of respondents prior to their mode switches and provide some insight into the perceptions and opinions about transit that may influence switching behavior.

A somewhat unexpected finding from Table 4-8 is that most of those who switched from transit actually rated its performance well in terms of the ability to arrive on time (and even better than those who switched to transit). This may indicated that most of those who switched did so for reasons other than the reliability of transit.

As might be expected, Table 4-8 shows that most view the bus mode's performance favorably in terms of not having to deal with traffic congestion. A higher percentage of those switching both to and from transit rate the bus well in this category, although the highest percentage (89 percent) is among those who switched from the SOV to transit. This indicates that these respondents do view the bus mode as an alternative for dealing with congestion.

Regarding a short travel time, the bus mode is rated relatively less favorably. Table 4-8 indicates, however, that both current and previous users of transit rate the travel time on bus better than all respondents as a whole. The table shows a similar finding for the day-to-day costs of using the bus mode.

Interestingly, current and previous users of transit rate the bus mode's flexibility when changing plans less favorably than respondents as a whole, with those switching to transit rating it the least favorably, according to Table 4-8. These results might indicate a difference in the perception versus reality of choosing the bus mode where, at least in this case, the reality might be worse than the overall perception.

Table 4-8 indicates that those switching from transit to the SOV rated the bus mode the least favorably in terms of freedom from threats to personal safety. This might indicate that some of those who switched did so because of an overall perception of safety issues associated with the bus or perhaps because of a particular incident or incidents where their safety felt threatened (further information is not available in the PSTP). 
Table 4-8: Performance Ratings for the Bus Mode* -

Puget Sound Transportation Panel Attitude Surveys (1990-1996)

\begin{tabular}{|c|c|c|c|}
\hline & To Transit & From Transit & All Responses \\
\hline \multicolumn{4}{|c|}{ Ability to Arrive on Time } \\
\hline Well & $55.6 \%$ & $81.8 \%$ & $58.0 \%$ \\
\hline Neutral & $22.2 \%$ & $9.4 \%$ & $16.8 \%$ \\
\hline Poor & $22.2 \%$ & $8.8 \%$ & $25.2 \%$ \\
\hline \multicolumn{4}{|c|}{ Not Having to Deal with Traffic Congestion } \\
\hline Well & $88.9 \%$ & $83.4 \%$ & $73.8 \%$ \\
\hline Neutral & $11.1 \%$ & $7.0 \%$ & $12.1 \%$ \\
\hline Poor & $0.0 \%$ & $9.6 \%$ & $14.1 \%$ \\
\hline \multicolumn{4}{|c|}{ Short Travel Time } \\
\hline Well & $38.9 \%$ & $51.0 \%$ & $35.0 \%$ \\
\hline Neutral & $33.3 \%$ & $18.5 \%$ & $19.3 \%$ \\
\hline Poor & $27.8 \%$ & $30.6 \%$ & $45.7 \%$ \\
\hline \multicolumn{4}{|c|}{ Day-to-Day Costs } \\
\hline Well & $83.3 \%$ & $82.7 \%$ & $69.7 \%$ \\
\hline Neutral & $16.7 \%$ & $12.8 \%$ & $15.4 \%$ \\
\hline Poor & $0.0 \%$ & $4.5 \%$ & $14.9 \%$ \\
\hline \multicolumn{4}{|c|}{ Flexibility to Change Plans } \\
\hline Well & $16.7 \%$ & $20.6 \%$ & $29.6 \%$ \\
\hline Neutral & $16.6 \%$ & $26.7 \%$ & $18.0 \%$ \\
\hline Poor & $66.7 \%$ & $52.7 \%$ & $52.4 \%$ \\
\hline \multicolumn{4}{|c|}{ Parking Availability (SOV) } \\
\hline Well & $72.2 \%$ & $49.1 \%$ & $18.6 \%$ \\
\hline Neutral & $5.6 \%$ & $17.0 \%$ & $12.7 \%$ \\
\hline Poor & $22.2 \%$ & $34.0 \%$ & $68.7 \%$ \\
\hline \multicolumn{4}{|c|}{ Freedom From Threats to Personal Safety } \\
\hline Well & $33.3 \%$ & $66.2 \%$ & $25.7 \%$ \\
\hline Neutral & $27.8 \%$ & $19.7 \%$ & $19.4 \%$ \\
\hline Poor & $38.9 \%$ & $14.0 \%$ & $54.9 \%$ \\
\hline \multicolumn{4}{|c|}{ Avoiding Stress } \\
\hline Well & $61.1 \%$ & $80.2 \%$ & $16.2 \%$ \\
\hline Neutral & $27.8 \%$ & $11.6 \%$ & $15.4 \%$ \\
\hline Poor & $11.1 \%$ & $8.2 \%$ & $68.4 \%$ \\
\hline
\end{tabular}

*Average over survey waves 1 through 6 (1990 - 1996). 
Also in Table 4-8, current and previous users of transit rate the bus mode much more favorably in terms of stress avoidance than all respondents as a whole. Those who switched from transit rated this factor most favorably, perhaps indicating that they enjoyed the aspect of stress avoidance associated with transit use and switched modes for another reason.

Finally, Table 4-8 summarizes the performance of parking availability for the SOV mode. In the Puget Sound region, nearly 68 percent of PSTP respondents rated parking availability as poor. However, both current and previous transit users rated it better than respondents as a whole.

The early attitude surveys also contained a series of agreement/disagreement statements, some of which referred to commuting in general and some of which referred to characteristics of specific travel modes. A selection of these are included in Table 4-9, along with the percentages of those who agreed with them (either "somewhat," "strongly," or "very strongly"). Responses are shown, averaged across all applicable survey waves, for those who switched from the SOV to transit, those who switched from transit to the SOV, and for all respondents.

The first statement in Table 4-9 is, "Riding the bus is a relaxing way to commute." While, on average, only 47 percent of all respondents agreed with this statement, approximately 56 percent of those switching to transit agreed. Of those switching from transit to the SOV, 73 percent agreed that the bus is relaxing to some degree. This indicates that most of those who switched did view the bus as relaxing and perhaps other factors were more important in the decision to switch modes.

Another statement in Table 4-9 is "I hate the idea of transferring buses." It is hypothesized that the need to transfer buses to complete a trip is a deterrent to the choice transit rider. Overall, 67 percent of respondents, on average, agreed with this statement. However, more than 69 percent of those who switched from transit agreed, perhaps indicating that the disdain for transferring buses might be a factor in the decision to switch from transit to driving. Only approximately 53 percent of those switching to transit agreed that they hate transferring buses, thus indicating a higher level of comfort with using transit and transferring vehicles.

Table 4-9 also indicates that a significant majority of respondents agree that "riding the bus helps reduce traffic congestion.” More than 90 percent of current and previous users agreed with this statement. 
Table 4-9: Agreement/Disagreement Statements* _ Puget Sound Transportation Panel Attitude Surveys (1990-1996)

\begin{tabular}{|c|c|c|c|}
\hline $\begin{array}{c}\text { Rated as Somewhat, Strongly, or } \\
\text { Very Strongly Agree" }\end{array}$ & To Transit & From Transit & All Responses \\
\hline Riding the Bus is a Relaxing Way to Commute & $55.6 \%$ & $73.0 \%$ & $46.9 \%$ \\
\hline I Hate the Idea of Transferring Buses & $52.6 \%$ & $69.3 \%$ & $67.2 \%$ \\
\hline $\begin{array}{l}\text { Riding the Bus Helps Reduce Traffic } \\
\text { Congestion }\end{array}$ & $94.4 \%$ & $92.6 \%$ & $83.5 \%$ \\
\hline It's a Hassle to Take the Bus & $38.9 \%$ & $34.2 \%$ & $58.5 \%$ \\
\hline I Like the Freedom of Driving My Own Car & $83.3 \%$ & $71.2 \%$ & $83.4 \%$ \\
\hline The Bus is an Enjoyable Way to Travel & $50.0 \%$ & $64.2 \%$ & $36.1 \%$ \\
\hline $\begin{array}{l}\text { People Only Ride the Bus to Work if They } \\
\text { Have To }\end{array}$ & $47.4 \%$ & $26.4 \%$ & $29.3 \%$ \\
\hline
\end{tabular}

*Average over survey waves 1 through 6 (1990 - 1996).

Approximately 59 percent of all respondents, on average, agreed to some degree that "it's a hassle to take the bus," according to Table 4-9. Significantly an average of fewer current and previous transit users agreed with this statement; 39 percent of those who switched to transit and 34 percent who switched from transit. This finding suggests that at least one-third of those who use transit or who previously used transit still find the mode to be a "hassle" to some degree.

Not surprisingly, a majority of respondents like the freedom of driving their own car. Table 4-9 indicates that 83 percent of respondents, on average, agree with this statement. A similar percentage of those who even switched to transit from the SOV also agreed. A somewhat lower percentage (71 percent) of those who switched from transit to the SOV agreed with this statement; while still a majority, it indicates that the switch likely occurred for other reasons that the simple freedom associated with driving one's own car.

Similar to the statement regarding the bus as a relaxing way to commute, survey participants were also asked to respond to the statement, "The bus is an enjoyable way to travel." On average, over the early survey waves, Table 4-9 indicates that 36 percent of all respondents agreed with this statement. As might be expected, higher percentages of current and previous transit users agreed that the bus is enjoyable. The highest percentage (64 percent) of those who agreed with the statement are previous transit users, who switched to the SOV. The fact that most ex-users continue to agree that the bus is enjoyable indicates that other factors likely influenced the decision to switch. 
The last statement in Table 4-9 is, "People only ride the bus to work if they have to." At least in the Puget Sound region, approximately 29 percent, on average, agree. Further, an average of only 26 percent of transit ex-users agree with the statement. Those switching from SOV to transit had the highest percentage of those who agree with the statement (47 percent), perhaps indicating that some of those who switched to transit felt they "had to."

The discussion of the Puget Sound data sets in Chapter 2 and earlier in this chapter outlined some of the differences in the eight attitude surveys conducted over the 10 survey waves. As mentioned previously, the latter four surveys differed significantly in format from the first four. As such, the results must be analyzed separately. The last four attitude surveys that were conducted did not include the importance ratings and performance ratings that were part of the first four surveys. However, several agreement/disagreement statements were found to be relevant to the analysis conducted for this chapter. Table 4-10 presents a selection of these statements, a few of which were only included in one of the surveys (as noted in the table).

In Table 4-10, the percentages of those who "agree" or "agree completely" are shown for those who switched to transit, from transit, and for all respondents as a whole. The percentages shown are averages over the applicable survey waves (waves 7 through 9, representing 1997 to 2000).

The first statement in Table 4-10 was only included in the 1997 survey: "I get annoyed easily when my travel is delayed.” Interestingly, the highest percentage, more than 72 percent, of those agreeing with this statement represents those who switched from transit to the SOV. Those switching to transit, and the responses as a whole, averaged approximately 60 percent. This indicates that those who are more easily annoyed by travel delays might be less inclined to use transit and/or stay with transit as a travel mode.

Table 4-10 shows that, on average, slightly more than half (approximately 54 percent) of all respondents “worry a lot about being late.” Relatively fewer percentages of current and former transit users agree with this statement.

Also included in Table 4-10 is the statement that, "At least twice per week, there is an unexpected delay on my route.” This statement refers to the general route of travel and is not mode specific. Among all responses, the table indicates that approximately 25 percent of respondents agreed with this statement. Responses are somewhat higher, on average, for new and previous transit users. Approximately 34 percent of those switching to transit agreed that 
they experienced a delay at least twice per week. However, approximately 57 percent of those switching from transit to the SOV agreed with this statement, providing some evidence that travel delays may be a factor in the decision to switch from transit.

The next three statements listed in Table 4-10 are specific to the bus mode and are therefore not reported for those switching to transit because these statements reflect respondents' attitudes in the year prior to their switch. More than 44 percent of those who switched from transit to the SOV mode agreed that they sometimes miss connections due to a bus or ferry being late. Over all respondents who use transit, only 21 percent agreed. Thus, those who switched from transit did experience more missed connections due to late transit vehicles, according to the results shown in the table.

While slightly more than 21 percent of all transit users indicated they would like to "switch to driving as soon as possible," the data in Table 4-10 show that, on average, approximately 24 percent of those agreeing with the statement did switch to the SOV. Thus, those who indicate a desire to switch tend to follow through with the switching behavior.

\section{Table 4-10: Agreement/Disagreement Statements* - Puget Sound Transportation Panel Attitude Surveys (1997-2000)}

\begin{tabular}{|c|c|c|c|}
\hline Rated as "Agree" or "Agree Completely" & To Transit & From Transit & All Responses \\
\hline $\begin{array}{l}\text { I Get Annoyed Easily When My Travel is } \\
\text { Delayed (1997) }\end{array}$ & $61.5 \%$ & $72.4 \%$ & $58.4 \%$ \\
\hline I Worry a Lot About Being Late & $42.0 \%$ & $50.0 \%$ & $53.6 \%$ \\
\hline $\begin{array}{l}\text { At Least Twice per Week There is an } \\
\text { Unexpected Delay on my Route }\end{array}$ & $34.2 \%$ & $57.1 \%$ & $24.6 \%$ \\
\hline $\begin{array}{l}\text { I Sometimes Miss My Connection if the Bus or } \\
\text { Ferry is Late }\end{array}$ & $\mathrm{n} / \mathrm{a}$ & $44.4 \%$ & $20.5 \%$ \\
\hline $\begin{array}{l}\text { I Would Like to Switch to Driving as Soon as } \\
\text { Possible }\end{array}$ & $\mathrm{n} / \mathrm{a}$ & $23.9 \%$ & $21.1 \%$ \\
\hline $\begin{array}{l}\text { I Do Not Mind the Delays So Much if I Can } \\
\text { Forecast Accurately When I Will Get There }\end{array}$ & $\mathrm{n} / \mathrm{a}$ & $36.9 \%$ & $31.4 \%$ \\
\hline $\begin{array}{l}\text { I Have Seriously Considered Changing Where I } \\
\text { Work/Live to Reduce Commuting Time (2000) }\end{array}$ & $12.5 \%$ & $31.8 \%$ & $18.9 \%$ \\
\hline
\end{tabular}

*Average over survey waves 7 through 9 (1997 - 2000). 
In Chapter 3, one finding is that real-time information can perhaps act as a proxy for on-time performance (reliability). In Table 4-10, approximately 31 percent of all respondents “do not mind the delays so much if (they) can forecast accurately when (they) will get there." A similar, but slightly higher, percentage of those who switched from transit agreed with this statement. In this case, these similar percentages seem to indicate that the ability to predict arrival times would not necessarily retain all users.

The last statement listed in Table 4-10 was only included in the 2000 and 2002 attitude surveys. Because attitudes are examined the survey year prior to a mode switch, the data shown in the table represent only the 2000 survey. The statement refers to the recent serious consideration of a residence or work relocation to reduce commuting times. Overall, 19 percent of respondents agreed with the statement. Only 12 percent of those switching to transit agreed, while nearly 32 percent of those switching from transit agreed; an interesting result.

\section{Conclusions}

The analysis conducted for this chapter aimed to gain a better understanding of the factors that cause mode switches away from transit, as well as to transit. Previous literature was examined, as well as several data sets including household travel surveys, the most comprehensive of which being the Puget Sound Transportation Panel (PSTP), a longitudinal household survey that also included a series of attitude questionnaires.

Some existing literature on the topic indicated the existence of a natural transit life cycle that tends to result in cessation of use. As such, ridership retention strategies should seek to prolong this life cycle. Data from household travel surveys in Washington, D.C. and Pinellas County, Florida, indicate that most users stop using transit when they gain access to a car (i.e., when they have a choice). The second most common reason is a change in job, job location, or residential location. Smaller percentages of respondents indicated dissatisfaction with transit service characteristics as their reason for ceasing transit usage. For example, only six percent of the respondents in the Washington, D.C., survey reported that they stopped using transit because it was not "reliable enough."

Similar findings emerged from a close examination of the 10 survey waves from the PSTP. Just prior to making a mode switch, most respondents indicated a change in occupation or job location. It is reasonable to assume that these changes might add or remove transit as a viable 
alternative mode, depending upon the hours and location of both the workplace, the residence, and the available transit service.

However, the PSTP also included a series of attitude surveys, which did indicate that those most concerned about being on time, those most annoyed by travel delays, and those who experienced problems associated with late transit vehicles are more likely to switch to driving. While the Puget Sound region appears to have more "choice” transit riders than, say, Pinellas County, Florida, the mode share for transit is still relatively small, so the actual number of transit customers lost due to service problems is also relatively small. It should be noted, though, that marketing research shows that, in general, approximately 45 percent of switching because of failed service encounters is due to a single act and that 75 percent of all switchers told many people about any negative experiences, thus circulating negative perceptions via word of mouth. ${ }^{2}$ The extent to which such research, done primarily for traditional goods and services, is applicable to public transit is unclear. However, with a pattern of service problems, choice riders will certainly be more likely to switch.

Since the transit industry cannot prevent the natural life progressions that lead to cessation, rider retention efforts should instead seek to prolong the ridership lifecycle by increasing the time period during which people are both able and willing to use transit. Thus, factors that motivate transit use, as well as those that deter or prevent it altogether, must be understood.

Insight into the motivations of people who use transit by choice rather than necessity might be useful for retaining riders, as well as attracting them, in larger numbers. For the rider who has the option of driving, the decision to use transit appears to be a matter of trade-offs. Market research suggests that choice riders may consider helping the environment, avoiding traffic, and saving money important enough to offset the additional time required to travel by transit. Market research also suggests that choice riders may be motivated to use transit by disincentives associated with driving (such as parking costs and congestion) rather than positive incentives associated with transit service.

Because the majority of research on transit consumer satisfaction is based on surveys of existing riders, transit operators have very limited information on ex-riders. As mentioned previously, riders tend to cease using transit it no longer meets their needs or driving becomes a viable option. Insight into why non-riders do not use transit may shed some light on the reasons why

${ }^{2}$ Dr. Paul Solomon, Marketing Management class notes, MBA Program, University of South Florida, Tampa, 2008. 
riders stop using transit, information that may prove quite useful in devising rider retention strategies. Non-riders appear to have a desire for many of the same travel benefits as transit riders, but have stricter standards and are less inclined to commit to using transit, even if their higher expectations are met. On-time performance and reliability are frequently ranked by nonusers as highly important criteria for using transit. Some of the obstacles to transit use that have been identified by non-riders include lack of convenience in terms of both schedule and location of origin/destination, lack of flexibility for multiple trips, lack of security, lengthy travel times, frustration with transfers, and lack of information.

It is also important to note the importance of customer satisfaction to retention and ridership growth. Consumers who are not completely satisfied with a product or service are likely to leave at the first opportunity and should be considered vulnerable to market competition. Moreover, transit ridership in the U.S. today is strongly linked to increasing the number of choice ridersexactly those people who have the option to switch to another mode if they choose. In light of this knowledge, as well as the significance of rider retention, it is reasonable to conclude that customer satisfaction and loyalty may be essential for achieving transit ridership growth. 


\section{CHAPTER FIVE: CHARACTERISTICS OF INFREQUENT RIDERS}

\section{Introduction}

There is a need to synthesize the characteristics of infrequent riders, the strategies that agencies use to encourage more frequent usage, and the successes from these strategies. A synthesis of these riders' characteristics is contained in this chapter, while a synthesis of successful strategies is included in Chapter 1. This information will allow transit agencies to learn from each other the state of the practice in inducing infrequent riders to become more frequent riders.

The chapter opens with a summary of relevant lessons from the literature which are discussed in detail in Chapter 1. Then, several data sources are fully explored to gain a better understanding of the infrequent rider. On-board survey data from across the country are used in this effort, with data from eight recent on-board surveys in Florida being examined in the most detail. In addition, data from the Puget Sound Transportation Panel (discussed in Chapter 2), particularly from the attitude surveys, are also used to uncover infrequent rider characteristics. Finally, data from a household travel survey in Pinellas County, Florida, are also examined.

The findings from this chapter include a summary of relevant information from all of the survey data and literature. Recommendations include a consideration of successful strategies found to increase frequency of use, as well as consideration of the characteristics of less frequent riders that can be used in targeted marketing efforts to those riders.

Based on a selection of on-board survey data, infrequent riders can represent a majority of a rider population. However, these riders represent a relatively small share of total transit trips and have the potential to become a much larger market. Because infrequent riders have already made the first step to try transit, it is potentially less difficult to induce them to use transit more often that to attract new riders. Transit agencies across the country have used a variety of strategies to increase the frequency of usage, including marketing, fare structure, network structure, and passenger information systems. 


\section{Lessons from the Literature}

The standard practice of the transit industry has been to cater to captive, regular riders who make large numbers of daily commuting trips. However, the emphasis on these conventional market segments reinforces outdated assumptions regarding transit users and may actually result in overlooking a bigger market opportunity. High turnover and occasional use more accurately describe today's ridership base. Thus, in addition to postponing rider cessation, transit agencies may successfully boost ridership by encouraging infrequent riders to increase and diversify their use of transit services. Indeed, there is a growing body of research suggesting that infrequent riders may be a critical market for building transit ridership and revenues. The relevant literature is discussed in Chapter 1. Given the conventional wisdom and standard practices within the transit industry, these findings are surprising, and suggest the need for new directions in transit marketing and pricing strategies.

\section{Characteristics Revealed by On-Board Surveys}

Transit on-board surveys typically ask riders how frequently they use the system. Responses can be categorized by number of days per week as well as number of times per month. This information, along with responses other pertinent questions dealing with trip information, customer satisfaction, and rider demographics, can reveal a profile of the infrequent rider.

Data and results from several on-board surveys were used in the analysis conducted for this chapter. The results from a total of 21 on-board surveys were collected and found to be useful for analysis. The surveys were conducted at transit agencies around the country. For further detailed analysis, raw data sets from eight recent on-board surveys conducted in Florida were obtained. In addition, results from the APTA Transit Performance Monitoring System (TPMS) and APTA's profile of demographics and travel characteristics from on-board surveys are referenced. This section begins with a synthesis of the results of 13 recent on-board surveys conducted outside Florida.

The 13 surveys were each conducted between 2001 and 2006. Results were obtained through direct contact with the agency or via online searches. The agencies represented are listed below:

- Alameda-Contra Costa Transit District (2003)

- Chapel Hill Transit (2003)

- City of Lawrence, Kansas (The T, 2006) 
- Colorado Springs Transit (2005)

- Dallas Area Rapid Transit (2004)

- Elk Grove, California (2005)

- Greater Cleveland Regional Transit Authority (2001)

- Metropolitan Atlanta Rapid Transit Authority - MARTA (2002)

- Sacramento Regional Transit (bus and rail, 2006)

- Santa Clara Valley Transportation Authority (2005)

- Tulsa Transit (2005)

- Valley Metro, Phoenix (2001)

- Washington Area Transit Authority (WMATA Regional Bus Study, 2001)

On average, infrequent riders comprise approximately 23 percent of all riders at these agencies. For the purposes of this study, infrequent riders were defined as those riding the system three days per week or less (a common survey category is 1 to 3 days per week). On average, less than 10 percent of riders use the transit system less than one day per week. Without raw data, additional quantitative analysis of these results was not possible. However, the following paragraphs summarize some findings relevant to frequency of use.

A common theme among these survey results is that the most frequent riders are work commuters. Specifically, the survey results from Valley Metro and Elk Grove show that users of their express and commuter routes are higher frequency riders than the typical local bus user. In addition, the majority of riders on Elk Grove's commuter routes are defined as choice riders, i.e., those with a vehicle available that could have been used to make their trip.

The WMATA study also found that high-frequency riders comprise a smaller share of weekend ridership as compared to weekday ridership. Not surprisingly, these frequent users are also more highly represented in the AM and PM peaks. These findings further the notion of the highfrequency rider as the work commuter.

If the high-frequency user tends to be the work commuter, then it can be reasoned that the infrequent user is not the typical work commuter. It could be concluded from this information, then, that a way to increase the frequency of transit use is to focus on the work commuter. This can be done by either emphasizing the attraction of new riders to use transit for the work trip or inducing infrequent work commuters to take transit for more (if not all) of their work trips. 
At MARTA (Atlanta), their survey results indicated that 93 percent of transit riders had recently increased their use of transit (or at least remained constant in their usage). No specific reasons were given for this change, other than the fact that service had increased.

In Chapel Hill, their 2003 survey results showed an increase in frequent riders (those riding five days per week) of approximately eight percent since their 1997 survey. In 2002, Chapel Hill Transit implemented fare free services as well as other service improvements that have likely attracted and retained riders. Also, one of the most common reasons for riding the system is the lack of convenient parking. A lack of adequate parking at major destinations can serve to attract riders as well as increase the frequency of use. Chapel Hill Transit has a relatively high turnover of ridership from the student population as well as other residents. The agency recognizes that ongoing marketing and information campaigns are crucial in attracting and retaining riders.

This sample of recent on-board surveys suggests that the most frequent riders are regular work commuters, thus implying that less frequent riders use the system for other types of trips, or for the occasional work trip. In the next section, raw data from eight on-board surveys are further analyzed with respect to the infrequent rider.

\section{Florida On-Board Surveys}

Raw data from eight recent Florida on-board ridership surveys were used to further analyze the characteristics and travel patterns of the infrequent user. Findings are revealed from crosstabulations of the survey question about frequency of use with several other questions about respondents' travel behavior, demographics, and customer satisfaction. Transit surveys in Florida typically contain nearly identical sets of questions, thus making it relatively easy to analyze and aggregate results.

The Center for Urban Transportation Research (CUTR) has conducted many of the on-board surveys in the state of Florida. From a database of 25 surveys, 7 recent surveys were selected for this study. Care was taken to include agencies from across the geography of the state and to have small, medium, and larger agencies represented. Data from an eighth survey, in Pinellas County, were obtained from Tindale-Oliver \& Associates, Inc., in Tampa. The agencies with surveys represented in this section are listed below: 
- Bay Town Trolley (Panama City)

- Collier Area Transit (Naples)

- Jacksonville Transportation Authority

- Lee County Transit (Fort Myers)

- Palm Tran (Palm Beach County)

- Pinellas Suncoast Transit Authority

- StarMetro (Tallahassee)

- VOTRAN (Volusia County)

Table 5-1 provides some information on these eight transit agencies. The year of the survey is shown, along with four indicators found in the 2006 National Transit Database: population, peak vehicles, revenue miles of service, and ridership (passenger trips).

Table 5-1: On-Board Surveys Used to Analyze Infrequent Riders

\begin{tabular}{|l|c|c|c|c|c||}
\hline \multicolumn{1}{|c|}{ Agency } & $\begin{array}{c}\text { Year of } \\
\text { Survey }\end{array}$ & $\begin{array}{c}\text { Population } \\
\text { Served* }\end{array}$ & $\begin{array}{c}\text { Peak } \\
\text { Vehicles** }\end{array}$ & $\begin{array}{c}\text { Revenue Miles } \\
\text { of Service* }\end{array}$ & Ridership* \\
\hline Bay Town Trolley (Panama City) & 2006 & 85,458 & 8 & 420,927 & 309,232 \\
\hline Collier Area Transit (Naples) & 2005 & 317,788 & 13 & 870,424 & $1,052,536$ \\
\hline Jacksonville Transportation Authority & 2006 & 827,453 & 186 & $10,157,162$ & $11,125,128$ \\
\hline Lee County Transit (Fort Myers) & 2006 & 429,057 & 48 & $2,961,160$ & $2,891,968$ \\
\hline Palm Tran (Palm Beach County) & 2006 & 958,582 & 117 & $6,858,765$ & $9,310,413$ \\
\hline Pinellas Suncoast Transit Authority & 2007 & 881,705 & 165 & $8,609,598$ & $11,141,685$ \\
\hline StarMetro (Tallahassee) & 2005 & 162,310 & 56 & $1,749,960$ & $4,333,213$ \\
\hline VOTRAN (Volusia County) & 2006 & 468,670 & 48 & $2,636,071$ & $3,061,944$ \\
\hline
\end{tabular}

*From the 2006 National Transit Database.

Table 5-2 summarizes the frequency of use responses from these on-board surveys. For purposes of this analysis, frequent riders are considered to be those who indicate that they use transit four to seven days per week. Infrequent riders are considered to be those who ride three days per week or less. A common breakdown in the on-board surveys is the response category of one to three days per week. To further refine the analysis based on the degree of infrequency of use, results are shown for riders in the one-to-three days per week category as well as for those who indicated that they use transit less than one day per week (once or twice per month, less than once per month, etc.). 
Table 5-2: Frequency of Use - Florida On-Board Surveys

\begin{tabular}{|c|c|c|c|}
\hline Agency & $\begin{array}{c}\text { Ride 4-7 } \\
\text { Days/Week }\end{array}$ & $\begin{array}{c}\text { Ride 1-3 } \\
\text { Days /Week }\end{array}$ & $\begin{array}{c}\text { Ride }<1 \\
\text { Day/Week }\end{array}$ \\
\hline Bay Town Trolley (Panama City) & $56.1 \%$ & $31.9 \%$ & $12.0 \%$ \\
\hline Collier Area Transit (Naples) & $71.3 \%$ & $22.1 \%$ & $6.7 \%$ \\
\hline Jacksonville Transportation Authority & $82.4 \%$ & $15.9 \%$ & $1.7 \%$ \\
\hline Lee County Transit (Fort Myers) & $72.2 \%$ & $23.2 \%$ & $4.6 \%$ \\
\hline Palm Tran (Palm Beach County) & $80.2 \%$ & $14.8 \%$ & $5.0 \%$ \\
\hline Pinellas Suncoast Transit Authority & $78.1 \%$ & $21.9 \%$ & $n / a^{*}$ \\
\hline StarMetro (Tallahassee) & $73.1 \%$ & $21.8 \%$ & $5.1 \%$ \\
\hline VOTRAN (Volusia County) & $79.3 \%$ & $16.2 \%$ & $4.4 \%$ \\
\hline Average & $74.1 \%$ & $21.0 \%$ & $5.6 \%$ \\
\hline
\end{tabular}

NOTE: Percentages may not add to 100 due to rounding.

*The survey instrument in Pinellas did not have an option for riding less than once per week.

As Table 5-2 shows, on average, 26 percent of riders at these transit agencies can be characterized as infrequent users. This is similar to the share (23 percent) found in the on-board surveys analyzed in the previous section. The infrequency of use can be further categorized into those who ride one to three days per week (21 percent) and those who ride less than once per week (approximately 5 percent). It should be noted, however, that infrequent users tend to be underrepresented in on-board surveys, as they have a lesser chance of being sampled on any given day that a survey is being conducted.

Tables 5-3 and 5-4 examine the trip purposes among infrequent riders. Specifically, the focus is on work trips and school trips, with all other purposes aggregated into an "other" category not shown in the tables. In these on-board surveys, these other purposes typically included medical, visiting/social, recreation, shopping, and personal business. There also tends to be an "other" category on the survey instrument, where respondents can write in their trip purpose. The responses in this "other" category tend to be very small and, for purposes of this analysis, were not included.

According to Table 5-3, infrequent riders use transit for the work trip less often, on average, than the rider population as a whole. This is consistent with findings of the on-board surveys discussed in the previous section. Table 5-4 indicates that infrequent users tend to use transit for a school trip more often than the average rider. On some surveys, the school trip purpose is 
identified by a single response category, and on others it is identified in two categories, such as college/technical school or high school. In some cases, such as with StarMetro, colleges are identified separately by name. This is an interesting finding that may reflect the wide variations in college course schedules.

Table 5-3: Work Trip Purpose for Infrequent Users - Florida On-Board Surveys

\begin{tabular}{|l|r|r|r||}
\hline \multirow{2}{*}{ Agency } & \multirow{2}{*}{ All Riders } & \multicolumn{2}{c||}{ Infrequent Riders } \\
\cline { 3 - 4 } & & 1-3 Days/Wk & \multicolumn{1}{c||}{ 1 Day/Wk } \\
\hline Bay Town Trolley (Panama City) & $38.6 \%$ & $17.2 \%$ & $9.0 \%$ \\
\hline Collier Area Transit (Naples) & $53.1 \%$ & $20.9 \%$ & $21.4 \%$ \\
\hline Jacksonville Transportation Authority & $42.5 \%$ & $44.1 \%$ & $17.1 \%$ \\
\hline Lee County Transit (Fort Myers) & $52.4 \%$ & $33.0 \%$ & $26.6 \%$ \\
\hline Palm Tran (Palm Beach County) & $55.8 \%$ & $36.5 \%$ & $22.4 \%$ \\
\hline Pinellas Suncoast Transit Authority & $48.6 \%$ & $26.1 \%$ & $\mathrm{n} / \mathrm{a}$ \\
\hline StarMetro (Tallahassee) & $24.1 \%$ & $10.9 \%$ & $17.8 \%$ \\
\hline VOTRAN (Volusia County) & $52.3 \%$ & $23.9 \%$ & $20.7 \%$ \\
\hline \multicolumn{1}{|c|}{ Average } & $45.9 \%$ & $26.6 \%$ & $19.3 \%$ \\
\hline \hline
\end{tabular}

*The survey instrument in Pinellas did not have an option for riding less than once per week.

Table 5-4: School Trip Purpose for Infrequent Users - Florida On-Board Surveys

\begin{tabular}{|c|c|c|c|}
\hline \multirow{2}{*}{ Agency } & \multirow{2}{*}{ All Riders } & \multicolumn{2}{|c|}{ Infrequent Riders } \\
\hline & & 1-3 Days/Wk & $<1$ Day/Wk \\
\hline Bay Town Trolley (Panama City) & $12.9 \%$ & $13.8 \%$ & $0.0 \%$ \\
\hline Collier Area Transit (Naples) & $14.2 \%$ & $11.9 \%$ & $35.4 \%$ \\
\hline Jacksonville Transportation Authority* & $\mathrm{n} / \mathrm{a}$ & $\mathrm{n} / \mathrm{a}$ & $\mathrm{n} / \mathrm{a}$ \\
\hline Lee County Transit (Fort Myers) & $9.5 \%$ & $10.0 \%$ & $8.9 \%$ \\
\hline Palm Tran (Palm Beach County) & $18.4 \%$ & $15.3 \%$ & $14.3 \%$ \\
\hline Pinellas Suncoast Transit Authority & $6.1 \%$ & $5.7 \%$ & $\mathrm{n} / \mathrm{a}^{\star *}$ \\
\hline StarMetro (Tallahassee) & $53.2 \%$ & $56.2 \%$ & $54.6 \%$ \\
\hline VOTRAN (Volusia County) & $15.6 \%$ & $18.7 \%$ & $22.9 \%$ \\
\hline Average & $18.6 \%$ & $18.8 \%$ & $22.7 \%$ \\
\hline
\end{tabular}

*The survey instrument in Jacksonville did not have an option for school trip purpose.

**The survey instrument in Pinellas did not have an option for riding less than once per week. 
The primary reason for using transit is explored in Table 5-5. From this survey question, all response choices were categorized into one of four options: "I don't drive," "no car is available," "parking and/or traffic is too bad," and "transit is more economical and/or convenient.” For example, the responses of “I don't drive” and “no valid driver’s license” were aggregated into "I don't drive.” As another example, a response choice of "the bus is less stressful” was included in the convenience category. As with many other questions, respondents had the option of writing in an "other" reason. As the frequency of such responses is quite small, the "other" responses are not included.

Table 5-5: Reason for Riding for Infrequent Users - Florida On-Board Surveys

\begin{tabular}{|c|c|c|c|c|c|c|c|c|c|c|c|c|}
\hline \multirow[b]{2}{*}{ Agency } & \multicolumn{3}{|c|}{ I Don't Drive } & \multicolumn{3}{|c|}{ No Car is Available } & \multicolumn{3}{|c|}{$\begin{array}{l}\text { Parking/Traffic is } \\
\text { Too Difficult }\end{array}$} & \multicolumn{3}{|c|}{$\begin{array}{c}\text { Bus is More } \\
\text { Economical/Convenient }\end{array}$} \\
\hline & $\begin{array}{c}\text { All } \\
\text { Riders }\end{array}$ & $\begin{array}{c}1-3 \\
\text { Daysl } \\
\text { Wk }\end{array}$ & $\begin{array}{c}<1 \\
\text { Dayl } \\
\text { Wk }\end{array}$ & $\begin{array}{c}\text { All } \\
\text { Riders }\end{array}$ & $\begin{array}{c}1-3 \\
\text { Daysl } \\
\text { Wk }\end{array}$ & $\begin{array}{c}<1 \\
\text { Dayl } \\
\text { Wk }\end{array}$ & $\begin{array}{c}\text { All } \\
\text { Riders }\end{array}$ & $\begin{array}{c}1-3 \\
\text { Daysl } \\
\text { Wk }\end{array}$ & $\begin{array}{c}<1 \\
\text { Dayl } \\
\text { Wk }\end{array}$ & $\begin{array}{c}\text { All } \\
\text { Riders }\end{array}$ & $\begin{array}{c}1-3 \\
\text { Daysl } \\
\text { Wk }\end{array}$ & $\begin{array}{l}<1 \\
\text { Dayl } \\
\text { Wk }\end{array}$ \\
\hline $\begin{array}{l}\text { Bay Town Trolley } \\
\text { (Panama City) }\end{array}$ & $41.3 \%$ & $31.0 \%$ & $18.2 \%$ & $42.4 \%$ & $55.2 \%$ & $36.4 \%$ & $0.0 \%$ & $0.0 \%$ & $0.0 \%$ & $16.3 \%$ & $10.3 \%$ & $45.4 \%$ \\
\hline $\begin{array}{l}\text { Collier Area Transit } \\
\text { (Naples) }\end{array}$ & $52.1 \%$ & $50.0 \%$ & $42.6 \%$ & $23.1 \%$ & $25.6 \%$ & $34.4 \%$ & $2.2 \%$ & $1.7 \%$ & $3.3 \%$ & $19.0 \%$ & $20.6 \%$ & $11.5 \%$ \\
\hline $\begin{array}{l}\text { Jacksonville } \\
\text { Transportation } \\
\text { Authority }\end{array}$ & $20.1 \%$ & $13.8 \%$ & $11.4 \%$ & $42.2 \%$ & $40.8 \%$ & $42.9 \%$ & $5.1 \%$ & $6.6 \%$ & $2.9 \%$ & $27.9 \%$ & $35.1 \%$ & $22.9 \%$ \\
\hline $\begin{array}{l}\text { Lee County Transit } \\
\text { (Fort Myers) }\end{array}$ & $19.0 \%$ & $14.0 \%$ & $17.7 \%$ & $47.0 \%$ & $48.5 \%$ & $55.7 \%$ & $4.4 \%$ & $5.0 \%$ & $2.6 \%$ & $27.6 \%$ & $31.0 \%$ & $20.3 \%$ \\
\hline $\begin{array}{l}\text { Palm Tran } \\
\text { (Palm Beach County) }\end{array}$ & $34.2 \%$ & $35.2 \%$ & $26.8 \%$ & $39.2 \%$ & $38.0 \%$ & $45.2 \%$ & $4.3 \%$ & $3.3 \%$ & $5.7 \%$ & $18.6 \%$ & $19.2 \%$ & $14.6 \%$ \\
\hline $\begin{array}{l}\text { Pinellas Suncoast } \\
\text { Transit Authority* }\end{array}$ & $18.5 \%$ & $17.3 \%$ & $\mathrm{n} / \mathrm{a}$ & $48.1 \%$ & $48.0 \%$ & $\mathrm{n} / \mathrm{a}$ & $2.7 \%$ & $3.4 \%$ & $\mathrm{n} / \mathrm{a}$ & $26.3 \%$ & $24.7 \%$ & $\mathrm{n} / \mathrm{a}$ \\
\hline $\begin{array}{l}\text { StarMetro } \\
\text { (Tallahassee) }\end{array}$ & $29.8 \%$ & $23.7 \%$ & $28.5 \%$ & $40.8 \%$ & $37.9 \%$ & $44.4 \%$ & $16.1 \%$ & $17.6 \%$ & $9.3 \%$ & $13.3 \%$ & $18.0 \%$ & $8.6 \%$ \\
\hline $\begin{array}{l}\text { VOTRAN } \\
\text { (Volusia County) }\end{array}$ & $52.5 \%$ & $45.5 \%$ & $37.2 \%$ & $29.8 \%$ & $29.9 \%$ & $48.8 \%$ & $1.0 \%$ & $0.6 \%$ & $2.3 \%$ & $12.6 \%$ & $17.5 \%$ & $2.3 \%$ \\
\hline Average & $33.4 \%$ & $28.8 \%$ & $26.1 \%$ & $39.1 \%$ & $40.5 \%$ & $44.0 \%$ & $4.5 \%$ & $4.8 \%$ & $3.7 \%$ & $20.2 \%$ & $22.1 \%$ & $17.9 \%$ \\
\hline
\end{tabular}

NOTE: Percentages may not add to 100 due to rounding and the exclusion of the "other" category.

*The survey instrument in Pinellas did not have an option for riding less than once per week.

Table 5-5 above indicates that infrequent users' primary reasons for using transit are similar to the average of all riders. The most common reasons are that the respondent does not drive or does not have a car available for the trip. It can be hypothesized that less frequent users of transit have other options available for their travel. As shown in the table, compared to the average of all riders, fewer infrequent users cited "I don't drive” as the main reason for riding transit. However, when compared to the average of all riders, slightly more infrequent users indicated 
that no car was available for their surveyed trip. It could be that a car was not available for that particular surveyed trip, but a car is available at other times and/or for other trips.

In each of the surveys included in this analysis (except for Collier Area Transit), respondents were also asked how they would make the surveyed trip if not by transit. The most interesting finding in Table 5-6 is that, as hypothesized, infrequent riders are more likely than the average rider to drive as an alternative to taking transit for their surveyed trip. Specifically, the table shows that, while on average approximately 11 percent of all riders have the option to drive for the surveyed trip, nearly 14 percent of those who ride one to three days per week and nearly 16 percent of those who ride less than one day per week have the option to drive. Only slightly fewer infrequent riders than the rider population as a whole would not make their trip if transit was not available.

Table 5-6: Alternative to Transit for Infrequent Users - Florida On-Board Surveys

\begin{tabular}{|c|c|c|c|c|c|c|c|c|c|c|c|c|}
\hline \multirow[b]{2}{*}{ Agency } & \multicolumn{3}{|c|}{ Drive } & \multicolumn{3}{|c|}{ Ride With Someone } & \multicolumn{3}{|c|}{ Bike/Walk/Taxi } & \multicolumn{3}{|c|}{ Would Not Make Trip } \\
\hline & $\begin{array}{c}\text { All } \\
\text { Riders }\end{array}$ & $\begin{array}{c}1-3 \\
\text { Daysl } \\
\text { Wk }\end{array}$ & $\begin{array}{c}<1 \\
\text { Dayl } \\
\text { Wk }\end{array}$ & $\begin{array}{c}\text { All } \\
\text { Riders }\end{array}$ & $\begin{array}{c}1-3 \\
\text { Days/ } \\
\text { Wk }\end{array}$ & $\begin{array}{c}<1 \\
\text { Dayl } \\
\text { Wk }\end{array}$ & $\begin{array}{c}\text { All } \\
\text { Riders }\end{array}$ & $\begin{array}{c}1-3 \\
\text { DaysI } \\
\text { Wk }\end{array}$ & $\begin{array}{c}<1 \\
\text { Dayl } \\
\text { Wk }\end{array}$ & $\begin{array}{c}\text { All } \\
\text { Riders }\end{array}$ & $\begin{array}{c}1-3 \\
\text { DaysI } \\
\text { Wk }\end{array}$ & $\begin{array}{c}<1 \\
\text { Dayl } \\
\text { Wk }\end{array}$ \\
\hline $\begin{array}{l}\text { Bay Town Trolley } \\
\text { (Panama City) }\end{array}$ & $6.6 \%$ & $3.4 \%$ & $9.1 \%$ & $31.9 \%$ & $37.9 \%$ & $0.0 \%$ & $37.4 \%$ & $41.4 \%$ & $45.5 \%$ & $24.2 \%$ & $17.2 \%$ & $45.5 \%$ \\
\hline $\begin{array}{l}\text { Collier Area Transit } \\
\text { (Naples)* }^{\star}\end{array}$ & $\mathrm{n} / \mathrm{a}$ & $\mathrm{n} / \mathrm{a}$ & $\mathrm{n} / \mathrm{a}$ & $\mathrm{n} / \mathrm{a}$ & $\mathrm{n} / \mathrm{a}$ & $\mathrm{n} / \mathrm{a}$ & $\mathrm{n} / \mathrm{a}$ & $\mathrm{n} / \mathrm{a}$ & $\mathrm{n} / \mathrm{a}$ & $\mathrm{n} / \mathrm{a}$ & $\mathrm{n} / \mathrm{a}$ & $\mathrm{n} / \mathrm{a}$ \\
\hline $\begin{array}{l}\text { Jacksonville } \\
\text { Transportation } \\
\text { Authority }\end{array}$ & $14.8 \%$ & $19.5 \%$ & $26.5 \%$ & $36.2 \%$ & $37.8 \%$ & $32.4 \%$ & $31.7 \%$ & $24.3 \%$ & $20.6 \%$ & $17.2 \%$ & $16.2 \%$ & $8.8 \%$ \\
\hline $\begin{array}{l}\text { Lee County Transit } \\
\text { (Fort Myers) }\end{array}$ & $12.2 \%$ & $16.6 \%$ & $12.0 \%$ & $33.3 \%$ & $33.4 \%$ & $36.0 \%$ & $32.9 \%$ & $27.3 \%$ & $32.0 \%$ & $21.7 \%$ & $22.7 \%$ & $20.0 \%$ \\
\hline $\begin{array}{l}\text { Palm Tran } \\
\text { (Palm Beach County) }\end{array}$ & $10.0 \%$ & $12.4 \%$ & $11.4 \%$ & $33.1 \%$ & $32.2 \%$ & $37.3 \%$ & $40.5 \%$ & $38.6 \%$ & $34.2 \%$ & $16.4 \%$ & $16.8 \%$ & $17.1 \%$ \\
\hline $\begin{array}{l}\text { Pinellas Suncoast } \\
\text { Transit Authority**}\end{array}$ & $8.9 \%$ & $16.3 \%$ & $\mathrm{n} / \mathrm{a}$ & $25.8 \%$ & $26.1 \%$ & $\mathrm{n} / \mathrm{a}$ & $37.9 \%$ & $35.4 \%$ & $\mathrm{n} / \mathrm{a}$ & $27.4 \%$ & $22.2 \%$ & $\mathrm{n} / \mathrm{a}$ \\
\hline $\begin{array}{l}\text { StarMetro } \\
\text { (Tallahassee) }\end{array}$ & $13.2 \%$ & $16.1 \%$ & $15.8 \%$ & $36.1 \%$ & $35.9 \%$ & $44.7 \%$ & $39.3 \%$ & $37.0 \%$ & $29.6 \%$ & $10.2 \%$ & $11.0 \%$ & $9.9 \%$ \\
\hline $\begin{array}{l}\text { VOTRAN } \\
\text { (Volusia County) }\end{array}$ & $10.1 \%$ & $12.2 \%$ & $18.6 \%$ & $26.5 \%$ & $29.5 \%$ & $30.2 \%$ & $48.7 \%$ & $46.2 \%$ & $44.2 \%$ & $14.7 \%$ & $12.2 \%$ & $7.0 \%$ \\
\hline Average & $10.8 \%$ & $13.8 \%$ & $15.6 \%$ & $31.8 \%$ & $33.3 \%$ & $30.1 \%$ & $38.3 \%$ & $35.7 \%$ & $34.3 \%$ & $18.8 \%$ & $16.9 \%$ & $18.0 \%$ \\
\hline
\end{tabular}

NOTE: Percentages may not add to 100 due to rounding and the exclusion of the "other" category.

*The survey for Collier Area Transit did not include this question.

**The survey instrument in Pinellas did not have an option for riding less than once per week. 
Table 5-7 compares the length of transit use among the rider population as a whole and the two categories of infrequent users. Significantly more infrequent riders have been using the transit system for less than six months when compared to the average rider. For example, an average of 44 percent of those who indicated that they ride less than one day per week reported that they have been using the transit system for less than six months. Of all riders, on average, 26 percent have been using the system less than six months. The remaining data in this table indicate that infrequent riders have not been using transit as long as the average rider.

Table 5-7: Length of Transit Use for Infrequent Users - Florida On-Board Surveys

\begin{tabular}{|c|c|c|c|c|c|c|c|c|c|}
\hline \multirow[b]{2}{*}{ Agency } & \multicolumn{3}{|c|}{ Less Than 6 Months } & \multicolumn{3}{|c|}{6 Months - 2 Years } & \multicolumn{3}{|c|}{ Longer Than 2 Years } \\
\hline & $\begin{array}{c}\text { All } \\
\text { Riders }\end{array}$ & $\begin{array}{c}1-3 \\
\text { Daysl } \\
\text { Wk }\end{array}$ & $\begin{array}{c}<1 \\
\text { Dayl } \\
\text { Wk }\end{array}$ & $\begin{array}{c}\text { All } \\
\text { Riders }\end{array}$ & $\begin{array}{c}1-3 \\
\text { Daysl } \\
\text { Wk }\end{array}$ & $\begin{array}{l}<1 \\
\text { Dayl } \\
\text { Wk }\end{array}$ & $\begin{array}{c}\text { All } \\
\text { Riders }\end{array}$ & $\begin{array}{c}1-3 \\
\text { Daysl } \\
\text { Wk }\end{array}$ & $\begin{array}{c}<1 \\
\text { Dayl } \\
\text { Wk }\end{array}$ \\
\hline $\begin{array}{l}\text { Bay Town Trolley } \\
\text { (Panama City) }\end{array}$ & $42.9 \%$ & $46.4 \%$ & $45.5 \%$ & $30.8 \%$ & $39.3 \%$ & $9.1 \%$ & $26.4 \%$ & $14.3 \%$ & $45.5 \%$ \\
\hline $\begin{array}{l}\text { Collier Area Transit } \\
\text { (Naples)* }^{*}\end{array}$ & $\mathrm{n} / \mathrm{a}$ & $\mathrm{n} / \mathrm{a}$ & $\mathrm{n} / \mathrm{a}$ & $\mathrm{n} / \mathrm{a}$ & $\mathrm{n} / \mathrm{a}$ & $\mathrm{n} / \mathrm{a}$ & $\mathrm{n} / \mathrm{a}$ & $\mathrm{n} / \mathrm{a}$ & $\mathrm{n} / \mathrm{a}$ \\
\hline $\begin{array}{l}\text { Jacksonville Transportation } \\
\text { Authority }\end{array}$ & $19.5 \%$ & $28.4 \%$ & $65.6 \%$ & $28.6 \%$ & $30.0 \%$ & $25.0 \%$ & $51.8 \%$ & $41.6 \%$ & $9.4 \%$ \\
\hline $\begin{array}{l}\text { Lee County Transit } \\
\text { (Fort Myers) }\end{array}$ & $20.2 \%$ & $29.9 \%$ & $25.0 \%$ & $32.6 \%$ & $29.2 \%$ & $23.7 \%$ & $47.2 \%$ & $40.9 \%$ & $51.3 \%$ \\
\hline $\begin{array}{l}\text { Palm Tran } \\
\text { (Palm Beach County) }\end{array}$ & $18.8 \%$ & $24.6 \%$ & $33.1 \%$ & $34.4 \%$ & $28.2 \%$ & $26.9 \%$ & $46.9 \%$ & $47.2 \%$ & $40.0 \%$ \\
\hline $\begin{array}{l}\text { Pinellas Suncoast Transit } \\
\text { Authority* }\end{array}$ & $\mathrm{n} / \mathrm{a}$ & $\mathrm{n} / \mathrm{a}$ & $\mathrm{n} / \mathrm{a}$ & $\mathrm{n} / \mathrm{a}$ & $\mathrm{n} / \mathrm{a}$ & $\mathrm{n} / \mathrm{a}$ & $\mathrm{n} / \mathrm{a}$ & $\mathrm{n} / \mathrm{a}$ & $\mathrm{n} / \mathrm{a}$ \\
\hline StarMetro (Tallahassee) & $33.2 \%$ & $40.4 \%$ & $44.7 \%$ & $25.1 \%$ & $26.5 \%$ & $17.8 \%$ & $41.7 \%$ & $33.1 \%$ & $36.8 \%$ \\
\hline $\begin{array}{l}\text { VOTRAN } \\
\text { (Volusia County) }\end{array}$ & $23.2 \%$ & $26.9 \%$ & $50.0 \%$ & $25.9 \%$ & $19.9 \%$ & $19.0 \%$ & $50.9 \%$ & $53.2 \%$ & $31.0 \%$ \\
\hline Average & $26.3 \%$ & $32.8 \%$ & $44.0 \%$ & $29.6 \%$ & $28.8 \%$ & $20.2 \%$ & $44.2 \%$ & $38.4 \%$ & $35.7 \%$ \\
\hline
\end{tabular}

NOTE: Percentages may not add to 100 due to rounding.

*The survey instruments for Collier and Pinellas did not include this question.

The frequency of use responses were also cross-tabulated with certain demographic characteristics including age, gender, ethnicity, income, and vehicle availability. When compared to the average rider, there were virtually no differences in the infrequent rider with respect to age, gender, and ethnicity. Like the average rider, the average infrequent rider tends to be white, female, and between the ages of 25 and 49. However, some differences were evident among the characteristics of income and vehicle availability. 
Table 5-8 provides information on the annual household incomes of less frequent transit users as compared to the average user. While a majority of both all riders and infrequent riders are in households that earn less than $\$ 20,000$ annually, the percentage is somewhat lower for the least frequent riders (approximately 59 percent versus 65 percent). The remaining numbers in the table provide further evidence that the infrequent rider has, on average, higher income than the rider population as a whole. Approximately six percent of all riders have household incomes greater than $\$ 50,000$ annually. In contrast, nearly 8 percent of those who ride only one to three days per week have household incomes of more than \$50,000 annually, and this figure increases to more than 14 percent for the least frequent category of riders (those who ride less than one day per week).

Table 5-8: Annual Income of Infrequent Users - Florida On-Board Surveys

\begin{tabular}{|c|c|c|c|c|c|c|c|c|c|c|c|c|}
\hline \multirow[b]{2}{*}{ Agency } & \multicolumn{3}{|c|}{ Less Than $\$ 20,000$} & \multicolumn{3}{|c|}{$\$ 20,000$ to $\$ 29,999$} & \multicolumn{3}{|c|}{$\$ 30,000$ to $\$ 50,000$} & \multicolumn{3}{|c|}{ More Than $\$ 50,000$} \\
\hline & $\begin{array}{c}\text { All } \\
\text { Riders }\end{array}$ & $\begin{array}{c}1-3 \\
\text { Daysl } \\
\text { Wk }\end{array}$ & $\begin{array}{l}<1 \\
\text { Dayl } \\
\text { Wk }\end{array}$ & $\begin{array}{c}\text { All } \\
\text { Riders }\end{array}$ & $\begin{array}{c}1-3 \\
\text { Daysl } \\
\text { Wk }\end{array}$ & $\begin{array}{l}<1 \\
\text { Dayl } \\
\text { Wk }\end{array}$ & $\begin{array}{c}\text { All } \\
\text { Riders }\end{array}$ & $\begin{array}{c}1-3 \\
\text { Daysl } \\
\text { Wk }\end{array}$ & $\begin{array}{l}<1 \\
\text { Dayl } \\
\text { Wk }\end{array}$ & $\begin{array}{c}\text { All } \\
\text { Riders }\end{array}$ & $\begin{array}{c}1-3 \\
\text { Daysl } \\
\text { Wk }\end{array}$ & $\begin{array}{l}<1 \\
\text { Dayl } \\
\text { Wk }\end{array}$ \\
\hline $\begin{array}{l}\text { Bay Town Trolley } \\
\text { (Panama City) }\end{array}$ & $75.3 \%$ & $81.8 \%$ & $60.0 \%$ & $6.8 \%$ & $9.1 \%$ & $10.0 \%$ & $12.4 \%$ & $4.5 \%$ & $10.0 \%$ & $5.5 \%$ & $4.5 \%$ & $20.0 \%$ \\
\hline $\begin{array}{l}\text { Collier Area Transit } \\
\text { (Naples)* }^{\star}\end{array}$ & $\mathrm{n} / \mathrm{a}$ & $\mathrm{n} / \mathrm{a}$ & $\mathrm{n} / \mathrm{a}$ & $\mathrm{n} / \mathrm{a}$ & $\mathrm{n} / \mathrm{a}$ & $\mathrm{n} / \mathrm{a}$ & $\mathrm{n} / \mathrm{a}$ & $\mathrm{n} / \mathrm{a}$ & $\mathrm{n} / \mathrm{a}$ & $6.9 \%$ & $4.9 \%$ & $17.5 \%$ \\
\hline $\begin{array}{l}\text { Jacksonville } \\
\text { Transportation } \\
\text { Authority }\end{array}$ & $64.6 \%$ & $70.2 \%$ & $50.0 \%$ & $17.5 \%$ & $13.8 \%$ & $10.0 \%$ & $12.1 \%$ & $10.7 \%$ & $16.7 \%$ & $5.6 \%$ & $5.2 \%$ & $20.0 \%$ \\
\hline $\begin{array}{l}\text { Lee County Transit } \\
\text { (Fort Myers) }\end{array}$ & $62.4 \%$ & $61.4 \%$ & $51.4 \%$ & $19.2 \%$ & $18.7 \%$ & $16.7 \%$ & $12.6 \%$ & $12.7 \%$ & $15.2 \%$ & $5.8 \%$ & $7.3 \%$ & $16.7 \%$ \\
\hline $\begin{array}{l}\text { Palm Tran } \\
\text { (Palm Beach County) }\end{array}$ & $61.7 \%$ & $62.0 \%$ & $59.7 \%$ & $13.9 \%$ & $12.5 \%$ & $8.5 \%$ & $18.1 \%$ & $17.7 \%$ & $24.0 \%$ & $6.3 \%$ & $7.9 \%$ & $7.8 \%$ \\
\hline $\begin{array}{l}\text { Pinellas Suncoast } \\
\text { Transit Authority**}\end{array}$ & $49.5 \%$ & $42.7 \%$ & $\mathrm{n} / \mathrm{a}$ & $19.7 \%$ & $17.0 \%$ & $\mathrm{n} / \mathrm{a}$ & $15.0 \%$ & $15.7 \%$ & $\mathrm{n} / \mathrm{a}$ & $5.5 \%$ & $8.0 \%$ & $\mathrm{n} / \mathrm{a}$ \\
\hline $\begin{array}{l}\text { StarMetro } \\
\text { (Tallahassee) }\end{array}$ & $69.9 \%$ & $64.7 \%$ & $71.1 \%$ & $10.0 \%$ & $7.4 \%$ & $5.5 \%$ & $10.7 \%$ & $10.1 \%$ & $10.9 \%$ & $9.4 \%$ & $14.5 \%$ & $12.5 \%$ \\
\hline $\begin{array}{l}\text { VOTRAN } \\
\text { (Volusia County) }\end{array}$ & $69.2 \%$ & $66.9 \%$ & $59.4 \%$ & $15.7 \%$ & $17.4 \%$ & $12.5 \%$ & $10.1 \%$ & $8.3 \%$ & $21.9 \%$ & $5.0 \%$ & $7.4 \%$ & $6.3 \%$ \\
\hline Average & $64.7 \%$ & $64.3 \%$ & $58.6 \%$ & $14.7 \%$ & $13.7 \%$ & $10.5 \%$ & $13.0 \%$ & $11.4 \%$ & $16.5 \%$ & $6.3 \%$ & $7.5 \%$ & $14.4 \%$ \\
\hline
\end{tabular}

NOTE: Percentages may not add to 100 due to rounding and the exclusion of the "other" category.

*The survey for Collier Area Transit did not include this question.

**The survey instrument in Pinellas did not have an option for riding less than once per week.

It is clear from the information presented in Table 5-9 that less frequent users tend to have more household vehicles available. While 49 percent of all riders, on average, have no vehicles available, 43 percent of those riding only one to three days per week have no vehicles. Among the least frequent users, those indicating that they ride less than one day per week, only 32 
percent have no household vehicles. Fifteen percent of the least frequent users have three or more household vehicles as compared to an average of only eight percent among all riders.

These findings are not incongruent with the earlier findings that the most common reason for the infrequent rider to use transit is that no car is available for the trip. It may be that, while a car might not available to the rider for a particular surveyed trip, his or her household may have one or more cars that are available at other times.

Table 5-9: Vehicle Availability of Infrequent Users - Florida On-Board Surveys

\begin{tabular}{|c|c|c|c|c|c|c|c|c|c|c|c|c|}
\hline \multirow[b]{2}{*}{ Agency } & \multicolumn{3}{|c|}{ Zero Vehicles } & \multicolumn{3}{|c|}{ One vehicle } & \multicolumn{3}{|c|}{ Two Vehicles } & \multicolumn{3}{|c|}{ Three or More Vehicles } \\
\hline & $\begin{array}{c}\text { All } \\
\text { Riders }\end{array}$ & $\begin{array}{c}1-3 \\
\text { Daysl } \\
\text { Wk }\end{array}$ & $\begin{array}{c}<1 \\
\text { Dayl } \\
\text { Wk }\end{array}$ & $\begin{array}{c}\text { All } \\
\text { Riders }\end{array}$ & $\begin{array}{c}1-3 \\
\text { DaysI } \\
\text { Wk }\end{array}$ & $\begin{array}{c}<1 \\
\text { Dayl } \\
\text { Wk }\end{array}$ & $\begin{array}{c}\text { All } \\
\text { Riders }\end{array}$ & $\begin{array}{c}1-3 \\
\text { Daysl } \\
\text { Wk }\end{array}$ & $\begin{array}{c}<1 \\
\text { Dayl } \\
\text { Wk }\end{array}$ & $\begin{array}{c}\text { All } \\
\text { Riders }\end{array}$ & $\begin{array}{c}1-3 \\
\text { Daysl } \\
\text { Wk }\end{array}$ & $\begin{array}{c}<1 \\
\text { Dayl } \\
\text { Wk }\end{array}$ \\
\hline $\begin{array}{l}\text { Bay Town Trolley } \\
\text { (Panama City) }\end{array}$ & $65.1 \%$ & $64.0 \%$ & $36.4 \%$ & $25.3 \%$ & $28.0 \%$ & $36.4 \%$ & $4.8 \%$ & $4.0 \%$ & $9.1 \%$ & $4.8 \%$ & $4.0 \%$ & $18.2 \%$ \\
\hline $\begin{array}{l}\text { Collier Area Transit } \\
\text { (Naples)* }^{\star}\end{array}$ & $\mathrm{n} / \mathrm{a}$ & $\mathrm{n} / \mathrm{a}$ & $\mathrm{n} / \mathrm{a}$ & $\mathrm{n} / \mathrm{a}$ & $\mathrm{n} / \mathrm{a}$ & $\mathrm{n} / \mathrm{a}$ & $\mathrm{n} / \mathrm{a}$ & $\mathrm{n} / \mathrm{a}$ & $\mathrm{n} / \mathrm{a}$ & $\mathrm{n} / \mathrm{a}$ & $\mathrm{n} / \mathrm{a}$ & $\mathrm{n} / \mathrm{a}$ \\
\hline $\begin{array}{l}\text { Jacksonville } \\
\text { Transportation } \\
\text { Authority }\end{array}$ & $49.3 \%$ & $44.2 \%$ & $31.3 \%$ & $31.0 \%$ & $31.8 \%$ & $28.1 \%$ & $13.5 \%$ & $18.5 \%$ & $18.8 \%$ & $6.2 \%$ & $5.5 \%$ & $21.9 \%$ \\
\hline $\begin{array}{l}\text { Lee County Transit } \\
\text { (Fort Myers) }\end{array}$ & $45.2 \%$ & $37.4 \%$ & $33.3 \%$ & $32.4 \%$ & $37.1 \%$ & $40.0 \%$ & $14.4 \%$ & $15.4 \%$ & $16.0 \%$ & $8.0 \%$ & $10.0 \%$ & $10.6 \%$ \\
\hline $\begin{array}{l}\text { Palm Tran } \\
\text { (Palm Beach County) }\end{array}$ & $41.7 \%$ & $35.8 \%$ & $27.5 \%$ & $33.5 \%$ & $33.8 \%$ & $40.1 \%$ & $16.8 \%$ & $18.7 \%$ & $23.2 \%$ & $7.8 \%$ & $11.4 \%$ & $9.2 \%$ \\
\hline $\begin{array}{l}\text { Pinellas Suncoast } \\
\text { Transit Authority* }\end{array}$ & $\mathrm{n} / \mathrm{a}$ & $\mathrm{n} / \mathrm{a}$ & $\mathrm{n} / \mathrm{a}$ & $\mathrm{n} / \mathrm{a}$ & $\mathrm{n} / \mathrm{a}$ & $\mathrm{n} / \mathrm{a}$ & $\mathrm{n} / \mathrm{a}$ & $\mathrm{n} / \mathrm{a}$ & $\mathrm{n} / \mathrm{a}$ & $\mathrm{n} / \mathrm{a}$ & $\mathrm{n} / \mathrm{a}$ & $\mathrm{n} / \mathrm{a}$ \\
\hline $\begin{array}{l}\text { StarMetro } \\
\text { (Tallahassee) }\end{array}$ & $42.4 \%$ & $31.0 \%$ & $36.0 \%$ & $30.1 \%$ & $34.1 \%$ & $28.7 \%$ & $15.8 \%$ & $17.8 \%$ & $20.7 \%$ & $11.7 \%$ & $17.1 \%$ & $14.7 \%$ \\
\hline $\begin{array}{l}\text { VOTRAN } \\
\text { (Volusia County) }\end{array}$ & $51.3 \%$ & $45.3 \%$ & $30.0 \%$ & $29.0 \%$ & $35.8 \%$ & $37.5 \%$ & $12.9 \%$ & $11.5 \%$ & $17.5 \%$ & $6.8 \%$ & $7.4 \%$ & $15.0 \%$ \\
\hline Average & $49.2 \%$ & $42.9 \%$ & $32.4 \%$ & $30.2 \%$ & $33.4 \%$ & $35.1 \%$ & $13.0 \%$ & $14.3 \%$ & $17.5 \%$ & $7.6 \%$ & $9.3 \%$ & $14.9 \%$ \\
\hline
\end{tabular}

NOTE: Percentages may not add to 100 due to rounding and the exclusion of the "other" category.

*The survey instruments for Collier and Pinellas did not include this question.

Each of the surveys analyzed for this effort also included a customer satisfaction component. Specific to the purposes of this study, the relative importance of transit reliability (i.e., on-time performance) was examined with respect to the infrequent rider. Interestingly, compared with all riders, infrequent riders tend to be slightly more satisfied with the reliability of service. As shown in Table 5-10, 59 percent of all riders, on average, indicated that they are satisfied or very satisfied with the on-time performance of their transit system, compared with an average of about 64 percent for both categories of infrequent riders. While nearly 18 percent of all riders reported being dissatisfied or very dissatisfied with the level of reliability, only 11 percent of the 
least frequent riders indicated dissatisfaction. At least according to these data, transit reliability does not appear to be a major factor in the frequency of transit use.

Table 5-10: Satisfaction with Transit Reliability among Infrequent Users -
Florida On-Board Surveys

\begin{tabular}{|c|c|c|c|c|c|c|c|c|c|}
\hline \multirow[b]{2}{*}{ Agency } & \multicolumn{3}{|c|}{$\begin{array}{c}\text { Satisfied or Very } \\
\text { Satisfied }\end{array}$} & \multicolumn{3}{|c|}{ Neutral } & \multicolumn{3}{|c|}{$\begin{array}{c}\text { Dissatisfied or Very } \\
\text { Dissatisfied }\end{array}$} \\
\hline & $\begin{array}{c}\text { All } \\
\text { Riders }\end{array}$ & $\begin{array}{c}1-3 \\
\text { Daysl } \\
\text { Wk }\end{array}$ & $\begin{array}{c}<1 \\
\text { Dayl } \\
\text { Wk }\end{array}$ & $\begin{array}{c}\text { All } \\
\text { Riders }\end{array}$ & $\begin{array}{c}1-3 \\
\text { Daysl } \\
\text { Wk }\end{array}$ & $\begin{array}{c}<1 \\
\text { Dayl } \\
\text { Wk }\end{array}$ & $\begin{array}{c}\text { All } \\
\text { Riders }\end{array}$ & $\begin{array}{c}1-3 \\
\text { Daysl } \\
\text { Wk }\end{array}$ & $\begin{array}{c}<1 \\
\text { Dayl } \\
\text { Wk }\end{array}$ \\
\hline $\begin{array}{l}\text { Bay Town Trolley } \\
\text { (Panama City) }\end{array}$ & $70.0 \%$ & $72.0 \%$ & $72.7 \%$ & $20.0 \%$ & $12.0 \%$ & $27.3 \%$ & $10.0 \%$ & $16.0 \%$ & $0.0 \%$ \\
\hline $\begin{array}{l}\text { Collier Area Transit } \\
\text { (Naples) }\end{array}$ & $69.2 \%$ & $68.0 \%$ & $77.4 \%$ & $20.7 \%$ & $23.2 \%$ & $15.1 \%$ & $9.9 \%$ & $8.8 \%$ & $7.5 \%$ \\
\hline $\begin{array}{l}\text { Jacksonville Transportation } \\
\text { Authority }\end{array}$ & $41.1 \%$ & $51.1 \%$ & $62.5 \%$ & $26.0 \%$ & $29.4 \%$ & $33.3 \%$ & $33.0 \%$ & $19.5 \%$ & $4.2 \%$ \\
\hline $\begin{array}{l}\text { Lee County Transit } \\
\text { (Fort Myers) }\end{array}$ & $65.9 \%$ & $68.1 \%$ & $65.6 \%$ & $20.2 \%$ & $18.9 \%$ & $20.9 \%$ & $13.9 \%$ & $13.0 \%$ & $13.5 \%$ \\
\hline $\begin{array}{l}\text { Palm Tran } \\
\text { (Palm Beach County) }\end{array}$ & $55.0 \%$ & $59.9 \%$ & $65.9 \%$ & $20.6 \%$ & $19.2 \%$ & $20.2 \%$ & $24.3 \%$ & $20.9 \%$ & $14.0 \%$ \\
\hline $\begin{array}{l}\text { Pinellas Suncoast Transit } \\
\text { Authority* }\end{array}$ & $65.0 \%$ & $77.8 \%$ & $\mathrm{n} / \mathrm{a}$ & $24.5 \%$ & $16.0 \%$ & $\mathrm{n} / \mathrm{a}$ & $10.5 \%$ & $6.2 \%$ & $\mathrm{n} / \mathrm{a}$ \\
\hline StarMetro (Tallahassee) & $37.3 \%$ & $41.3 \%$ & $44.4 \%$ & $34.2 \%$ & $32.7 \%$ & $34.1 \%$ & $28.5 \%$ & $26.1 \%$ & $21.5 \%$ \\
\hline $\begin{array}{l}\text { VOTRAN } \\
\text { (Volusia County) }\end{array}$ & $70.3 \%$ & $71.6 \%$ & $57.9 \%$ & $17.9 \%$ & $14.2 \%$ & $26.3 \%$ & $11.8 \%$ & $14.2 \%$ & $15.8 \%$ \\
\hline Average & $59.2 \%$ & $63.7 \%$ & $63.8 \%$ & $23.0 \%$ & $20.7 \%$ & $25.3 \%$ & $17.7 \%$ & $15.6 \%$ & $10.9 \%$ \\
\hline
\end{tabular}

NOTE: Percentages may not add to 100 due to rounding.

*The survey instrument in Pinellas did not have an option for riding less than once per week.

After asking respondents to rate various aspects of customer satisfaction, including reliability, the survey instruments directed them to list their top three areas for transit service improvements from the given list. As seen in Table 5-11, on average, four percent of infrequent riders indicated that reliability should be a first priority for improvements, compared with 10 percent of all riders. For reliability as a second or third priority, results were more similar between the averages of the infrequent riders and all riders. Again, these data do not appear to indicate that transit reliability is a significant factor in the frequency of transit use. 
Table 5-11: Relative Importance of Transit Reliability Among Infrequent Users Florida On-Board Surveys

\begin{tabular}{|c|c|c|c|c|c|c|c|c|c|}
\hline \multirow[b]{2}{*}{ Agency } & \multicolumn{3}{|c|}{$\begin{array}{l}\text { First Priority for } \\
\text { Improvement }\end{array}$} & \multicolumn{3}{|c|}{$\begin{array}{l}\text { Second Priority for } \\
\text { Improvement }\end{array}$} & \multicolumn{3}{|c|}{$\begin{array}{l}\text { Third Priority for } \\
\text { Improvement }\end{array}$} \\
\hline & $\begin{array}{c}\text { All } \\
\text { Riders }\end{array}$ & $\begin{array}{c}1-3 \\
\text { Daysl } \\
\text { Wk }\end{array}$ & $\begin{array}{c}<1 \\
\text { Dayl } \\
\text { Wk }\end{array}$ & $\begin{array}{c}\text { All } \\
\text { Riders }\end{array}$ & $\begin{array}{c}1-3 \\
\text { Daysl } \\
\text { Wk }\end{array}$ & $\begin{array}{c}<1 \\
\text { Dayl } \\
\text { Wk }\end{array}$ & $\begin{array}{c}\text { All } \\
\text { Riders }\end{array}$ & $\begin{array}{c}\text { 1-3 } \\
\text { Days/ } \\
\text { Wk }\end{array}$ & $\begin{array}{c}<1 \\
\text { Dayl } \\
\text { Wk }\end{array}$ \\
\hline $\begin{array}{l}\text { Bay Town Trolley } \\
\text { (Panama City) }\end{array}$ & $1.1 \%$ & $3.4 \%$ & $0.0 \%$ & $2.1 \%$ & $3.4 \%$ & $0.0 \%$ & $3.2 \%$ & $3.4 \%$ & $0.0 \%$ \\
\hline $\begin{array}{l}\text { Collier Area Transit } \\
\text { (Naples) }\end{array}$ & $13.0 \%$ & $1.2 \%$ & $6.2 \%$ & $\mathrm{n} / \mathrm{a}$ & $5.2 \%$ & $3.1 \%$ & $\mathrm{n} / \mathrm{a}$ & $2.0 \%$ & $1.5 \%$ \\
\hline $\begin{array}{l}\text { Jacksonville Transportation } \\
\text { Authority }\end{array}$ & $8.3 \%$ & $5.9 \%$ & $0.0 \%$ & $7.1 \%$ & $5.6 \%$ & $11.4 \%$ & $4.4 \%$ & $3.6 \%$ & $0.0 \%$ \\
\hline $\begin{array}{l}\text { Lee County Transit } \\
\text { (Fort Myers) }\end{array}$ & $2.1 \%$ & $1.0 \%$ & $1.2 \%$ & $2.7 \%$ & $2.9 \%$ & $3.8 \%$ & $2.0 \%$ & $1.7 \%$ & $1.2 \%$ \\
\hline $\begin{array}{l}\text { Palm Tran } \\
\text { (Palm Beach County) }\end{array}$ & $6.4 \%$ & $3.2 \%$ & $0.6 \%$ & $7.8 \%$ & $7.0 \%$ & $3.7 \%$ & $6.1 \%$ & $3.4 \%$ & $3.7 \%$ \\
\hline $\begin{array}{l}\text { Pinellas Suncoast Transit } \\
\text { Authority* }\end{array}$ & $\mathrm{n} / \mathrm{a}$ & $\mathrm{n} / \mathrm{a}$ & $\mathrm{n} / \mathrm{a}$ & $\mathrm{n} / \mathrm{a}$ & $\mathrm{n} / \mathrm{a}$ & $\mathrm{n} / \mathrm{a}$ & $\mathrm{n} / \mathrm{a}$ & $\mathrm{n} / \mathrm{a}$ & $\mathrm{n} / \mathrm{a}$ \\
\hline StarMetro (Tallahassee) & $37.3 \%$ & $8.7 \%$ & $9.7 \%$ & $\mathrm{n} / \mathrm{a}$ & $12.2 \%$ & $5.2 \%$ & $\mathrm{n} / \mathrm{a}$ & $5.1 \%$ & $3.9 \%$ \\
\hline $\begin{array}{l}\text { VOTRAN } \\
\text { (Volusia County) }\end{array}$ & $4.7 \%$ & $3.8 \%$ & $11.4 \%$ & $5.3 \%$ & $7.7 \%$ & $4.5 \%$ & $3.8 \%$ & $3.8 \%$ & $6.8 \%$ \\
\hline Average & $10.4 \%$ & $3.9 \%$ & $4.2 \%$ & $5.0 \%$ & $6.3 \%$ & $4.5 \%$ & $3.9 \%$ & $3.3 \%$ & $2.5 \%$ \\
\hline
\end{tabular}

NOTE: Percentages may not add to 100 due to rounding.

*The survey instrument for Pinellas did not include this question.

A basic profile of the infrequent rider emerges from the data and analysis presented above. In general, approximately 26 percent of riders can be characterized as infrequent users (riding three days per week or less). The least frequent riders, those who ride less than one day per week, comprise approximately five percent of all riders, on average. Based on the eight on-board surveys included in this section, when compared to the average rider, the infrequent rider:

- Makes fewer work trips;

- Is more likely to drive if transit is not available;

- Has higher household income; and

- Has more household vehicles available. 


\section{APTA Efforts}

The results above can be supplemented with the results of two APTA efforts. The first is the Transit Performance Monitoring System (TPMS). As discussed previously in Chapter 2, The TPMS was designed to collect data on transit customers via on-board surveys. The project was sponsored jointly by the Federal Transit Administration (FTA) and the American Public Transportation Association (APTA) and aimed to develop an approach that local transit agencies could use to evaluate performance and identify the benefits of their transit services. The TPMS project was conducted in three phases.

From the first two phases, it was found that, based on the averages of participating transit agencies, slightly more than 16 percent of respondents use transit one to three days per week. An additional seven percent use transit less frequently, at one or two times per month. Combining the two categories results in 23 percent of riders being categorized as infrequent users, as defined in this Chapter. This result is identical to the finding from the analysis of the non-Florida on-board surveys and very similar to the finding from the analysis of the Florida onboard surveys (26 percent).

In the third phase of the TPMS project, frequency of use was categorized in a slightly different manner. Approximately 16 percent of riders use transit three or four days per week, approximately 9 percent use transit one or two days per week, and approximately 6 percent use transit one or two days per month. The total of these three categories is 31 percent, which is congruent with the above results considering it includes those who ride four days per week, as well.

In addition, the third phase of the TPMS project further investigated transit usage by infrequent riders. The project defined infrequent riders as those riding less than five days per week. Of the participating systems, it was found that these infrequent riders account for only 31 percent of all transit trips. However, it was determined that the infrequent riders comprise 67 percent of all persons using transit. As such, it is suggested that the experience of these riders could have a significant impact on the overall perception of a transit agency's services.

A second APTA effort, A Profile of Public Transportation Passenger Demographics and Travel Characteristics Reported in On-Board Surveys, compiled data from 150 on-board surveys conducted by public transportation agencies from 2000 through 2005. As discussed in Chapter 2 , the surveys summarized results based on more than 496,000 sampled transit riders from 
systems that carry more than 60 percent of all transit trips in the United States. Similar results to what has been presented earlier in this Chapter were reported: approximately 20 percent ride one to three days per week and approximately 6 percent ride less than one day per week. The total is 26 percent, which is nearly identical to the shares of infrequent riders established in the previous analyses in this Chapter.

\section{Characteristics Revealed by Household Travel Surveys}

This section includes an analysis of the Puget Sound Transportation Panel (PSTP) data sets discussed previously and in detail in Chapter 2. In addition, data from a recent household travel survey in Pinellas County, Florida are analyzed.

\section{Puget Sound Transportation Panel}

According to documentation on the PSTP, it was the first general-purpose travel panel survey conducted in an urban area of the United States. It originated in 1989 by the entity now known as the Puget Sound Regional Council. The information acquired from the panel survey results assists the Puget Sound Regional Council in long-range transportation planning and analysis for decisions such as highway and road construction, transit development, and policies for carpooling and parking.

The panel comprises approximately 1,700 households across the four-county Puget Sound region (King, Kitsap, Pierce, and Snohomish Counties), and specifically includes households that contain at least one member who regularly uses transit and households with at least one member who carpools regularly. Other households with members who drive alone for most of their trips are also included. The household members recorded all of their trip activity for a two-day period in each wave. In addition, a sample of the household members was asked to complete a separate survey on their attitudes and perceptions of various modes of transportation.

The first wave of the PSTP was conducted in 1989, and was followed by the first attitude survey in early 1990. The second wave occurred later in 1990 and was again followed by an attitude survey in 1991. Successive waves took place in 1992, 1993, 1994, 1996, 1997, 1999, 2000, and 2002. Attitude surveys were administered along with the 1990, 1991, 1993, 1996, 1997, 1999, 2000, and 2002 waves. 
The PSTP began with 1,712 participating households in 1989 and was maintained at between 1,700 and 1,900 over the 10 waves. For each wave, approximately 20 percent of the households needed to be replaced, mainly due to households relocating.

Table 5-12 presents the share of those using the single-occupant vehicle (SOV), transit, or a combination of a car and transit as the primary work mode. On average, over the 10 survey waves, 67 percent of PSTP participants reported the SOV as their primary work mode. More than eight percent of PSTP participants used transit as the primary work mode and an additional four percent used a combination of a car and bus.

Table 5-12: Primary Work Mode - Puget Sound Transportation Panel

\begin{tabular}{|c|c|c|c|c|c|c|c|c|c|c|c|}
\hline & $\begin{array}{c}\text { Wave } 1 \\
\text { (1989) }\end{array}$ & $\begin{array}{c}\text { Wave } 2 \\
(1990)\end{array}$ & $\begin{array}{c}\text { Wave } 3 \\
\text { (1992) }\end{array}$ & $\begin{array}{c}\text { Wave } 4 \\
\text { (1993) }\end{array}$ & $\begin{array}{c}\text { Wave } 5 \\
\text { (1994) }\end{array}$ & $\begin{array}{c}\text { Wave } 6 \\
\text { (1996) }\end{array}$ & $\begin{array}{c}\text { Wave } 7 \\
\text { (1997) }\end{array}$ & $\begin{array}{c}\text { Wave } 8 \\
\text { (1999) }\end{array}$ & $\begin{array}{c}\text { Wave } 9 \\
(2000)\end{array}$ & $\begin{array}{c}\text { Wave } \\
10 \\
(2002)\end{array}$ & Avg. \\
\hline SOV & $69.0 \%$ & $68.9 \%$ & $62.4 \%$ & $68.1 \%$ & $69.4 \%$ & $68.7 \%$ & $67.3 \%$ & $66.0 \%$ & $63.3 \%$ & $67.0 \%$ & $67.0 \%$ \\
\hline Transit & $13.2 \%$ & $10.5 \%$ & $4.7 \%$ & $6.3 \%$ & $6.7 \%$ & $8.1 \%$ & $7.5 \%$ & $9.4 \%$ & $10.0 \%$ & $7.1 \%$ & $8.4 \%$ \\
\hline Car/Bus Combination & $4.5 \%$ & $5.0 \%$ & $3.1 \%$ & $4.6 \%$ & $3.9 \%$ & $4.8 \%$ & $4.4 \%$ & $3.2 \%$ & $0.9 \%$ & $2.2 \%$ & $3.7 \%$ \\
\hline Carpool & $12.2 \%$ & $12.0 \%$ & $20.4 \%$ & $13.5 \%$ & $12.8 \%$ & $9.4 \%$ & $14.1 \%$ & $14.6 \%$ & $15.9 \%$ & $12.1 \%$ & $13.7 \%$ \\
\hline
\end{tabular}

NOTE: Percentages do not add to 100 due to rounding and the exclusion of other modes/responses (walk/bike, ferry, other, refused, work at home).

Table 5-13 provides some additional information about those who use the SOV as the primary mode to work. Over the 10 waves, an average of four percent of those who use an SOV as the primary work mode had used the bus at least one time in the previous six months (interestingly, this percentage was particularly high in the sixth wave, at slightly more than 12 percent). For more than 36 percent of the SOV users, their car is required at work and, for nearly 21 percent, their car is required to transport children. For those using a combination of a car and bus, approximately 17 percent indicated that the car was required for transporting children. It should be noted that the relevant questions regarding this mode combination were worded differently enough in the first, eighth, and ninth waves so as not be comparable with the other waves. 


\section{Table 5-13: Additional Characteristics of the SOV User- Puget Sound Transportation Panel}

\begin{tabular}{|l|r|r|r|r|r|r|r|r|r|r|r|}
\hline \hline & $\begin{array}{c}\text { Wave 1 } \\
\mathbf{( 1 9 8 9 )}\end{array}$ & $\begin{array}{c}\text { Wave 2 } \\
\text { (1990) }\end{array}$ & $\begin{array}{c}\text { Wave 3 } \\
\mathbf{( 1 9 9 2 )}\end{array}$ & $\begin{array}{c}\text { Wave 4 } \\
\text { (1993) }\end{array}$ & $\begin{array}{c}\text { Wave 5 } \\
\text { (1994) }\end{array}$ & $\begin{array}{c}\text { Wave 6 } \\
\text { (1996) }\end{array}$ & $\begin{array}{c}\text { Wave 7 } \\
\text { (1997) }\end{array}$ & $\begin{array}{c}\text { Wave 8 } \\
\text { (1999) }\end{array}$ & $\begin{array}{c}\text { Wave 9 } \\
\text { (2000) }\end{array}$ & $\begin{array}{c}\text { Wave } \\
\text { (2002) }\end{array}$ & Avg. \\
\hline $\begin{array}{l}\text { Used the Bus in the } \\
\text { Past 6 Months }\end{array}$ & $2.9 \%$ & $2.2 \%$ & $5.3 \%$ & $4.0 \%$ & $3.0 \%$ & $12.3 \%$ & $2.0 \%$ & $2.2 \%$ & $2.8 \%$ & $2.4 \%$ & $3.9 \%$ \\
\hline $\begin{array}{l}\text { Car is Required at } \\
\text { Work }\end{array}$ & $39.7 \%$ & $38.6 \%$ & $32.6 \%$ & $35.9 \%$ & $36.5 \%$ & $37.9 \%$ & $35.7 \%$ & $37.0 \%$ & $39.3 \%$ & $30.8 \%$ & $36.4 \%$ \\
\hline $\begin{array}{l}\text { Car is Required for } \\
\text { Children - SOV }\end{array}$ & $18.8 \%$ & $20.5 \%$ & $18.9 \%$ & $20.2 \%$ & $22.6 \%$ & $22.6 \%$ & $19.9 \%$ & $21.8 \%$ & $20.8 \%$ & $19.9 \%$ & $20.6 \%$ \\
\hline $\begin{array}{l}\text { Car is Required for } \\
\text { Children - Car/Bus }\end{array}$ & $\mathrm{n} / \mathrm{a}$ & $21.7 \%$ & $15.7 \%$ & $18.6 \%$ & $19.7 \%$ & $18.3 \%$ & $9.8 \%$ & $\mathrm{n} / \mathrm{a}$ & $\mathrm{n} / \mathrm{a}$ & $11.9 \%$ & $16.5 \%$ \\
\hline
\end{tabular}

The PSTP survey instruments asked participants to indicate their frequency of bus usage by reporting the number of times (not days) per week they ride. Table 5-14 summarizes these results over the 10 survey waves for those using transit as their primary work mode (transit alone and in combination with a car). As the table indicates, the share of transit only users riding transit one to six times per week averaged nearly 19 percent over the 10 waves. For those using the car/bus combination, the average share of those riding the bus six times per week or less was approximately double that of those who solely use transit, at nearly 38 percent. It is reasonable that those who use the car/bus combination as a primary mode may, at times, require the use of their cars for other reasons leading to an overall lesser frequency of their transit use. To determine an average share of infrequent riders comparable to that reported in the findings of onboard surveys earlier in this chapter, the transit mode and car/bus mode can be combined to represent all transit users. Thus, the average of the one-to-six times per week category for both modes in Table 5-14 (18.8 percent and 37.6 percent, respectively) is approximately 28 percent, which is close to the shares of infrequent riders found in the on-board survey analysis (23 percent for a selection of surveys from across the U.S. and 26 percent for a selection of Florida surveys). 
Table 5-14: Frequency of Bus Use per Week- Puget Sound Transportation Panel

\begin{tabular}{|c|c|c|c|c|c|c|c|c|c|c|c|}
\hline & $\begin{array}{c}\text { Wave } 1 \\
\text { (1989) }\end{array}$ & $\begin{array}{c}\text { Wave } 2 \\
\text { (1990) }\end{array}$ & $\begin{array}{c}\text { Wave } 3 \\
\text { (1992) }\end{array}$ & $\begin{array}{c}\text { Wave } 4 \\
\text { (1993) }\end{array}$ & $\begin{array}{c}\text { Wave } 5 \\
\text { (1994) }\end{array}$ & $\begin{array}{c}\text { Wave } 6 \\
\text { (1996) }\end{array}$ & $\begin{array}{c}\text { Wave } 7 \\
\text { (1997) }\end{array}$ & $\begin{array}{c}\text { Wave } 8 \\
\text { (1999) }\end{array}$ & $\begin{array}{c}\text { Wave } 9 \\
(2000)\end{array}$ & $\begin{array}{c}\text { Wave } \\
10 \\
(2002)\end{array}$ & Avg. \\
\hline \multicolumn{12}{|c|}{ Primary Work Mode Reported as Transit } \\
\hline 1-6 Times per Week & $23.4 \%$ & $24.2 \%$ & $12.4 \%$ & $12.3 \%$ & $12.8 \%$ & $\mathrm{n} / \mathrm{a}$ & $\mathrm{n} / \mathrm{a}$ & $20.5 \%$ & $29.3 \%$ & $15.9 \%$ & $18.8 \%$ \\
\hline 7+ Times per Week & $76.6 \%$ & $75.8 \%$ & $87.6 \%$ & $87.7 \%$ & $87.2 \%$ & $\mathrm{n} / \mathrm{a}$ & $\mathrm{n} / \mathrm{a}$ & $79.5 \%$ & $70.7 \%$ & $84.1 \%$ & $81.2 \%$ \\
\hline \multicolumn{12}{|c|}{ Primary Work Mode Reported as Car/Bus Combination } \\
\hline $1-6$ Times per Week & $44.6 \%$ & $49.6 \%$ & $36.7 \%$ & $38.2 \%$ & $28.4 \%$ & $\mathrm{n} / \mathrm{a}$ & $\mathrm{n} / \mathrm{a}$ & $45.1 \%$ & $37.0 \%$ & $21.4 \%$ & $37.6 \%$ \\
\hline 7+ Times per Week & $55.4 \%$ & $50.4 \%$ & $63.3 \%$ & $61.8 \%$ & $71.6 \%$ & $\mathrm{n} / \mathrm{a}$ & $\mathrm{n} / \mathrm{a}$ & $54.9 \%$ & $63.0 \%$ & $78.6 \%$ & $62.4 \%$ \\
\hline
\end{tabular}

The breakdown in the number of times per week using the bus as shown in Table 5-14 above is used to define an infrequent user for purposes of this study. Use of the bus six times per week can translate to one round trip for three days in a week. Thus, this definition of one to six times per week for an infrequent user is equivalent to the definition used in the earlier section detailing on-board survey results of an infrequent user riding three days per week or less. For the remainder of the analysis in this section, an infrequent user is defined as one who rides transit one to six times per week. It should be noted that information on the frequency of transit use was not available (in this form) in the sixth and seventh waves of the survey.

To understand some additional characteristics of infrequent transit users from the PSTP, frequency of use was cross-tabulated with several household-level variables. Three of those are discussed here: lifecycle, household income, and the number of household vehicles. The data contained in Table 5-15 were obtained through merging variables from different data sets in the PSTP. For these variables, this was accomplished only for the three most recent waves of the survey.

Table 5-15 indicates that, of transit users, the lifecycle groups riding the least are households with children under 18 (32 percent) and households with two adults age 35 to 64 and no children (23 percent). Also, the highest income groups tend use transit the least. Over the three waves shown in the table, an average of 40 percent of those with incomes greater than $\$ 55,000$ annually ride transit three days per week or less. Still, an average of 16 percent have incomes of less than $\$ 25,000$ annually. This low-income group tends to comprise the largest income category of all transit users, according to on-board and other survey data. Finally, while most transit rider 
populations as a whole are characterized by those with no household vehicles available, the segment of infrequent riders tends to have more vehicles available. As shown in Table 5-15, a majority have two or more vehicles available and 24 percent have three or more. Only 11 percent have no vehicles available.

Table 5-15: Select Household Characteristics of the Infrequent Transit UserPuget Sound Transportation Panel

\begin{tabular}{|c|c|c|c|c|}
\hline & $\begin{array}{c}\text { Wave } 8 \\
\text { (1999) }\end{array}$ & $\begin{array}{c}\text { Wave } 9 \\
(2000)\end{array}$ & $\begin{array}{c}\text { Wave } 10 \\
(2002)\end{array}$ & Average \\
\hline \multicolumn{5}{|c|}{ Lifecycle } \\
\hline Children < Age 18 & $37.5 \%$ & $24.5 \%$ & $33.1 \%$ & $31.7 \%$ \\
\hline 1 Adult $<$ Age 35 & $1.7 \%$ & $3.8 \%$ & $1.7 \%$ & $2.4 \%$ \\
\hline 1 Adult Age 35-64 & $5.1 \%$ & $18.1 \%$ & $8.4 \%$ & $10.5 \%$ \\
\hline 1 Adult Age 65+ & $5.8 \%$ & $13.9 \%$ & $7.7 \%$ & $9.1 \%$ \\
\hline $2+$ Adults $<$ Age 35 & $6.3 \%$ & $4.6 \%$ & $3.8 \%$ & $4.9 \%$ \\
\hline 2+ Adults Age 35-64 & $24.8 \%$ & $21.1 \%$ & $24.4 \%$ & $23.4 \%$ \\
\hline 2+ Adults Age 65+ & $18.7 \%$ & $13.5 \%$ & $20.9 \%$ & $17.7 \%$ \\
\hline \multicolumn{5}{|c|}{ Annual Household Income } \\
\hline$<=\$ 25,000$ & $14.8 \%$ & $22.4 \%$ & $10.8 \%$ & $16.0 \%$ \\
\hline$\$ 25,000-\$ 35,000$ & $7.5 \%$ & $8.4 \%$ & $6.3 \%$ & $7.4 \%$ \\
\hline$\$ 35,000-\$ 45,000$ & $17.8 \%$ & $14.3 \%$ & $10.8 \%$ & $14.3 \%$ \\
\hline$\$ 45,000-\$ 55,000$ & $10.9 \%$ & $5.9 \%$ & $10.8 \%$ & $9.2 \%$ \\
\hline$\$ 55,000-\$ 75,000$ & $19.2 \%$ & $15.6 \%$ & $14.2 \%$ & $16.4 \%$ \\
\hline$>\$ 75,000$ & $23.4 \%$ & $19.0 \%$ & $30.2 \%$ & $24.2 \%$ \\
\hline \multicolumn{5}{|c|}{ Number of Household Vehicles } \\
\hline Zero & $8.8 \%$ & $13.1 \%$ & $9.7 \%$ & $10.5 \%$ \\
\hline One & $29.4 \%$ & $36.7 \%$ & $21.2 \%$ & $29.1 \%$ \\
\hline Two & $37.5 \%$ & $31.2 \%$ & $38.5 \%$ & $35.7 \%$ \\
\hline Three or More & $24.3 \%$ & $18.6 \%$ & $29.9 \%$ & $24.3 \%$ \\
\hline
\end{tabular}


As discussed previously, a series of attitude surveys was conducted as part of the Puget Sound Transportation Panel. The results of these surveys provide insight into participants' opinions and perceptions of various characteristics and modes of travel. The first four attitude surveys (conducted in 1990, 1991, 1993, and 1996), were different in structure than the later surveys (conducted in 1997, 1999, 2000, and 2002). Thus, the two groups of surveys are analyzed separately.

Relevant results from the earlier attitude surveys are presented first. Cross-tabulations of frequency of transit use with select questions or statements from the attitude surveys were used to compile the information that follows. To accomplish this, the attitude survey data sets were merged with data sets containing variables relating to an individual person's travel. A unique person identifier number was contained (or was easily computed using other identifiers consistent among the data sets) in the data sets being merged, to ensure the information among the data sets could be matched with the correct individual responses. However, because information on the frequency of transit use was not included in the 1996 survey wave, the numbers shown in Tables 5-16 through 5-18 represent only the 1990, 1991, and 1993 surveys.

In these early attitude surveys, participants were provided with a list of several travel mode characteristics and were asked to rate them in importance in deciding how to get to work or school (i.e., how important they are in mode choice). Because it is surmised that infrequent transit riders tend to have other transportation options, it was expected that some of the importance ratings would differ between the infrequent and more frequent riders. However, Table 5-16 indicates that, on average, the differences are not that significant. When looking at differences among the individual survey years, it is important to remember that approximately 20 percent of the panel participants were replaced for each wave of the survey, mainly due to household relocation.

Table 5-16 reports how both infrequent and frequent transit riders responded to a series of select travel mode characteristics. Specifically, the percentages shown represent the share of riders who rated a given characteristic as a 6 or 7 on a scale of 1 to 7 , where 1 represents "not at all important" and 7 represents "extremely important." The first characteristic shown in the table, "ability to arrive on time," is quite relevant to the purposes of this project, and was also the highest rated characteristics, in terms of importance, among the others listed. On average, 84 percent of infrequent riders rated the ability to arrive on time as extremely important in the mode choice decision. 
The second-highest rated attribute in Table 5-16 deals with personal safety. More than 74 percent of infrequent riders rated "freedom from threats to personal safety" as extremely important in making a mode choice.

A majority of infrequent riders rated each of the characteristics listed in Table 5-16 as extremely important, with the exception of two: ability to change vehicles (48 percent) and short travel time (46 percent). An item such as "parking availability" would likely be more important to infrequent users because they are more likely to have a car available for a given trip, and this is reflected in the results (54 percent among infrequent riders; 49 percent among more frequent riders).

The next section of the attitude surveys asked respondents to rate the performance of the singleoccupant vehicle (SOV), transit, and carpooling with respect to the same attributes from the importance ratings section. For this study, the focus was on the performance of only the SOV and transit modes. Table 5-17 presents the share of infrequent riders rating the performance of these modes highly with respect to the given attributes.

As would be expected, Table 5-17 shows that the SOV is rated significantly better than the transit mode for several of the attributes, such as the ability to travel without changing vehicles, having a short travel time, a short wait time, and the flexibility to change plans. Also, it is reasonable that transit outperforms the SOV when dealing with traffic congestion and stress are considered.

In the importance ratings, the characteristic of "freedom from threats to personal safety" was rated very highly by infrequent transit riders. Table 5-17 indicates that, in the performance ratings section, 44 percent of the infrequent transit riders rated the SOV's performance in this attribute "extremely well.” Only 17 percent of infrequent riders rated transit's performance in this area as "extremely well." The perception of personal safety on transit may impact the frequency with which one chooses to ride.

Regarding the ability to arrive on time, Table $5-17$ shows that 54 percent of infrequent transit users rated the SOV, on average, as performing extremely well in this area. As for transit, 26 percent of infrequent riders rated its performance extremely well. An additional 52 percent of infrequent riders rated on-time performance of transit as a 5 or 6 on the scale of 1 to 7 (not shown in the table). This indicates that approximately 78 of infrequent riders rate the on-time performance of transit better than "neutral," according to these results. 
Table 5-16: Importance Ratings for Deciding Travel Mode: Share of Riders Rating Characteristics as "Extremely Important"* Puget Sound Transportation Panel Attitude Surveys (1990-1993)

\begin{tabular}{|c|c|c|c|c|}
\hline & 1990 & 1991 & 1993 & Average \\
\hline \multicolumn{5}{|c|}{ Ability to Arrive on Time } \\
\hline Infrequent Riders (1 to 6 times/week) & $82.1 \%$ & $86.3 \%$ & $84.0 \%$ & $84.1 \%$ \\
\hline Frequent Riders (7+ times/week) & $90.7 \%$ & $85.5 \%$ & $87.7 \%$ & $88.0 \%$ \\
\hline \multicolumn{5}{|c|}{ Ability to Travel without Changing Vehicles } \\
\hline Infrequent Riders (1 to 6 times/week) & $52.8 \%$ & $47.5 \%$ & $43.4 \%$ & $47.9 \%$ \\
\hline Frequent Riders (7+ times/week) & $48.4 \%$ & $47.5 \%$ & $35.5 \%$ & $43.8 \%$ \\
\hline \multicolumn{5}{|c|}{ Not Having to Deal with Traffic Congestion } \\
\hline Infrequent Riders (1 to 6 times/week) & $62.6 \%$ & $63.4 \%$ & $50.9 \%$ & $59.0 \%$ \\
\hline Frequent Riders (7+ times/week) & $70.5 \%$ & $73.3 \%$ & $68.4 \%$ & $70.7 \%$ \\
\hline \multicolumn{5}{|c|}{ Short Travel Time } \\
\hline Infrequent Riders (1 to 6 times/week) & $51.9 \%$ & $26.0 \%$ & $59.4 \%$ & $45.8 \%$ \\
\hline Frequent Riders (7+ times/week) & $49.8 \%$ & $59.3 \%$ & $49.0 \%$ & $52.7 \%$ \\
\hline \multicolumn{5}{|c|}{ Short Wait Time } \\
\hline Infrequent Riders (1 to 6 times/week) & $62.5 \%$ & $71.3 \%$ & $66.3 \%$ & $66.7 \%$ \\
\hline Frequent Riders (7+ times/week) & $69.9 \%$ & $28.7 \%$ & $57.4 \%$ & $52.0 \%$ \\
\hline \multicolumn{5}{|c|}{ Flexibility to Change Plans } \\
\hline Infrequent Riders (1 to 6 times/week) & $50.9 \%$ & $59.6 \%$ & $60.0 \%$ & $56.8 \%$ \\
\hline Frequent Riders (7+ times/week) & $54.0 \%$ & $57.0 \%$ & $45.2 \%$ & $52.0 \%$ \\
\hline \multicolumn{5}{|c|}{ Parking Availability } \\
\hline Infrequent Riders (1 to 6 times/week) & $53.3 \%$ & $56.0 \%$ & $53.3 \%$ & $54.2 \%$ \\
\hline Frequent Riders (7+ times/week) & $56.9 \%$ & $50.0 \%$ & $38.6 \%$ & $48.5 \%$ \\
\hline \multicolumn{5}{|c|}{ Freedom From Threats to Personal Safety } \\
\hline Infrequent Riders (1 to 6 times/week) & $76.4 \%$ & $80.8 \%$ & $66.0 \%$ & $74.4 \%$ \\
\hline Frequent Riders (7+ times/week) & $84.1 \%$ & $82.6 \%$ & $82.5 \%$ & $83.0 \%$ \\
\hline \multicolumn{5}{|c|}{ Avoiding Stress } \\
\hline Infrequent Riders (1 to 6 times/week) & $67.0 \%$ & $58.4 \%$ & $50.9 \%$ & $58.8 \%$ \\
\hline Frequent Riders (7+ times/week) & $72.1 \%$ & $68.0 \%$ & $66.7 \%$ & $68.9 \%$ \\
\hline
\end{tabular}

*Characteristics rated as a 6 or 7 on a scale of 1 to 7 , with 1 being "not at all important" and 7 being "extremely important." 
Table 5-17: Performance Ratings by Mode:

Share of Infrequent Riders Rating Mode as Performing “Extremely Well”* Puget Sound Transportation Panel Attitude Surveys (1990-1993)

\begin{tabular}{|c|c|c|c|c|}
\hline & 1990 & 1991 & 1993 & Average \\
\hline \multicolumn{5}{|c|}{ Ability to Arrive on Time } \\
\hline Single-Occupant Vehicle (SOV) & $45.5 \%$ & $63.6 \%$ & $53.6 \%$ & $54.2 \%$ \\
\hline Bus & $18.3 \%$ & $42.5 \%$ & $15.8 \%$ & $25.5 \%$ \\
\hline \multicolumn{5}{|c|}{ Ability to Travel without Changing Vehicles } \\
\hline Single-Occupant Vehicle (SOV) & $77.0 \%$ & $82.8 \%$ & $81.4 \%$ & $80.4 \%$ \\
\hline Bus & $17.5 \%$ & $13.9 \%$ & $17.0 \%$ & $16.1 \%$ \\
\hline \multicolumn{5}{|c|}{ Not Having to Deal with Traffic Congestion } \\
\hline Single-Occupant Vehicle (SOV) & $10.1 \%$ & $11.1 \%$ & $8.2 \%$ & $9.8 \%$ \\
\hline Bus & $31.4 \%$ & $27.7 \%$ & $30.0 \%$ & $29.7 \%$ \\
\hline \multicolumn{5}{|c|}{ Short Travel Time } \\
\hline Single-Occupant Vehicle (SOV) & $33.0 \%$ & $31.3 \%$ & $33.3 \%$ & $32.5 \%$ \\
\hline Bus & $6.9 \%$ & $6.9 \%$ & $6.1 \%$ & $6.6 \%$ \\
\hline \multicolumn{5}{|c|}{ Short Wait Time } \\
\hline Single-Occupant Vehicle (SOV) & $79.8 \%$ & $79.6 \%$ & $80.0 \%$ & $79.8 \%$ \\
\hline Bus & $11.8 \%$ & $7.0 \%$ & $11.1 \%$ & $10.0 \%$ \\
\hline \multicolumn{5}{|c|}{ Flexibility to Change Plans } \\
\hline Single-Occupant Vehicle (SOV) & $80.8 \%$ & $82.7 \%$ & $84.4 \%$ & $82.6 \%$ \\
\hline Bus & $6.9 \%$ & $4.0 \%$ & $7.1 \%$ & $6.0 \%$ \\
\hline \multicolumn{5}{|c|}{ Parking Availability } \\
\hline Single-Occupant Vehicle (SOV) & $23.0 \%$ & $26.5 \%$ & $16.7 \%$ & $22.1 \%$ \\
\hline Bus & $67.7 \%$ & $62.5 \%$ & $77.4 \%$ & $69.2 \%$ \\
\hline \multicolumn{5}{|c|}{ Freedom From Threats to Personal Safety } \\
\hline Single-Occupant Vehicle (SOV) & $47.0 \%$ & $42.9 \%$ & $41.7 \%$ & $43.9 \%$ \\
\hline Bus & $19.6 \%$ & $18.0 \%$ & $12.1 \%$ & $16.6 \%$ \\
\hline \multicolumn{5}{|c|}{ Avoiding Stress } \\
\hline Single-Occupant Vehicle (SOV) & $10.0 \%$ & $10.2 \%$ & $11.5 \%$ & $10.6 \%$ \\
\hline Bus & $29.1 \%$ & $22.0 \%$ & $19.2 \%$ & $23.4 \%$ \\
\hline
\end{tabular}

*Characteristics rated as a 6 or 7 on a scale of 1 to 7 , with 1 being "extremely poorly" and 7 being "extremely well." 
The attitude surveys also had a section of statements for which the respondents could indicate their agreement or disagreement on a numeric scale. Table 5-18 shows the share of infrequent transit riders that agree with a selection of these statements.

Table 5-18: Agreement/Disagreement Statements*, Infrequent Riders Puget Sound Transportation Panel Attitude Surveys (1990_1993)

\begin{tabular}{|c|c|c|c|c|}
\hline & 1990 & 1991 & 1993 & Average \\
\hline \multicolumn{5}{|c|}{ Riding a Bus is a Relaxing Way to Commute } \\
\hline Agree & $56.6 \%$ & $51.5 \%$ & $41.3 \%$ & $49.8 \%$ \\
\hline Strongly Agree & $17.9 \%$ & $13.9 \%$ & $9.6 \%$ & $13.8 \%$ \\
\hline \multicolumn{5}{|c|}{ I Hate the Idea of Bus Transfers } \\
\hline Agree & $47.1 \%$ & $41.0 \%$ & $29.5 \%$ & $39.2 \%$ \\
\hline Strongly Agree & $23.1 \%$ & $18.0 \%$ & $25.7 \%$ & $22.3 \%$ \\
\hline \multicolumn{5}{|c|}{ Riding the Bus Helps Reduce Traffic Congestion } \\
\hline Agree & $48.1 \%$ & $46.0 \%$ & $37.9 \%$ & $44.0 \%$ \\
\hline Strongly Agree & $42.5 \%$ & $42.0 \%$ & $56.3 \%$ & $46.9 \%$ \\
\hline \multicolumn{5}{|c|}{ Taking the Bus is an Enjoyable Way to Travel } \\
\hline Agree & $43.4 \%$ & $46.5 \%$ & $34.3 \%$ & $41.4 \%$ \\
\hline Strongly Agree & $12.3 \%$ & $13.1 \%$ & $11.4 \%$ & $12.3 \%$ \\
\hline \multicolumn{5}{|c|}{ It's a Hassle to Take the Bus } \\
\hline Agree & $36.2 \%$ & $41.4 \%$ & $34.3 \%$ & $37.3 \%$ \\
\hline Strongly Agree & $7.6 \%$ & $19.2 \%$ & $12.4 \%$ & $13.1 \%$ \\
\hline \multicolumn{5}{|c|}{ Getting Bus Schedule Information is Easy } \\
\hline Agree & $n / a$ & $55.0 \%$ & $47.6 \%$ & $51.3 \%$ \\
\hline Strongly Agree & $n / a$ & $24.0 \%$ & $22.9 \%$ & $23.5 \%$ \\
\hline
\end{tabular}

*Statements rated on a scale of 1 to 7 , with 1 being "strongly disagree" and 7 being "strongly agree." A rating of 5 or 6 represents "agree” in this table.

As listed in the table, on average, a majority of infrequent riders agree that the bus is a "relaxing way to commute” (64 percent) and that it is an “enjoyable way to travel” (54 percent). These results, however, also imply that nearly half of those who ride infrequently do not agree that the bus is relaxing or enjoyable. Three-quarters of infrequent riders agree that getting information on bus schedules is "easy," although it should be remembered that this result is specific to the Puget Sound region. On average, approximately 90 percent of infrequent riders agree that riding 
the bus helps to reduce traffic congestion. These results suggest that there are other reasons why this segment of transit users does not ride more often.

While, on average, a majority agree that the bus is "relaxing” or "enjoyable," a smaller majority also agree that they "hate" the idea of bus transfers (62 percent) and find taking the bus to be a "hassle" (50.4 percent). Additional cross-tabulations (not shown in Table 5-18) revealed that, on average, of those responding that they agree that the bus is "relaxing," 60 percent also responded that they "hate" transferring buses and 43 percent agree that the bus is a "hassle." Further, of those who agree the bus is “enjoyable,” 63 percent "hate” bus transfers and 39 percent agree that taking the bus is a "hassle."

The attitude surveys conducted in 1997, 1999, 2000, and 2002 were constructed differently than those previously discussed and so were analyzed separately. For an analysis similar to that above, two data sets would need to be merged together so that the attitudes of infrequent transit riders could be isolated and examined. However, due to the lack of a unique person identifier common to both data sets, this was not possible for the 1999 and 2000 survey years. In addition, frequency of transit use was not available in the 1997 survey wave. As a result, 2002 is the only survey year that can be analyzed for this section.

In the 2002 attitude survey, transit users were asked to indicate to what extent they agree/disagree with statements regarding their work or school travel on transit. The scale is from 0 to 10, with 0 being “disagree completely" and 10 being "agree completely." Three of those statements are included in Table 5-19. Nearly 30 percent reported that they "sometimes" miss their connection because a bus, train, or ferry is late. Thus, nearly one-third of infrequent riders experience schedule unreliability at least “sometimes.” However, approximately 85 percent are "happier" if they know when a transit vehicle will arrive, suggesting that real-time bus information reduces anxiety when service is not running according to schedule.

Transit users were also asked to respond to the statement, “As soon as I can, I'd like to switch to driving to and from work/school.” For those infrequent users who do ride for work or school trips, approximately 26 percent agreed with that statement, as shown in Table 5-19. Nearly 17 percent agreed completely with the statement. This implies that approximately three-quarters of infrequent users plan to continue using transit. 

Table 5-19: Agreement/Disagreement Statements*, Infrequent Riders -
Puget Sound Transportation Panel Attitude Surveys (2002)

\begin{tabular}{|c|c|}
\hline & 2002 Attitude Survey \\
\hline \multicolumn{2}{|c|}{ I Sometimes Miss My Connection Because a Bus, Ferry, or Train is Late } \\
\hline Agree & $20.2 \%$ \\
\hline Agree Completely & $9.6 \%$ \\
\hline \multicolumn{2}{|c|}{$\begin{array}{l}\text { When I'm Waiting for a Bus, Ferry, or Train, I'm Happier if I Know } \\
\text { When it Will Arrive }\end{array}$} \\
\hline Agree & $29.6 \%$ \\
\hline Agree Completely & $55.9 \%$ \\
\hline \multicolumn{2}{|c|}{ As Soon as I Can, I'd Like to Switch to Driving To and From Work/School } \\
\hline Agree & $9.1 \%$ \\
\hline Agree Completely & $16.5 \%$ \\
\hline \multicolumn{2}{|c|}{ I Worry a Lot About Being Late } \\
\hline Agree & $39.8 \%$ \\
\hline Agree Completely & $14.1 \%$ \\
\hline \multicolumn{2}{|c|}{ At Least Twice per Week, There is an Unexpected Delay on My Route } \\
\hline Agree & $25.7 \%$ \\
\hline Agree Completely & $5.9 \%$ \\
\hline \multicolumn{2}{|c|}{$\begin{array}{l}\text { I Don't Mind Delays So Much if I Can Forecast Accurately When } \\
\text { I'm Going to Get There }\end{array}$} \\
\hline Agree & $37.3 \%$ \\
\hline Agree Completely & $5.9 \%$ \\
\hline \multicolumn{2}{|c|}{$\begin{array}{l}\text { Within the Past Three Years, I have Seriously Considered Changing Where I } \\
\text { Work to Reduce the Amount of Time I Spend Commuting }\end{array}$} \\
\hline Agree & $11.2 \%$ \\
\hline Agree Completely & $5.9 \%$ \\
\hline \multicolumn{2}{|c|}{$\begin{array}{c}\text { Within the Past Three Years, I Have Seriously Considered Changing Where I } \\
\text { Live to Reduce the Amount of Time I Spend Commuting }\end{array}$} \\
\hline Agree & $8.5 \%$ \\
\hline Agree Completely & $5.9 \%$ \\
\hline
\end{tabular}

* Statements rated on a scale of 0 to 10, with 0 being "disagree completely" and 10 being "agree completely.” Ratings of $6-9$ represent "agree” in this table. 
Also in the 2002 attitude survey, users of all modes responded to the statement, "I worry a lot about being late.” Among infrequent transit users, approximately 60 percent agreed with this statement to some extent, as presented in Table 5-19. This logically coincides with results from earlier attitude surveys showing the importance of arriving on time in choosing how to travel.

Table 5-19 also shows that approximately 32 percent of infrequent riders agree that an "unexpected delay" occurs on their work or school commute trip at least twice per week. This is congruent with the earlier finding that approximately 30 percent sometimes miss connections due to late transit vehicles (also in Table 5-19). Approximately 43 percent indicated that they do not mind the delays "so much" as long as they can accurately forecast when they will arrive.

The 2002 attitude survey also sought to determine if commuters had recently considered changing their place of employment or residential location to reduce commuting times. Table 519 shows that, among infrequent transit users, 17 percent had considered changing their work location and approximately 14 percent had considered changing where they live. The survey did not ask whether a change in either work or residential location was actually made.

Data from the PSTP is certainly most relevant to the Puget Sound region; however, due to the breadth of the data, it is reasonable to assume that these results provide information about infrequent transit riders in general. Certainly, the data show that the demographic characteristics of infrequent users in the Puget Sound region are similar to those found in on-board survey data across the country. In addition, the share of less frequent riders is also similar to that at many transit agencies across the country, as evidenced by the on-board survey data analyzed for this study.

These data show that infrequent riders are more likely to be choice riders: they have, on average, higher incomes and more household vehicles available for their travel needs. They are also less likely to use transit for work commutes, although some do, as the analysis in this section shows. Overall, their attitudes about transit are relatively positive, and most are not eager to switch to driving. These findings suggest that most of the infrequent riders have chosen to use transit for a certain portion of their travel needs and are relatively satisfied with it. Given the results of the attitude surveys, it does seem plausible that this segment can be induced to ride more frequently, perhaps for more work or school commute trips. 


\section{Pinellas County, Florida, Household Travel Survey}

In 2007, Pinellas County, Florida, which contains the cities of St. Petersburg and Clearwater, conducted a household travel survey. Data from this survey can also provide insight into the characteristics of infrequent transit riders. Nine percent of the survey respondents define themselves as transit users, while 91 percent are transit non-users. Forty-six percent are employed, and an additional 42 percent classify themselves as retired. Of those who do work, 83 percent drive alone to their place of employment and 3 percent ride the bus.

Fifty percent of respondents indicate that, once per week or more, they are "seriously delayed" by traffic congestion. Thirty-six percent agree that "taking a bus one or two days a week while still owning a car would save enough money to be worth it.” In addition, 49 percent agree that if the price of gas were to rise to $\$ 4.00$ per gallon (which has actually happened recently in this area), they would "consider using the bus a few times per week instead of using (their) personal vehicle to commute to/from work." These findings suggest that, especially with still-rising fuel costs, the attraction of some new riders to the transit system is possible, and that these riders would most likely fall into the segment of infrequent users.

A few additional findings of interest include that 52 percent of respondents agree that the Pinellas County Transit Authority (PSTA) is mostly a "social service" that provides transportation primarily for low-income individuals who do not have a car. However, 75 percent agree that PSTA provides transit service that is "good enough to use regularly."

Of those who do use transit, 58 percent indicate that they use it three days per week or less, which is the definition of infrequent use that has been used throughout this chapter. This percentage is much higher than the average share of infrequent riders found in the on-board surveys analyzed for this study (including the on-board survey conducted in Pinellas County). It should be remembered, though, that less frequent users tend to be underrepresented in on-board surveys because they are less likely to be riding during the few days that a survey is being conducted. However, this share of infrequent users is also higher than that found in the Puget Sound Transportation Panel (19 percent for those using transit alone and 38 percent for those using a car/bus combination). For the Pinellas County survey, the infrequent users are further analyzed below.

Table 5-20 provides some income and vehicle availability information for transit users in Pinellas County, Florida, based on the household survey. The percentages shown in the table 
differ from those found in the PSTA on-board survey, also conducted in 2007 and included in the analysis of on-board surveys presented earlier in this chapter. One reason for this might be the relatively small number of observations in the travel survey. The travel survey contains 402 observations, while the on-board survey contains 2,738 observations. It is likely that transit users are underrepresented in the travel survey. However, the trends are the same when comparing the infrequent rider population to the rider population as a whole. Table 5-20 shows that infrequent riders tend to have higher incomes and more vehicles available, as found in the other analyses in this chapter.

\section{Table 5-20: Select Household Characteristics of Transit Users - Pinellas County Household Travel Survey (2007)}

\begin{tabular}{|c|c|c|}
\hline & All Riders & $\begin{array}{l}\text { Infrequent } \\
\text { Riders }\end{array}$ \\
\hline \multicolumn{3}{|c|}{ Annual Household Income } \\
\hline$<=\$ 25,000$ & $36.0 \%$ & $28.6 \%$ \\
\hline$\$ 25,000-\$ 35,000$ & $11.1 \%$ & $14.3 \%$ \\
\hline$\$ 35,000-\$ 50,000$ & $8.3 \%$ & $4.8 \%$ \\
\hline$\$ 50,000-\$ 75,000$ & $11.1 \%$ & $9.5 \%$ \\
\hline$>\$ 75,000$ & $13.9 \%$ & $23.8 \%$ \\
\hline \multicolumn{3}{|c|}{ Number of Household Vehicles } \\
\hline Zero & $36.1 \%$ & $23.8 \%$ \\
\hline One & $33.3 \%$ & $38.1 \%$ \\
\hline Two & $25.0 \%$ & $33.3 \%$ \\
\hline Three or More & $5.6 \%$ & $4.8 \%$ \\
\hline
\end{tabular}

NOTE: Percentages may not sum to 100 due to rounding and the exclusion of other responses such as “don’t know” or "refused.”

Table 5-21 provides information on trip purposes of transit riders in Pinellas County. As expected, the infrequent riders take a smaller percentage of work trips than riders in general. This trend is evident in these data despite the differences with the on-board survey data discussed above. 
Table 5-21: Trip Purposes of Transit Users -

Pinellas County Household Travel Survey (2007)

\begin{tabular}{||l|r|r||}
\hline & All Riders & \multicolumn{1}{|c|}{$\begin{array}{c}\text { Infrequent } \\
\text { Riders }\end{array}$} \\
\hline Work & $27.8 \%$ & $9.5 \%$ \\
\hline School & $2.8 \%$ & $0.0 \%$ \\
\hline Other & $69.4 \%$ & $90.5 \%$ \\
\hline
\end{tabular}

\section{Conclusions}

This chapter sought to determine characteristics of infrequent transit riders and to understand the patterns of transit use among this segment of the rider population. To achieve this, several sources of data were obtained and analyzed. On-board survey data and results from across the U.S. were used to explore frequency of transit use. Data from eight on-board surveys in Florida, representing small, medium, and larger transit systems, were analyzed in-depth. In addition, data from household travel surveys including the Puget Sound Transportation Panel (PSTP) and a survey conducted in Pinellas County, Florida were analyzed. The PSTP information was particularly useful as it contained a time series of attitude surveys that provided information on perceptions and opinions regarding various modes of transportation.

From the data analyzed for this chapter, it was determined that, on average, between 23 percent and 28 percent of transit users can be characterized as infrequent users. The Pinellas County travel survey found a higher percentage of infrequent riders based on the definition applied in this chapter (even higher than the Pinellas on-board survey), however, this may be due to the smaller overall sample size and very small sample of transit riders. For purposes of this study, an infrequent user was defined as one who rides transit three days per week or less. The response category of riding one to three days per week is common on on-board surveys (some surveys do have a separate response category for one day per week, two days per week, etc.), and a response category of riding less than one day per week is also found in many surveys. Where possible, results have been separated based on those who ride one to three days per week and those who ride even less frequently (less than one day per week). 
Overall, the data analysis in this chapter consistently found that, compared with the transit user population as a whole, the segment of infrequent users has the following characteristics:

- Fewer work trips;

- More likely to drive if transit is not available;

- Higher incomes; and

- More household vehicles available for their use.

These characteristics suggest that the infrequent rider is a choice rider. While this rider may make fewer work trips overall, there is evidence that a percentage does ride for the work commute. However, this rider may be using transit for the commute just a few days per week or less and may drive alone the rest of the time.

As mentioned, the attitude surveys conducted as part of the Puget Sound Transportation Panel were quite useful. The factors considered in the mode choice decision that were analyzed for their impact on frequency of transit use included:

- Ability to arrive on time

- Ability to travel without changing vehicles

- Not having to deal with traffic congestion

- Short travel time

- Short wait time

- Flexibility to change plans

- Parking availability

- Freedom from threats to personal safety

- Avoiding stress

The attribute "ability to arrive on time" is quite relevant to the purposes of this project, and was also the highest rated characteristics, in terms of importance, among the others listed. On average, 84 percent of infrequent riders rated the ability to arrive on time as extremely important in the mode choice decision. A total of 26 percent of infrequent riders rated transit's ability to arrive on time "extremely well" (a rating of 7 on a scale of 1 to 7 ). An additional 52 percent of infrequent riders rated the on-time performance of transit as a 5 or 6 on this scale. This indicates that approximately 78 of infrequent riders rate the on-time performance of transit better than 
"neutral," according to these results. The on-board surveys also indicated a general satisfaction with transit's on-time performance.

The second-highest rated attribute deals with personal safety: more than 74 percent of infrequent riders rated "freedom from threats to personal safety" as extremely important in making a mode choice. Only 17 percent of infrequent riders rated transit's performance in this area as "extremely well.” The perception of personal safety on transit may impact the frequency with which one chooses to ride.

Approximately 26 percent of infrequent transit users agreed with that statement, “As soon as I can, I'd like to switch to driving to and from work/school.” This implies that approximately three-quarters of the infrequent users represented in these data are not looking to switch modes in the near term.

Overall, the attitudes of infrequent users regarding transit are relatively positive, and most are not eager to switch to driving. These findings suggest that most of the infrequent riders have chosen to use transit for a certain portion of their travel needs and are relatively satisfied with it. However, marketing research has shown that approximately 50 percent of customers switch service providers because of "failed service encounters" or the "response to failed service," i.e., uncaring, impolite, unresponsive, unknowledgeable, or otherwise negative encounters with service personnel $^{3}$. Such research has also found that 45 percent of all switching is due to a single act and that 75 percent of all switchers told many people about the experience, thus circulating negative word-of-mouth ${ }^{4}$. The extent to which these marketing research findings apply to a product such as transit service is unclear; however, the training of bus operators in the provision of excellent customer service cannot be emphasized enough, in that the operators are the face of the transit agency and often the only point of contact for the customer. If the infrequent user has other alternatives available, especially his or her own car, a few negative experiences (or even one such experience) might result in that user riding even less frequently, or not at all.

Given the results of the PSTP attitude surveys, it does seem plausible that this segment can be induced to ride more frequently, perhaps for more work or school commute trips. That infrequent users might be induced to ride more often to some extent is also seen in the data from the Pinellas County travel survey. Thirty-six percent agree that "taking a bus one or two days a

\footnotetext{
${ }^{3}$ Dr. Paul Solomon, Marketing Management class notes, MBA Program, University of South Florida, Tampa, 2008.

${ }^{4}$ Ibid.
} 
week while still owning a car would save enough money to be worth it.” Also, 49 percent agree that if the price of gas were to rise to $\$ 4.00$ per gallon (which has actually happened recently in Pinellas County), they would “consider using the bus a few times per week instead of using (their) personal vehicle to commute to/from work.” These findings suggest that, especially with fuel prices continuing to rise, the attraction of some new riders to transit is possible, and these riders would most likely fall into the segment of infrequent users. Marketing theory indicates that it can be difficult to induce infrequent users of a product or service to use it more often: it is typically advised to focus the heaviest marketing efforts on retaining the most frequent users ${ }^{5}$. Rather than expend significant resources to convert infrequent users of a product or service to be heavier users of that same product or service, some marketers believe in conducting research into what those infrequent users do use more often, and tailor a product or service to match that need. In the case of transit, most infrequent users have a car available that they can use for their trips. Transit cannot compete directly with the car, but can develop services that provide appropriate service spans and frequencies, faster travel times, and amenities such as passenger information, and comfortable vehicles and facilities, among others. According to the data analysis in this chapter, because the most frequent riders make more work trips, services tailored for the typical work commuter will likely help retain existing frequent and infrequent riders, and possibly induce more use by the infrequent rider.

Although knowledge regarding infrequent riders is limited, the literature discussed in Chapter 1 reveals some additional characteristics, suggesting that new riders are disproportionate as infrequent riders, tend to be younger and more affluent than longer-term riders, and are likely to stop riding. While infrequent riders, new users, and riders with shifting trip frequencies tend to pay cash, fare prepayment correlates with more trips, stable trip rates, and longer periods of ridership. Interestingly, riders who pay cash are disproportionate as new or infrequent riders, which suggests that they are more likely to stop riding. In regard to their inclination toward infrequent use, new riders are more likely to use transit for occasional work trips rather than offpeak or non-work trips. Their trip rates appear to increase with duration of riding, possibly expanding into off-peak use. All of these findings underscore the importance of using strategies such as promotional outreach, information materials, and pricing strategies to secure the commitment of new and infrequent riders.

\footnotetext{
${ }^{5}$ Dr. Paul Solomon, Marketing Management class notes, MBA Program, University of South Florida, Tampa, 2008.
} 


\section{CHAPTER SIX: OVERALL FINDINGS AND CONCLUSIONS}

This research project sought to explore three primary factors that affect transit ridership: travel time reliability (on-time performance), rider cessation, and the characteristics of infrequent riders. It has been recognized that transit travel time reliability, or on-time performance, may have a significant impact on attractiveness of transit to many current and prospective riders. In addition, transit agencies are continually working to keep the riders they have and attract new riders to their services. Increased rider retention might be a more realistic approach to building ridership than attracting new riders. Finally, increased trip making by infrequent riders also represents a promising potential growth market.

This document includes six chapters. Chapter 1 presented a summary of existing literature on these topics. Next, Chapter 2 contained a synthesis and analysis of existing data which were used to develop analyses in the later chapters. The data included results and raw data from onboard surveys, customer satisfaction surveys, household travel surveys, and the comprehensive Puget Sound Transportation Panel, a longitudinal study encompassing 10 survey waves and 8 related attitude surveys. The third chapter focused on transit reliability, or on-time performance, and ridership. In addition to a full analysis of existing data, a selection of agency experiences with transit service reliability improvements were discussed. Chapter 4 addressed cessation of transit usage as well as those factors contributing to the usage of transit. The characteristics of infrequent transit riders, a little understood segment of transit ridership, is the subject of Chapter 5. Finally, this last chapter, Chapter 6 , ties together the major findings and conclusions derived from each of the earlier chapters, thus presenting a clearer understanding of the relationships among public transit ridership, reliability, and retention.

\section{Transit Reliability}

Attitudes and perceptions about travel time and reliability were analyzed among transit users and non-users. Data from on-board surveys and customer satisfaction surveys from within Florida and across the country were used to explore these attitudes among transit users, while data from non-user surveys were also used. Data from the Puget Sound Transportation Panel, while certainly most relevant in the Puget Sound region, provided insight into attitudes and perceptions regarding such things as trip delays and on-time arrivals, not just for transit, but for other modes and travel in general. The findings from the surveys were further enhanced by additional contact 
with many transit agencies across the country. Some of the most interesting experiences from these agencies were also shared in Chapter 3.

Among those who use transit, the survey information indicates that reliability is very important and is often among the most-requested service improvements. Riders dissatisfied with schedule reliability at their transit agency tend to have more characteristics that would describe them as being more transit-dependent (e.g., lower incomes, fewer household vehicles). It could be that, although they are dissatisfied, they may have fewer transportation options available. Transit users concerned with reliability also tend to be more frequent users, and younger users. The Puget Sound data indicate that only a small share of transit users want to switch to driving as soon as they can; although, that share of users also had a higher rate of incidences of missed connections due to late transit vehicles than users as a whole, which can have an impact on their travel choices.

The data analyzed for this effort indicate that those who do not use transit tend to have a somewhat negative perception of the ability of transit to provide reliable service. However, both transit users and non-users tend to agree that they do not mind delays as much when they have accurate information regarding when they will arrive at their destination. For transit, such information takes the form of real-time information on bus arrivals. This type of information may even act as a proxy for reliability.

Reliability certainly appears to be one of the service characteristics most important to transit customers, while service quality and customer satisfaction have in turn been linked to higher levels of retention, and possibly even ridership gain. Interestingly, studies of travel behavior suggest that, depending on trip length and total travel time, the cost of unreliable service may actually be greater than the cost of travel time. Over time, the inconvenience, uncertainty, and added time costs of unreliable service diminish user confidence and may result in ridership declines. Thus, improving the consistency of transit waiting and travel time might foster a larger, more satisfied, and more committed base of customers.

BRT and other limited-stop services show great promise for boosting customer satisfaction and ridership by improving reliability, particularly for the work commute. As discussed in the literature, improved service reliability, as well as significant increases in customer satisfaction and ridership, have occurred following the implementation of many of these services. Improved reliability was attributed to the fewer stops and more efficient boarding (i.e. shorter dwell times) typical of BRT lines. However, factors and improvements that coincided with the 
implementation of these services make it difficult to determine the degree to which the ridership increases were caused by improved travel time reliability. Thus, the nature of the relationship between reliability and ridership growth remains unclear. More than any single factor, it is perhaps the right combination of a wide range of quality service elements that will cultivate a growing clientele.

In light of the importance of reliability to customer satisfaction, it should be noted that passengers and transit agencies have been shown to differ in their conceptions of reliability. The conventional measure used by transit agencies to evaluate reliability is on-time performance (OTP), a discrete "on-time" window, generally no more than one minute early or five minutes late. However, using a continuous measure (such as departure delay), as well as taking into account the severity of the delay and the time of day, would probably result in a more accurate assessment of a passenger's experience.

A number of advanced technologies offer some promising solutions for improved reliability. Agencies can use advanced communications and location technologies to manage the unforeseen events that interfere with service reliability. These technologies enable agencies to monitor schedule adherence in real time and adjust service instantaneously. One of the most robust examples is Portland's Bus Dispatching System (BDS), which tracks buses in space and time by using a combination of advanced technologies including a computer-aided dispatch (CAD) and control center, automatic passenger counting (APC) systems, a two-way radio system enabling voice and data communication between drivers and dispatchers, and automatic vehicle location and control (AVLC) in tandem with global positioning system (GPS) technology. Such technologies are often able to achieve considerable improvements in OTP merely by providing schedule adherence information to operators in real time.

Aside from supplying transit operators with on-the-spot information, emerging technologies such as AVLC may decrease the anxiety of waiting by providing real-time schedule information to customers. Research suggests that out-of-vehicle waiting time is perceived to pass more slowly than an equal amount of in-vehicle travel time. Additional analysis has shown that a higher degree of certainty regarding the duration of a wait will reduce a traveler's burden of waiting, and that real-time customer information may have the ability to act as a surrogate for reliability. Informing riders of when vehicles will actually arrive allows them to plan their arrival to meet with that of the vehicle. Thus, real-time information shows promise not only for reducing the hardship of uncertainty while waiting, but also for reducing the length of the wait. 
Of course, without adequate fleet maintenance and practical route and schedule design, even the most advanced technologies will be of little use for achieving reliable transit service. Planning actions and policies that may improve reliability include parking restrictions to ease traffic congestion, prohibiting left turns, simplifying route structures and avoiding long routes, reducing the number of stops and duration of dwell times, giving signal priority to transit vehicles, and designating transit-only lanes.

\section{Transit Cessation and Retention}

Some existing literature on this topic indicated the existence of a natural transit life cycle that tends to result in the eventual cessation of use. As such, ridership retention strategies should seek to prolong this life cycle. Data from household travel surveys in Washington, D.C. and Pinellas County, Florida, indicate that most users stop using transit when they gain access to a car (i.e., when they have a choice). The second most common reason is a change in job, job location, or residential location. Smaller percentages of respondents indicated dissatisfaction with transit service characteristics as their reason for ceasing transit usage. For example, only six percent of the respondents in the Washington, D.C., survey reported that they stopped using transit because it was not "reliable enough."

Similar findings emerged from a close examination of the 10 survey waves from the Puget Sound Transportation Panel (PSTP). Just prior to making a mode switch, most respondents indicated a change in occupation or job location. It is reasonable to assume that these changes might add or remove transit as a viable alternative mode, depending upon the hours and location of both the workplace and residence, and the available transit services.

However, the PSTP also included a series of attitude surveys, which did indicate that those most concerned about being on time, those most annoyed by travel delays, and those who experienced problems associated with late transit vehicles are more likely to switch to driving. While the Puget Sound region appears to have more “choice” transit riders than, say, Pinellas County, Florida, the mode share for transit is still relatively small, so the actual number of transit customers lost due to service problems is also relatively small (although the number of choice riders not gained could be quite large). It should be noted, though, that marketing research has shown that, in general, approximately 45 percent of switching because of failed service encounters is due to a single act and that 75 percent of all switchers told many people about any negative experiences, thus circulating negative perceptions via word of mouth. The extent to 
which such research, done primarily for traditional goods and services, is applicable to public transit is unclear. However, with a pattern of service problems, choice riders will certainly be more likely to switch. In addition, the training of bus operators in the provision of excellent customer service cannot be emphasized enough. The operators are the "face" of the agency and often the only point of contact for the customer. If the user has other alternatives available, especially his or her own car, a few negative experiences (or even a single such experience) might result in less frequent use or a cessation of use altogether.

Successful rider retention strategies require an understanding of the factors that motivate transit use, as well as those that deter or prevent it altogether. As mentioned previously, the examination of the attitudes and needs of both choice and non-riders can prove quite useful in extending the window of time during which people are able and willing to use transit. As discussed in the literature, discretionary riders seem to be motivated by disincentives associated with driving (such as parking costs and congestion) rather than positive incentives associated with transit service. Also, some choice riders appear to consider certain factors, such as helping the environment, avoiding traffic, and saving money, important enough to offset the additional time required for transit travel.

Insight into why non-riders do not currently use transit may aid retention efforts by shedding some light on why current riders might eventually stop using transit. According to the literature, non-riders desire many of the same travel benefits as transit riders, and rank on-time performance and reliability as highly important criteria for using transit. However, non-riders tend to have stricter standards of satisfaction and are less inclined to commit to using transit, even if their higher expectations are met. Lack of security and lack of information are unique among the barriers to transit use that cited by non-riders. However, the other obstacles that nonriders identified (lack of convenience of schedule and/or destination/origin, lack of flexibility for making multiple trips, lengthy travel times, and frustration with transfers) seem to represent different aspects of the simple but pervasive attitude that using transit is simply not as convenient as driving.

It is also important to re-emphasize the importance of customer satisfaction to retention and ridership growth. Successful niche marketing can be used to improve service quality and boost customer satisfaction levels. Research discussed in the literature evaluates the success of niche marketing based on its ability to influence customers to use, reuse, and recommend public transit to other consumers. Survey analysis indicated that consumers are most likely to reuse, expand, and recommend transit services that they perceive as safe, well-organized, and more convenient 
than driving. This finding suggests that promoting these three aspects of service may allow transit agencies to most effectively leverage their investments in niche service marketing. Moreover, if transit agencies want to use niche marketing strategies to increase ridership on their traditional services, they must not only deliver service excellence, but promote it as well, using the best operators and equipment available.

As with reliability, customer satisfaction and loyalty are often assessed according to internal agency specifications. However, agencies will likely be more successful at achieving higher service ratings (and, in turn, more loyal customers) with customer-derived measures of loyalty and satisfaction, followed by improvements in the service features that are most important to customers. Thus, promotional efforts and market research should focus on the transit performance measures that are most attractive to riders. To identify key characteristics and travel needs of existing and potential rider groups, several transit agencies have used the market segmentation approach with great success. Of particular interest is the growing body of evidence suggesting that the infrequent rider segment may be critical to growth in transit ridership.

\section{Infrequent Riders}

In addition to postponing rider cessation, transit agencies may successfully boost ridership by encouraging infrequent riders to increase and diversify their use of transit services. Indeed, there is a growing body of evidence suggesting that infrequent riders may be a critical market for building transit ridership and revenue. Given the conventional wisdom and standard practices within the transit industry, these findings are surprising, and suggest the need for new directions in transit marketing and pricing strategies.

Although knowledge regarding infrequent riders is limited, studies suggest that new riders are disproportionate as infrequent riders and are more likely to use transit for occasional work trips rather than off-peak or non-work trips. These newer, less frequent riders also tend to be younger and more affluent than longer-term riders. Their trip rates appear to increase with duration of riding, and may eventually expand into off-peak use; however, this is unlikely, given the high rate of turnover. In fact, infrequent riders may be particularly vulnerable to cessation, possibly due in part to their fare payment patterns. Fare prepayment has been shown to correlate to greater frequency, duration, and stability of ridership. Interestingly, riders who pay cash are disproportionate as new or infrequent riders, suggesting that they are more likely to stop riding. These findings underscore the importance of cultivating the commitment of new and infrequent 
riders through outreach, distribution of information, promotional programs, and pricing strategies.

Overall, the data analyzed for this effort indicate that the attitudes of infrequent users regarding transit are relatively positive, and most are not eager to switch to driving. These findings suggest that most of the infrequent riders have chosen to use transit for a certain portion of their travel needs and are relatively satisfied with it. However, as mentioned previously, marketing research has shown that a high number of users are likely to switch (i.e., stop using a product of service) because of failed service encounters. As such, emphasis on customer service, particularly among bus operators, is essential.

Given the results of the PSTP attitude surveys, it does seem plausible that this segment can be induced to ride somewhat more frequently, perhaps for more work or school commute trips. That infrequent users might be induced to ride more often to some extent is also seen in the data from the Pinellas County travel survey. Thirty-six percent agree that "taking a bus one or two days a week while still owning a car would save enough money to be worth it.” Also, 49 percent agree that if the price of gas were to rise to $\$ 4.00$ per gallon (which has, of course, actually happened recently), they would "consider using the bus a few times per week instead of using (their) personal vehicle to commute to/from work." These findings suggest that, especially with fuel prices continuing to rise, the attraction of some new riders to transit is possible, and these riders would most likely fall into the segment of infrequent users. Marketing theory indicates that it can be difficult to induce infrequent users of a product or service to use it more often: it is typically advised to focus the heaviest marketing efforts on retaining the most frequent users ${ }^{6}$. Rather than expend significant resources to convert infrequent users of a product or service to be heavier users of that same product or service, some marketers believe in conducting research into what those infrequent users do use more often, and tailor a product or service to match that need. In the case of transit, most infrequent users have a car available that they can use for their trips. Transit cannot compete directly with the car, but can develop services that provide appropriate service spans and frequencies, faster travel times, and amenities such as passenger information, and comfortable vehicles and facilities, among others. According to the data analysis in this chapter, because the most frequent riders make more work trips, services tailored for the typical commuter can likely help retain existing frequent and infrequent riders, and possibly induce more use by the infrequent rider.

\footnotetext{
${ }^{6}$ Dr. Paul Solomon, Marketing Management class notes, MBA Program, University of South Florida, Tampa, 2008.
} 
Research also indicates that inducing occasional riders to modestly increase their transit use is more reasonable and perhaps a more easily-achieved goal than attempting to fully convert them to regular, daily use. Survey data from the literature on the Commuter Check fare subsidy program in the San Francisco Bay Area supports this hypothesis. Not only were most induced trips from previous infrequent riders, but most of the increases were light- just one to two, three to four, or five to six new trips per week. Formerly infrequent riders who are still not regular riders make up the largest single group of induced riders, which further confirms the role of infrequent users as a new rider market.

Deep discounting has also been demonstrated as a broadly applicable but powerful fare strategy that can harness low frequency and high turnover to better serve transit agency goals. Deep discounting uses the perception of a discount to induce more riders to display the greater frequency, duration, and stability of ridership often associated with fare prepayment. By raising cash fares while leaving the price of multi-ride tickets unchanged, deep discounting separates the infrequent rider market into fare-sensitive and fare-insensitive segments. Deep discounting has been shown to raise ridership by a small percentage and offset ridership loss during fare increases, as well as raising revenue by 15 to 20 percent without losing riders.

As mentioned in the literature, comparatively little attention has been directed toward developing a better understanding of how consumer marketing approaches might be utilized by public transit agencies. One marketing approach for building transit ridership, the direct mail promotion, was used by the Wisconsin Department of Transportation to great success in persuading non-riders to trial use and increasing the riding frequency of existing customers. Survey analysis indicates that the promotion was successful in persuading infrequent riders to significantly increase their trip-making frequency during the incentive period, as well as increasing their use of paid transit trips after the end of the promotion. When queried regarding their likelihood of recommending the service to others, over 90 percent of survey respondents definitely or probably would recommend the service to other people. It should be emphasized that the willingness of customers to sustain their ridership patterns and recommend transit service to other people depends largely on the service quality they encounter early on in their experience of transit.

Special-purpose or "niche” marketing efforts are also an effective strategy for attracting and retaining new or infrequent riders, as well as influencing them to expand their service usage. In terms of service quality and customer satisfaction, the success of niche marketing depends on its ability to influence customers to (1) reuse the niche service, (2) use other transit services, and (3) recommend public transit to other consumers. These findings suggest that if transit agencies 
want to use niche marketing strategies to increase ridership on their traditional services, they must not only deliver service excellence, but promote it as well, using the best operators and equipment available. Of all the elements of service quality, the analysis in the literature revealed that consumers are most likely to reuse, expand, and recommend transit services that they perceive as safe, well-organized, and more convenient than driving. Thus, promoting these three aspects of service may allow transit agencies to leverage their investments in niche marketing most effectively.

Niche strategies will be most effective at attracting and retaining riders when they are used as a promotional tactic rather than as a public service. By using entertainment-based venues to promote the quality of their services, transit agencies have an opportunity to provide a level of satisfaction that will encourage infrequent or first-time riders to consider public transit as an option for their daily travel needs. Moreover, these services do not have to be given away. Sponsors of events or the riders themselves are often perfectly happy to pay for the convenience of using such services. Thus, niche marketing strategies are not only one of the most effective investments for reaching new markets, but are often profitable in their own right.

\section{Further Research}

While this project sought to comprehensively analyze and synthesize the relationships among transit ridership, reliability, and retention, the effort uncovered the need for even further research in these areas. Transit agencies do not generally collect significant amounts of data and information from their users, aside from what can be generalized from on-board surveys or other household surveys. While many providers of typical goods and services can track individual use of their offerings, locating infrequent users or ex-users of a public transit service in order to obtain additional information is difficult. This lack of information also prevents an even deeper understanding of the behavior of these rider (and ex-rider) segments. Additional market segmentation research of other transit user groups and their regional differences can further uncover user preferences.

Also, the precise relationship between travel time reliability and transit ridership, while certainly significant, remains somewhat elusive. Transit agencies should continue moving toward customer-oriented measures of reliability and satisfaction. Even if this research had determined and used a particular definition for reliability, or on-time performance, the meaning of any result might be obscured because of the varying subjective values that transit users and non-users place 
on mode reliability and travel time (as well as other mode characteristics). It is possible that the values placed on reliability and travel time might vary not only based on individual

characteristics but also on regional characteristics, and this value of time is an area requiring additional research. 


\section{REFERENCES}

American Public Transportation Association. 2007. A profile of public transportation passenger demographics and travel characteristics reported in on-board surveys.

Baltes, Michael. 2003. The importance customers place on specific service elements of bus rapid transit. Journal of Public Transportation 6:4, 1-19.

Barlow, Selena and Hugh Clark. 2006. Findings of customer surveys conducted for Sacramento Regional Transit. http://www.sacrt.com/documents/Custsatisfactionfinal.pdf,

Bowman, L.A. and Turnquist, M.A. 1981. Service frequency, schedule reliability, and passenger wait times at transit stops. Transportation Research 15A, 465-471.

Bush, J. 2000. Increasing transit ridership with a direct mail promotion. Proceedings of the 2000 Bus and Paratransit Conference, American Public Transportation Association. 1-7.

California Department of Transportation. 2003. An analysis of public transportation to attract non-traditional riders in California. Sacramento, CA: Business, Transportation and Housing Agency.

CB\&A Research, Inc. 2004. Town of Chapel Hill fall 2003 on-board rider profile survey, report of findings. http://townhall.townofchapelhill.org/agendas/ca040414/5d\%20attach\%201\%20Survey\%20Report.pdf

Center for Urban Transportation Research. 2008. 2007 Florida Transit Handbook. University of South Florida, Tampa.

Center for Urban Transportation Research. 2006. Florida transit agency on-board survey database (survey instruments, raw data, and results). University of South Florida, Tampa.

Chang, G.L. and Mahmassani, H.S. 1988. Travel time prediction and departure time adjustment behavior dynamics. Transportation Research B, 22: 217-232.

Chen, C., A. Skabardonis and P. Varaiya. 2003. Travel-time reliability as a measure of service. Transportation Research Record 1855: 74-79.

Chicago Transit Authority. 2004. Survey reveals CTA customer satisfaction remains steady. http://www.transitchicago.com/news/archpress.wu?action=displayarticledetail\&articleid= $\underline{109253}$ 
CJI Research Corporation. 2003. An on-board survey of Wheels riders.

Conlon, et. al. 2001. Successful arterial street limited-stop express bus service in Chicago. Transportation Research Record 1760: 74-80.

Cronin, J., R. Hightower and M. Brady. 2000. Niche marketing strategies: the role of specialpurpose transportation efforts in attracting and retaining transit users. Journal of Public Transportation 3:3. 63-84.

Dallas Area Rapid Transit. 2004. Survey results. http://www.dart.org/about/publications.

Dan Boyle and Associates, Inc. 2006. City of Lawrence coordinated public transportation development plan. Chapter 4, on-board survey results for the $\mathrm{T}$.

Eichler, Henning. Research Manager for Southern California Regional Rail Authority. Telephone interview, November 2008.

Foote, P., D. Stuart and R. Elmore-Yalch. 2001. Exploring customer loyalty as a transit performance measure. Transportation Research Record 1753: 93-101.

Foote, P. 2004. Making buses better in Chicago. Transportation Research Record 1884: 18-26.

Fujii, S. and R. Kitamura, R. 2000. Anticipated travel time, information acquisition and actual experience: the case of Hanshin Expressway route closure. Paper presented at the $79^{\text {th }}$ annual meeting of the Transportation Research Board, January 9-13, in Washington, D.C.

Gilmore Research. 2007. Pierce Transit 2007 fixed-route customer satisfaction results.

Greater Cleveland Regional Transit Authority. 2001. Demographic and market analysis research, appendix C.

Handy, S. L., and K. Clifton. 2001. Evaluating neighborhood accessibility: possibilities and practicalities. Journal of Transportation and Statistics 4:3. 67-78.

Huffer, M. 1997. Planning and marketing for destination services: how special services can add to your ridership base. Proceedings of the 1997 Bus Operations, Technology, and Management Conference, American Public Transportation Association. 18-20.

Iida, Y., T. Akiyama and T. Uchica. 1992. Experimental analysis of dynamic route choice behavior. Transportation Research B, 26: 17-32. 
Kimpel, T. J. 2001. Time point-level analysis of transit service reliability and passenger demand. $\mathrm{PhD}$ dissertation, Portland State University.

Kittelson and Associates, Inc., et. al. 2003. Transit Capacity and Quality of Service Manual, Second Edition, TCRP Report 100. Transportation Research Board, National Research Council. Washington, D.C.: National Academy Press.

Kotler, Philip and Kevin Lane Keller. 2006. Marketing management. $12^{\text {th }}$ ed. New Jersey: Pearson/Prentice Hall.

Leclerc, F., B. Schmitt and L. Dube. 1995. Waiting time and decision making: is time like money? Journal of Consumer Research 22:1. 110-119.

Levinson, Herbert S. 2005. The reliability of transit service: an historical perspective. Journal of Urban Technology 12:1. 99-118.

LSC Transportation Consultants, Inc. 2005. Springs Transit on-board survey final report.

McCollom Management Consulting, et. al. 2002. Transit Performance Monitoring System (TPMS) results, summary report phases I and II. American Public Transportation Association.

McCollom Management Consulting. 2004. Transit Performance Monitoring System (TPMS) results, summary report phase III. American Public Transportation Association.

Meagher, J. 2005. Dublin’s quality bus corridors. Public Transport International 5: 18-20.

Metropolitan Council, Minneapolis, MN. 2007. Metro Transit customer satisfaction remains strong, survey says. http://www.metrocouncil.org/directions/index.htm.

Mohring, H., J. Schroeter and P. Wiboonchutikula. 1987. The values of waiting time, travel time, and a seat on a bus. Rand Journal of Economics 18:1. 40-56.

Moore and Associates. 2005. City of Elk Grove, California on-board survey analysis.

Multisystems, Inc. 2001. Washington Metropolitan Area Transit Authority summary report on the on-board surveys of Metrobus and jurisdiction bus services, regional bus study.

National Transit Database. http://www.ntdprogram.gov.

Nam, D., D. Park and A. Khamkongkhun. 2005. Estimation of value of travel time reliability. Journal of Advanced Transportation 39:1. 39-61. 
Noland, R. and J. Polak. 2002. Travel time variability: a review of theoretical and empirical issues. Transport Reviews 22:1. 39-54.

Norwood, J. and J. Casey. 2002. Key transportation indicators: summary of a workshop. Division of Behavioral and Social Sciences and Education, National Research Council. Washington, D.C.: National Academy Press.

NuStats, Inc. and GeoStats. 2002. Atlanta Regional Commission regional on-board transit survey, 2001-2002.

NuStats, Inc. and Multisystems, Inc. 2001. Washington Metropolitan Area Transit Authority telephone survey of bus non-riders, regional bus study.

Oram, R. and S. Stark. 1996. Infrequent riders: one key to new transit ridership and revenue. Transportation Research Record 1521: 37-41.

Oxygen Research, Inc. 2007. York Region Transit conventional transit customer satisfaction survey 2006 report.

Pinjari, A.R. and C. Bhat. 2006. Nonlinearity of response to level of service variables in travel mode choice models. Transportation Research Record 1977: 67-74.

Polak, J.W. and F. Oladeinde. 2000. An empirical model of travelers' day-to-day learning in the presence of uncertain travel times. In Reliability in transport networks, ed. M.G.H. Bell and C. Cassir. Hertfordshire: Research Studies Press.

Public Research Institute. 2003. 2002 on-board passenger survey system-wide results, AlamedaContra Costa Transit District.

Puget Sound Regional Council. Puget Sound Transportation Panel, Data Sets for Waves 1 through 10 (1989 - 2002), including attitude survey data sets. Acquired April 2006.

Reed, T., 1995. Reduction in the burden of waiting for public transit due to real-time schedule information: a conjoint analysis study. 1995 Vehicle and Information System Conference Proceedings, Institute of Electrical and Electronics Engineers. 83-89.

Santa Clara Valley Transportation Authority and NuStats, Inc. 2006. 2005-2006 on-board passenger survey final report. 
Small et. al., 1999. Valuation of travel time savings and predictability in congested conditions for highway user-cost estimation, NCHRP Report 431. Transportation Research Board, National Research Council. Washington, D.C.: National Academy Press.

Solomon, Paul. 2008. Class notes, Marketing Management (MAR 6815-901). University of South Florida, College of Business Administration, MBA Program, Tampa.

Strathman, J., K. Dueker and T. Kimpel. 1999. Automated bus dispatching, operations control, and service reliability: the initial Tri-Met experience. Portland: Portland State University, Center for Urban Studies.

Tindale-Oliver and Associates, Inc. Data sets and survey instruments for the 2007 Pinellas Suncoast Transit Authority on-board rider survey and household travel survey. Acquired January 2008.

TNS Intersearch Corporation. 2003. Southeastern Pennsylvania Transportation Authority (SEPTA) customer satisfaction survey summary of findings.

TNS Intersearch Corporation. 2005. Southeastern Pennsylvania Transportation Authority (SEPTA) customer satisfaction survey summary of findings.

Tucson Department of Transportation. 2004. Transit on the move: a major transit investment study for Tucson.

Tulsa Transit. 2005. Tulsa Transit survey shows more "choice riders.” http://www.tulsatransit.org/riders-survey/

Valley Metro, Phoenix, Arizona. 2001 origin and destination survey. http://www.valleymetro.org/valley_metro/publications. 
